\author{
Universidade de São Paulo \\ Instituto de Física
}

\title{
Elementos Traço em Soro Sanguíneo Medidos pelos Métodos PIXE e ICP-MS
}

\author{
Suene Bernardes dos Santos
}

Orientador: Prof. Dr. Manfredo Harri Tabacniks

Dissertação de mestrado apresentada ao Instituto de Física para a obtenção do título de Mestre em Ciências

Comissão examinadora:

Prof. Dr. Manfredo Harri Tabacniks (IFUSP)

Prof. Dr ${ }^{\mathrm{a}}$. Elisabeth Mateus Yoshimura (IFUSP)

Prof. Dr ${ }^{\mathrm{a}}$. Cibele Bugno Zamboni (IPEN) 
FICHA CATALOGRÁFICA

Preparada pelo Serviço de Biblioteca e Informação

do Instituto de Física da Universidade de São

Paulo

Santos, Suene Bernardes dos

Elementos traço em soro sanguíneo medidos pelos métodos PIXE e ICP-MS. São Paulo, 2007

Dissertação (Mestrado) - Universidade de São Paulo. Instituto de Física. Departamento de Física Aplicada.

Orientador: Prof. Dr. Manfredo Harri Tabacniks

Área de Concentração: Física

Unitermos: 1. Física nuclear 2. Física nuclear aplicada; 3 . Física aplicada à biologia e medicina 
Dedico este trabalho aos meus avós Sebastião Bernardes (em memória) e Maria Alves Bernardes 


\section{A gradecimentos}

Ao meu orientador Manfredo Harri Tabacniks pela dedicação, paciência e apoio durante a realização deste trabalho.

Ao Marcel D. L. Barbosa pela colaboração, ajudando com as medidas PIXE quando necessário, incluindo noites e finais de semana e também pelas dúvidas sanadas durante estes últimos anos.

À professora Marina B. Martinez e à Juliana B. A. Machado pela colaboração, ajuda com a aprovação do Comitê de ética do Hospital universitário da USP e com a coleta das amostras.

À professora Sandra Andrade e à Margareth S. Navarro que ajudaram com as medidas ICPMS, com dúvidas sobre o equipamento e sobre o método de medida adotado.

Ao amigo Julian Shorto pela revisão do texto e discussões sobre o trabalho.

Aos professores do grupo de Física Nuclear Aplicada, Márcia de Almeida Rizzutto e Nemitala Added, pelo apoio e colaboração no andamento do trabalho.

A toda minha família que tanto amo, em especial à minha mãe Vaina, ao padrasto Valmir, à tia Aparecida (mais conhecida como tia Pepê), à minha avó Maria (dona Cóta) e ao meu avô Sebastião (em memória), ao tio José Francisco, às minhas irmãs Niele e Andreza e aos meus sobrinhos Arthur Henrique e Luiz Hermano. Agradeço também ao meu pai Wilson, madrasta Vilma e irmãos Júnior, Leonardo e Laura.

Aos técnicos do laboratório LAMFI do IFUSP, Marquinhos e Vinícius. 
Aos doadores que LITERALMENTE deram o sangue pelo meu trabalho: Ana, Adriana Rocha, Adriana Delgado, Alexandre Inácio, André Kolalski, Atenágoras Souza, Áttila Rodrigues, Camila Cristina Pacheco, Carolina Nunes, Giorgio Botteira, Jairo, José Pedretti, Junior de Oliveira, Karina Lopes, Leandro, Leandro Leal, Marcelo, Marcos, Orli Camargo, Paulo Cardoso, Pedro Campos, Priscila Santos, Rafael Ferreira, Rafael Leandro, Rafaello Vargilli, Roberto Paiva, Silas Carvalho, Thiago Souza.

Às minhas companheiras de apartamento Elis, Di e Dri, que foram além de amigas uma família durante esse tempo que dividiram comigo as "gororobas" que chamávamos de almoço.

Aos amigos e donos do albergue mais cobiçado de Sampa, Márcia, Bebeto, Paty, Floyd e Pink, que me acolheram com carinho quando precisei de um teto. Além é claro, das aulas de artesanato da Marcinha.

Aos amigos que muito ajudaram durante as minhas crises de desespero, Elisangela, Jéssica, Julian (Bá), Anne, Flaviane, Karina (KK), Florence, Dimas (Deusa), Silas, Marcelos, Djalma, Pedro, Silvana, Roberto, Carlos, Guilherme, Gil, Júlio, Henady, Thiago, Leandro, Rone, Kelly e Karin.

Aos amigos do grupo de Física Nuclear Aplicada.

Aos amigos de Londrina e Frutal, que mesmo de longe colaboraram com este trabalho, dando apoio nas horas difíceis e dividindo os bons momentos também.

À agência financiadora deste trabalho CAPES. 


\section{Sumário}

1 Introdução 1

2 Revisão Bibliográfica

3 Técnicas 10

3.1 O Método PIXE 12

3.1.1 Introdução 12

3.1.2 Fundamentos Físicos 13

3.1.3 Arranjo Experimental 14

3.1.4 Formulação PIXE 15

3.1.4.1 Seção de Choque de Ionização 18

3.1.4.2 Rendimento Fluorescente 18

3.1.4.3 Poder de Freamento 20

3.1.5 Limite de Alvos Finos 20

3.1.6 Medidas Absolutas por Dopagem 21

3.1.7 Detectores Semicondutores $\quad 22$

3.2 O Método ICP-MS 24

3.2.1 Introdução 24

3.2.2 O ICP-MS 26

3.2.3 Introdução de Amostras

3.2.4 Fonte de Íons - Tocha e Plasma 28

3.2.5 Interface 31

3.2.6 Analisadores 32

- Analisadores de Massa de Tempo de Vôo 32

- Analisadores de Dupla focalização 33

- Analisadores de Massa Quadrupolares 33

3.2.7 Sistemas de Detecção 35

- Multiplicador de Elétrons $\quad 35$ 
- O Copo de Faraday 36

- O Detector Daly 37

- O Detector Analógico 38

- Sistema de Detecção Dual 39

3.2.8 Interferências 40

3.2.8.1 Interferências Espectroscópicas $\quad 40$

- Interferências Isobáricas 40

- Interferências por Íons Poliatômicos 41

- Íons de Dupla Carga 41

- Interferências por Espécies Óxido e Hidróxido 42

3.2.8.2 Interferências não Espectroscópicas 43

- Efeitos de Matriz 43

- Efeito Memória 44

3.2.9 O DRC 44

3.2.10 Correção do Drift Instrumental 45

4 Validação de Método $\quad 48$

$\begin{array}{ll}4.1 \text { Curvas de Calibração } & 48\end{array}$

4.1.1 PIXE 49

$\begin{array}{ll}\text { 4.1.2 ICP-MS } & 51\end{array}$

4.2 Precisão $\quad 57$

$\begin{array}{lll}\text { 4.2.1 PIXE } & 57\end{array}$

4.2.2 ICP-MS

$\begin{array}{ll}4.3 \text { Exatidão } & 59\end{array}$

4.4 Teste Estatístico $\quad 60$

4.5 Limite de Detecção e Quantificação 62

4.5.1 PIXE 62

4.5.2 ICP-MS 63

5 Materiais e Métodos $\quad 65$

5.1 Equipamentos Utilizados $\quad 65$

5.1.1 O Sistema PIXE do LAMFI - IFUSP 65

5.1.2 O Sistema de ICP-MS - IGUSP 67 
$\begin{array}{ll}\text { 5.2 Materiais Utilizados } & 68\end{array}$

5.3 Coleta da Amostras $\quad 69$

5.4 Preparação de Amostras $\quad 69$

5.4.1 PIXE 69

$\begin{array}{ll}\text { 5.4.2 ICP-MS } & 71\end{array}$

5.5 Tratamento de Brancos $\quad 72$

$\begin{array}{lll}\text { 5.5.1 PIXE } & 73\end{array}$

$\begin{array}{ll}\text { 5.5.2 ICP-MS } & 74\end{array}$

6 Resultados e Discussão 76

6.1 Elementos Medidos 76

$\begin{array}{ll}\text { 6.2 Comportamento dos Dados } & 79\end{array}$

6.3 Testes de Normalidade $\quad 82$

6.3.1 Testes de Assimetria e Curtose 83

6.3.2 Teste de Shapiro-Wilk

6.3.3 Indícios de Normalidade $\quad 84$

6.3.4 Indícios de Lognormalidade $\quad 87$

6.3.5 Distribuições não Determinadas $\quad 89$

6.4 Tratamento Estatístico 91

6.5 Comparação com a Literatura 94

7 Conclusões 96

8 Referências 99

Apêndice A 110

$\begin{array}{ll}\text { Apêndice B } & 120\end{array}$

Apêndice C 123

Apêndice D 132

Apêndice E 134

$\begin{array}{ll}\text { Apêndice F } & 137\end{array}$

$\begin{array}{ll}\text { Apêndice G } & 140\end{array}$

Apêndice H 146 


\section{R esumo}

O principal objetivo deste trabalho foi desenvolver uma metodologia de análise de soro sanguíneo utilizando os métodos Proton Induced X-ray Emission (PIXE) e Inductively Coupled Phasma Mass Spectrometry (ICP-MS). O PIXE é um método de análise multielementar baseado na detecção dos raios-X característicos emitidos pelas amostras, quando bombardeadas com feixes de íons $\left(\mathrm{H}^{+}, \mathrm{He}^{+}, \ldots\right)$ com energia da ordem de alguns $\mathrm{MeV}$. Já o ICP-MS é um espectrômetro de massa que analisa componentes de amostras ionizadas, separados de acordo com suas razões massa carga (m/z). Para a realização deste estudo, as amostras de sangue dos voluntários (30 jovens com idade entre 18 e 25 anos) foram coletadas

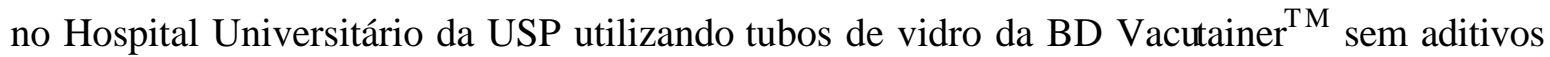
(Processo do Comitê de Ética: HU-615/05). O soro foi obtido pela centrifugação dos tubos a $3000 \mathrm{rpm}$ As amostras foram pipetadas sobre Nuclepore $(10 \mu \mathrm{m}$ de espessura) e secas a temperatura ambiente, para o método PIXE, e diluídas de 1:10, para as análises com ICP-MS. A acurácia dos resultados foi verificada analisando materiais de referências de soro do National Institute of Public Health - Québec (ICP-03B-02 e ICP-02-S-05). A análise dos padrões apresentou $78 \%$ dos dados entre $\pm 1 \mathrm{~s}, 14 \%$ entre $\pm 2 \mathrm{~s}$ e $4 \%$ além de $\pm 3 \mathrm{~s}$. Este estudo de elementos traço em soro humano revelou um total de 22 elementos: $\mathrm{Be}, \mathrm{Al}, \mathrm{P}, \mathrm{S}, \mathrm{Cl}, \mathrm{K}, \mathrm{Ca}$, V, Cr, Mn, Fe, Co, Ni, Cu, Zn, Se, Br, Mo, Cd, Sn, Tle Pb, com concentrações entre 9 ng/l e 6 $\mathrm{g} / \mathrm{l}$, o que compreende 9 ordens de grandeza, e também permitiu o estudo das funções de distribuição de probabilidades dos elementos. As técnicas utilizadas foram eficientes e complementares na realização deste trabalho. Os resultados das concentrações elementares medidas neste trabalho concordaram com os valores da literatura. 


\section{A bstract}

The main objective of this work was to develop a methodology for the analysis of blood serum by Proton Induced X-ray Emission (PIXE) and Inductively Coupled Plasma Mass Spectrometry (ICP-MS). PIXE is a multi elementary spectrometric method that relies on the detection of characteristics X-rays emitted by a sample bombarded with an energetic $(\sim \mathrm{MeV})$ ion beam $\left(\mathrm{H}^{+}, \mathrm{He}^{+}, \ldots\right)$. With the ICP-MS one measures the elementary components in an ionised sample, separated according to their mass to charge ratio $(\mathrm{m} / \mathrm{z})$. For this study, the blood samples were collected from 30 young healthy adult volunteers with age between 18 and 25 years, in the University Hospital using additiveless BD Vacutainer ${ }^{\mathrm{TM}}$ tubes (Authorisation agreement HU-615/05). Blood serum was obtained by centrifugation of the tubes at $3000 \mathrm{rpm}$. For PIXE analysis, the serum samples were pipetted on Nuclepore film $(10 \mu \mathrm{m}$ thick) and dried at room temperature. For the ICP-MS analysis, the serum samples were diluted 1:10. Accuracy of both methods was obtained analysing serum reference materials supplied by the National Institute of Public Health - Québec (ICP-03B-02 and ICP02-S-05). The analysis of the reference materials presented results for the elementary concentrations within $\pm 1 \mathrm{~s}$ for $78 \%$ of the data, $14 \%$ of the data lied within $\pm 1 \mathrm{~s}$ and $\pm 2 \mathrm{~s}$, and $4 \%$ above $\pm 3 \mathrm{~s}$. The analysis of trace elements in human blood serum by PIXE and ICP-MS revealed a total of 22 elements, ranging over 9 orders of magnitude: $\mathrm{Be}, \mathrm{Al}, \mathrm{P}, \mathrm{S}, \mathrm{Cl}, \mathrm{K}, \mathrm{Ca}, \mathrm{V}$, $\mathrm{Cr}, \mathrm{Mn}, \mathrm{Fe}, \mathrm{Co}, \mathrm{Ni}, \mathrm{Cu}, \mathrm{Zn}, \mathrm{Se}, \mathrm{Br}, \mathrm{Mo}, \mathrm{Cd}, \mathrm{Sn}, \mathrm{Tl}$ e Pb, with concentrations between 9 ng/l and $6 \mathrm{~g} / \mathrm{l}$. The PIXE and ICP-MS techniques were efficient and complimentary for the accomplishment of this work. The elementary concentrations measured in this work agreed with overall data in literature. 


\section{Introdução}

A pesquisa e a identificação de elementos químicos no meio ambiente e em materiais biológicos é um campo da ciência moderna que tem crescido muito nos últimos anos. É conhecido que esses elementos, também conhecidos como elementos traço ou ultra traço ${ }^{1}$, são essenciais para a vida e muitos deles desempenham importantes funções em processos bioquímicos do organismo humano, por isso, um grande esforço tem sido feito no sentido de entender sua ação [Hasegawa, 2001; Hernández-Caraballo, 2003]. Sabe-se, por exemplo, que mesmo os elementos químicos essenciais e não essenciais, quando em excesso, podem ser tóxicos, constituindo área de grande interesse para a toxicologia. $\mathrm{O}$ monitoramento contínuo desses minerais tem grande interesse comercial, pois permite identificar e corrigir deficiências dietéticas, revelar a incidência de doses excessivas, verificar as condições gerais de pacientes, e quem sabe, futuramente fazer um diagnóstico precoce de doenças associando desordens no metabolismo humano com composição e/ou contaminação nutricional. Entretanto, muito pouco ainda é conhecido sobre o comportamento bioquímico destes elementos e apenas medi los não é suficiente, é importante também saber se esses elementos estão livres ou ligados a proteínas ou moléculas e conhecer sua função [Cornélis, 1993].

Para tentar conhecer a importância e a função dos elementos químicos no corpo humano, vários fluidos do organismo vêm sendo estudados desde a década de 70. Existem vários trabalhos que estudam a composição química da saliva, sangue, suor e urina. Dentre os quais destaca-se, o sangue, um dos fluidos biológicos mais usados em análises clínicas para diagnósticos médicos [Hasegawa, 2001]. Ele representa o mais importante de todos os líquidos

\footnotetext{
${ }^{1}$ Os elementos traço são aqueles presentes de $100 \mu \mathrm{g} / \mathrm{g}$ a $0,01 \mu \mathrm{g} / \mathrm{g}$, enquanto o termo ultra traço é aplicado a

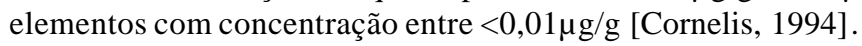


do organismo, é responsável pela nutrição dos tecidos, controle da temperatura corporal, transporte de oxigênio e de excreção metabólica (uréia, ácido úrico e creatina). As modificações de volume e composição do sangue se refletem nos demais líquidos do meio interno. Por isso é importante conhecer bem o nível desses elementos em sangue e soro de pessoas sadias [Vilella, 1961; Rodushkin, 1999].

O sangue é uma suspensão de células (eritrócitos, leucócitos e plaquetas) em um líquido complexo, chamado plasma, constituído por água, sais minerais, vitaminas, proteínas, glicídios e lipídios. Fora do organismo, o sangue coagula e libera uma fase líquida chamada soro. O soro difere do plasma por não conter fibrinogênio, proteína que ajuda na coagulação sanguínea ${ }^{2}$. Na centrifugação do sangue total separam-se os glóbulos do plasma, como mostra o esquema abaixo. O volume total do sangue é de aproximadamente 5,5 litros para o home m e 4,8 para a mulher. Excluindo os elementos que compõem a parte orgânica, H, C, O e N, o principal elemento químico no sangue é o ferro. Constituinte da molécula de hemoglobina, a concentração média de ferro no sangue do homem adulto é da ordem de $380 \mathrm{mg} . \mathrm{l}^{-1}$ (ppm) [Verrastro, 1996; Vilella, 1961].

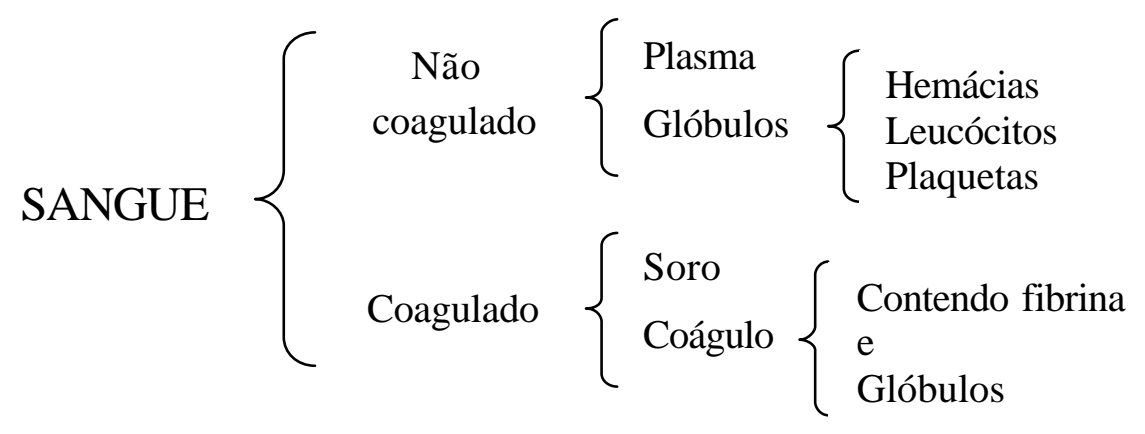

A composição química do sangue é muito complexa e normalmente varia com a idade, o sexo, a alimentação, ambiente e outros fatores. A idade tem influência nas variações de alguns constituintes como proteínas, o cálcio, o fósforo inorgânico, o colesterol, a glicose e a uréia. No recém nascido, por exemplo, os valores para a fosfatemia são mais elevados e o

\footnotetext{
2 A coagulação do sangue consiste na transformação de fibrinogênio do plasma em fibrina insolúvel. Esta transformação do fibrinogênio se processa pela ação da trombina, a enzima diretamente responsável pela coagulação do sangue. A trombina não existe no sangue circulante, ela é formada pela combinação do $\mathrm{Ca}^{++}$e da tromboplastina com a protrombina.
} 
colesterol é mais baixo do que no adulto. A hemoglobina é mais elevada ao nascer, decrescendo com a idade, para novamente se elevar um pouco até o fim da puberdade. Quanto ao sexo, o ferro e a hemoglobina (proteína) possuem valores mais elevados para o homem do que para a mulher. A gravidez é uma condição que produz variações sensíveis na composição do sangue, sobretudo no que se refere à hemoglobina e às proteínas do plasma, as quais se apresentam em geral diminuídas [Vilella, 1961].

Alguns estudos da concentração elementar em sangue e soro reportam a importância de alguns elementos no organismo humano. O sódio, por exemplo, é essencial para equilibrar o pH dos fluidos extracelulares e também é importante na transmissão nervosa e na contração muscular. Um alto nível de sódio pode resultar em hipertensão, problemas nos rins e no coração. O potássio é importante para a manutenção dos fluidos, do balanço eletrólito e da integridade das células [Besteman, 1999]. Vários investigadores têm reportado que as concentrações de $\mathrm{Zn}$ e $\mathrm{Cu}$ estão, respectivamente, reduzidas e aumentadas em adultos fumantes [Kim, 2003]. Elementos como o $\mathrm{Cd}$ e $\mathrm{Pb}$ também podem estar relacionados com o hábito de fumar [Bárány, 2002a].

O crescente interesse nos efeitos destes elementos no organismo humano gerou uma procura por medidas cada vez mais confiáveis e precisas, o que evidenciou a necessidade de técnicas analíticas mais eficazes. Atualmente, as mais conhecidas nesse tipo de pesquisa são: NAA (Neutron Activation Analysis), AAS (Atomic Absorption Spectrometry), XRF (X-ray Fluorescence), TXRF (Total Reflection X-ray Fluorescence), PIXE (Particle Induced X-Ray Emission), ICP-OES (Inductively Plasma Optical Emission Spectrometry) e ICP-MS (Inductively Coupled Plasma Mass Spectrometry). Destacaremos os métodos PIXE e ICP-MS que são duas das técnicas mais utilizadas no estudo de minerais em sangue e soro e que também foram empregadas neste trabalho.

O método PIXE é baseado na análise elementar de amostras, por meio de raios-X característicos emitidos, quando bombardeados com feixes de íons $\left(\mathrm{H}^{+}, \mathrm{He}^{+}, \ldots\right)$ com energia da ordem de alguns MeV. É sensível para todos os elementos da tabela periódica acima do alumínio e destaca-se pela sua alta sensibilidade (da ordem de ppm, podendo chegar a ppb) e também pela necessidade de pequenas amostras. Aplicações do método PIXE para a análise de amostras biológicas têm sido publicadas em numerosos trabalhos desde o surgimento da 
técnica, como pode ser verificado no livro de Johanssen et al. (1988) e em revisão de Aldape et $\mathrm{al}(1996)$.

O espectrômetro de massa com plasma indutivamente acoplado, ICP-MS é uma evolução da espectrometria de absorção atômica, AAS. Em ambas as técnicas a amostra é nebulizada, ionizada e seus componentes analisados. Na AAS, a amostra é nebulizada numa chama de metano ao mesmo tempo em que se registram as linhas de absorção atômica de uma lâmpada espectral. A intensidade da absorção da linha característica pode ser relacionada com a concentração elementar na amostra. Na ICP-MS a amostra também é nebulizada, porém num forno indutivamente acoplado e com temperatura muito mais alta que na AAS, cerca de $10^{4}{ }^{\circ} \mathrm{C}$. Nestas condições, os componentes atômicos da amostra são totalmente ionizados. Um quadrupolo eletrostático analisa os íons e classifica-os conforme sua massa atômica. O sinal resultante no ICP-MS é muito mais simples de ser interpretado e os limites de detecção são bastante inferiores aos da AAS, além de ser uma técnica multielementar. Os limites de detecção para análises por ICP-MS são melhores que 1 ppm (ou mg/l para líquidos) para quase todos elementos da tabela periódica, chegando a valores menores que $1 \mathrm{ppb}$ (ou $\mu \mathrm{g} / \mathrm{l}$ para líquidos) para os elementos mais pesados com Z> 37 [Montaser, 1998].

A rapidez, sensibilidade e capacidade analítica multi-elementar dos métodos PIXE e do ICP-MS fazem dessa linha de pesquisa, um poderoso instrumento para compreensão da influência do meio ambiente nos sistemas biológicos uma vez que estas técnicas se complementam na identificação dos minerais. No estudo de soro espera-se um limite de detecção da ordem de ppm para o método PIXE e ppb para o ICP-MS.

Baseado em tudo que foi exposto aqui, pudemos perceber a importância da identificação dos elementos químicos no soro sanguíneo, entretanto, primeiramente é necessário saber medir com qualidade as amostras em questão. Por isso, o principal objetivo deste trabalho foi estudar e desenvolver uma metodologia adequada de análise de soro sanguíneo pelas técnicas PIXE e ICP-MS e, conseqüentemente, aplicar experimentalmente os métodos de medida em amostras de 30 voluntários que vivem na cidade de São Paulo, estudantes (de ambos os sexos) com idade entre 18 e 25 anos. Além disso, para verificar a qualidade dos métodos analíticos empregados, o estudo das concentrações elementares medidas nas amostras de soro foi estabelecido como um objetivo secundário. 


\section{R evisão B ibliográfica}

A enorme sensibilidade dos atuais equipamentos de análise elementar vem permitindo a detecção de quase todos os elementos da tabela periódica em amostras biológicas e ambientais. A revisão bibliográfica realizada neste trabalho mostra o que já foi possível medir em amostras de sangue total e soro sanguíneo de doadores considerados sadios.

A busca sobre a concentração elementar em sangue total e soro na literatura especializada resultou em um conjunto de aproximadamente 50 artigos, nos quais foram encontrados dados de concentrações para 70 elementos em sangue total e 58 elementos em soro. Esta pesquisa possibilitou a compilação das tabelas A.1 e A.2 mostradas no apêndice A e a construção dos gráficos das figuras 2.1 e 2.2 .

Os dados encontrados na literatura foram medidos, principalmente, pelos métodos PIXE, TXRF, ICP-OES e ICP-MS com amplitude que excedem 10 ordens de grandeza em concentração.

Para construir os gráficos foi necessário encontrar um valor que melhor representasse os dados da literatura, obtidos por medições realizadas com diferentes métodos, experimentadores e, principalmente, com doadores de diferentes locais e com diferentes costumes. As medianas das médias encontradas na literatura, método mais apropriado neste caso, possibilitaram a confecção das figuras 2.1 e 2.2. As incertezas consideradas foram os valores máximos e mínimos da literatura.

Entretanto alguns trabalhos não forneceram as médias, que foram calculadas para posteriormente possibilitar o cálculo das medianas. Quando os valores fornecidos eram apenas os máximos e mínimos, foram calculas médias simples dos dois valores. No caso dos trabalhos de Zarkadas et al. (2001), Maenhaut et al. (1980) e Rodushkin et al. (2000), que apresentaram médias de medições de uma mesma amostra realizadas por diferentes métodos, a média 
ponderada foi calculada para os $n$ valores individuais $x_{i}$ com incertezas padrão $s_{i}$, um peso $p_{i}$, proporcional ao quadrado do inverso da incerteza, conforme a equação 2.1. Estes valores também foram utilizados no cálculo das medianas representadas nos gráficos.

$$
\bar{x}=\frac{\sum_{i=1}^{n} p_{i} x_{i}}{\sum_{i=1}^{n} p_{i}}
$$

onde o peso é dado por: $p_{i}=\frac{1}{\sigma_{i}^{2}}$.

O desvio padrão ponderado foi obtido pela seguinte expressão [Vanin, 1981]:

$$
\sigma_{\bar{x}}=\sqrt{\frac{1}{\sum_{i=1}^{n} \frac{1}{\sigma_{i}^{2}}}} .
$$

Em alguns casos foi encontrado apenas um valor na literatura, impossibilitando o cálculo da mediana. Neste caso, para completar os gráficos de sangue total e soro foram usadas as médias fornecidas pelos trabalhos. As incertezas consideradas agora foram os valores máximos e mínimos para o sangue total e o desvio padrão para o soro. Estabelecidos para melhor agrupar todos os dados. 


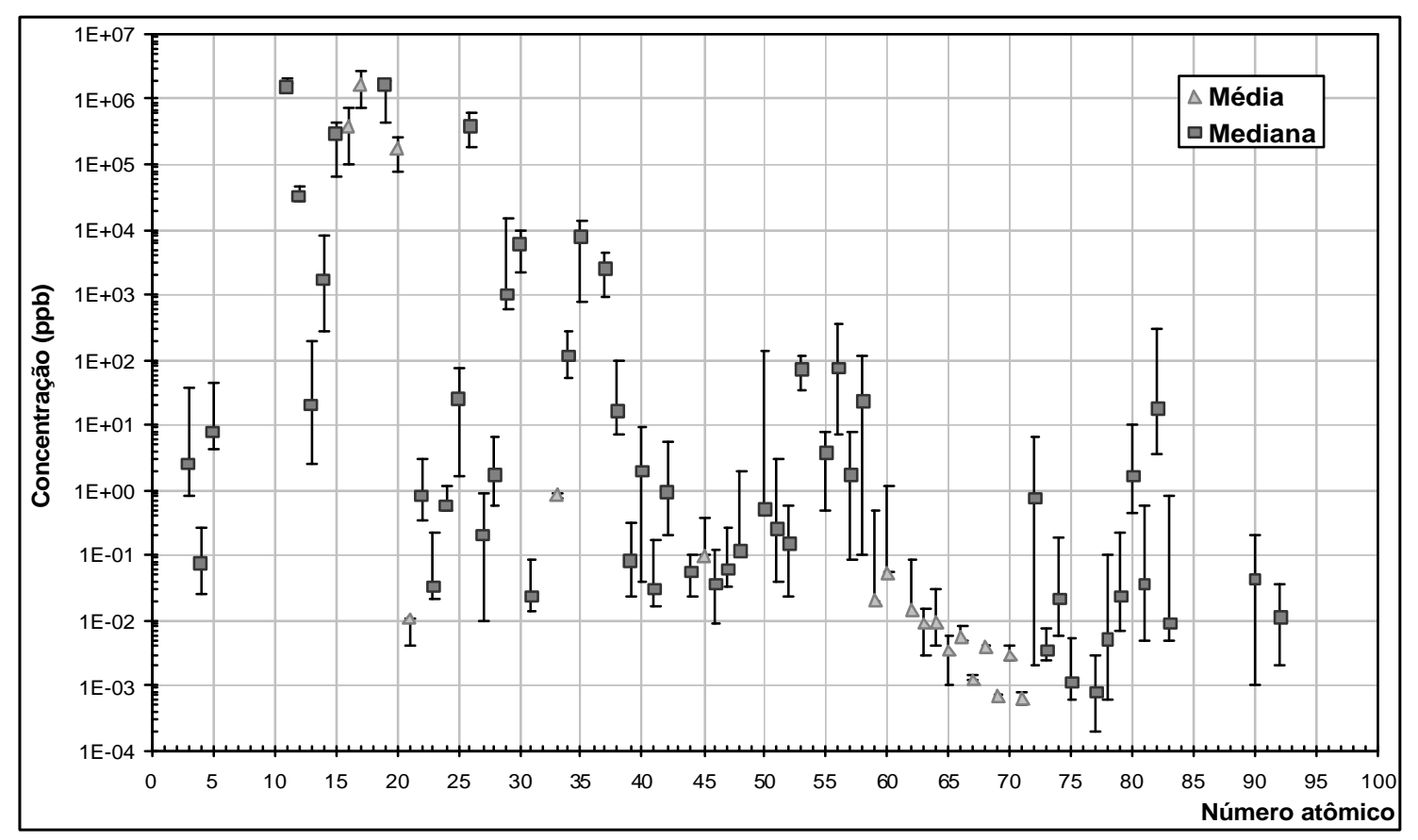

Figura 2.1 - Concentração elementar em sangue total. Os quadrados ( $\boldsymbol{\square}$ ) representam os valores de medianas e os triângulos ( ( ) as médias. As barras indicam os valores de máximo e mínimo.

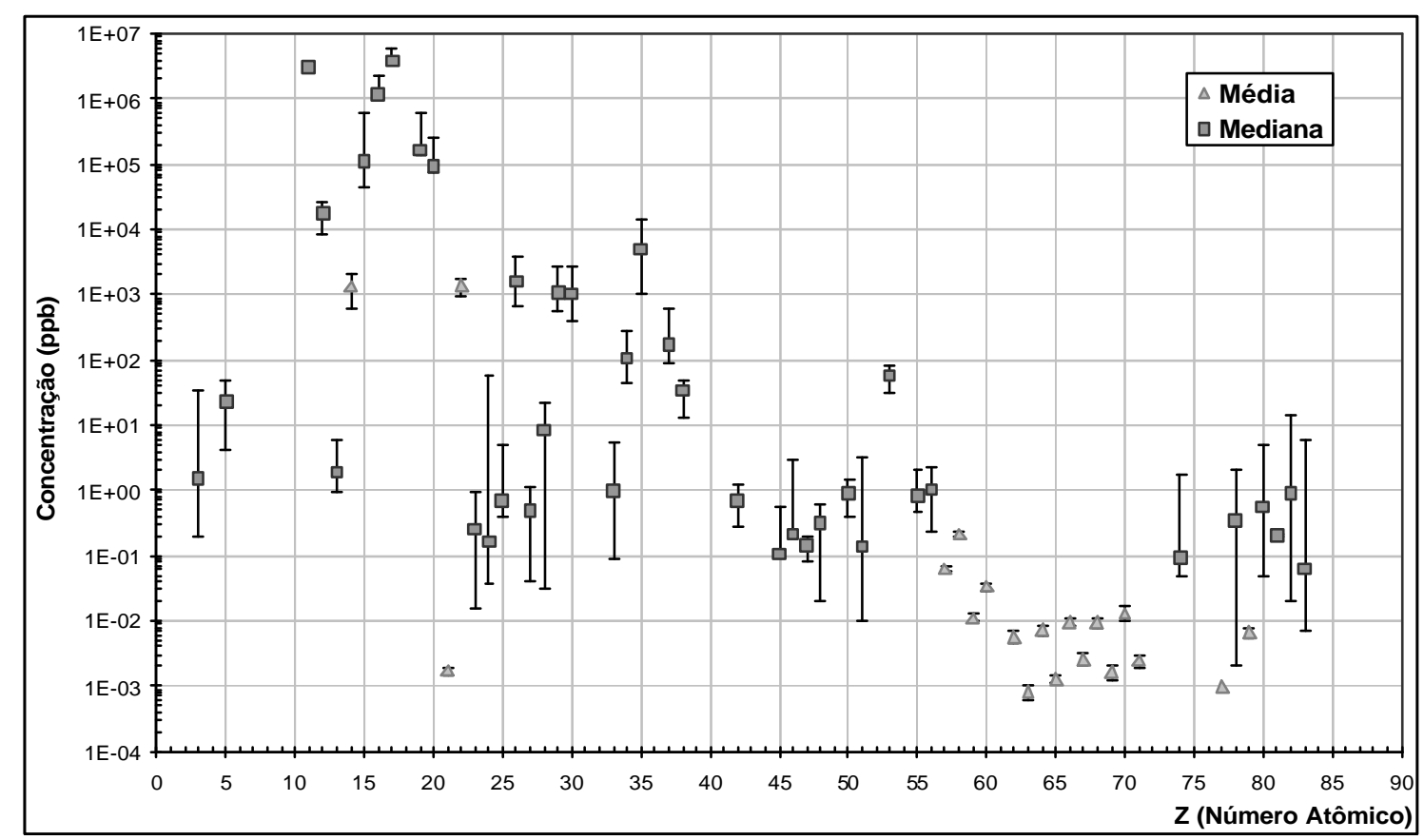

Figura 2.2 - Concentração elementar em soro sanguíneo. Os quadrados (ש) representam os valores de medianas e os triângulos (• ) as médias. As barras indicam os valores de máximo e mínimo, no caso das medianas, e desvio padrão, no caso das médias. 
Como dito anteriormente, a concentração elementar do organismo pode variar com a alimentação e localização. Para mostrar tal influência podemos, como exemplo adicional, citar também uma compilação da composição elementar na água do mar superficial e na crosta terrestre, figuras 2.3 e 2.4, respectivamente. Estas figuras apresentam uma semelhança visual com os gráficos de soro e sangue total. Os dados dos gráficos anteriores mostram a importância da determinação de elementos traço em amostras bio médicas e ambientais, uma vez que sua variação pode ser relacionada com processos internos e/ou externos.

Nas concentrações elementares na água do mar, na crosta terrestre e no sangue humano verifica-se com certa freqüência a abundância de elementos com número de massa par maior que a de seus vizinhos com número de massa ímpar. Esse comportamento é essencialmente visível na região de terras raras, com $71=\mathrm{Z}=58$. Este fato é explicado como consequiência da maior estabilidade dos núcleos pares que seus vizinhos ímpares [Harkins, 1919; Hecht, 2003].

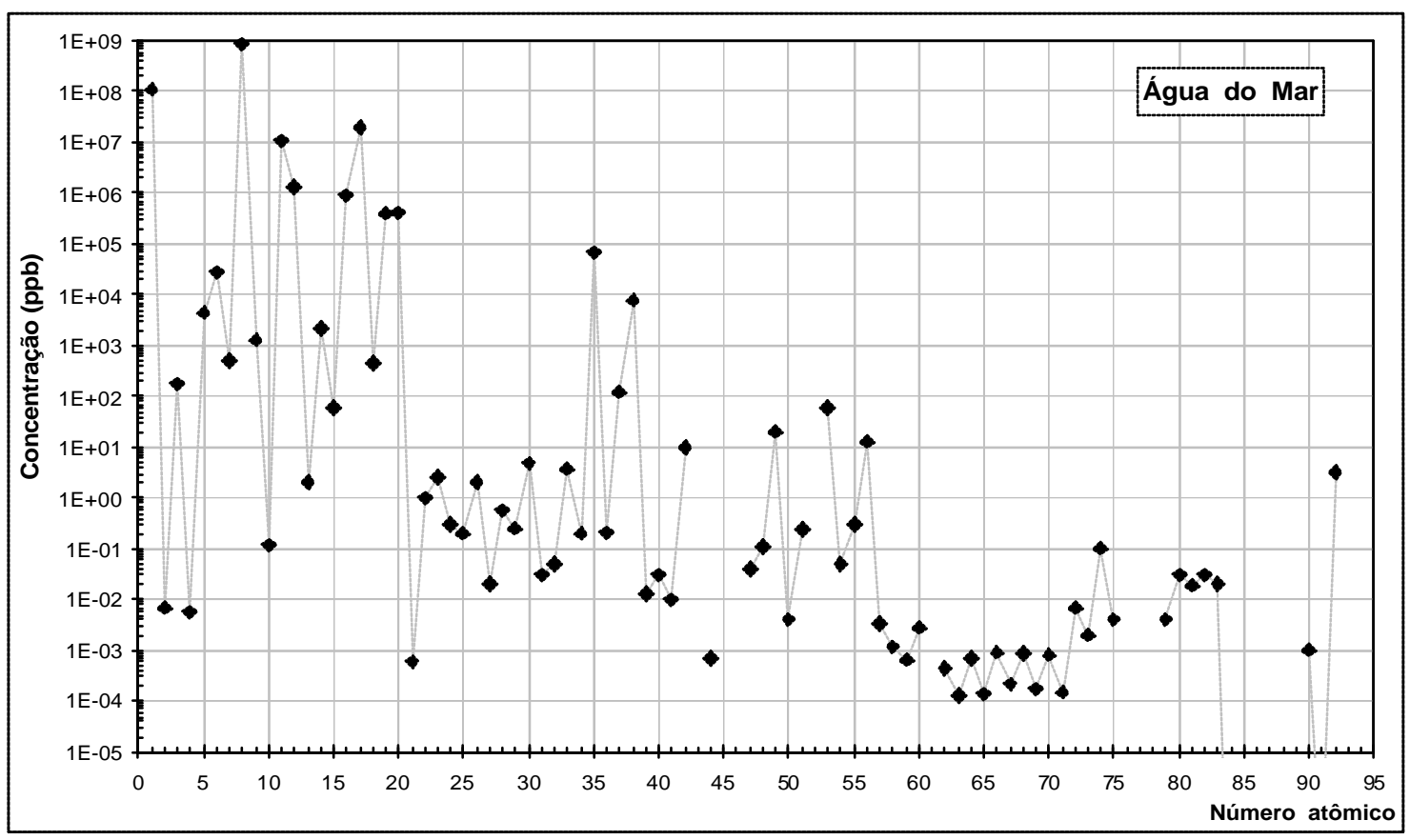

Figura 2.3 - Mediana da composição da água do mar na superfície [Lide, 2002]. As linhas tracejadas servem apenas de guia visual. Os valores citados podem variar mais de uma ordem de grandeza conforme o local. 


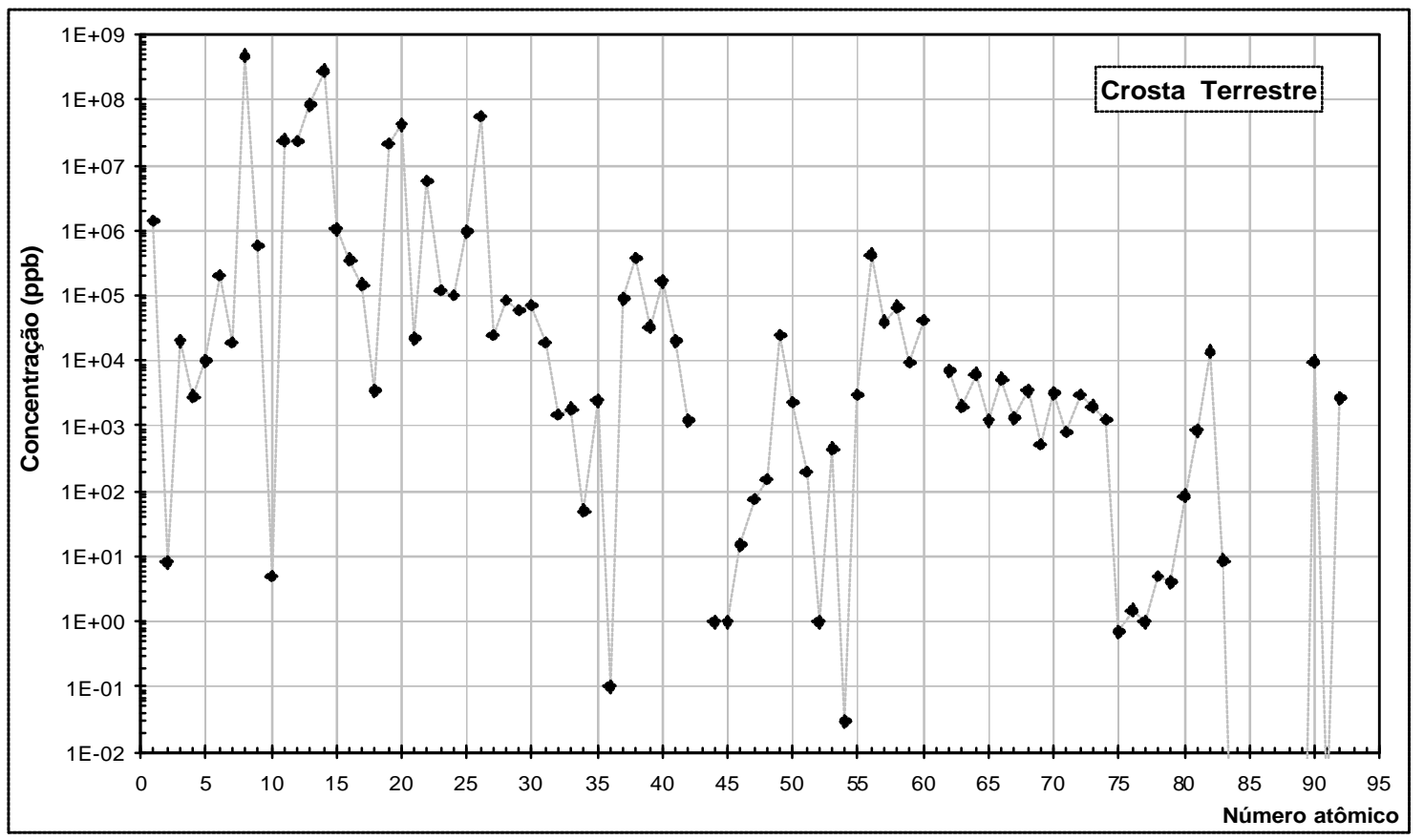

Figura 2.4 - Mediana de concentração elementar em crosta terrestre [Lide, 2002]. As linhas tracejadas servem apenas de guia visual. 


\section{Técnicas}

O desenvolvimento de técnicas elementares cada vez mais sensíveis e a detecção de elementos traço em materiais, e mais especificamente em materiais biológicos, começaram a ser realizadas antes de 1950 [Maenhaut, 1988 e Jenkins, 1981]. Inicialmente, muitos estudos relacionados à investigação toxicológica trataram da detecção de contaminantes em concentrações relativamente elevadas (como: Pb, Hg, Cd etc.) [Maenhaut, 1981]. Em busca de compreender o papel dos elementos traço no ambiente e nos seres vivos, foram requeridos limites de detecção mais baixos. Os métodos físicos espectrométricos são apropriados para este tipo de análise. Começando em torno de 1950, as análises com Fluorescência de Raios-X (XRF) e por Ativação com Nêutrons (NAA) estenderam e complementaram a Espectrometria de Absorção Atômica (AAS) (e por emissão - AES), "mono-elementar", equipamento comum disponível em muitos laboratórios químicos desde o começo do século 20. Com o desenvolvimento e a disseminação mundial da análise PIXE nos anos 70 [Johansson, 1970], a busca por elementos traço no ambiente e na biologia tiveram um impulso notável. Em 10 anos este método cresceu e se tornou poderoso devido a sua boa sensibilidade (na escala do ppm) e à necessidade de pequenas amostras [Johansson, 1988]. Além disso, é uma técnica multielementar relativamente simples e rápida. Entretanto, havia ainda a necessidade de diminuir ainda mais os limites de deteç̧ão. O Espectrômetro de Emissão Atômica com Plasma Induzido (ICP-AES) e seu sucessor, o Espectrômetro de Massa com Fonte de Plasma Induzido (ICP-MS), desenvolvidos no final dos anos 60 e início dos anos 80, respectivamente, conseguiram alcançar baixos limites de detecção (chegando a alcançar níveis de ppb e ppt) em um custo razoável [Potts, 1987 e Giné-Rosias, 1999]. Nos anos subseqüentes, o sucesso da técnica de ICP-MS despertou um interesse devido a sua habilidade de analise multielementar com maior eficiência e à determinação de uma ampla faixa de concentração da mesma 
amostra, características importantes que permitem uma análise mais completa, quando comparada com outras técnicas [Ulrich, 2001].

Neste trabalho serão usados os métodos PIXE e ICP-MS. Por isso, estes serão abordados em maior detalhe. 


\subsection{M étodo PIXE}

\subsubsection{Introdução}

Aplicações do método PIXE (Particle Induced X-Ray Emission) na análise de diversos materiais têm sido publicadas em numerosos trabalhos. Suas principais aplicações descrevem a irradiação de amostras geológicas, sangue, cabelo e aerossol. A análise de materiais biológicos pelo método PIXE tem em comum a necessidade de pré-preparo e adequação das amostras para análise em vácuo [Tanaka, 2006].

O PIXE, proposto por Johansson em 1970, faz parte de um conjunto de métodos nuclear-espectroscópicos amplo, denominados métodos de análise de materiais por feixes iônicos. Esses métodos têm como particularidade a utilização de íons $\left(\mathrm{H}^{+}, \mathrm{He}^{+}, \mathrm{He}^{2+}, \ldots\right)$ monoenergéticos, com energia da ordem de alguns $\mathrm{MeV}$, para a determinação da composição elementar de filmes finos e materiais em geral. A energia utilizada limita a profundidade alcançada pelo feixe a alguns $\mu \mathrm{m}$. É uma técnica multielementar relativamente simples e rápida $(\sim 10$ min por amostra), capaz de identificar e quantificar elementos com $\measuredangle 10$ (os raios- $\mathrm{X}$ dos elementos com baixo número atômico são absorvidos na janela do detector). Destaca-se por sua alta sensibilidade (com limite de detecção da ordem de $\mu \mathrm{g} / \mathrm{g}$ ) e também pela necessidade de pequenas amostras [Johansson, 1988].

Além das medidas em vácuo também é possível fazer medidas em pressão atmosférica extraindo o feixe através de uma fina janela, portanto, não limitando as características da amostra quanto ao tamanho e composição por isso vem sendo bastante utilizada no estudo de diversos materiais geológicos e arqueológicos. 


\subsubsection{F undamentos F ísicos}

No método PIXE, o material a ser analisado é irradiado com um feixe de íons de alguns $\mathrm{MeV}$ de energia. A interação das partículas do feixe com os átomos da amostra faz com que, dentre outros efeitos, ocorra a ionização das camadas mais internas dos átomos. O preenchimento das vacâncias resultantes, por elétrons mais periféricos, induz a emissão de raios-X característicos. Transições para as camadas $\mathrm{K}, \mathrm{L}$ e $\mathrm{M}$ são denominados raios-X $\mathrm{K}$, raios- $\mathrm{X} L$ e raios- $\mathrm{X} \mathrm{M}$, respectivamente. $\mathrm{O}$ diagrama representativo das principais transições de raios-X é mostrado na figura 3.1 [Aburaya, 2005; Tabacniks, 2005].

As camadas L e M são um conjunto de níveis muito próximos, existindo assim, várias energias muito próximas, uma para cada subcamada. Isto torna o espectro de raios $\mathrm{X}$ bastante complexo, pois, a cada vacância podem corresponder várias transições possíveis, cada uma associada a uma energia bem definida [Pinho, 1979]. As possíveis superposições de linhas e espectros podem ser resolvidas com a ajuda de programas de computador contendo informações sobre a energia e intensidades das linhas, tal como o programa AXIL [Van Espen et al., 1986].

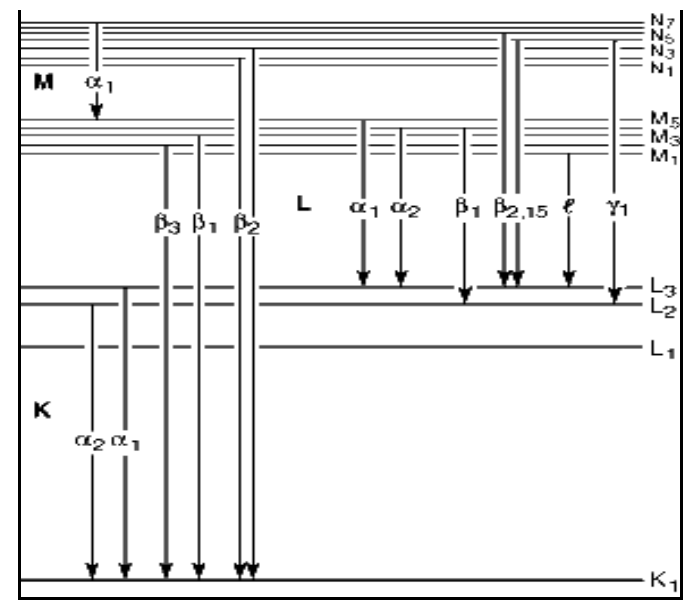

Figura 3.1 Diagrama de níveis eletrônicos e principais transições de raios X. As linhas finas indicam transições de fraca intensidade [Thompson et al, 2001]. 


\subsubsection{A rranjo E xperimental}

Um arranjo experimental típico é esquematizado na figura 3.2. A amostra é bombardeada com um feixe de íons, com alguns $\mathrm{MeV}$ de energia, produzido por um acelerador de partículas ${ }^{1}$ e colimado por um conjunto de fendas.

Para controlar o número de partículas incidentes utiliza-se, no caso de amostra “transparente ao feixe”, um copo de Faraday ligado a um integrador de carga, colocado após o alvo. Geralmente, utiliza-se também um absorvedor de raios-X, entre a amostra e o detector, que tem duas funções: evita a entrada no detector de partículas (prótons) espalhadas na amostra e otimiza as condições experimentais, absorvendo raios-X com baixa energia e demasiadamente intensos. Os raios-X emitidos são normalmente coletados por um detector semicondutor: $\mathrm{Si}(\mathrm{Li}), \mathrm{SiPIN}, \mathrm{Ge}$ intrínseco ou Ge(Li).

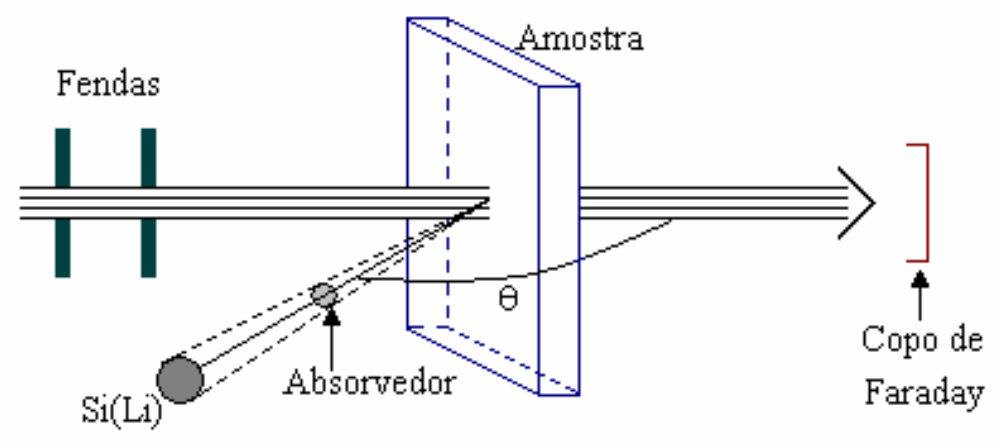

Figura 3.2 Arranjo experimental do método PIXE

Nos arranjos experimentais mais comuns, o alvo, o detector de partículas e o copo de Faraday se encontram numa câmara de irradiação diretamente acoplada ao acelerador, onde se mantém vácuo abaixo de $10^{-5} \mathrm{~mm} \mathrm{Hg}$, diretamente acoplada ao acelerador. O detector de raios$\mathrm{X}$ é colocado externamente, havendo uma fina janela (mylar, $\mathrm{Be}, \ldots$ ) defronte do detector para permitir a saída dos raios-X. Em alguns arranjos, o detector de raios-X é colocado dentro da câmara evitando-se, dessa forma, a absorção em janelas.

\footnotetext{
${ }^{1}$ Geralmente aceleradores eletrostáticos (Van de Graaff, Pelletrons, etc...), lineares ou ciclotrons.
} 
Fótons de diferentes energias (isto é, raios-X correspondentes a diferentes transições em diferentes elementos) possuem diferentes amplitudes, que são identificadas pelo analisador e registradas em canais diferentes [Pinho, 1979].

\subsubsection{F ormulação PIXE}

Seja um elemento de volume $d v^{\prime}$ de uma amostra contendo $M_{n}$ átomos por unidade de volume de um elemento $n$ estudado. Escolhendo o eixo $x$ como a direção dos prótons incidentes e considerando $P\left(y^{\prime}, z^{\prime}\right)$ sua densidade superficial, o número de partículas que atingem o elemento de volume é dado por $P\left(y^{\prime}, z^{\prime}\right) d y d z$. Sendo $s_{i}(E)$ a seção de choque de produção de raios-X por prótons com energia $E$, o número de raios-X produzidos por um átomo irradiado por um feixe de íons monoenergético é dado por [Margulis, 1977]:

$$
\begin{aligned}
& d U_{i}=\sigma_{i}(E) \cdot P\left(y^{\prime}, z^{\prime}\right) \cdot M_{n}\left(x^{\prime}, y^{\prime}, z^{\prime}\right) \cdot d v^{\prime} \\
& \text { com: } d v^{\prime}=d x^{\prime} d y^{\prime} d z^{\prime}=d x^{\prime} d s^{\prime}
\end{aligned}
$$

Para calcular a fração desses fótons que é detectada, deve-se considerar a eficiência do sistema de detecção $\varepsilon_{i}$ (detector e absorvedores), a probabilidade dos fótons serem emitidos numa direção compreendida pelo ângulo sólido do detector $(\Omega / 4 \pi)$ e a auto-absorção dos raios- $\mathrm{X}$ ao longo do caminho $d$, mostrado no esquema de coordenadas da figura 3.3. Dessa forma, o número de raios- $\mathrm{x}$ detectados proveniente do elemento de volume $d v^{\prime}$ é dado por:

$$
d N_{i}=\frac{\Omega}{4 \pi} \cdot \varepsilon_{i} \cdot T \cdot \sigma_{i}(E) \cdot P\left(y^{\prime}, z^{\prime}\right) \cdot M_{n}\left(x^{\prime}, y^{\prime}, z^{\prime}\right) \cdot d v^{\prime}
$$




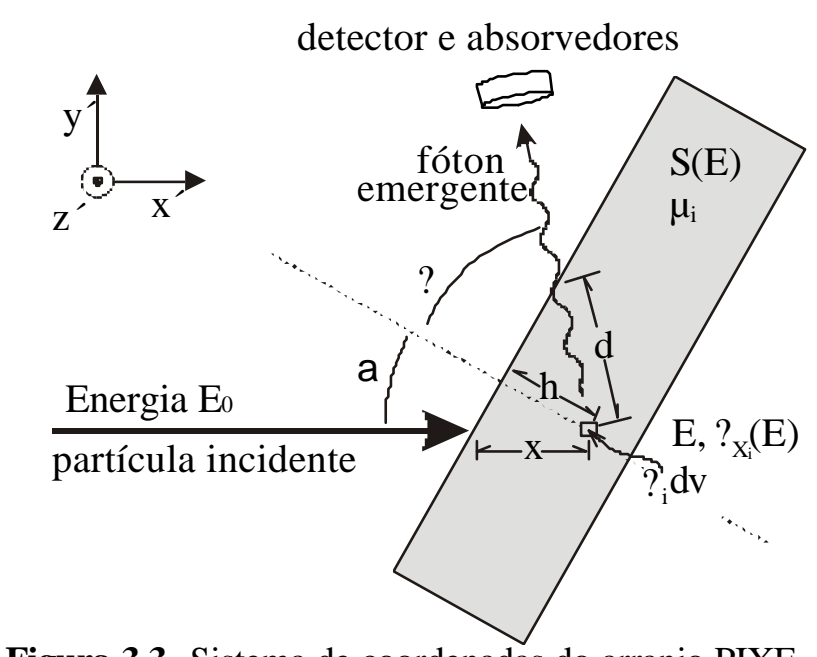

Figura 3.3 Sistema de coordenadas do arranjo PIXE.

A atenuação devido à atenuação $(\mathrm{T})$ é calculada a partir da lei de Lambert-Beer [Leighton, 1959], equação 3.3:

$$
\begin{gathered}
T=e^{-\mu_{i} d} \\
\text { com: } \quad d=\frac{\cos \alpha}{\cos \theta} x \quad \text { e } \quad \mu_{i}=\sum \frac{\rho_{j}}{\rho} \mu_{i, j}
\end{gathered}
$$

onde $\mu_{\mathrm{i}}$ é o coeficiente de atenuação para a dada linha de raios-X $i$ do elemento $j$ calculado a partir da regra de Bragg, como combinação linear dos componentes da matriz, ?=? ? é a densidade de massa da amostra e a distância $d$, caminho de saída, pode ser escrita como função dos ângulos de entrada e saída do feixe.

As densidades superficial do feixe $P\left(y^{\prime}, z^{\prime}\right)$ e a atômica $M_{n}$ do elemento $n$ na amostra, podem ser representadas pelas equações 3.4 e 3.5 , respectivamente:

$$
\begin{gathered}
P\left(y^{\prime}, z^{\prime}\right)=\frac{Q}{q \cdot e \cdot s} \cdot p\left(y^{\prime}, z^{\prime}\right) \\
M_{n}=\frac{N_{0}}{A_{n}} \rho_{n}
\end{gathered}
$$


onde: $Q$ é a carga total depositada sobre o alvo, $p(x, y)$ é a função adimensional de densidade transversal do feixe, $q$ é o estado de carga do íon incidente, $e$ é a carga elementar, s é a seção reta transversal do feixe, $N_{0}$ é o número de Avo gadro e $A_{n}$ é massa molar do elemento.

Substituindo as equações anteriores na equação 3.2, temos:

$$
N_{i}=\frac{\Omega}{4 \pi} \varepsilon_{i} \frac{N_{0}}{A_{n}} \frac{Q}{q \cdot e \cdot s} \iint_{s} \int_{0}^{z} p\left(x^{\prime}, y^{\prime}\right) \cdot \rho_{n} \cdot \sigma_{i}(E) \cdot e^{-\mu_{i} \frac{\cos \alpha}{\cos \theta} x^{\prime}} d x^{\prime} d y^{\prime} \cdot d z^{\prime}
$$

Considerando o feixe incidente homogêneo, a integral em $d s$ é imediata e o número de raios- $\mathrm{X}$ pode ser escrito como:

$$
N_{i}=\frac{\Omega}{4 \pi} \varepsilon_{i} \frac{N_{0}}{A_{n}} \frac{Q}{q \cdot e \cdot s} \rho_{n} \int_{0}^{z} \sigma_{i}(E) \cdot e^{-\mu_{i} \frac{\cos \alpha}{\cos \theta} x^{\prime}} d x^{\prime}
$$

A seção de choque depende da energia do feixe, que por sua vez é função de $x$. O poder de freamento, equação 3.8, fornece a relação entre a energia $E$ e $x$.

$$
d x^{\prime}=-\frac{1}{\rho} \frac{d E^{\prime}}{S(E)} \quad \text { onde } \quad S(E)=\sum_{n} \frac{\rho_{n}}{\rho} S_{n}(E)
$$

onde $S(E)$ é o poder de freamento total e $S_{n}(E)$ é o valor do poder de freamento do n-ésimo elemento químico na amostra.

Juntando as equações 3.7 e 3.8 encontramos a expressão geral para uma análise PIXE em função da energia do íon incidente.

$$
N_{i}=\frac{\Omega}{4 \pi} \varepsilon_{i} \frac{N_{0}}{A_{n}} \frac{Q}{q \cdot e} \frac{\rho_{n}}{\rho} \int_{E_{0}}^{E} \frac{\sigma_{i}\left(E^{\prime}\right) \cdot e^{-\frac{\mu_{i} \cos \alpha}{\rho} \cos \theta} \int_{E_{0}}^{E^{\prime}} \frac{\left(-d E^{\prime \prime}\right)}{S\left(E^{\prime}\right)}}{S\left(E^{\prime}\right)}\left(-d E^{\prime}\right)
$$




\subsubsection{Seção de Choque de I oniz ação}

A seção de choque de produção de raios-X, na equação 3.10, depende da probabilidade de um próton incidente ionizar um elétron de uma camada atômica, ou seja, depende da seção de choque de ionização da camada $\left(s_{i}{ }^{k}\left(E_{0}\right)\right)$ [Tabacniks, 1991]. Uma opção suficientemente precisa para calcular a seção de choque de ionização das camadas $K$ e $L$ é a parametrização polinomial proposta por Johanson e Johanson (1976) mostrada na equação 3.11.

$$
\begin{gathered}
\sigma_{i}(E)=\sigma_{i}^{k}\left(E_{0}\right) \boldsymbol{\sigma}_{i} K \\
\sigma_{i}^{k}(E)=\frac{1}{u_{i}^{2}} \exp \left\{\sum_{n=0}^{5} b_{n}\left[\ln \left(\frac{E_{p}}{\lambda u_{i}}\right)\right]^{n}\right\}
\end{gathered}
$$

onde: ? ${ }_{i}$ é o rendimento fluorescente, $K$ é a razão das intensidades $K_{\beta} / K_{a}, u_{i}$ é a energia de ionização das camadas $\mathrm{K}$ ou L $[\mathrm{eV}]$, para a camada $\mathrm{L}: u_{L}=\frac{1}{4}\left(u_{L 1}+u_{L 2}+2 u_{L 3}\right)$, ? é a razão das massas do próton e elétron $\left(?=\mathrm{m}_{\mathrm{p}} / \mathrm{m}_{\mathrm{e}}=1836,1514\right), E_{p}$ é a energia do próton $[\mathrm{eV}]$. A seção de choque $\mathrm{s}_{\mathrm{i}}$ é dada em $10^{-14} \mathrm{~cm}^{2}$ e os coeficientes $b_{n}$ estão na tabela 3.1 .

Tabela 3.1 Coeficientes do polinômio para o cálculo da seção de choque de ionização da camada K e L [Johanson 1988].

\begin{tabular}{ccccccc}
\hline Camada & $\boldsymbol{b}_{\boldsymbol{0}}$ & $\boldsymbol{b}_{\boldsymbol{1}}$ & $\boldsymbol{b}_{\mathbf{2}}$ & $\boldsymbol{b}_{\mathbf{3}}$ & $\boldsymbol{b}_{\boldsymbol{4}}$ & $\boldsymbol{b}_{\mathbf{5}}$ \\
\hline $\mathbf{K}$ & 2.0471 & -0.0065906 & -0.47448 & 0.09919 & 0.046063 & 0.0060853 \\
$\mathbf{L}$ & 3.6082 & 0.37123 & -0.36971 & $-0.78593 \times 10^{-4}$ & $0.25063 \times 10^{-2}$ & $0.12613 \times 10^{-2}$ \\
\hline
\end{tabular}

\subsubsection{R endimento F luorescente}

A probabilidade de emissão de um fóton no processo de preenchimento de uma vacância numa camada atômica é chamada rendimento fluorescente. Ele pode ser calculado 
usando o ajuste polinomial dado pela equação 3.12 [Johansson, 1988; Bambynec, 1972]. A figura 3.4 mostra o rendimento fluorescente em função do número atômico para transições da camada K.

$$
\varpi_{i}=\frac{\sum_{i=0}^{3} B_{i} Z^{i}}{\left[1+\sum_{i=0}^{3} B_{i} Z^{i}\right]}
$$

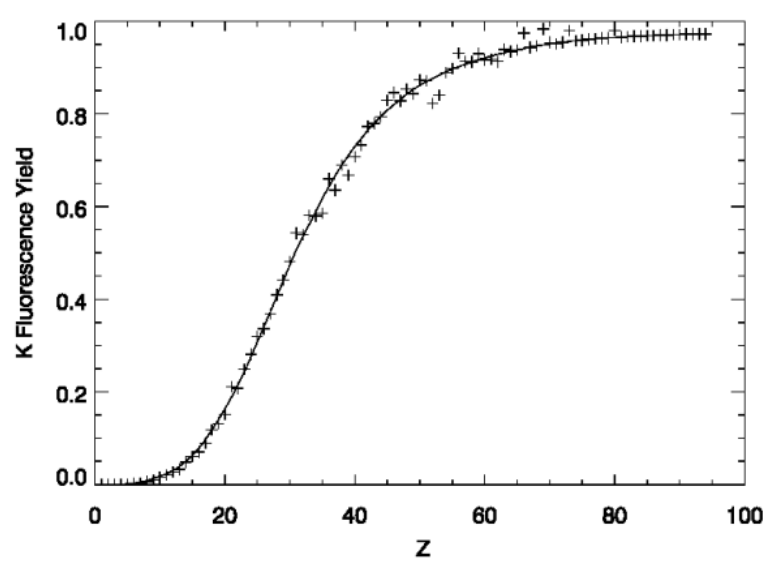

Figura 3.4 Rendimento fluorescente para transições da camada K.

Os coeficientes $B_{i}$ são mostrados na tabela 3.2.

Tabela 3.2 Coeficientes do polinômio para o cálculo do rendimento fluorescente das camadas K e L [Johanson 1988].

\begin{tabular}{ccc}
\hline & $\mathbf{K}$ & $\mathbf{L}$ \\
\hline $\mathbf{B}_{\mathbf{0}}$ & $(3.70 \pm 0.52) \times 10^{-2}$ & 0.17765 \\
$\mathbf{B}_{1}$ & $(3.112 \pm 0.044) \times 10^{-2}$ & $2.98937 \times 10^{-3}$ \\
$\mathbf{B}_{2}$ & $(5.44 \pm 0.11) \times 10^{-5}$ & $8.91297 \times 10^{-5}$ \\
$\mathbf{B}_{3}$ & $-(1.25 \pm 0.07) \times 10^{-6}$ & $-2.67184 \times 10^{-7}$ \\
\hline
\end{tabular}




\subsubsection{Poder de F reamento}

Os valores de perda de energia para prótons incidentes de $25 \mathrm{keV}$ a $10 \mathrm{MeV}$ podem ser obtidos pela parametrização proposta por Ziegler et. al. (1985), para o poder de freamento dada por:

$$
\begin{gathered}
S(E)=\frac{602,22}{A_{n}}\left(\frac{1}{S_{L}}+\frac{1}{S_{H}}\right)^{-1} \\
S_{L}=a \cdot E^{b}+c \cdot E^{d}
\end{gathered}
$$

$A_{n}$ é a massa molar e os coeficientes $a-h$ são tabelados em função de cada elemento (Apêndice B).

\subsubsection{L imite de alvos finos}

Para alvos finos, nos quais o feixe praticamente não perde energia ao atravessar a amostra, a energia da partícula incidente (E) e a seção de choque podem ser consideradas constantes, $\sigma_{\mathrm{i}}(\mathrm{E}) \cong \sigma_{\mathrm{i}}\left(\mathrm{E}_{0}\right)$. Neste caso, os efeitos de auto-absorção pela amostra podem ser desprezados, $\cong 1$ e conseqüentemente a integral da equação 3.9 se torna:

$$
\int_{E_{0}}^{E} \frac{\sigma_{i}\left(E^{\prime}\right) \cdot e^{-\frac{\mu_{i}}{\rho} \frac{\cos \alpha}{\cos \theta} \int_{E_{0}}^{E^{\prime}} \frac{d E^{\prime \prime}}{S\left(E^{\prime \prime}\right)}}}{S\left(E^{\prime}\right)} d E^{\prime} \cong \sigma_{i}\left(E_{0}\right) \rho \cdot \frac{\ell}{\cos \theta}
$$

onde $\rho$ é a densidade de massa da amostras e $\ell$ é a espessura da amostra.

Substituindo a equação 3.14 na 3.9 encontramos o limite para alvo fino. 


$$
N_{i}=\frac{\Omega}{4 \pi} \varepsilon_{i} \frac{N_{0}}{A_{n}} \frac{Q}{q \cdot e \cdot \cos \alpha} \sigma_{i}\left(E_{0}\right) \cdot \rho_{n} \cdot \ell
$$

A equação acima pode ser reduzida na equação 3.16, onde $r_{i}$ (eq. 3.17) é definido como fator resposta ou coeficiente de calibração do sistema PIXE e $(? n l)$ é a espessura do alvo de calibração em massa por unidade de área do elemento $n$.

$$
\begin{gathered}
N_{i}=r_{i} \cdot Q \cdot\left(\rho_{n} \cdot \ell\right) \\
r_{i}=\frac{\Omega}{4 \pi} \varepsilon_{i} \frac{N_{0}}{A_{n}} \frac{1}{q \cdot e \cdot \cos \alpha} \sigma_{i}\left(E_{0}\right)
\end{gathered}
$$

Conhecendo-se o fator resposta para cada elemento e a área total do feixe, pode-se determinar a massa dos elementos presentes na amostra desconhecida, uma vez que:

$$
m_{n}=\left(\rho_{n} \cdot \ell\right) \cdot S_{a}
$$

onde $S_{a}$ é a área total do feixe.

\subsubsection{M edidas A bsolutas por D opagem}

Uma técnica simples para realizar medidas quantitativas de massa consiste em dopar as amostras a serem analisadas com quantidades conhecidas de um elemento padrão interno. As concentrações elementares encontrados na amostra são obtidas em relação à massa irradiada do elemento padrão dopante. Para isso, é necessário que se conheça o número de contagens de raios- $\mathrm{X}$ que se detecta dos elementos, tanto os de interesse como o elemento usado como padrão interno. Denotando-se por $p$ o índice relativo ao padrão interno e $i$ o índice relativo ao elemento de interesse, tem-se para alvos finos: 


$$
\begin{gathered}
\frac{m_{i}}{m_{p}}=\frac{\left(\rho_{n} l\right)_{i} S_{a}}{\left(\rho_{n} l\right)_{i} S_{a}}=\frac{\frac{N_{i}}{r_{i} \cdot Q}}{\frac{N_{p}}{r_{p} \cdot Q}} \\
m_{i}=\frac{N_{i}}{r_{i}} \cdot \frac{r_{p}}{N_{p}} m_{p}
\end{gathered}
$$

Uma vez realizada a calibração, podem-se medir quantidades absolutas de massa de elementos presentes em amostras. Entretanto, para que haja reprodutibilidade nas medidas, devem ser satisfeitas condições quanto à homogeneidade das amostras, à uniformidade do feixe de partículas incidentes e à manutenção da configuração geométrica da experiência [Margulis 1977].

\subsubsection{D etectores Semicondutores}

Os detectores de semicondutores têm assumido maior importância na detecção de raios-X. A maioria desses dispositivos são feitos de silício com lítio difundido $\mathrm{Si}(\mathrm{Li})$ ou de germânio com lítio difundido $\mathrm{Ge}(\mathrm{Li})$. A popularidade destes materiais se deve principalmente a sua capacidade de transporte de carga [Skoog, 2002].

O detector de $\mathrm{Si}(\mathrm{Li})$ é um detector de raios X com alta resolução, suficiente para resolver a linha do silício $(1740 \mathrm{eV})$ da do alumínio $(1485 \mathrm{eV})$, por exemplo. A resolução de um detector de raios $\mathrm{X}$ é usualmente medida pela largura à meia altura da linha Ka do Manganês, que tem energia de $5895 \mathrm{eV}$. O detector é um pequeno diodo de Si dopado com $\mathrm{Li}$, denominado $\mathrm{Si}(\mathrm{Li})$. O cristal de $\mathrm{Si}$ tem o tamanho de um cilindro com aproximadamente 4 a $16 \mathrm{~mm}$ de diâmetro por 3 a $5 \mathrm{~mm}$ de espessura. $\mathrm{O}$ diodo é polarizado reversa mente, abaixo do limite de ruptura de condução. Quando um fóton é absorvido no cristal, produz uma cascata de ionizações e igual número de elétrons quase livres. O campo elétrico aplicado faz com que os elétrons sejam recolhidos no ânodo antes de se recombinarem com as vacâncias. $O$ pulso formado tem amplitude proporcional ao número de elétrons gerados, que por sua vez é 
proporcional à energia do fóton absorvido. Com a tecnologia atual, um detector de $\mathrm{Si}(\mathrm{Li})$ tem resolução da ordem de $140 \mathrm{eV}$.

A figura 3.5, mostra um cristal detector de $\mathrm{Si}(\mathrm{Li})$, os contatos elétricos e também uma fina camada morta (insensível à radiação). O cristal é montado num dedo frio mantido em nitrogênio líquido para reduzir o ruído térmico e assim melhorar a resolução. O cristal tem que ser mantido refrigerado e em vácuo. Uma fina janela de Berílio, com espessura entre 5 e 25 $\mu \mathrm{m}$ é usada para isolar o cristal de $\mathrm{Si}(\mathrm{Li})$ do meio ambiente. A radiação, para ser detectada, deve atravessar a janela de Berílio, o contato frontal ( $\mathrm{Au} \sim 20 \mathrm{~nm}$ ), a camada morta de Si $(\sim 0,1 \mu \mathrm{m})$ e eventualmente uma fina camada de gelo que com tempo costuma condensar em volta (e na frente) do cristal. As diversas espessuras da janela de Be e do cristal determinam a curva de eficiência de detecção, conforme mostrado na Figura 3.6 [Jenkins, 1981]. O tamanho do cristal determina a quantidade de raios- $\mathrm{X}$ absorvidos e que induzem sinal eletrônico para $\mathrm{o}$ sistema de aquisição [Aburaya, 2005].

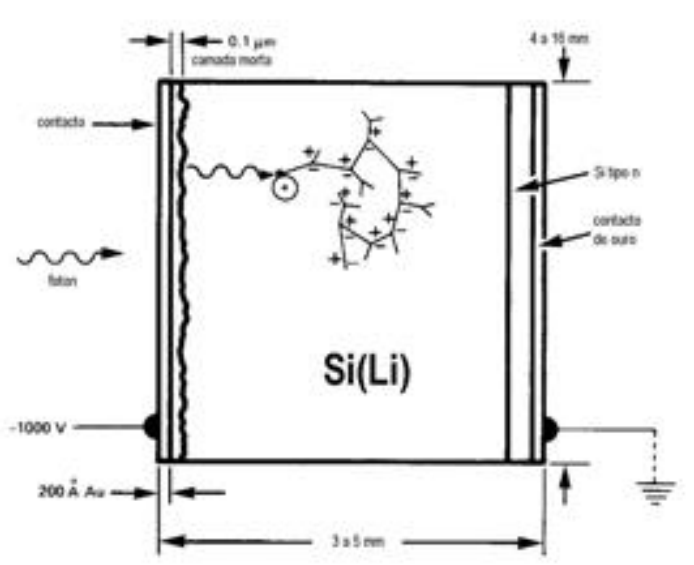

Figura 3.5 Um cristal detector do tipo $\mathrm{Si}(\mathrm{Li})$, os contatos elétricos e também uma fina camada morta (insensível à radiação) [Jenkins, 1981].

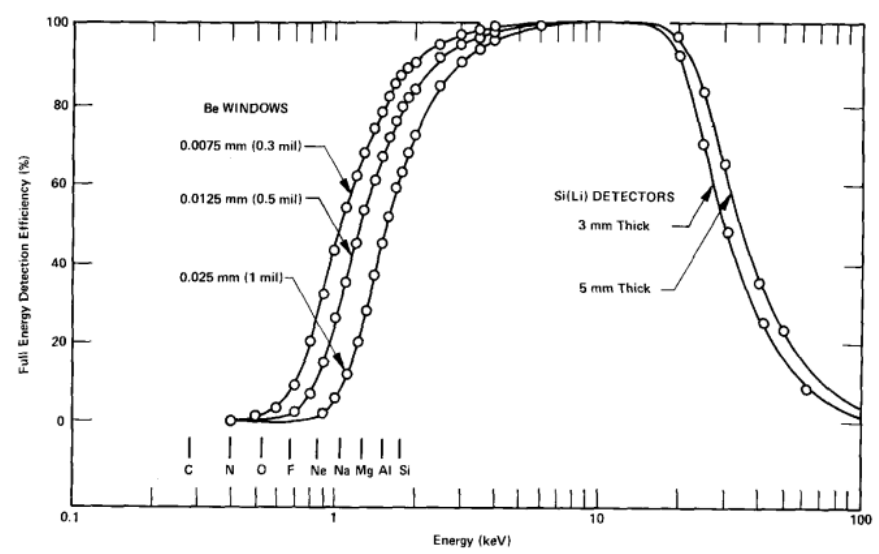

Figura 3.6 Curvas de eficiência relativa de um detector de $\mathrm{Si}(\mathrm{Li})$ com opção para 3 janelas de berílio e duas espessuras do cristal [Jenkins 1981]. 


\section{$3.20 \mathrm{M}$ étodo ICP.M S}

\subsubsection{Introdução}

O espectrômetro de massa é um instrumento que separa íons em movimento, com base em suas razões massa-carga $(\mathrm{m} / \mathrm{z})$. O espectrômetro de massa com fonte de plasma induzido (ICP-MS) começou a ser estudado no começo dos anos 70 com a procura de uma técnica complementar à espectrometria de emissão atômica com fonte de plasma induzido (ICP-AES), principalmente para análise multielementar em amostras geológicas. As principais razões para o surgimento desta nova técnica eram a necessidade de minimizar as interferências espectrais e atingir limites de detecção menores do que os alcançados pelo ICP-AES [Ulrich, 2001].

$\mathrm{Na}$ espectrometria de emissão, os elementos pre sentes em uma amostra são atomizados (podendo também ser ionizados) e excitados. A energia emitida na desexcitação dos átomos (na forma de radiação eletromagnética) é então medida. Na espectrometria atômica de massa, as amostras também são atomizadas, mas os átomos gasosos são convertidos em íons positivos e separados com base em suas razões massa-carga [Skoog, 2002].

No começo dos anos 80 iniciourse a comercialização do ICP-MS, que com o decorrer dos anos cresceu e se tornou uma das técnicas mais importantes para análise elementar. $\mathrm{O}$ significante crescimento de publicações científicas com a técnica desde 1980 até 1996 pode ser visto na figura 3.7 [Montaser, 1998]. Os espectrômetros de massa mais utilizados são o de massa quadrupolar, o de tempo de vôo e o de dupla focalização. 


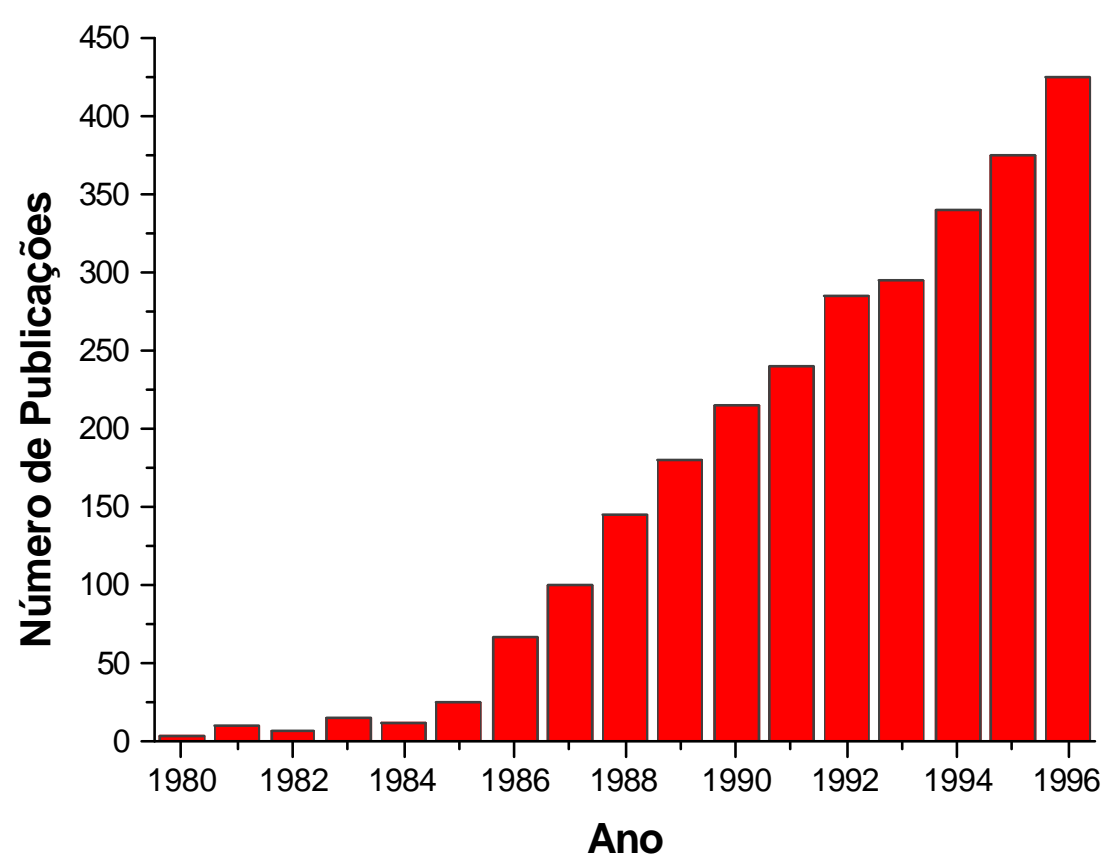

Figura 3.7 Crescimento do número de publicações utilizando o método ICP-MS desde 1980 até 1996 [Montaser, 1998].

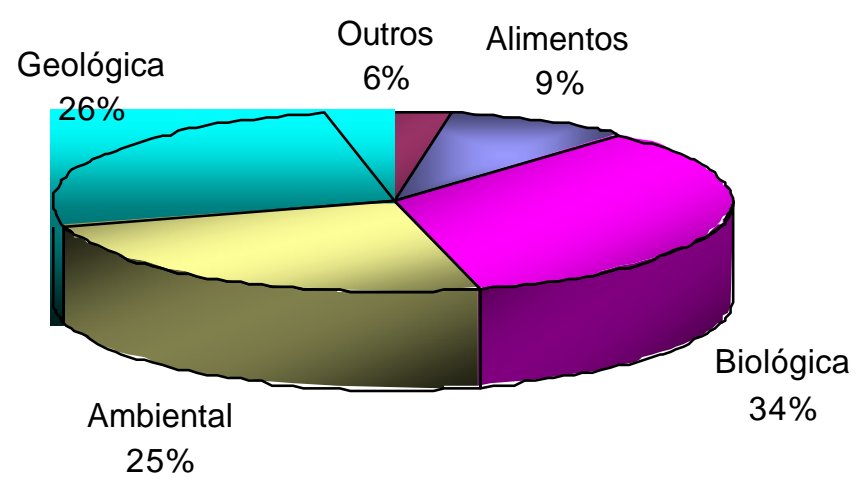

Figura 3.8 Publicações nas diferentes áreas de aplicação do ICP-MS desde 1980 até 1995, em porcentagem [Montaser, 1998]. 
O ICP-MS é uma ferramenta versátil e largamente usada na identificação dos elementos presentes em diversas amostras. Suas principais aplicações são na geoquímica, área ambiental, biológica e de alimentos, como mostra a figura 3.8, e isto se deve aos baixos limites de detecção, a seu alto grau de seletividade, a sua razoável precisão e exatidão, à rápida detecção das razões isotópicas, ao pequeno volume de amostras, além, é claro, à capacidade multielementar. Cerca de $90 \%$ dos elementos podem ser determinados com limites de detecção na faixa de 0,1 a $0,001 \mu \mathrm{g} / 1$ (ppb) em soluções aquosas [Veiga, 2000].

\section{2 .20 ICP-MS}

Um espectrômetro de massa com fonte de plasma induzido (ICP-MS) é composto por 5 parte principais: sistema de introdução de amostras, ICP (fonte de íons), interface (focalização), sistema analisador e sistema de detecção de íons. $\mathrm{Na}$ figura 3.9 podemos observar um esquema de um ICP-MS convencional.

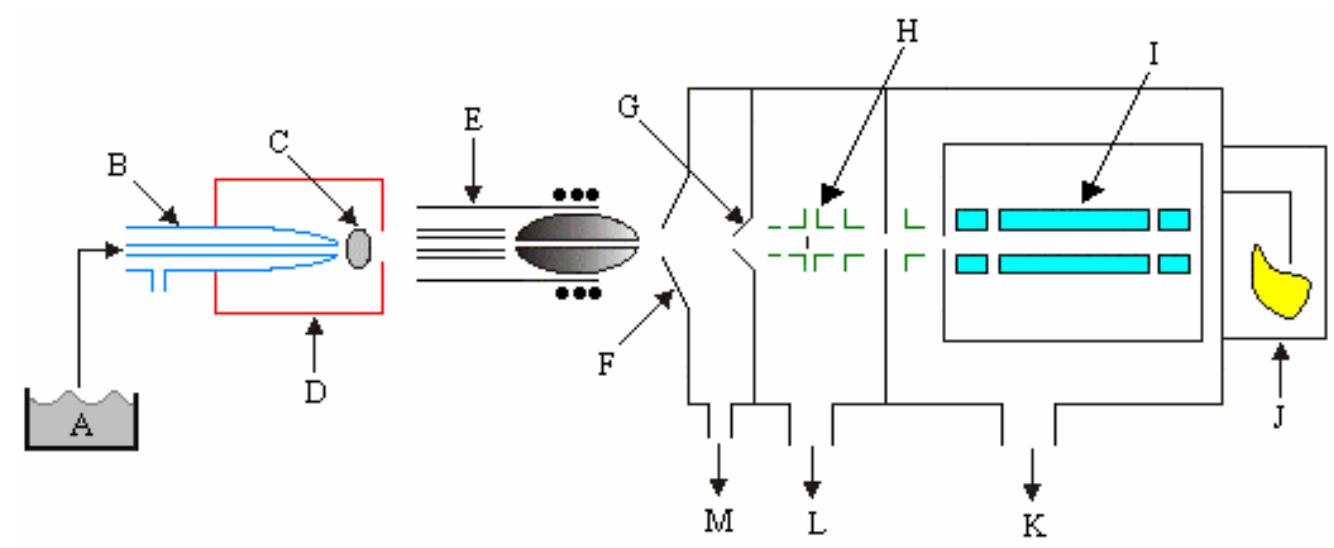

Figura 3.9 Esquema de um sistema ICP-MS convencional. Onde: A é a amostra líquida; B, o nebulizador; C, o aerossol; D, a câmara de nebulização; E, a tocha de ICP; F, o cone amostrador; G, o cone skimmer; H são as lentes iônicas; I é o analisador de massa; J, o sistema de detecção; Ke L são bombas de vácuo turbo-molecular (alcançam vácuo de $5 \times 10^{-9}$ barr e $<1 \times 10^{-7}$ barr, respectivamente) e M é a bomba de vácuo mecânica ( $2 \times 10^{-3}$ barr). 


\subsubsection{Introdução de A mostras}

As amostras podem ser introduzidas no estado sólido, líquido ou gasoso. A introdução mais utilizada é de amostras líquidas, apresentando vantagens de homogeneidade, facilidade de manipulação e disponibilidade de solução padrão para calibração.

Para a análise de amostras líquidas, o sistema de introdução de amostras conve ncional é formado por uma bomba peristáltica, um nebulizador pneumático do tipo Meinhard (PN) e uma câmara de nebulização, como mostra a figura 3.10. A amostra é bombeada até o nebulizador onde é transformada em uma fina névoa. O fluxo de argônio carrega a amostra vaporizada até a tocha do ICP, onde é ionizada. [Skoog et al., 2002]. Os nebulizadores ultrasônico (USN) e microconcêntrico (MCN), que necessitam de um menor fluxo de solução, também podem ser utilizados [Mc Leon, 1998].

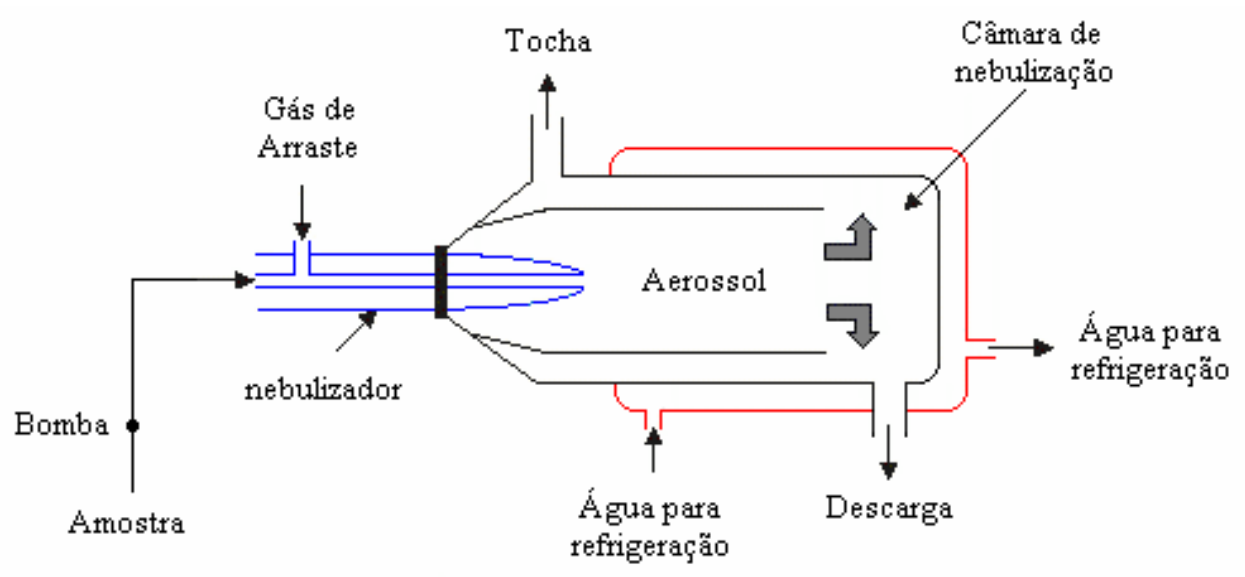

Figura 3.10 Esquema de introdução de amostras constituído por um nebulizador e uma câmara de nebulização. O gás de arraste normalmente utilizado é o argônio.

O nebulizador PN tem boa eficiência, com a vantagem de tolerar soluções com uma maior quantidade de sólidos e de ser menos susceptível a instabilidades. O MCN, por outro lado, é mais eficiente que o PN, assim, consegue aumentar em duas vezes a sensibilidade para a maioria dos elementos, porém é mais susceptível a variações na pressão do gás de arraste e na viscosidade da solução. Não aceita soluções com elevado teor de sólidos devido ao 
diâmetro extremamente pequeno do capilar central. O nebulizador ultra-sônico é mais eficiente que os anteriores, nele a amostra é bombeada para a superfície de um cristal piezoelétrico que vibra com uma frequîencia de $20 \mathrm{kHz}$ a vários $\mathrm{MHz}$. Ele é capaz de produzir gotículas de solução muito pequenas e aerossóis mais densos e homogêneos. Neste caso, chega de 10 a 20 vezes mais solução ao plasma, aumentando a eficiência de determinação analítica [Potts, 1987 e Furusawa, 1999].

O sistema de introdução de amostras sólidas mais comum é o de Laser Ablation, onde a amostra é atingida por um feixe de raio laser, vaporizando um determinado volume de amostra. Um gás de arraste, geralmente Ar, carrega as partículas resultantes até o ICP [Skoog et al, 2002].

A introdução de amostras gasosas, Hydride Genarator, é mais comum em processos de geração de vapor frio, tais como As, Hg e Se [Skoog et al., 2002].

\subsubsection{F onte de Íons - Tocha e Plasma}

O plasma é um gás com os átomos em estado excitado e total ou parcialmente ionizado. Ele é gerado na tocha, que consiste de três tubos ${ }^{1}$ concêntricos para o transporte de gás, como mostra a figura 3.11a). As temperaturas máximas alcançadas no plasma são da ordem de $10000 \mathrm{~K}$ no centro e aproximadamente $800 \mathrm{~K}$ nas extremidades.

O fluxo de gás externo, designado fluxo refrigerante, isola termicamente as paredes do tubo, evitando o superaquecimento e protegendo as paredes da tocha (10 a $15 \mathrm{~L} / \mathrm{min}$ ). O fluxo auxiliar, introduzido no tubo intermediário, é usado para assegurar que o plasma quente mantenha-se claro e límpido na ponta do tubo injetor do capilar central, prevenindo sua fusão, sendo, portanto, utilizado para estabilizar o plasma durante a introdução de amostras. A vazão usada depende da geometria da tocha empregada e pode variar de 0 a 1,5 L/min. $\mathrm{O}$ gás interno, também chamado de gás de arraste ou carregador, transporta a amostra nebulizada até o plasma (0,5 a 1,5 L/min) [Potts, 1987 e Skoog, 2002].

\footnotetext{
${ }^{1}$ Os tubos são geralmente de quartzo e suas dimensões aproximadas variam de 3 a 20mm de diâmetro para os tubos injetor e externo, respectivamente.
} 
A tocha é adaptada a uma bobina de indução, resfriada por água ou ar, alimentada por um gerador de radiofreqüência (RF) que é capaz de produzir de 2 a $5 \mathrm{~kW}$ de potência, com frequiência de 27 ou $41 \mathrm{MHz}$. A corrente de RF que circula através da bobina gera um campo magnético oscilante, figura 3.11b), que produz uma região de indução. A ionização do fluxo de argônio é iniciada por uma faísca proveniente da bobina Tesla, que fornece alguns íons e elétrons livres [Skoog, 2002]. Estes íons e elétrons livres giram em torno das linhas do campo magnético em órbitas circulares e a energia fornecida pela bobina é convertida em energia cinética dos elétrons. Os elétrons ${ }^{2}$ são assim, acelerados e produzem mais íons à medida que colidem com os átomos do gás, fazendo com que a temperatura alcance 7500-8000K nas regiões mais quentes. Uma vez que as temperaturas de ionização são atingidas, o processo é auto-sustentável, e um plasma é formado quase que instantaneamente [Veiga, 2000].

A figura 3.12 mostra os estágios pelos quais atravessa o analito durante a atomização por chama. Primeiramente, a amostra líquida é nebulizada, transforma-se em aerossol, e, no canal central do plasma sofre dessolvatação, passando a sólido. As partículas são, então, volatilizadas (passando a gás) e em seguida as moléculas de vapor são atomizadas (dissociação). Os átomos formados são, então, excitados e ionizados. O analito emerge da tocha como uma mistura de íons e átomos, fragmentos moleculares que podem, ainda, permanecer não dissolvidos. Uma vez que o gás no canal central deixa a tocha, a temperatura começa a cair possibilitando a recombinação dos íons, levando à formação de óxidos [Veiga, 2000].

A fonte de íons é necessária para produzir partículas carregadas que interajam com os campos elétricos e magnéticos e sejam desviadas conforme sua razão m/z. O plasma utilizado na produção de íons do ICP-MS é o mesmo utilizado nas técnicas de emissão atômica (ICPAES), porém, operando em condições ligeiramente diferentes para que favoreça a produção de íons e não a emissão de radiação, embora os dois fenômenos ocorram simultaneamente [Furusawa, 1999].

\footnotetext{
${ }^{2}$ Os íons de argônio e os elétrons livres são acelerados pelo campo magnético, mas os elétrons são acelerados a maiores velocidades, devido a suas pequenas massas, por esta razão as transferências de energia no plasma são dominadas pelos processos envolvendo os elétrons.
} 
(a)

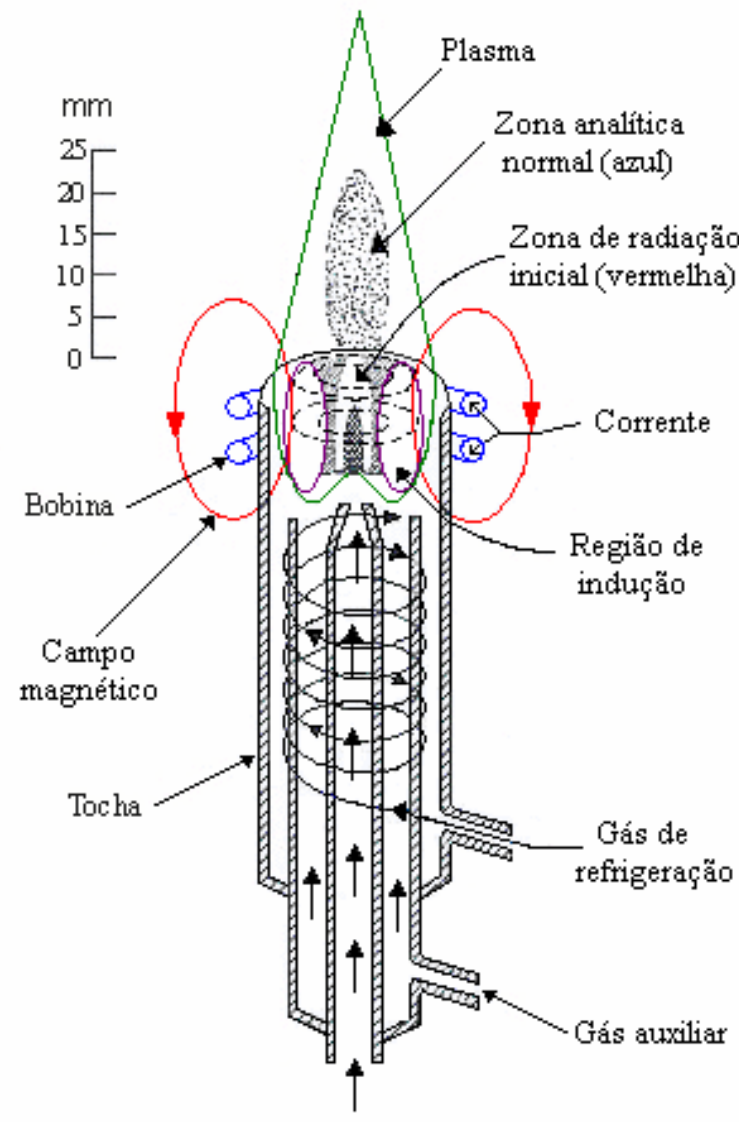

Gás de arraste (b)

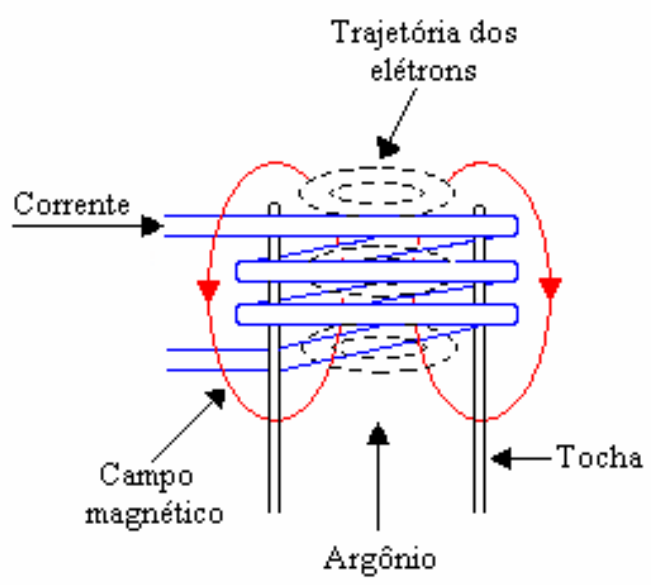

Figura 3.11 (a) Esquema de uma tocha, constituída de três tubos concêntricos, acoplada a uma bobina de indução de um gerador de RF, (b) Representação do campo magnético gerado pela corrente que circula a bobina [Potts, 1987].

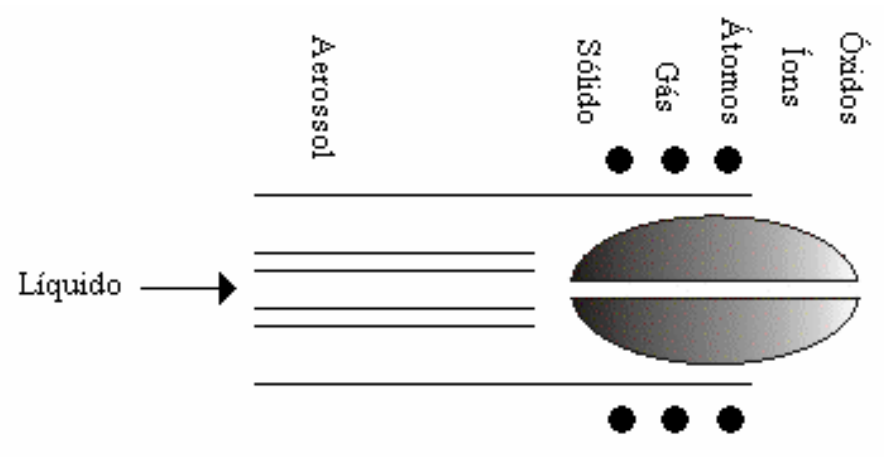

Figura 3.12 Representação dos processos que ocorrem no plasma. 


\subsubsection{Interface}

A interface acopla a tocha de ICP ao espectrômetro de massa (analisador) ${ }^{3}$. O feixe de íons formado no plasma é extraído desta região por uma diferença de pressão e lançado para a região de alto vácuo. O plasma gasoso atravessa o pequeno orifício $(<1 \mathrm{~mm})$ do cone de amostragem, figura 3.13, para uma região com aproximadamente 1 torr (pré-vácuo). Nesta região ocorre uma rápida expansão do gás, o que resulta em seu resfriamento. Da mesma forma, uma fração deste gás passa através do pequeno orifício de um segundo cone $(<1 \mathrm{~mm})$ denominado Skimmer, e em seguida para uma câmara mantida à pressão do espectrômetro de massa. Nesta câmara, os íons positivos são separados dos elétrons e das espécies moleculares por um ptencial negativo, são acelerados e focalizados por uma lente magnética de íons, seguindo então para o orifício de entrada de um analisador de massa quadrupolar [Skoog 2002].

A principal função da interface é reduzir a pressão e a densidade do feixe, minimizando a perda de íons. As lentes melhoram a sensibilidade e limites de detecção instrumental [Pedreira Filho, 2000].

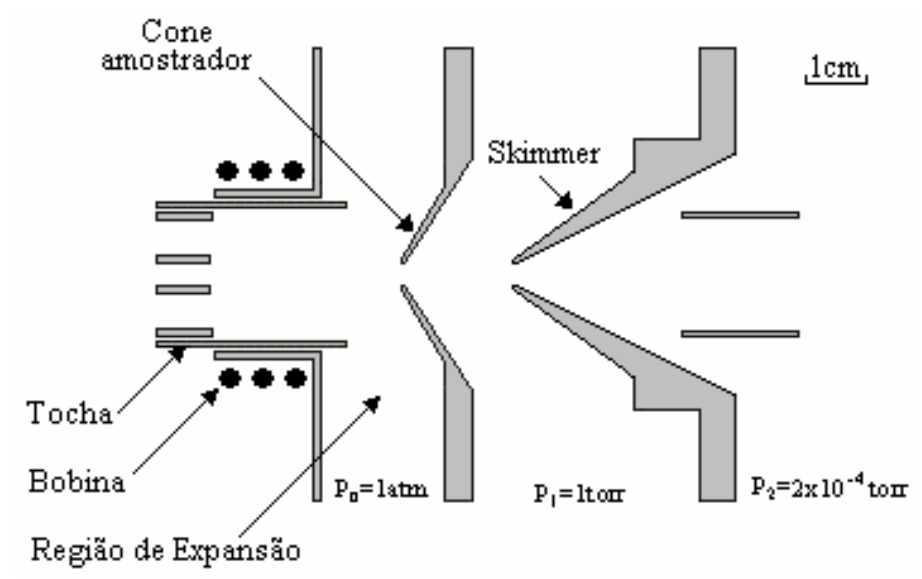

Figura 3.13 Configuração do cone de amostragem, do estágio de expansão e do cone Skimmer.

\footnotetext{
${ }^{3}$ A tocha de ICP opera a pressão atmosférica e o espectrômetro de massa requer pressões menores que $10^{-4}$ torr.
} 


\subsubsection{A nalisadores}

\section{- Analisadores de M assa de Tempo de V ôo}

Nos instrumentos tipo tempo de vôo, conforme ilustra a figura 3.14, os íons vindos da fonte de plasma são acelerados por um pulso de campo elétrico de $10^{3}$ a $10^{4} \mathrm{~V}$. As partículas aceleradas passam por um tubo de separação livre de campo. Como todos os íons no tubo têm, idealmente, a mesma energia cinética, suas velocidades devem variar inversamente com suas massas, de modo que \& íons de mesma massa atingem o detector no mesmo intervalo de tempo, enquanto os íons de maior massa gastem um tempo maior para percorrer a distância do acelerador até o detector e assim é possível identificar diferentes massas pela duração do tempo de vôo de cada uma. No detector, é focalizado apenas o íon de determinado tempo de vôo que corresponde à massa de interesse, rejeitando-se outros com tempos de vôo diferentes.

A resolução e a reprodutibilidade dos instrumentos que empregam separadores por tempo de vôo não são tão satisfatórias como os baseados em separadores magnéticos ou de quadrupolo descritos adiante. Entretanto, muitas vantagens reduzem parcialmente estas limitações, incluindo a simplicidade, a facilidade de acesso à fonte de íons, o intervalo de massas virtualmente ilimitado e a alta velocidade de aquisição de dados. Este tipo de espectrômetro é menos utilizado que o espectrômetro de massa quadrupolar [Skoog et al., 2002 e Sato \& Kawashita, 2002].

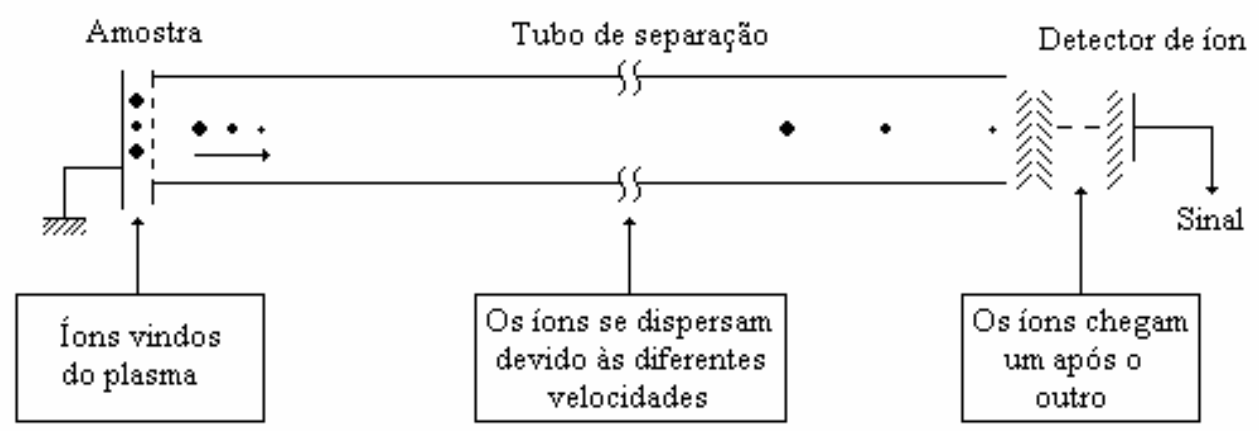

Figura 3.14 Princípios de um analisador de massa de tempo de vôo. Um pacote de íons vindos do plasma é acelerado e separado em um tubo de deriva. 


\section{- A nalisadores de D upla focalização}

O espectrômetro de massa de dupla focalização contém dois dispositivos para a focalização de um feixe de íons: um analisador eletrostático e um analisador de setor magnético, como mostra a figura 3.15. Neste instrumento, os íons de uma fonte são acelerados ao passarem através de uma fenda na direção do campo elétrico radial, que serve para focalizar um feixe de íons, com energia cinética compreendida dentro de um intervalo estreito de valores. Ao sair desta primeira fenda, o feixe é dirigido a uma outra fenda, que leva a um campo magnético radial. Dentro desse campo, os íons mais leves são defletidos ao máximo e os mais pesados, ao mínimo. Os íons dispersos caem na placa fotográfica e são registrados [Skoog, 2002].

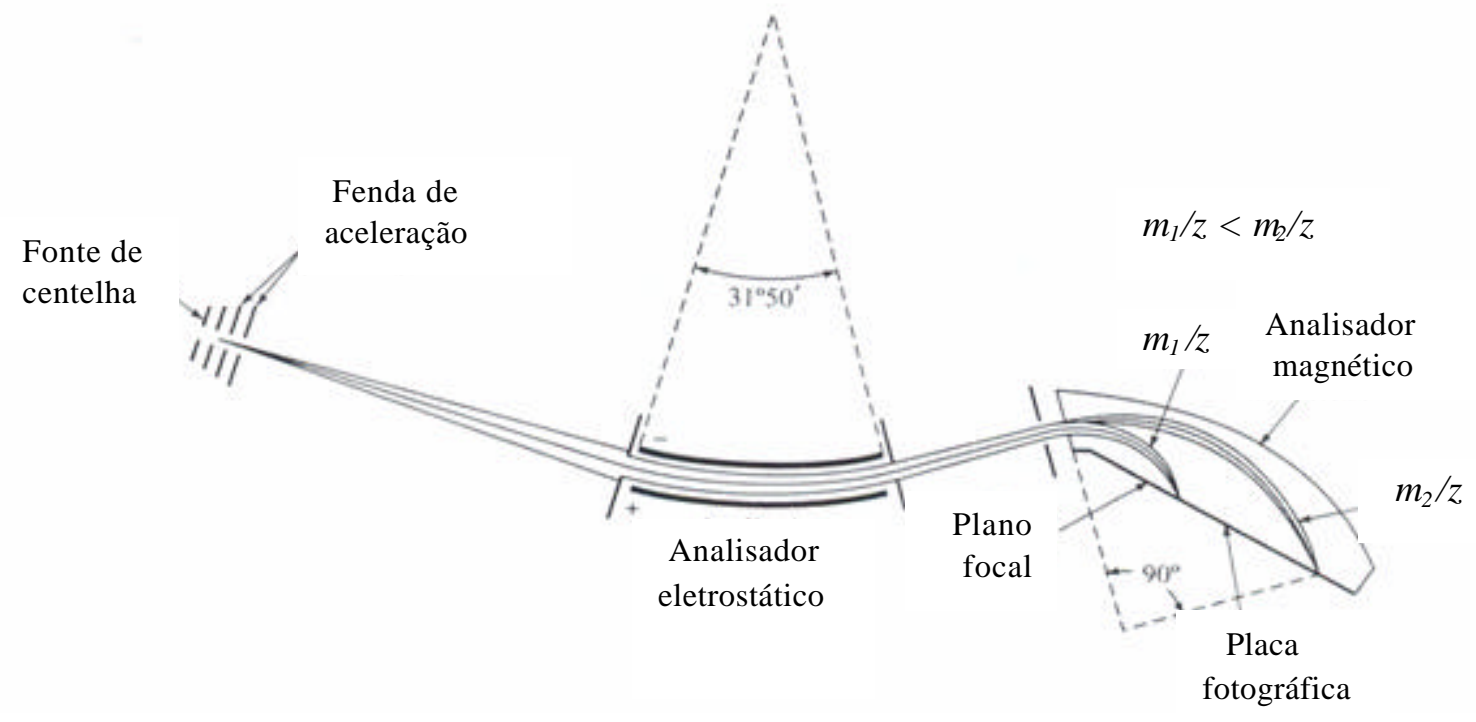

Figura 3.15 Espectrômetro de massa de dupla focalização tipo Mattacuh-Herzog. Resoluções $>10^{5}$ têm sido atingidas.

\section{- A nalisadores de M assa Quadrupolares}

O analisador de massa quadrupolar é o mais usado em espectrometria de massa atômica. Esse instrumento é mais compacto, mais barato e mais robusto que os outros tipos de 
espectrômetro de massa. Tem a vantagem de possuir altas velocidades de varredura, de forma que um espectro inteiro pode ser obtido em menos de 100ms [Shoog, 2002].

Um analisador quadrupolar é composto por quatro hastes condutoras paralelas mantidas numa configuração duas a duas (figura 3.16a). Cada vareta deveria ser idealmente de formato hiperbólico para gerar a distribuição de campo elétrico exigida. Na prática, muitos sistemas são produzidos usando hastes arredondadas com um espaço entre os eletrodos, obtendo-se desta forma a melhor aproximação do campo ótimo com custo reduzido e facilidade na construção [Montaser, 1998].

a)

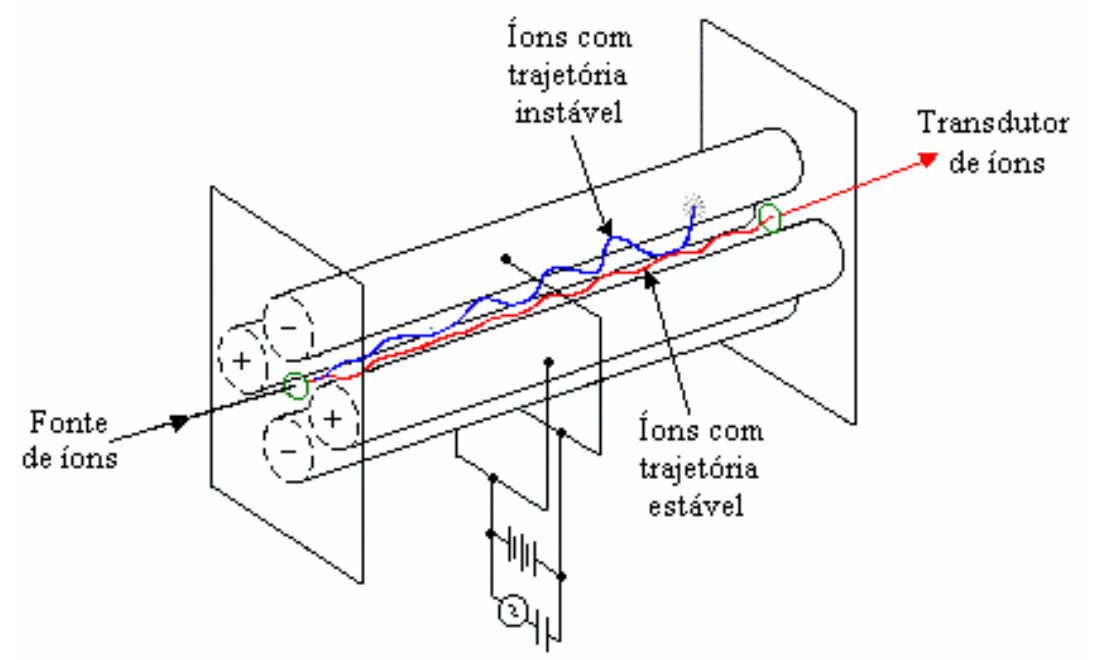

b)

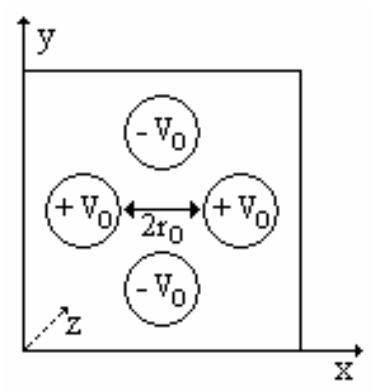

Figura 3.16 a) Esquema de um espectrômetro de massa quadrupolar. A figura mostra também o movimento dos íons através do campo gerado entre as hastes. b) Vista frontal das hastes.

As hastes opostas são conectadas eletricamente, um par sendo ligado ao lado positivo de uma fonte CC e o outro par ligado ao terminal negativo estabelecendo assim, um campo quadrupolar bidimensional no plano x-y. Os íons que entram no espectrômetro são acelerados pelo potencial aplicado nas varetas, de 5 a $10 \mathrm{~V}$, e viajam na direção z (figura 3.16b). Além disso, são aplicados a cada par de hastes, potenciais CA de radiofrequiência variável, que são iguais, mas de fase oposta [Montaser, 1998; Shoog, 2002]. 
A seletividade do filtro quadrupolar é estabelecida variando-se as magnitudes das voltagens CA e CC simultaneamente de forma que sua razão seja mantida constante para cada par de hastes. A variação das voltagens provoca um movimento oscilatório complexo do feixe de íons nas direções $x$ e $y$. A dispersão do movimento depende da magnitude dos campos aplicados CA e CC. Esta é uma propriedade da razão massa/carga dos íons individuais. Portanto, íons com uma razão específica de massa/carga reagirão todos igualmente em relação ao potencial elétrico imposto pelo arranjo quadrupolar. Sob condições elétricas apropriadas, os íons com uma única razão massa/carga terão uma trajetória estável para o caminho total do quadrupolo. Normalmente um instrumento quadrupolar consegue separar espécies que diferem por menos de uma unidade de massa [Shoog, 2002; Potts, 1987].

\subsubsection{Sistemas de D etecção}

A detecção dos íons mos instrumentos mais antigos era feita com uma tela fluorescente. As versões mais atualizadas de ICP-MS são dotadas de um sistema de detecção simultânea de íns, tais como: multiplicador de elétrons, o copo de Faraday e o detector Daly.

\section{- Multiplicador de Elétrons}

A figura 3.17 mostra um esquema de um multiplicador de elétrons de dinodo discreto, projetado para a detecção de íons positivos. O catodo e os dinodos têm superfícies de $\mathrm{Cu} / \mathrm{Be}$ a partir das quais os elétrons são expelidos quando atingidos por íons ou elétrons mais energéticos. Fornecem um ganho de corrente de $10^{7}$ e tem até 20 dinodos, com cada um deles sendo submetido a uma voltagem sucessivamente crescente [Skoog, 2002].

Um outro tipo de multiplicador de elétrons é o de dinodo contínuo, figura 3.18, feito de vidro em forma de trompa e dopado com chumbo. Os íons que atingem a superfície ejetam elétrons que, a cada impacto, ejetam mais elétrons formando uma cascata. Transdutores desse 
tipo fornecem ganho de corrente de $10^{5}$, que em alguns casos chega a $10^{8}$, e tem um potencial acelerador de 1,8 a $2 \mathrm{kV}$.

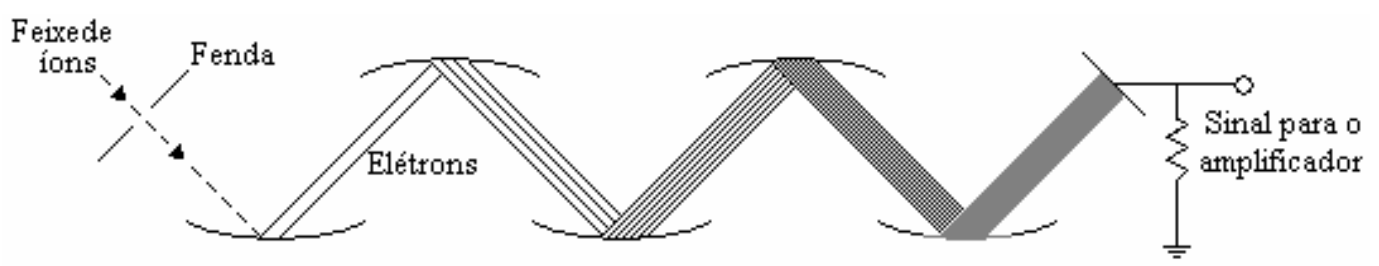

Figura 3.17 Multiplicador de elétrons de dinodo discreto. Os dinodos são submetidos a potenciais sucessivamente mais altos por meio de um divisor de voltagem multiestágio.

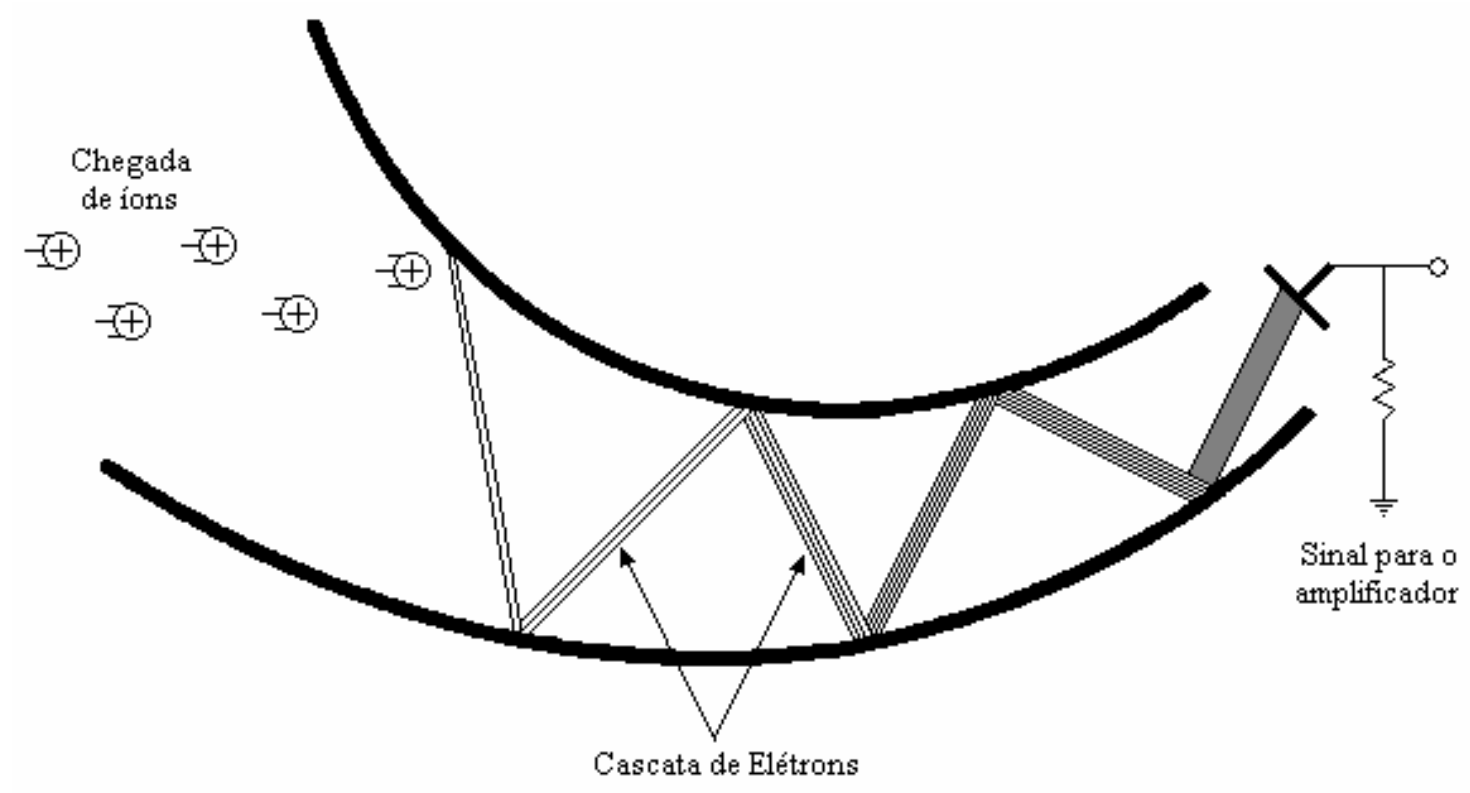

Figura 3.18 Multiplicador de elétrons de dinodo contínuo.

\section{- 0 Copo de F araday}

A figura 3.19 mostra um esquema de um coletor tipo copo de Faraday. O eletrodo coletor está inclinado em relação ao feixe dos íons que chega, de forma que as partículas que 
atingem ou deixam o eletrodo sejam refletidas para longe da entrada do copo. O eletrodo coletor e a gaiola estão conectados ao terra através de um resistor. O fluxo de íons positivos que chega continuamente à placa é neutralizado por elétrons provenientes do terra, que sobem através do resistor. A queda de potencial resultante através do resistor é amplificada por um amplificador de alta impedância. A resposta desse transdutor é independente da energia, da massa e da natureza química do íon. Um copo Faraday é eletricamente simples e barato, sua principal desvantagem é a necessidade de um amplificador de alta impedância, que limita a velocidade com que um espectro pode ser varrido. Ele também é menos sensível que os multiplicadores de elétrons, porque não fornece amplificação interna [Skoog et al, 2002 e Sato \& Kawashita, 2002].

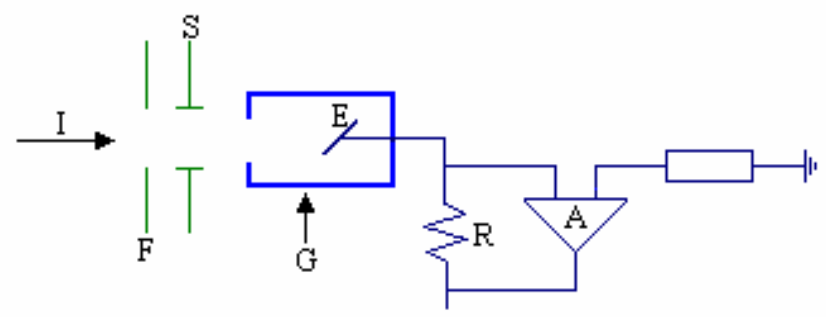

Figura 3.19 Detector tipo copo de Faraday. Os elétrons fluem através do resistor neutralizando os íons. Onde: I representa o feixe de íons; F, a fenda; S, o supressor de íons; E, o eletrodo coletor; G, a gaiola de Faraday; R, o resistor e A, o amplificador.

\section{- 0 Detector Daly}

Alguns espectrômetros de massa oferecem dois detectores de íons: o copo de Faraday, para a maioria das aplicações, e o detector Daly, quando é necessário maior sensibilidade. $\mathrm{O}$ detector Daly é o detector de íons mais sensível disponível em rotinas com o espectrômetro de massa e é usado quando um sinal muito pequeno precisa ser medido. Ele consiste em um eletrodo mantido em alto potencial negativo $(-30 \mathrm{kV})$ e um faiscador acoplado a um fotomultiplicador, figura 3.20. 
Os íons transmitidos, através de uma fenda de saída do analisador de massa, são acelerados e desviados para o eletrodo por um alto potencial negativo. No impacto são ejetados, em média, oito elétrons secundários por íon que são repelidos na direção oposta, onde se encontra um cintilador a base de fósforo. Estes elétrons emitidos são convertidos em pulsos de luz no cintilador e são acusados pelo eletrodo fotossensível da válvula fotomultiplicadora. Este detector pode oferecer contagens de fundo extremamente baixas, se comparados com outros detectores [Potts, 1987 e Sato \& Kawashita, 2002].

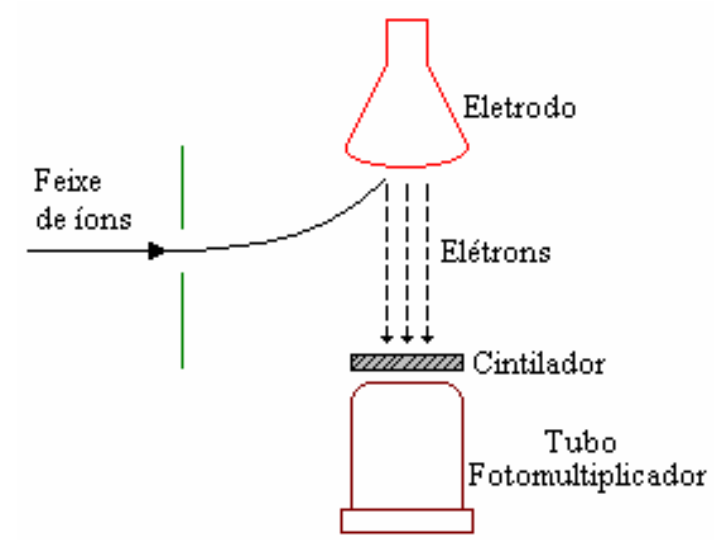

Figura 3.20 Esquema de um detector tipo Daly.

\section{- 0 Detector Analógico}

Grandes concentrações elementares necessitam de um dispositivo analógico para a medida do sinal, pois a contagem de íons não pode ser usada acima de aproximadamente $10^{6}$ íons/s. Isto pode ser realizado de duas maneiras. Primeiramente, é possível reduzir a tensão aplicada ao multiplicador de elétrons secundário usado no sistema de contagem de íons, de modo que o ganho médio seja reduzido de $10^{8}$ para algo em torno de $10^{3}$. Desta forma, a corrente de saída do coletor pode ser usada como uma medida direta da corrente de entrada. Alternativamente, o feixe de íons pode ser dirigido a um coletor tipo copo de Faraday junto com um sistema amplificador dc. Este dispositivo pode ser usado para medir diretamente 
correntes até o limite inferior de $10^{-15} \mathrm{~A}\left(10^{4}\right.$ íns/s), assim há uma sobreposição com a escala superior do sistema de contagem de íons.

O coletor de Faraday é extremamente robusto e pode ser usado eficazmente, sem prejuízo do sistema multiplicador, para medir amostras desconhecidas que podem conter elevadas concentrações de elementos não especificados. A linearidade é excelente, de modo que as medidas da razão isotópica podem ser conduzidas com mais exatidão. As desvantagens do detector de Faraday são a alta constante de tempo, que impossibilita uma leitura rápida, e a uma menor sensibilidade, a qual resulta em limites de detecção $10^{3}$ mais elevados do que aqueles obtidos por detectores multiplicadores.

\section{- Sistema de Detecção Dual}

Os instrumentos de alta resolução de ICPMS são equipados tipicamente com detectores similares àqueles usados em sistemas quadrupolares de baixa resolução. Para um analisador de dois setores, o sistema de contagem de íons deve ter uma baixa taxa de contagem de fundo, devido a sua alta capacidade de filtragem, o ruído inerente no coletor é quase duas ordens de grandeza menor do que aquele do analisador de massa quadrupolar. As taxas de contagem de fundo do sistema podem estar bem abaixo de 0,02 contagens/s, para o quadrupolo este valor varia de 2 a 50 contagens/s. Este fundo baixo conduz a limites de detecção muito baixos para instrumentos magnéticos. Um arranjo ligeiramente diferente daquele descrito acima pode ser usado para tratar da grande extensão dos sinais que chegam no coletor para os sistemas quadrupolo ou setorizados (ou de dois setores). Em vez de usar um coletor de Faraday para correntes elevadas, o modo analógico de um multiplicador de elétrons secundário de um analisador de dois setores é utilizado. O sinal pode ser extraído em dois pontos: no fim da corrente do multiplicador ou em algum ponto ao longo da corrente. Para sinais baixos, o pulso normal de saída é usado, mas em níveis elevados de sinal, um sinal de saída analógico pode ser obtido ao longo da corrente do multiplicador. Um sistema de monitoramento automático pode ser usado para selecionar a modalidade apropriada. A mudança é rápida. Inclusive, é possível mudar coletores dentro de uma única varredura. Esta mudança rápida não é possível 
em um sistema do coletor tipo Faraday. Entretanto, a modalidade analógica do multiplicador é menos estável do que o sistema de Faraday. O ganho do multiplicador de elétron analógico depende exponencialmente do valor do coeficiente secundário de emissão de elétrons da superfície multiplicadora, e pequenas mudanças neste coeficiente causarão modificações substanciais no ganho analógico. As próprias mudanças induzidas na superfície multiplicadora pela cascata de elétrons causarão uma variação do ganho. Em alguns instrumentos ICPMS, os dois sistemas de contagem podem ser conduzidos simultaneamente.

\subsubsection{Interferências}

Embora o ICP-MS seja uma poderosa técnica, um de seus maiores problemas é a susceptibilidade a interferências, que podem ser dividas em duas categorias: interferências espectroscópica s e não-espectroscópicas [Veiga, 2000].

\subsubsection{Interferências E spectroscópicas}

As interferências espectroscópicas podem ocorrer quando uma espécie iônica no plasma tem a mesma razão massa-carga ( $\mathrm{m} / \mathrm{z})$ que um íon do analito [Skoog, 2002]:

\section{- Interferências I sobáricas}

A sobreposição isobárica ocorre quando dois elementos possuem isótopos de mesma massa. Esta interferência raramente impede uma determinação, pois a maioria dos elementos da tabela periódica possui um, dois ou até três isótopos que estão livres da superposição isobárica. Uma exceção é o índio, que tem dois isótopos estáveis ${ }^{113} \operatorname{In}$ e ${ }^{115} \mathrm{In}$. O primeiro superpõe-se com o ${ }^{113} \mathrm{Cd}$ e o segundo com o ${ }^{115} \mathrm{Sn}$. Normalmente, uma interferência isobárica 
ocorre com os isótopos mais abundantes. Um exemplo é a superposição do pico de ${ }^{40} \mathrm{Ar}$ com o pico do isótopo mais abundante do cálcio, o ${ }^{40} \mathrm{Ca}(97 \%)$, tornando necessário o uso do segundo isótopo mais abundante, o ${ }^{44} \mathrm{Ca}(2,1 \%)$. O maior problema, neste caso, é se o isótopo escolhido for de abundancia muito pequena e a concentração a ser determinada for muito baixa. Como as superposições isobáricas são previstas pelas tabelas de abundancia, as correções deste problema podem ser feitas com uso de um software apropriado que leva em consideração as abundâncias isotópicas naturais dos elementos químicos [Veiga, 2000; Skoog, 2002 e Navarro, 2004].

\section{- Interferências por Í ons Poliatômicos}

As espécies poliatômicas são formadas pela combinação de espécies abundantes no plasma (Ar do gás de arraste, $\mathrm{O}$ e $\mathrm{H}$ da água e ácidos, $\mathrm{N}, \mathrm{S}$ e $\mathrm{Cl}$ dos ácidos utilizados na preparação das amostras) e na matriz do analito. Os possíveis íons moleculares formados podem interferir. Essas interferências são mais encontradas em valores de m/z abaixo de 82, sendo uma das principais causas dos pobres limites de detecção nesta fixa de massa. Algumas das interferências poliatômicas mais sérias incluem: ${ }^{14} \mathrm{~N}_{2}{ }^{+}$com ${ }^{28} \mathrm{Si}^{+}, \mathrm{NOH}^{+}$com ${ }^{31} \mathrm{P}^{+}$, ${ }^{16} \mathrm{O}_{2}{ }^{+} \mathrm{com}{ }^{32} \mathrm{~S}^{+},{ }^{40} \mathrm{ArO}^{+}$com ${ }^{56} \mathrm{Fe}^{+}$e ${ }^{40} \mathrm{Ar}_{2}{ }^{+}$com ${ }^{80} \mathrm{Se}^{+}$. Alguns dos problemas podem ser corrigidos com vários métodos propostos, tais como: o uso de um branco, uso de um isótopo diferente do analito [Veiga, 2000], correções matemáticas, ajuste experimental das condições do plasma, dessolvatação, introdução de um gás alternativo, separação cromatográfica entre outros [Veiga, 2000 e Skoog, 2002].

\section{- Íons de Dupla Carga}

Os íons de dupla carga aparecerão no espectro com metade da massa do íon desejado, pois eles são filtrados no analisador de massa com base na razão m/z Com isso, poderá ocorrer uma pequena perda de sinal e interferências em massas semelhantes. Os elementos 
mais sensíveis a esta interferência são os alcalinos terrosos, alguns metais de transição e os elementos terras-raras, por possuírem baixo potencial de ionização. Este problema pode ser controlado aume ntando a vazão do gás carregador e (ou) diminuindo a potê ncia de $\mathrm{RF}^{4}$.

\section{- Interferências por Espécies Óxido e Hidróxido}

A espécie de interferências mais séria no ICP-MS envolve óxidos e hidróxidos formados pelo analito, pela matriz dos componentes, pelos gases do plasma [Skoog, 2002] e pelo vapor de água transportado, uma vez que o analito poderá ser atomizado em um excesso de átomos de oxigênio. A quantidade de água introduzida no plasma também poderá afetar o equilíbrio do plasma. Quase todas as espécies formam, até certo ponto, íons $\mathrm{MO}^{+}$e $\mathrm{MOH}^{+}$, onde $\mathrm{M}$ representa o analito ou o elemento de matriz.

A eliminação ou atenuação dos óxidos é fundamental, pois a razão $\mathrm{m} / \mathrm{z}$ de um óxido pode se sobrepor a uma razão $\mathrm{m} / \mathrm{z}$ de um analito. Um exemplo são os íons de óxidos dos isótopos naturais de titânio ${ }^{5}$, com massas $62,63,64,65$ e 66, que podem interferir com os picos de ${ }^{62} \mathrm{Ni}^{+},{ }^{63} \mathrm{Cu}^{+},{ }^{64} \mathrm{Zn}^{+},{ }^{65} \mathrm{Cu}^{+} \mathrm{e}{ }^{66} \mathrm{Zn}^{+}$do analito. Alguns problemas criados por óxidos e hidróxidos são mostrados na tabela 3.1 [Veiga, 2000].

É conhecido que as razões $\mathrm{MO}^{+} / \mathrm{M}^{+}$dependem de parâmetros de operação como a potência do plasma, a velocidade do fluxo do gás carregador e as condições instrumentais, como a distância entre a bobina de RF e o cone amostrador, assim como o tamanho dos orifícios dos cones (sampler e skimmer). A otimização dos parâmetros instrumentais, o uso de plasma de alta potência e a baixa velocidade de fluxo de gás carregador para aumentar o tempo de residência são caminhos para reduzir e controlar a produção das razões de óxidos para níveis menores que $0,02(2 \%)$. Uma outra alternativa para tentar minimizar este tipo de interferência é utilizar uma Célula de Reação Dinâmica (DRC), que reduz drasticamente a produção de óxidos [Navarro, 2004].

\footnotetext{
${ }^{4}$ Aumentando a velocidade do gás carregador e diminuindo a potência de RF a temperatura do plasma diminui.

${ }^{5}$ Isótopos naturais de titânio: ${ }^{46} \mathrm{Ti},{ }^{47} \mathrm{Ti},{ }^{48} \mathrm{Ti},{ }^{49} \mathrm{Ti} \mathrm{e}{ }^{50} \mathrm{Ti}$.
} 
Tabela 3.1 Algumas espécies de Óxidos e Hidróxidos do Cálcio e outras interferências na região de determinação de massa do Ni.

\begin{tabular}{ccc}
\hline $\mathrm{m} / \mathrm{z}$ & Elemento $^{a}$ & Interferências \\
\hline 56 & $\mathrm{Fe}(91,66)$ & ${ }^{40} \mathrm{ArO},{ }^{40} \mathrm{CaO}$ \\
57 & $\mathrm{Fe}(2,19)$ & ${ }^{40} \mathrm{ArOH},{ }^{40} \mathrm{CaOH}$ \\
58 & $\mathrm{Ni}(67,77), \mathrm{Fe}(0,33)$ & ${ }^{42} \mathrm{CaO}, \mathrm{NaCl}$ \\
59 & $\mathrm{Co}(100)$ & ${ }^{43} \mathrm{CaO},{ }^{42} \mathrm{CaOH}$ \\
60 & $\mathrm{Ni}(26,16)$ & ${ }^{43} \mathrm{CaOH},{ }^{44} \mathrm{CaO}$ \\
61 & $\mathrm{Ni}(1,25)$ & ${ }^{44} \mathrm{CaOH}$ \\
62 & $\mathrm{Ni}(3,66)$ & ${ }^{46} \mathrm{CaO}, \mathrm{Na} \mathrm{O}, \mathrm{NaK}$ \\
63 & $\mathrm{Cu}(69,1)$ & ${ }^{46} \mathrm{CaOH},{ }^{40} \mathrm{ArNa}$ \\
64 & $\mathrm{Ni}(1,16), \mathrm{Zn}(48,89)$ & ${ }^{32} \mathrm{SO}_{2},{ }^{32} \mathrm{~S}_{2},{ }^{48} \mathrm{CaO}$ \\
65 & $\mathrm{Cu}(30,9)$ & ${ }^{33} \mathrm{~S}^{32} \mathrm{~S}^{33} \mathrm{SO}_{2},{ }^{48} \mathrm{CaOH}$ \\
\hline
\end{tabular}

${ }^{\mathrm{a}}$ Abundância percentual natural entre parênteses.

\subsubsection{Interferências não E spectroscópicas}

Esta classe de interferências é basicamente representada pelos efeitos de supressão e aumento de sinal, como o efeito matriz, e por efeitos físicos como o efeito memória.

\section{- Efeitos de M atriz}

No ICP-MS, os efeitos de matriz mais severos são aqueles causados por elementos em concentrações maiores que 500 até $1000 \mu \mathrm{g} / \mathrm{ml}$, presentes na matriz. Normalmente esses efeitos causam redução no sinal do analito, embora em alguns casos o aumento do sinal possa ser observado ${ }^{6}$. Geralmente os efeitos de matriz podem ser minimizados pela diluição das amostras, pela alteração do procedimento de introdução de amostras, pela separação das espécies interferentes ou pelo uso de padrões internos apropriados, isto é, pela introdução de um elemento que tenha a mesma massa e potencial de ionização que a do analito, como padrão interno [Veiga, 2000 e Skoog 2002].

\footnotetext{
${ }^{6}$ Alguns elementos como: $\mathrm{Na}, \mathrm{Mg}, \mathrm{Ca}$, Cs e $\mathrm{K}$ causam um aumento no sinal do analito, já o Li causa pouco efeito, enquanto que o $\mathrm{Al}$ e o $\mathrm{U}$ causam uma queda no sinal.
} 


\section{- E feito M emória}

Alguns elementos apresentam efeitos de memória após a passagem de amostras com concentrações elevadas, devido à sua aderência a partes do sistema de introdução de amostras [Correia, 2003].

\section{$3.2 .9 \mathrm{DRC}$}

A célula de reação dinâmica (DRC) é um acessório que pode ser adicionado ao ICPMS para reduzir interferências espectrais entre íons e moléculas formadas pela combinação de espécies abundantes no gás do plasma, no solvente e na matriz da amostra. Ele atua como uma interface entre as lentes e o analisador de massa e promove a reação íon-molécula para conter as interferências e, assim, realçar a sensibilidade do analito. Este dispositivo consiste em um quadrupolo que pode ser pressurizado com um gás de reação e se comporta como um dispositivo multipolo de transferência de íons, figura 3.21 [Tanner, 2000; Hattendorf, 2000].

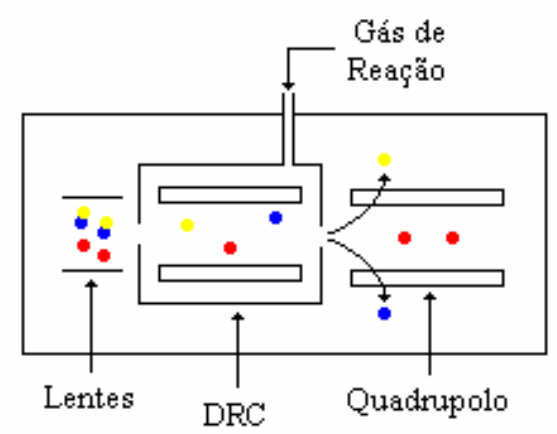

$$
\begin{aligned}
& { }^{40} \mathrm{Ar}^{16} \mathrm{O}^{+} \\
& { }^{56} \mathrm{Fe}^{+}
\end{aligned}
$$

Figura 3.21 Esquema de um DRC acoplado a um ICP-MS. O DRC é um quadrupolo que pode ser pressurizado com um gás de reação. 
A reação íon-molécula ocorre entre o gás reativo e as espécies do feixe de íons. Estas reações transformam interferentes em produtos inofensivos que não interferem com o analito. A equação 3.21 mostra alguns exemplos de reações com a amônia $\left(\mathrm{NH}_{3}\right)$ e o hidrogênio $\left(\mathrm{H}_{2}\right)$, dois materiais que podem ser usados como gases de reação. Para a determinação do ${ }^{52} \mathrm{Cr}^{+}$e do ${ }^{53} \mathrm{Cr}^{+}$as interferências com alguns cloretos como o ${ }^{35} \mathrm{Cl}^{16} \mathrm{OH}^{+}(\mathrm{m} / \mathrm{z} 52)$, o ${ }^{37} \mathrm{Cl}^{16} \mathrm{O}^{+}(\mathrm{m} / \mathrm{z} 52)$ e o ${ }^{37} \mathrm{Cl}^{18} \mathrm{O}^{+}$podem ser resolvidas com o uso da amônia. Já para as interferências do ${ }^{40} \mathrm{Ar}^{35} \mathrm{Cl}^{+}$ sobre o arsênio $\left({ }^{75} \mathrm{As}^{+}\right)$, uma boa alternativa é usar o hidrogênio como gás de reação [Neubauer, 1999].

Nota-se que estas reações (equação 3,21) reduzem significativamente algumas interferências, mas em alguns casos o uso do DRC induz a formação de produtos de reação, que, dependendo do gás usado, podem introduzir novas interferências que não são comuns em uma operação padrão do ICP-MS. Por isso, para experimentos que não necessitam do DRC o fluxo de gás é cortado e o acessório é isolado para dar saída ao analito [Tanner, 1999; Hattendorf, 2000].

$$
\begin{gathered}
\mathrm{ClOH}^{+} \mathrm{NH}_{3} \rightarrow \mathrm{ClO}+\mathrm{NH}_{4}^{+} \\
\mathrm{ClO}^{+} \mathrm{NH}_{3} \rightarrow \mathrm{ClO}+\mathrm{NH}_{3}^{+} \\
\mathrm{ArCl}^{+}+\mathrm{H}_{2} \rightarrow \mathrm{ArH}_{2}^{+}+\mathrm{HCl}
\end{gathered}
$$

Alguns estudos de razões isotrópicas são usados para demonstrar a extensão da redução de interferências e para ilustrar o potencial do DRC na determinação de elementos traço em matrizes que são previamente consideradas como difíceis de serem analisadas pelo ICP-MS, quando devidamente aplicado [Neubauer, 1999].

\subsubsection{Correção do D rift I nstrumental}

O ICP-MS encontra atualmente larga aplicação na análise química de metais em diferentes áreas, dada a sua reconhecida capacidade de produzir dados com rapidez e 
qualidade para uma ampla gama de elementos químicos. Para alcançar a elevada exatidão requerida na análise elementar é necessário adotar cuidadosos procedimentos de controle da flutuação (drift) do sinal como por exemplo, a utilização de padrões internos [Walsh, 1992].

O drift de sinal, um dos principais problemas enfrentados em análises com o ICP, é proveniente especialmente de variações nas condições de introdução da amostra no plasma, provocada pela alteração na eficiência de produção e no transporte de amostra. As causas da maior ou menor eficiência de nebulização podem ser várias, citando-se entre elas a variações no fluxo do gás de transportador ou na taxa de ascensão da solução, bloqueios parciais do nebulizador (por deposição de sais ou de minúsculas partícula s de grafite provenientes da solução analisadora), e mudanças na temperatura da solução e/ou da câmara de nebulização [Carré, 1992].

O tipo e a magnitude do drift são bastante variáveis de dia para dia, e mudam até para diferentes elementos ou mesmo para diferentes linhas do mesmo elemento; variações da ordem de 3\% em espaço de tempo de 2-3 horas são comuns, e resultam em sensível deterioração da qualidade analítica.

Uma opção é adotar um procedimento de controle off-line do drift, que envolve a normalização dos sinais obtidos em relação à variação do sinal dos elementos usados como controle, ou seja, os padrões internos (equação 3.22). O procedimento envolve a dopagem das amostras e materiais de referencia com alguns elementos, usados como padrões internos (mesma concentração em todas as amostras), uma vez que cada elemento reage de maneira totalmente diferente durante a análise. Como o comportamento varia muito para massas muito diferentes, geralmente escolhe-se um elemento para cada grupo de massas que não sejam muito diferentes.

$$
I=\frac{A M}{P_{a}} \cdot P_{i}
$$

onde I é a intensidade corrigida, AM é intensidade do elemento de interesse na amostra, $\mathrm{P}_{\mathrm{i}}$ é a intensidade do padrão interno inicial, usado na primeira amostra a ser medida e $\mathrm{P}_{\mathrm{a}}$ é a intensidade do padrão interno na amostra $\mathrm{AM}$, medida num tempo t após o inicio das medidas. 
Esse procedimento melhora a repetibilidade dos resultados, mantendo o desvio padrão relativo baixo para a maioria dos elementos. Entretanto pode haver deterioração da exatidão dos resultados se ocorrer algum drift significativo do sinal [Janasi, 1995]. 


\section{V alidação de $M$ étodo}

A validação de método é um processo que prova que um determinado método analítico é aceitável para certa finalidade. Em geral esse processo inclui estudos de exatidão, precisão, limites de detecção (LD) e limites de quantificação (LQ) [ABNT IMETRO, 1998; Navarro, 2004]. A seguir serão descritos os procedimentos e métodos usados neste trabalho para garantir a qualidade das medidas.

\subsection{Curvas de Calibração}

No caso do PIXE, a qualidade das medidas é garantida com calibrações periódicas do instrumento (a cada provável alteração do arranjo experimental), enquanto, o ICP-MS requer sessões de calibração diárias, realizadas sob estrito controle de qualidade segundo um protocolo estabelecido pelo laboratório. Além disso, a qualidade analítica do laboratório LAMFI é verificada através de ensaios internacionais tipo "Robin Round", o último promovido em 1998 pela Agência Internacional de Energia Atômica - IAEA [Bleise, 2003]. Nestes testes, os programas de análise usados para deconvolução dos espectros de raios X são eventualmente comparados e analisados pela IAEA [IAEA, 2003]. Do mesmo modo, a qualidade das medidas do laboratório de Química e ICP também é garantida com a participação em testes inter laboratoriais - GEOPT realizados a cada 6 meses. A partir da comparação dos resultados obtidos em cada laboratório é possível estabelecer um valor mais apropriado para cada concentração na amostra. 


\subsubsection{PIXE}

O fator resposta do método PIXE é o fator de calibração do equipamento usado para obter as concentrações elementares ma amostra. Ele é determinado por meio de ajuste de um modelo físico que descreve as principais características do arranjo experimental [Tabacniks 2005] sobre medidas experimentais colhidas na análise de amostras padrão de Filme Fino Monoelementar ${ }^{1}$.

Como visto na equação 3.16, o fator de resposta está relacionado com a quantidade de raios- $\mathrm{X}$ detectados (integral do pico no espectro), com a carga total acumulada e com a espessura do material. Deste modo, a calibração quantitativa do sistema PIXE pode ser obtida experimentalmente a partir da irradiação de alvos finos de espessura/concentração conhecida.

Uma vez que se usa um modelo físico que descreve o funcionamento do sistema de análise é possível usar apenas alguns elementos no ajuste experimental e interpolar todos os outros. Assim, obtido o fator de resposta para alguns elementos, é possível superpor uma curva, calculada a partir de princípios fundamentais e parâmetros nominais, aos dados, como mostra a figura 4.1. Isso permite obter o $r$ de elementos para os quais não se dispõe de padrões. Aqui um total de 20 padrões de calibração fabricados pela MicroMatter foram utilizados.

\footnotetext{
${ }^{1}$ MicroMatter Co. 123 Madrona Lane. Deer Harbor, WA 98243 USA.
} 
a)

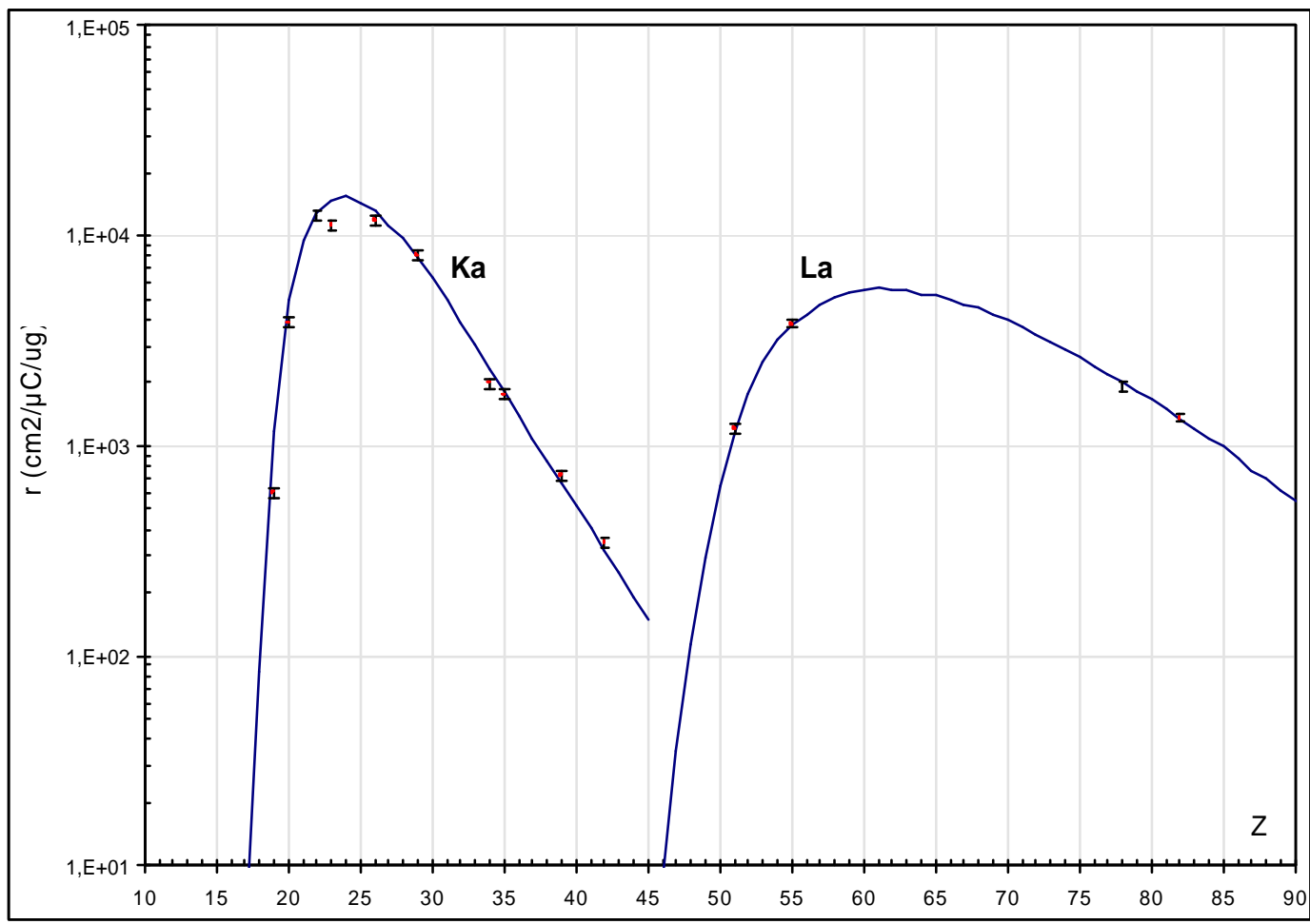

b)

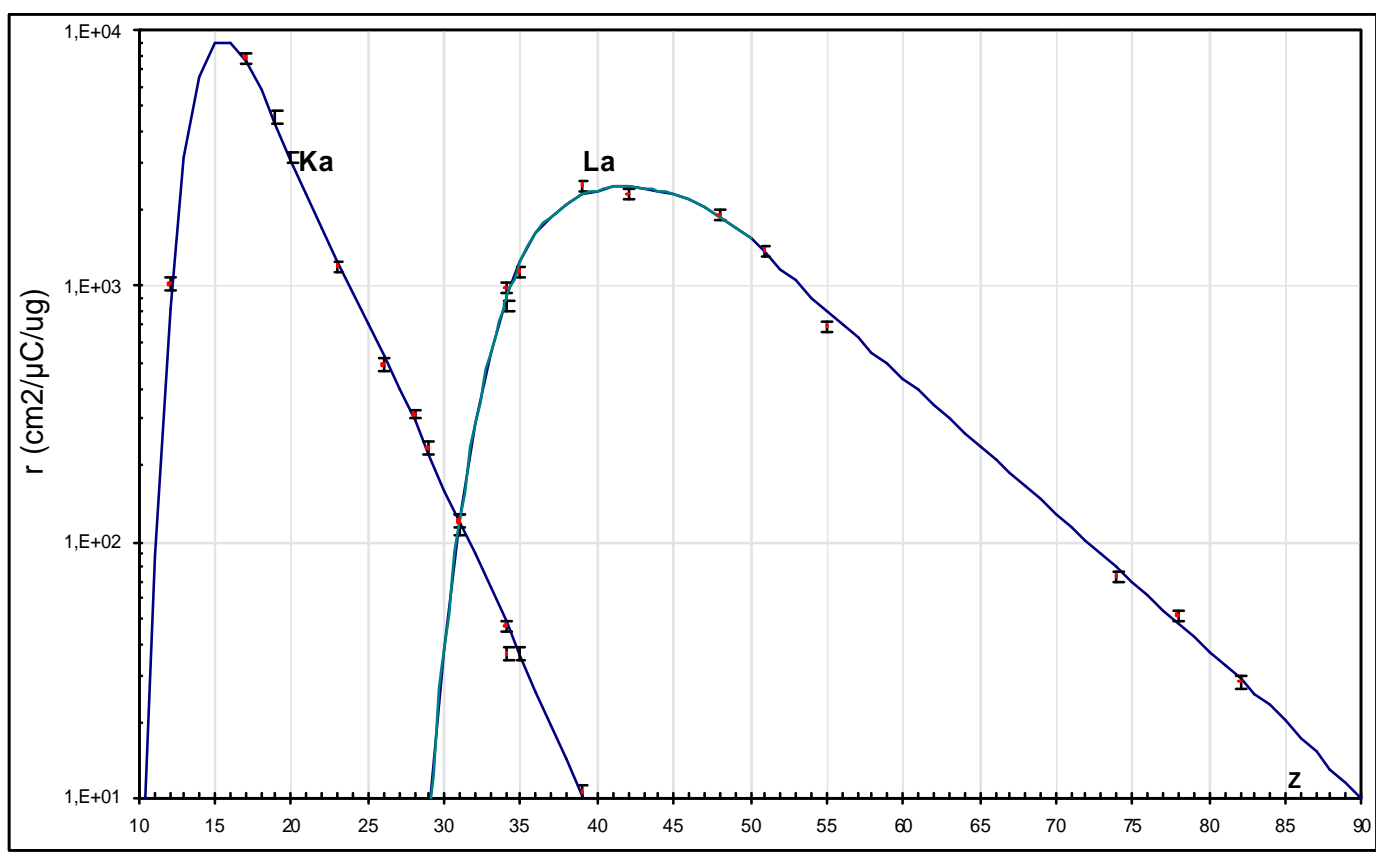

Figura 4.1 Fator de Resposta de Alvo Fino (r) para as linhas $\mathrm{K} \alpha$ e $\mathrm{L} \alpha$. A figura a) mostra o fator de calibração de alta energia enquanto a figura b) mostra o de baixa energia. 


\subsubsection{ICP-M S}

Uma vez que o ICP-MS não dispõe de um modelo físico que descreve quantitativamente a resposta do equipamento com suficiente precisão, a determinação quantitativa por esta técnica requer a construção de curvas de calibração diárias, que serão referência para converter as intensidades registradas nas análises das soluções-problema em concentrações dos respectivos elementos. Ao contrário do método PIXE, a calibração do ICPMS exige padrões e curvas de calibração para todos os elementos medidos.

Uma curva é gerada com no mínimo 3 pontos, que idealmente devem cobrir o intervalo de concentração esperado nas amostras (portanto, com dois pontos extremos, um menor que a mínima e outro maior que a máxima concentração esperada). Neste trabalho, foram utilizados 4 padrões artificiais, confeccionados no laboratório de química e ICP do instituto de Geociências da USP. Estes padrões foram obtidos adicionando concentrações elementares diferentes, mostradas na tabela 4.1, em uma das amostras de soro, diluída de 1:10, com concentração previamente estabelecida. As concentrações elementares do soro puro, um dos padrões artificiais, foram subtraídas de todos os padrões.

As curvas de calibração foram construídas no dia das medidas usando a intensidade das leituras e a concentração final dos padrões (do soro + o valor adicionado). Por isso a figura 4.2 apresenta duas curvas para cada elemento, uma para cada período de máquina. Além disso, também foi adicionado o ponto com intensidade e concentração zero $(0,0)$ às curvas, uma vez que as retas deveriam passar por este ponto.

A resposta do ICP deve ser linear com a concentração elementar. Assim, ajustando retas às curvas de sensibilidade versus concentração, descritas pela equação 4.1, o ajuste se mostra estatisticamente satisfatório como pode ser verificado na figura 4.2.

$$
C=a+b I
$$

onde: $C$ é a concentração em ppb, $a$ e $b$ são, respectivamente, os coeficientes linear e angular da reta e $I$ é a taxa de contagens (em cps). 
Tabela 4.1 Concentração elementar (em ppb) adicionada em cada padrão artificial (no 1 nada foi adicionado).

\begin{tabular}{cccc}
\hline Elemento & Padrão 2 & Padrão 3 & Padrão 4 \\
\hline $\mathrm{Be}$ & 0,1 & 0,2 & 0,5 \\
$\mathrm{Al}$ & 10 & 20 & 50 \\
$\mathrm{~V}$ & 0,1 & 0,2 & 0,5 \\
$\mathrm{Cr}$ & 0,1 & 0,2 & 0,5 \\
$\mathrm{Mn}$ & 0,1 & 0,2 & 0,5 \\
$\mathrm{Co}$ & 0,1 & 0,2 & 0,5 \\
$\mathrm{Ni}$ & 0,1 & 0,2 & 0,5 \\
$\mathrm{Cu}$ & 100 & 200 & 300 \\
$\mathrm{Zn}$ & 100 & 200 & 300 \\
$\mathrm{Se}$ & 10 & 20 & 30 \\
$\mathrm{Mo}$ & 0,1 & 0,2 & 0,5 \\
$\mathrm{Cd}$ & 0,1 & 0,2 & 0,5 \\
$\mathrm{Sn}$ & 0,1 & 0,2 & 0,5 \\
$\mathrm{Tl}$ & 0,1 & 0,2 & 0,5 \\
$\mathrm{~Pb}$ & 10 & 20 & 30 \\
\hline Lembrando que as concentrações adicionadas são na solução final \\
de soro diluído de 1:10. & \multicolumn{2}{|}{}
\end{tabular}

Alguns casos apresentaram certa divergência entre as curvas de calibração de cada período de máquina. Nota-se que houve uma melhora significativa nas curvas no segundo dia de medidas, com exceção do $\mathrm{Be}$ e do $\mathrm{Ni}$, mas algumas ( $\mathrm{Sn}$, Mo e $\mathrm{Se}$ ) ainda precisam ser melhoradas. Essa diferença foi provocada, principalmente, pela variação na estabilidade do equipamento. Isso mostra a necessidade de calibrações diárias do instrumento. 

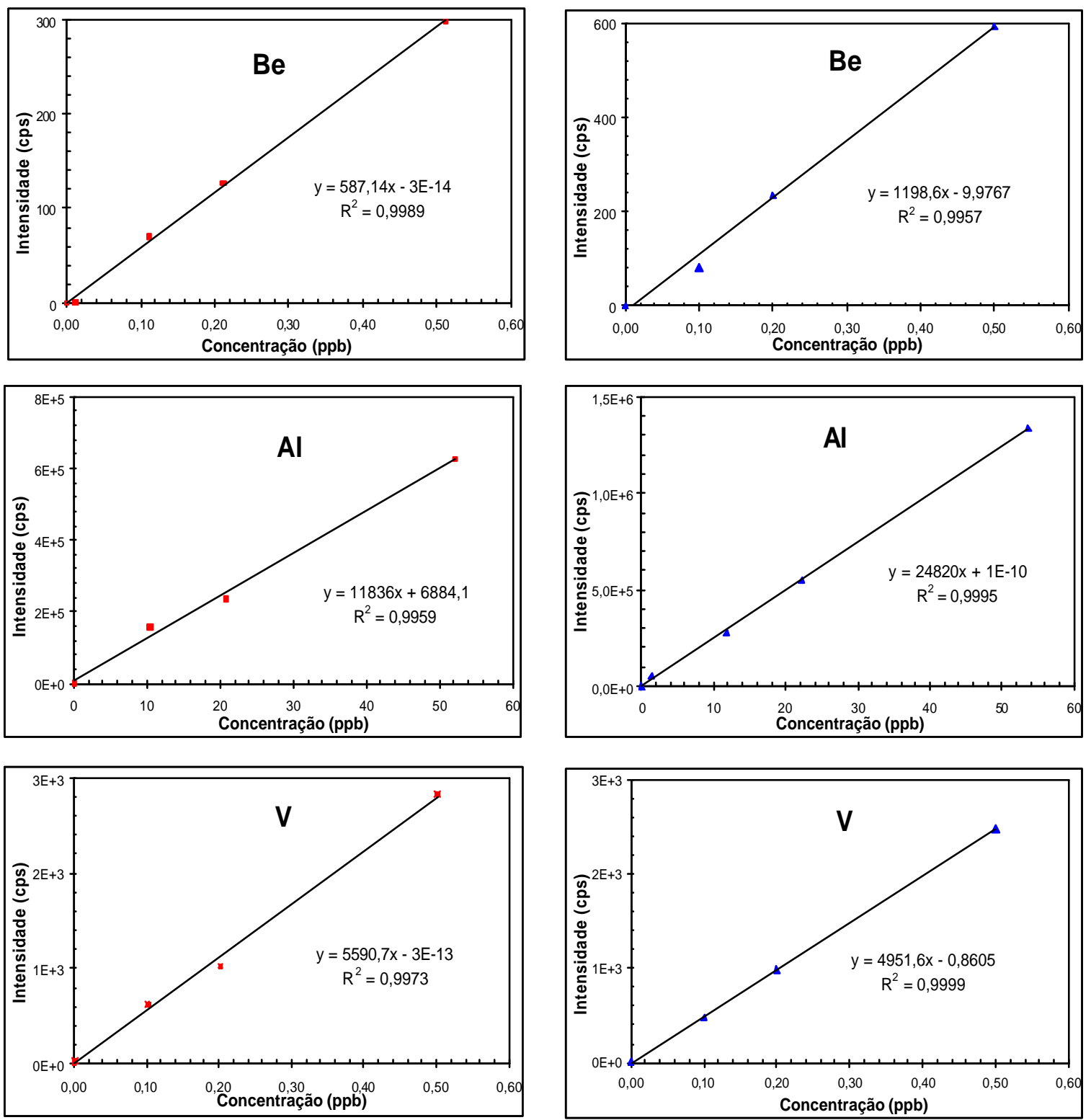

Figura 4.2 Curvas de calibração construídas para as análises com ICP-MS. As curvas foram feitas em dois dias diferentes. Os quadrados e os triângulos representam, respectivamente, as curvas construídas no primeiro dia e as curvas construídas no segundo dia de medidas (continua até a página 56). 

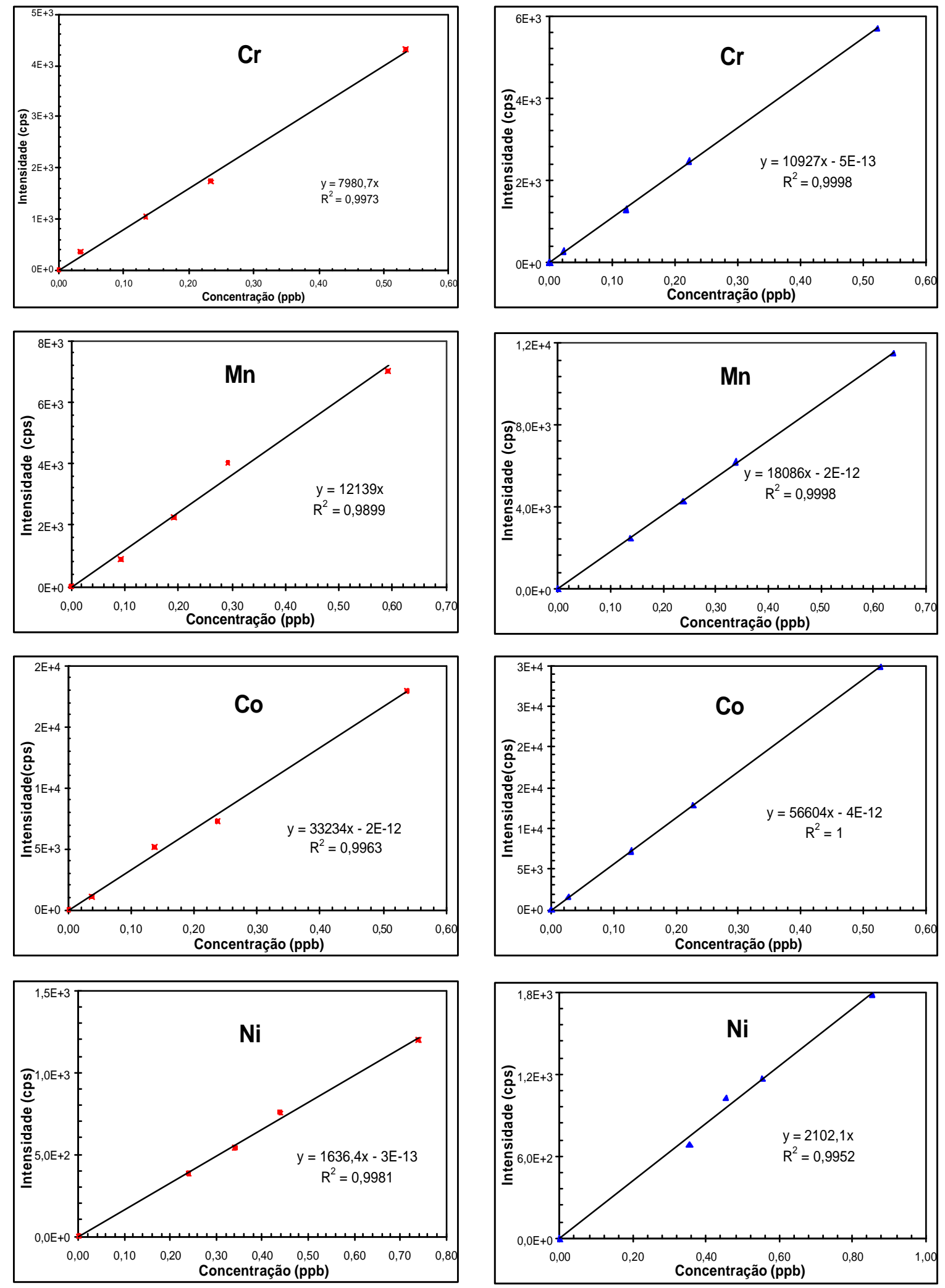

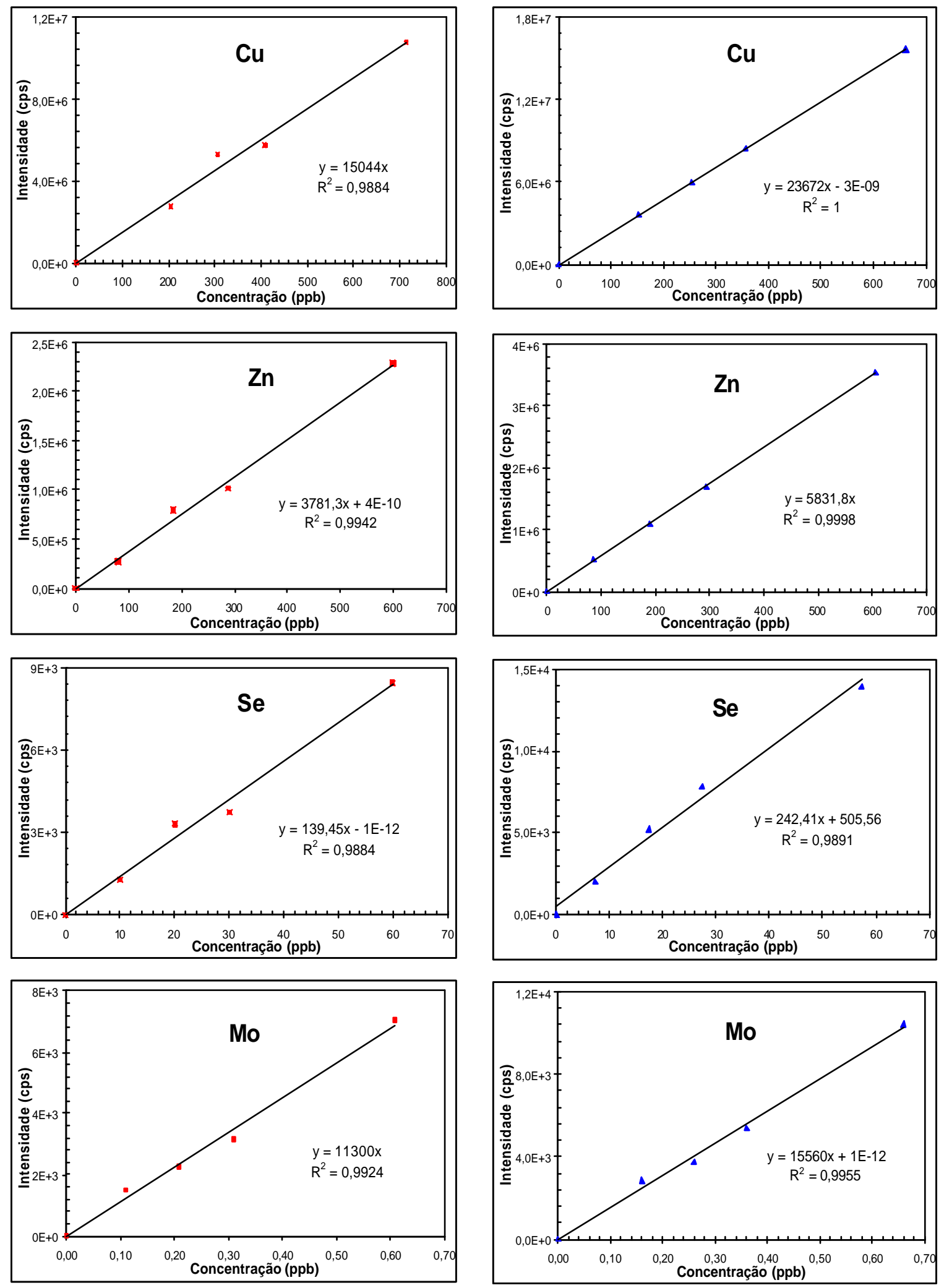

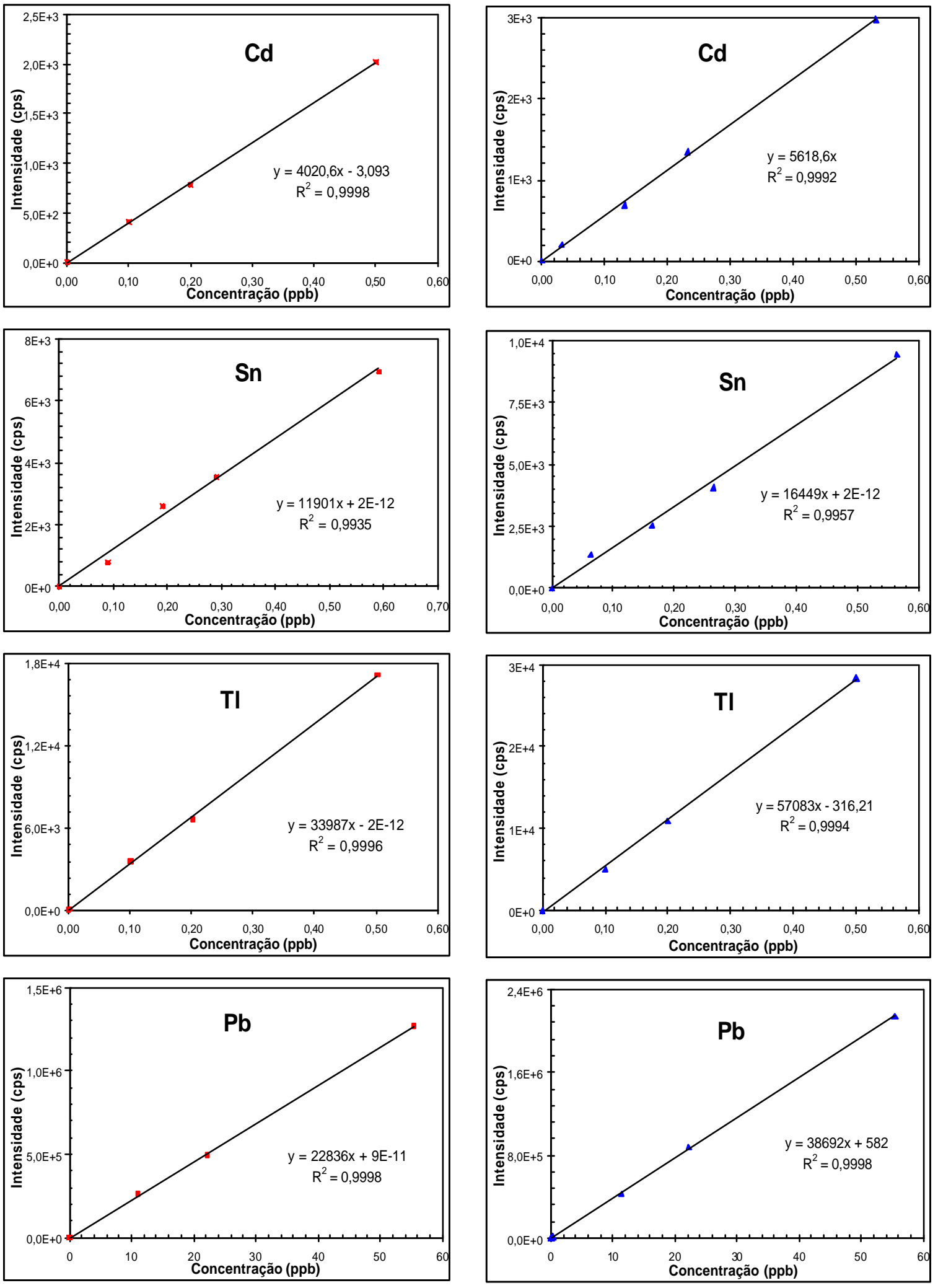


\subsection{Precisão}

A precisão indica o grau de concordância entre os diversos resultados experimentais obtidos em condições de repetitividade ${ }^{2}$. Assim, "boa precisão" significa erro estatístico pequeno, de forma que os resultados apresentam boa repetitividade [Vuolo, 1996].

\subsubsection{PIXE}

Como visto anteriormente, a concentração elementar para análise de amostras líquidas pelo método PIXE, foi calculada em relação a um padrão interno, conforme mostra a equação 3.20 do capitulo 3 .

O fator de calibração PIXE possui uma incerteza média nominal da ordem de 5\% proveniente dos padrões de filme fino da MicroMatter, usados na calibração do sistema, que têm uma incerteza da mesma ordem. A incerteza na medida da carga é da ordem de 3\%, na concentração do padrão interno é de no máximo $4 \%$ e a incerteza estatística do ajuste depende da área dos picos das linhas espectrais (supostas distribuição Poisson), mas em geral é menor que 5\%. O erro final é obtido por soma em quadratura das incertezas do ajuste da área dos picos, do Fator de Resposta, da carga de feixe integrada e da concentração do padrão interno de Ítrio, resultando em média numa precisão de $8 \%$ a $10 \%$.

A dispersão dos resultados foi verificada com leituras de uma única amostra preparada 5 vezes $^{3}$ da mesma maneira ${ }^{4}$. Os valores do desvio padrão relativo das 5 leituras, calculados usando a equação 4.2 , podem ser vistos na tabela 4.1 .

\footnotetext{
${ }^{2}$ Grau de concordância entre resultados de medições de uma mesma amostra, usando o mesmo equipame nto e sob as mesmas condições de análise.

${ }^{3}$ Isto foi feito para verificar (e confirmar) a precis ão total, incluindo a precisão do equipamento e a precisão da preparação de amostras.

${ }^{4}$ Para isso foram preparadas 5 amostras (com soro do mesmo doador), da mes ma maneira e pipetados $6 \mu 1$ de cada solução sobre filtro Nuclepore e em seguida irradiados no PIXE.
} 


$$
\sigma_{R}=\frac{\sigma .100}{\bar{X}}
$$

onde: $\mathrm{s}_{\mathrm{R}}$ é o desvio padrão relativo, s é o desvio padrão das leituras e $\bar{X}$ é o valor médio das leituras.

\subsubsection{ICP-M S}

$\mathrm{Na}$ análise por ICP-MS a precisão pode variar com a intensidade do elemento a ser medido na amostra, uma vez que o erro da leitura é o desvio padrão relativo $\left(\mathrm{s}_{\mathrm{R}}\right)$ de 3 leituras consecutivas que, no caso de intensidades muito baixas (próximas do limite de detecção), podem levar a desvios padrão elevados [Currie, 1968]. Em geral, em amostras com concentração elementar muito maior que o limite de detecção, a precisão analítica do método é de aproximadamente $5 \%$.

Seguindo protocolo estabelecido desde a instalação dos espectrômetros no Laboratório de Química e ICP-OES/MS, a estabilidade do arranjo foi verificada com medidas de uma amostra secundária em duplicata ${ }^{5}$ realizada a cada 10 amostras desconhecidas. As duplicatas permitem verificar as possíveis flutuações do equipamento com o tempo de análise. Além disso, a precisão foi determinada com medidas de uma mesma amostra 5 vezes, realizadas em dois dias diferentes ${ }^{6}$. Os valores dos desvios padrão relativos das 5 análises estão na tabela 4.2 junto com os valores para o método PIXE, citados anteriormente.

A menor precisão na determinação de $\mathrm{V}$ e $\mathrm{Cr}$ pode estar relacionada com proximidade de suas concentrações aos limites de detecção e quantificação do ICP-MS, discutidas mais adiante, enquanto a precisão do $\mathrm{Fe}, \mathrm{C}_{\mathrm{p}}$ e $\mathrm{Zn}_{\mathrm{p}}$ (medidos pelo método PIXE) foram prejudicadas pela presença destes elementos no substrato utilizado na preparação das amostras.

\footnotetext{
5 A mesma amostra preparada 2 vezes sob as mesmas condições.

${ }^{6}$ É importante levar em conta a flutuação do equipamento em dias diferentes, uma vez que nem sempre isso ocorre da mesma maneira para este equipamento.
} 
Tabela 4.2 Desvio padrão relativo para análises pelos métodos PIXE e ICP-MS, calculados a partir de 5 leituras da mesma amostra.

\begin{tabular}{ccc}
\hline \multirow{2}{*}{ Elemento } & \multicolumn{2}{c}{ Precisão(\%) } \\
\cline { 2 - 3 } $\mathrm{Be}$ & PIXE & ICP-MS \\
$\mathrm{Al}$ & & 8,1 \\
$\mathrm{P}$ & 9,0 & 6,8 \\
$\mathrm{~S}$ & 4,8 & \\
$\mathrm{Cl}$ & 3,7 & \\
$\mathrm{~K}$ & 4,2 & \\
$\mathrm{Ca}$ & 5,2 & 22 \\
$\mathrm{~V}$ & & 29 \\
$\mathrm{Cr}$ & & 10 \\
$\mathrm{Mn}$ & & \\
$\mathrm{Fe}$ & 25 & 3,2 \\
$\mathrm{Co}$ & & 6,9 \\
$\mathrm{Ni}$ & & 1,8 \\
$\mathrm{Cu}$ & 24 & 3,7 \\
$\mathrm{Zn}$ & 25 & 8,1 \\
$\mathrm{Se}$ & & \\
$\mathrm{Br}$ & 16 & 2,3 \\
$\mathrm{Mo}$ & & 1,4 \\
$\mathrm{Cd}$ & & 4,7 \\
$\mathrm{Sn}$ & & 1,0 \\
$\mathrm{Tl}$ & & 10 \\
$\mathrm{~Pb}$ & &
\end{tabular}

\subsection{Exatidão}

A exatidão, grau de concordância entre o valor obtido e o verdadeiro ou mais provável, dos resultados deste trabalho foi verificada usando um método comparativo que consiste em utilizar materiais de referência ${ }^{7}$ de soro, medidos como amostras. A diferença entre a média dos resultados e a quantidade real do constituinte no material certificado representa a medida da exatidão do método [Vuolo, 1996]. Os materiais de referência de soro utilizados neste trabalho foram adquiridos do National Institute of Public Health - Québec, Canadá (ICP02S-

\footnotetext{
${ }^{7}$ Materiais cujo conteúdo tenha sido determinado diversas vezes por vários métodos analíticos e obtido um valor considerado "exato".
} 
05, ICP04S-06 e QMEQAS05S-03). Os certificados analíticos desses materiais podem ser vistos no Apêndice C.

A dispersão dos resultados foi verificada aplicando o teste estatístico $z$ score nas concentrações obtidas para os materiais de referência, os resultados são discutidos a seguir.

\subsection{Teste E statístico}

Vários testes estatísticos têm sido utilizados para avaliar a confiança das medidas analíticas. Para validar estatisticamente o método de análise de soro por PIXE e ICP-MS, as concentrações elementares medidas para os materiais de referência neste trabalho foram comparadas com os valores certificados usando o teste estatístico z score, equação 5.1. Este teste mostra o número de desvios padrão que a variável $x$ está do valor esperado $\mu$ e permite verificar a existência de diferenças significativas entre os valores medidos e certificados [Navarro, 2004; Bevington, 1969].

$$
\begin{gathered}
z=\frac{(x-\mu)}{\sigma} \\
\text { onde } \sigma=\sqrt{\sigma_{1}^{2}+\sigma_{2}^{2}}
\end{gathered}
$$

onde: $x$ é o valor médio obtido, $\mu$ é o valor recomendado, $\mathrm{s}$ é o desvio padrão combinado, $\mathrm{s}_{l}$ é o desvio padrão dos resultados obtidos e $s_{2}$ é o desvio padrão dos valores certificados.

Supondo que $z$ possa ser descrito por uma distribuição normal $\mathrm{N}(0,1)$ cuja tabela de probabilidades integrada foi reproduzida no Apêndice $\mathrm{D}$, podemos perceber que quando $z=1$ a probabilidade $P=0,3413$. Logo, espera-se cerca de $34 \%$ dos valores de $x$ entre $\mu$ e $s$. Como a distribuição é simétrica, a probabilidade dos valores de $x$ estarem entre $-s$ e $\mu$ é a mesma que entre $\mu$ e $s$, então espera-se encontrar cerca de $68 \%$ entre $\pm s$. Para $z=2$ a probabilidade $P=0,4772$, então, espera-se cerca de $95 \%$ entre $\pm 2 s$. Para $z=3, P=0,4986$. Neste caso espera-se encontrar 99,7\% entre $\pm 3 s$ [Bevington, 1969; Vuolo, 1996]. 
Os materiais de referênc ia ICP04S-06, QMEQAS05S-03 e ICP04S-05 foram medidos 5,2 e 1 vez respectivamente e o resultado do teste $z^{8}$ aplicado nas concentrações médias de cada material pode ser visto no gráfico da figura 4.2. Podemos observar que $78 \%$ dos dados estão entre $\pm s, 92 \%$ estão entre $\pm 2 s$ e $96 \%$ entre $\pm 3 s$. Os resultados obedecem e até superam a regra de probabilidade do teste zpara $1 s$. Entretanto, para $2 s$ e $3 s$ os números ficaram um pouco abaixo do esperado. Esta pequena diferença foi gerada por alguns pontos fora de $2 s$ e/ou $3 s$ e podem ser explicados.

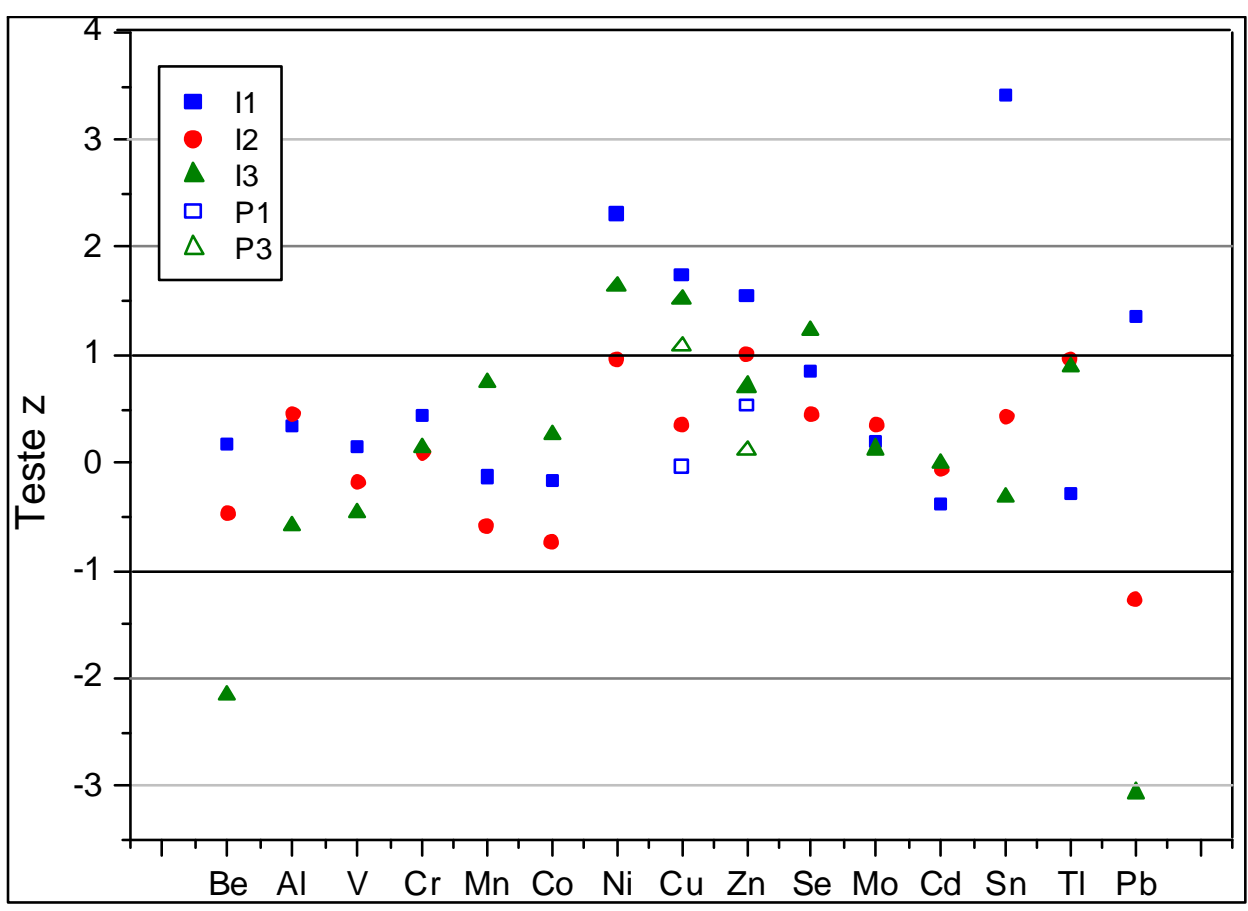

Figura 5.1 Gráfico do teste z comparando os valores medidos neste trabalho e os valores certific ados dos materiais. As letras I e P indicam as técnicas ICP e PIXE e os números 1, 2 e 3 representam os padrões ICP04S-06, QMEQAS05S-03 e ICP04S-05, respectivamente.

\footnotetext{
${ }^{8}$ Os valores medidos para cada material de referência com suas res pectivas incertezas e os resultados do teste $\mathrm{z}$ podem ser vistos no Apêndice E.
} 
O material ICP04S-05 tinha uma concentração de Be um pouco acima dos valores usados na construção da curva de calibração, gerando um ponto fora da curva, isto pode ter provocado uma medida menos confiável. O Sn do material ICP04S-06 foi medido várias vezes em dias diferentes e o valor obtido foi sempre acima do valor certificado $(3,71 \pm 0,11)$. No entanto, para os outros padrões, os valores medidos ficaram bastante próximos do valor de esperado, o que nos leva a acreditar que este material apresentava algum problema, especificamente, para este elemento. A calibração para o $\mathrm{Pb}$ ficou excelente, apesar de nenhum dos dados estarem entre $-s$ e $+s$, mas a pequena dispersão dos resultados somente pode ser explicada através da análise dos procedimentos experimentais.

\subsection{L imite de $D$ etecção e Quantificação}

Além da precisão e exatidão dos métodos é interessante determinar também os limites de detecção e quantificação definido s, respectivamente, como a menor concentração elementar mensurável, adotando um intervalo de confiança de 3 desvios padrão, e a menor concentração necessária para a quantificação, adotando um intervalo de confiança de 10 desvios padrão [Currie, 1968; Pinho, 1979]. Entretanto, é importante destacar que o limite de detecção é uma figura de mérito, especialmente útil para a comparação de métodos de medida e estimativa de sensibilidade mínima de um método. Pode ocorrer todavia que algumas medidas estejam abaixo deste limite sem configurarem falsos positivos.

\subsubsection{PIXE}

Numa análise PIXE, o principal fator que determina o limite de detecção é o sinal de fundo, uma vez que os picos estão sobrepostos a um fundo contínuo. Uma ve z que tanto o fundo como o pico obedecem distribuições de Poisson, o limite de detecção para cada elemento é determinado para o valor de contagens quando o desvio padrão da intensidade da 
linha espectral é maior que três vezes a raiz quadrada da intensidade do fundo, como mostra a equação a seguir:

$$
L D=\geq 3 \sqrt{B G}
$$

onde $B G$ é a soma do fundo contínuo sob a largura a meia altura (FWHM) do pico, como mostra a figura 4.3 [Bevington, 1969].

A figura 4.4 mostra os limites de detecção para o método PIXE, na qual se verifica que o método é mais sensível para elementos com $25<Z<35$ e $Z>65$.
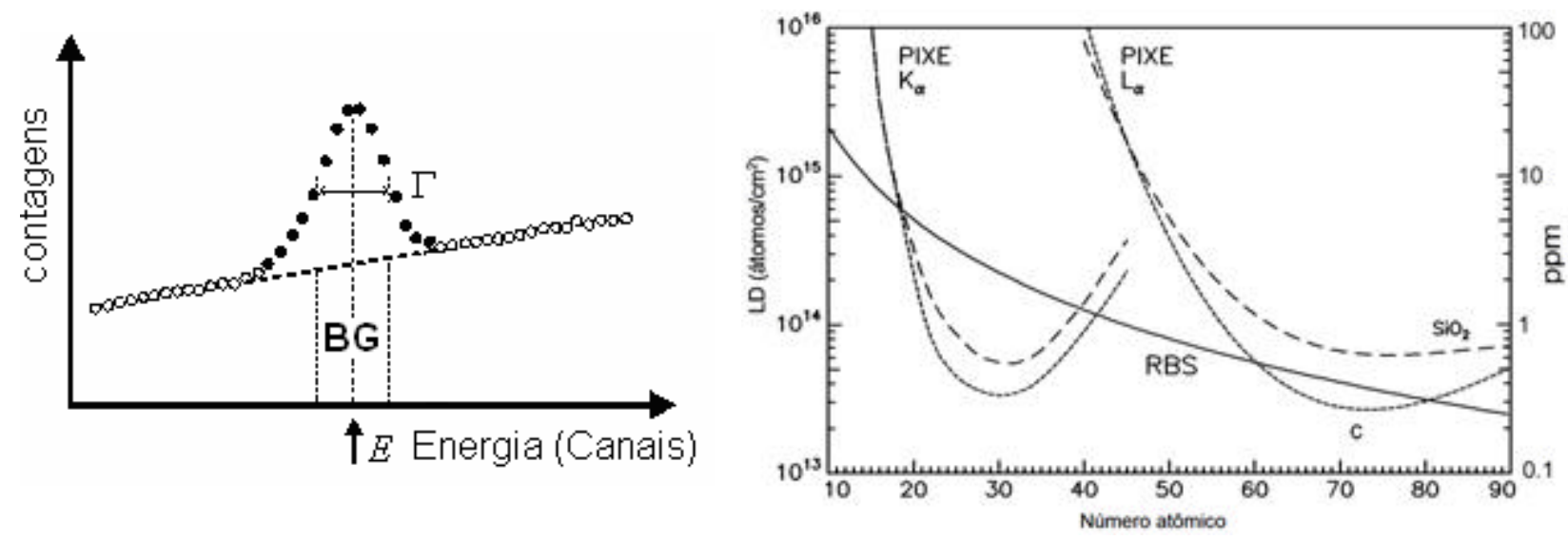

Figura 4.3 - Esquema de um pico sobre o Figura 4.4 - Curva do limite de detecção do método fundo contínuo $(B G)$ usado na determinação do PIXE [Tabacniks,1996].

limite de detecção do método PIXE [Jenkins, 1981].

\subsubsection{ICP-M S}

Para o ICP-MS o limite de detecção ocorre quando a média de 3 leituras do analito é maior do que 3 desvios padrão (das 3 leituras) e o limite de quantificação ocorre quando a média do sinal é maior que 10 desvios padrão das leitura, equação 4.5 [Potts, 1987]. 


$$
\begin{array}{cl}
3 \sigma<\bar{S}_{x}<10 \sigma & \text { Região de detecção } \\
\bar{S}_{x}>10 \sigma & \text { Região de quantificação }
\end{array}
$$

Os valores dos limites de detecção e quantificação obtidos para os métodos PIXE e ICP-MS são mostrados na tabela 4.2 .

Tabela 4.3 - Limites de detecção (LD) e quantificação (LQ) obtidos para os métodos PIXE e ICP-MS

\begin{tabular}{|c|c|c|c|c|}
\hline & \multicolumn{2}{|c|}{ PIXE (ppm) } & \multicolumn{2}{|c|}{ ICP-MS (ppb) } \\
\hline & LD & LQ & LD & LQ \\
\hline Be & & & 0,032 & 0,11 \\
\hline Al & & & 9,1 & 30 \\
\hline $\mathbf{P}$ & 1,2 & 4,1 & & \\
\hline $\mathbf{S}$ & 1,3 & 4,3 & & \\
\hline Cl & 1,3 & 4,3 & & \\
\hline $\mathbf{K}$ & 1,3 & 4,4 & & \\
\hline Ca & 1,4 & 4,8 & & \\
\hline V & & & 0,029 & 0,10 \\
\hline $\mathrm{Cr}$ & & & 0,049 & 0,16 \\
\hline Mn & & & 0,052 & 0,17 \\
\hline $\mathbf{F e}$ & 0,14 & 0,46 & & \\
\hline Co & & & 0,010 & 0,033 \\
\hline $\mathbf{N i}$ & & & 0,091 & 0,30 \\
\hline $\mathrm{Cu}$ & 0,098 & 0,27 & 0,15 & 0,50 \\
\hline $\mathbf{Z n}$ & 0,12 & 0,21 & 3,1 & 10 \\
\hline Se & & & 0,67 & 2,2 \\
\hline $\mathbf{B r}$ & 0,42 & 1,4 & & \\
\hline Mo & & & 0,086 & 0,29 \\
\hline Cd & & & 0,010 & 0,033 \\
\hline Sn & & & 0,13 & 0,44 \\
\hline Tl & & & 0,025 & 0,083 \\
\hline $\mathbf{P b}$ & & & 0,094 & 0,31 \\
\hline
\end{tabular}
para amostras de soro sanguíneo. 


\section{$5 M$ ateriais $\mathrm{e} M$ étodos}

\subsection{E quipamentos U tilizados}

\subsubsection{O Sistema PIXE do L A M F I - IF U SP}

O sistema PIXE do laboratório LAMFI (Laboratório de Análise de Materiais por Feixes Iônicos) do IFUSP (Instituto de física da USP), figura 5.1, é composto por um acelerador eletrostático tipo Pelletron-tandem, modelo 5SDH, fornecido pela NEC, National Electrostatic Corporation dos EUA, que pode alcançar até 1,7 MV de tensão no terminal, uma fonte de íons SNICS (Source of Negative Ions by Cesium Sputtering), uma câmara de análise de alto vácuo, construída no IF USP, e dois detectores de raios- $\mathrm{X}$ do tipo $\mathrm{Si}(\mathrm{Li})$.

A câmara para análise s PIXE, representada na figura 5.2, contém um porta-amostras linear com capacidade para 18 discos de $25 \mathrm{~mm}$ de diâmetro com controles XY manuais e externos e dois detectores semicondutores, um ajustado para detectar raios- $\mathrm{X}$ com energia $\mathrm{E}<6 \mathrm{keV}$ e o outro para raios-X com energia $\mathrm{E}>4 \mathrm{keV}$, que têm por objetivo otimizar os limites de detecção [Tabacniks, 1983]. 


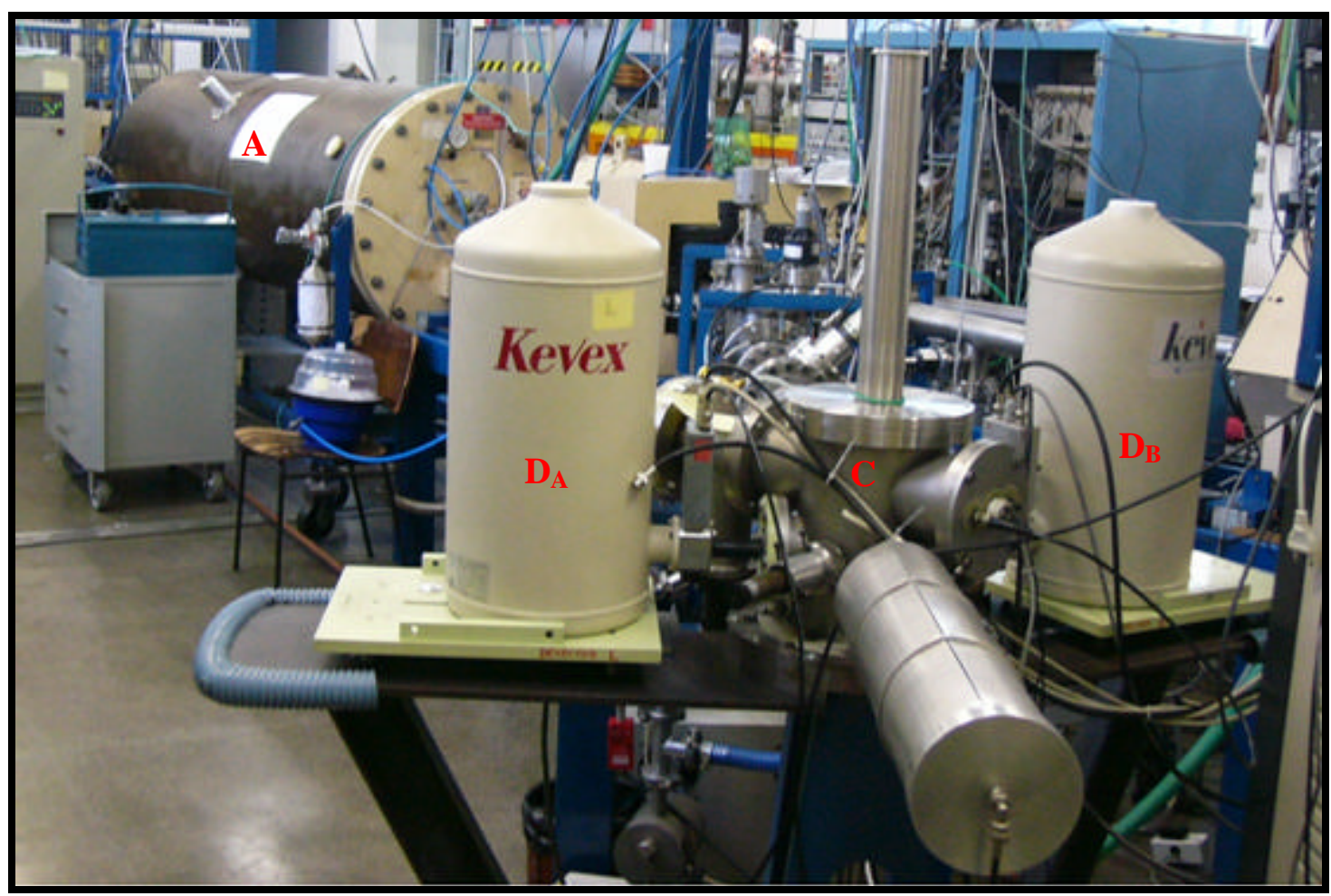

Figura 5.1 Foto do laboratório LAMFI. O acelerador de partículas (A) fica acoplado à câmara PIXE (C) e aos detectores de alta energia $\left(D_{A}\right)$ e de baixa energia $\left(D_{B}\right)$.

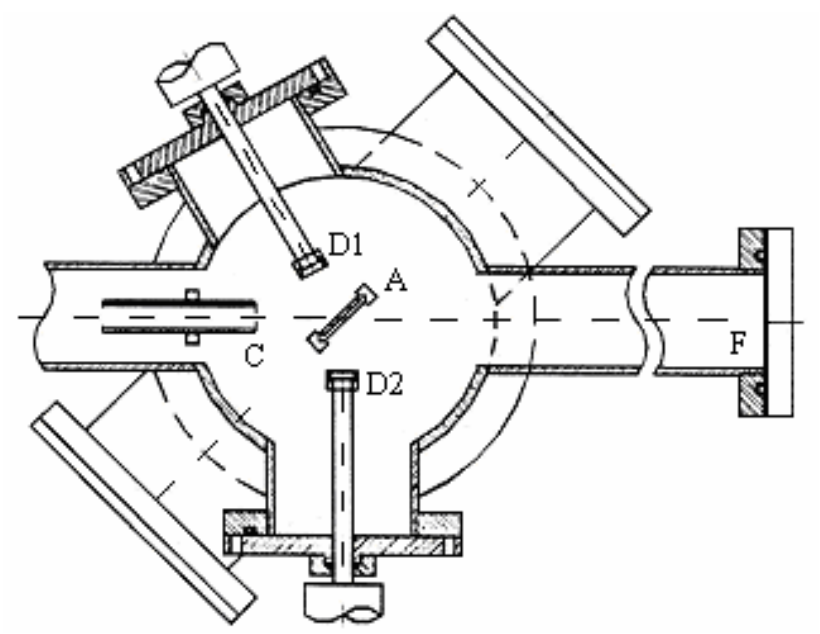

Figura 5.2 Câmara para análises PIXE, onde C representa o colimador de feixe, D1 e D2 indicam, respectivamente, os detectores de $\mathrm{Si}(\mathrm{Li})$ para as energias $\mathrm{E}<6 \mathrm{keV}$ e E $>4 \mathrm{keV}$; A, o porta-amostras e F, o copo Faraday. 


\subsubsection{Sistema de ICP -M S - I G U SP}

O equipamento de ICP-MS do Laboratório de Química e ICP do IGUSP (Instituto de Geociências da USP) é um ELAN 6100 da Perkin Elmer, figura 5.3, que trabalha com um nebulizador do tipo Meinhard acoplado a uma bobina peristáltica e câmara ciclônica em quartzo, que possibilita maior estabilidade no fluxo da amostra e níveis de detecção mais baixos do que os encontrados em espectrômetros similares no mercado. Esse dispositivo trabalha em conjunto com uma célula de reação dinâmica (DRC) com gás de amônia, o qual é acionado quando necessário. Possui um analisador de massa do tipo quadrupolar e as intensidades são medidas utilizando um detector tipo Dual, explicado anteriormente no capítulo 3. As condições operacionais adotadas neste trabalh o estão apresentadas na tabela 5.1.

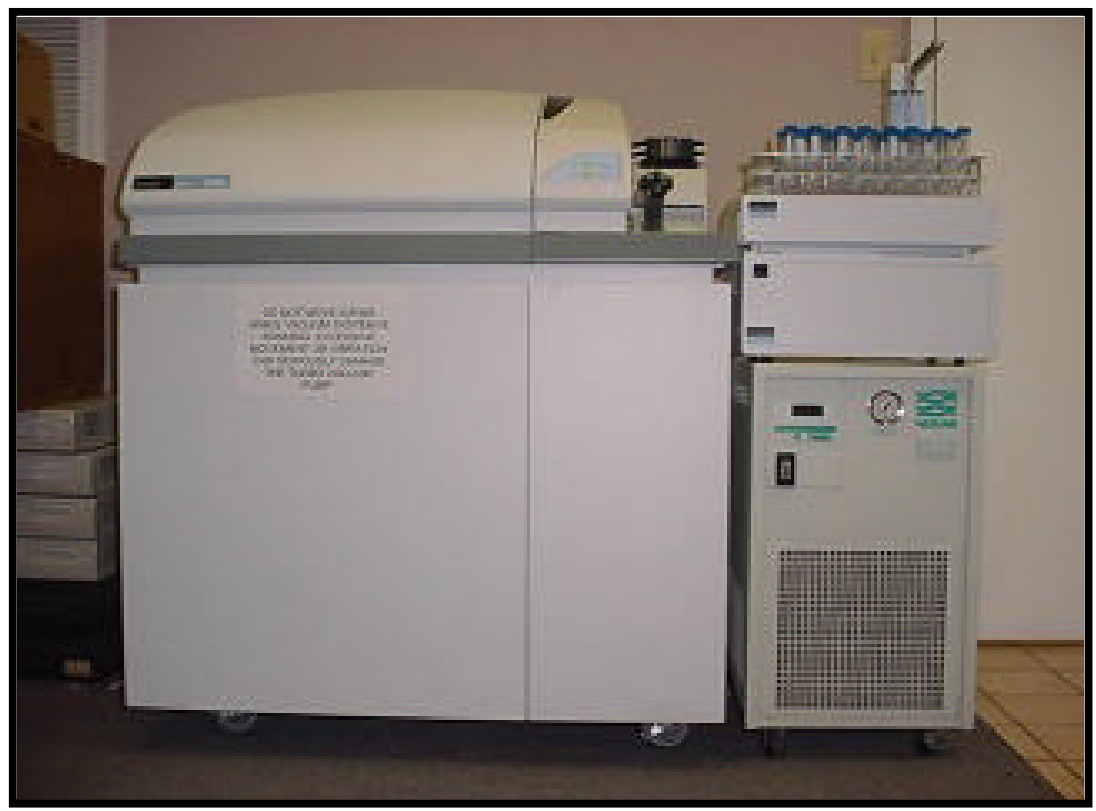

Figura 5.3 Foto de um ICP-MS ELAN 6100 da Perkin Elmer. 
Tabela 5.1 Condições experimentais e parâmetros instrumentais do ICP-MS.

\begin{tabular}{c} 
Fluxo de gás carregador: $0,901 / \mathrm{min}$ \\
Fluxo de gás auxiliar: $1,21 / \mathrm{min}$ \\
Fluxo de gás do plasma: $15 \mathrm{l} / \mathrm{min}$ \\
Voltagem das lentes: $8,25 \mathrm{~V}$ \\
Potência de radio frequiência: $1100 \mathrm{~W}$ \\
Tensão do estágio analógico: $-2050 \mathrm{~V}$ \\
Tensão do estágio digital: $1400 \mathrm{~V}$ \\
Nebulizador: Tipo Meinhard \\
Fluxo de NH $_{3}$ na DRC: $0,61 / \mathrm{min}$ \\
\hline
\end{tabular}

\section{2 $M$ ateriais $U$ tilizados}

A coleta das amostras de soro foi realizada utilizando agulhas de aço inoxidável e tubos de vidro da BD Vacuntainer de $7 \mathrm{ml}$ com heparina ${ }^{1}$ (BD 367735) e sem aditivos (BD 367737), próprio s para a análise de elementos traço.

As amostras foram armazenadas e preparadas em tubos de polipropileno com capacidades de 1.8 e 50ml, respectivamente, utilizando ponteiras descartáveis e micropipetas.

As soluções utilizadas na preparação foram: água Milli-Q, padrão certificado de ítrio (1000ppm) ${ }^{2}$ e Se (1000ppm), padrão multielementar certificado MICPG2 ${ }^{3}$ (100ppm de Al, B, $\mathrm{Ba}, \mathrm{Be}, \mathrm{Bi}, \mathrm{Ca}, \mathrm{Cd}, \mathrm{Co}, \mathrm{Cr}, \mathrm{Cu}, \mathrm{Fé}, \mathrm{K}, \mathrm{Li}, \mathrm{Mg}, \mathrm{Mn}, \mathrm{Mo}, \mathrm{Na}, \mathrm{Ni}, \mathrm{P}, \mathrm{Pb}, \mathrm{Sn}, \mathrm{Sr}, \mathrm{Ti}, \mathrm{Tl}, \mathrm{V}$ e Zn), padrões de $\mathrm{Cu}, \mathrm{Zn}, \mathrm{Sc}$, In e Re, Triton-X, EDTA, e 3 materiais de referência de soro do Instituto Nacional de Saúde Pública - Québec (ICP04S-06, ICP02S-05 e QMEQAS05S-03).

Todo o procedimento foi realizado em salas limpas, para evitar contaminação das amostras, e usando materiais de proteção pessoal como luvas, óculos e jaleco.

\footnotetext{
1 A Heparina é um anticoagulante usado para impedir a coagulação do sangue total.

${ }^{2}$ Os certificados dos materiais utilizados neste trabalho estão no apêndice C.

${ }^{3}$ Os padrões de $\mathrm{Cu}$, Zn, Se e o MICPG2 foram utilizados na construção das curvas de calibração para as análises com ICP-MS.
} 


\subsection{Coleta da A mostras}

Esta pesquisa foi aprovada pelo Comitê de Ética em Pesquisa do Hospital Universitário da USP de São Paulo (Registro CEP/HU; 615/05). Para este estudo foram previamente selecionados como doadores 30 estudantes universitários (22 homens e 8 mulheres) que vivem na cidade de São Paulo, com idade entre 18 e 25 anos. É importante acrescentar que os indivíduos desta população estavam devidamente informados sobre os objetivos do presente estudo. Cada doador assinou uma carta de consentimento para a doação do sangue e respondeu um questionário sobre o próprio estado de saúde, mostrados no apêndice F.

As amostras de sangue foram coletadas no serviço de laboratório clínico do Hospital Universitário da USP após 12 horas de jejum. A coleta foi feita em tubos de vidro da BD Vacuntainer com heparina, para o sangue total, e sem aditivos, para o soro. Este último foi obtido pela centrifugação do sangue coagulado a 3000rpm durante 20 minutos.

O volume de sangue coletado foi estimado em $35 \mathrm{ml}$, uma vez que os valores necessários não eram bem conhecidos. Destes, $14 \mathrm{ml}$ foram coletados para a análise de sangue total $^{4}$ e $21 \mathrm{ml}$ para a análise de soro. A obtenção deste requer um volume maior de amostra, porque uma parte considerável do sangue é constituída de glóbulos vermelhos, os quais são perdidos durante a centrifugação.

As amostras de sangue total e soro foram separadas em alíquotas de $1 \mathrm{ml}$ usando micropipetas e ponteiras descartáveis e mantidas a $-18^{\circ} \mathrm{C}$ até a análise.

\subsection{Preparação de A mostras}

\subsubsection{PIXE}

Na análise pelo método PIXE, as amostras devem ser preferencialmente sólidas e finas, com espessura inferior a $1 \mathrm{mg} / \mathrm{cm}^{2}$. Isso permite o uso direto do modelo de alvo fino,

\footnotetext{
${ }^{4}$ Não foi analis ado neste trabalho.
} 
aumentando assim a exatidão dos resultados em virtude da redução das correções [Tanaka, 2006]. As amostras brutas, sólidas ou líquidas, também podem ser analisadas, mas em geral, fornecem resultado não muito satisfatórios devido ao maior limite de detecção. Tais amostras devem ser transformadas numa solução homogênea ou num pó fino, que pode ser comprimido em uma pastilha homogênea.

Os métodos de preparação de amostras líquidas mais conhecidos e utilizados para análises PIXE são impregnação de papel de filtro ${ }^{5}$, dissolução ultra-sônica ${ }^{6}$, liofilização ${ }^{7}$, LTA $^{8}$ (Low Temperature Ashing) e micropipetagem tecnicamente denominado préconcentração. Este último, usado neste trabalho, consiste em depositar um volume entre 5 e 10 $\mu 1$ de uma amostra líquida em um substrato ${ }^{9}$ e deixá-la secar por evaporação livre, eliminando assim o solvente da amostra. Tal método é relativamente rápido, menos trabalhoso que a nebulização, menos grosseiro que a impregnação em papel de filtro e fornece resultados precisos com um limite de detecção satisfatório [Tabacniks, 2005 e Tanaka, 2006].

As amostras de soro foram preparadas em tubos de polipropileno com capacidade de 1,8ml para evitar perda de material por contato com a superfície. A solução final (figura 5.4) foi obtida adicionando $100 \mu \mathrm{l}$ de ítrio (y -1000ppm, usado como padrão interno) em $1 \mathrm{ml}$ de soro, resultando em 91ppm de y em solução final. Em seguida, $6 \mu 1$ desta solução foram micropipetados sobre Nuclepore ${ }^{10}(10 \mu \mathrm{m}$ de espessura $)$ e mantidas a temperatura ambiente, numa capela de fluxo laminar para evitar contaminações, até a secagem.

As amostras foram irradiadas durante 10 minutos e os espectros obtidos foram analisados pelo programa AXIL [Van Espen 1986].

\footnotetext{
5 É o método mais rápido, visto que consiste simplesmente em impregnar a solução no substrato (papel de filtro) e deixar secar a temperatura ambiente.

${ }^{6}$ Consiste em nebulizar a amostra líquida usando um nebulizador ultra-sônico e evaporar as gotículas formadas numa câmara de ar seco, o aerossol formado é coletado em filtros de policarbonato (Nuclepore).

${ }^{7}$ É a remoção da água por sublimação do gelo. Neste método o material é congelado, em seguida a água é sublimada sob pressão reduzida e por fim, o vapor de água é removido pelo sistema de vácuo. O material liofilizado se apresenta na forma de pequenos blocos maciços, que triturados, geram um pó fino (abaixo de $10 \mu \mathrm{m}$ de diâmetro) e homogêneo.

${ }^{8}$ Promove a redução da matriz orgânica sem aquecer a amostra e, portanto sem risco de perda dos elementos constituintes voláteis a temperaturas mais elevadas.

${ }^{9}$ Geralmente, os substratos mais utilizados nas análises PIXE são Mylar, Kimfol e Nuclepore.

${ }^{10}$ As amostras de soro não aderem bem aos substratos Kimfol e Mylar, materiais bastante utilizados em análises PIXE.
} 


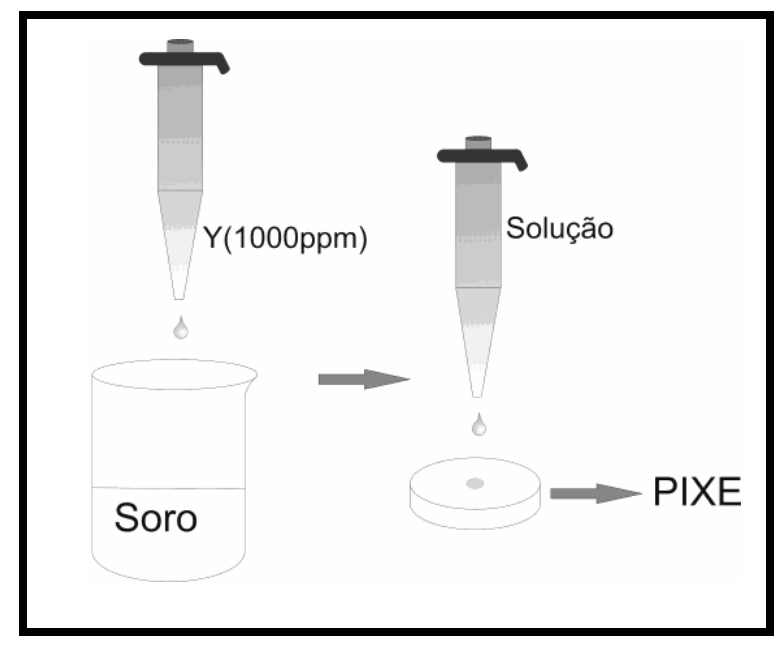

Figura 5.4 Esquema de preparação das amostras de soro para as análises PIXE.

\section{4 .2 ICP-M S}

Os espectrômetros de massa com fonte de plasma induzido que possuem acessórios como o Laser Ablation ou Hydride Genarator permitem a análise de amostras nos estados sólido e gasoso, respectivamente, mas o ICP-MS tradicional utilizado neste trabalho requer amostras na forma líquida. Para o soro, elas podem ser diluídas, com alguns cuidados para evitar a precipitação da amostra e perda de material, ou liofilizadas, neste caso, o pó gerado é reconstituído com água. A diluição da amostra é necessária para reduzir a supressão do sinal causada pelo efeito matriz e também para evitar a obstrução da tocha de plasma e do nebulizador [St'astná, 1999].

Neste trabalho, a amostras foram analisadas pelo ICP-MS após simples diluição do soro de 1:10, figura 5.5. O diluente utilizado continha $0,05 \%$ de triton-X, $1 \mathrm{~g} / \mathrm{l}$ de EDTA e $1 \mu \mathrm{g} / \mathrm{l}$ dos elementos Sc, Y Re e In, usados como padrão interno. A solução final ficou com aproximadamente $0,2 \%$ de $\mathrm{HNO}_{3}$, o ideal para evitar a precipitação do soro, que ocorre em meio ácido. A pequena acidez resultante nas amostras é proveniente dos padrões utilizados na preparação das amostras, os qua is possuem em torno de 5\% do ácido. 
O Triton-X é um detergente utilizado para impedir a perda de material durante a análise e para reduzir a obstrução no injetor da tocha, ele ajuda a evitar que o soro se deposite nos cones e nas paredes do nebulizador e do equipamento, o EDTA é um anticoagulante quelante que ajuda a impedir a perda de metais menores por precipitação. Os padrões foram utilizados para corrigir o drift instrumental [Rodushkin, 2000].

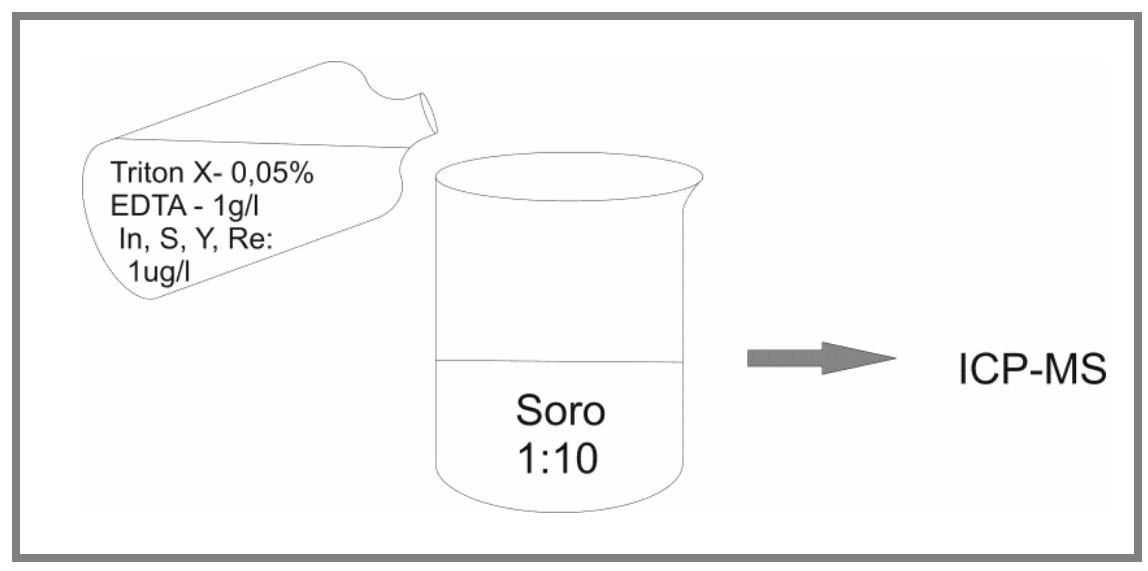

Figura 5.5 Esquema da preparação das amostras de soro para as análises com ICP-MS.

\subsection{Tratamento de B rancos}

As eventuais contaminações das amostras ocorridas durante a manipulação foram monitoradas com a utilização de amostras controle (brancos) específicas para cada método de medida utilizado. As concentrações elementares medidas nos brancos foram subtraídas das amostras. 


\subsubsection{PIXE}

A figura 5.6 mostra um esquema de uma amostra de soro preparada para a análise PIXE, pipetada sobre um substrato. Podemos separar o conjunto visto pelo feixe em três partes: o substrato, o branco e a amostra de soro.

a)

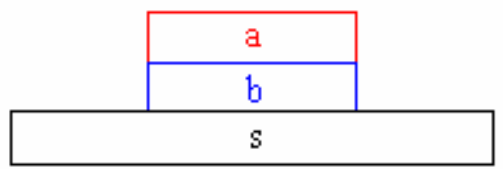

b)

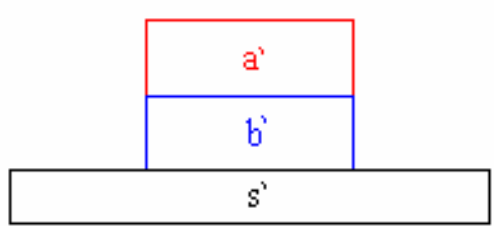

Figura 5.6 Esquema de amostras pipetadas sobre o substrato, onde $a, b$ e $s$ representam, respectivamente, a concentração elementar na amostra de soro, no branco e no substrato. No caso a) temos um volume $\mathrm{V}$ de amostra pipetada e no caso b) temos um volume V'.

A concentração elementar (a) a ser determinada em cada amostra de soro pode ser obtida a partir da seguinte equação.

$$
\begin{gathered}
C=a+b+s \\
C^{\prime}=a^{\prime}+b^{\prime}+s^{\prime}
\end{gathered}
$$

onde: $C$ é a concentração elementar total, $a$ é a concentração do soro, $b$ é a concentração do branco e $s$ é a concentração do substrato.

Como neste trabalho foi utilizado um único substrato e o volume das amostras pipetado sobre o substrato foi o mesmo em todos os casos podemos dizer que $s=s^{\prime}$ e que $b=b^{\prime}$, uma vez que as amostras foram preparadas da mesma maneira. Assim, $b+s=b^{\prime}+s^{\prime}=d$, onde $d$ é uma constante e também pode ser chamada de branco da amostra. Então, a concentração elementar na amostra pode ser representada pela equação 5.2. 


$$
a=C-d
$$

O valor de $d$ foi obtido medindo a solução de branco, preparada como as amostras exceto pelo uso de água milli-Q no lugar do soro, depositada sobre o substrato.

\section{5 .2 ICP.M S}

No ICP-MS as amostras são introduzidas ao equipamento na forma líquida. Neste caso podemos separar a amostra preparada em duas partes, o soro e o branco, figura 5.7.

a)

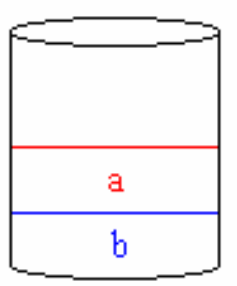

b)

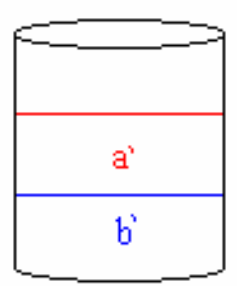

Figura 5.7 Esquema das amostras preparadas para análise pelo método ICP-MS, onde $a$ e $b$ representam, respectivamente, a concentração elementar na amostra de soro e no branco. No caso a) temos um volume V de amostra preparada e no caso b) temos um volume V'.

A concentração elementar total na solução é a concentração presente no soro (a) somada à conce ntração presente no branco, como mostra a equação a seguir.

$$
\begin{aligned}
C & =a+b \\
C^{\prime} & =a^{\prime}+b^{\prime}
\end{aligned}
$$

onde: $C$ é a concentração elementar total, $a$ é a concentração na amostra e $b$ é a concentração no branco. 
Como todas as amostras foram preparadas da mesma maneira, as quantidades de soro e branco em cada caso eram constantes, então, podemos dizer que $b=b^{\prime}$. Assim, a concentração elementar no soro pode ser representada pela equação 5.4.

$$
a=C-b
$$

Neste caso, a concentração do branco foi obtida medindo o diluente usado na preparação das amostras. Esta solução continha todas as substâncias presentes nas amostras preparadas com exceção do soro. 


\section{R esultados e D iscussão}

\subsection{E lementos M edidos}

As concentrações elementares medidas pelo método PIXE foram determinadas a partir da área do pico de cada elemento em relação ao padrão interno $\mathrm{Y}$, como mencionado anteriormente. As figuras 6.1a e 6.1b mostram um exemplo dos espectros PIXE de baixa e alta energia para uma amostra de soro, analisados pelo programa AXIL. A relação entre um canal e a energia desses espectros é sua calibração em energia: $E=E_{0}+G * C$, onde $C$ é o canal e $G$ [eV/canal] é o ganho do sistema de detecção. A calibração experimental é feita identificando alguns picos conhecidos no espectro e associando o canal central à energia da linha.

O arranjo experimental foi optimizado para melhorar o limite de detecção dos espectros de baixa e alta energia para elementos com número atômico entre $12<Z<26$ e $20<Z<40$, respectivamente, (para os raios- $X$ Kalfa). Por isso, apenas parte de cada espectro foi utilizada. No espectro de baixa foi considerado até o pico de cálcio enquanto no de alta foram considerados os picos a partir do ferro. As regiões preferenciais apresentam picos mais definidos e, conseqüentemente, menor variação nos resultados.

No ICP-MS as intensidades de cada elemento são determinadas na forma de taxa de contagens que são convertidas para massa através de um fator de calibração.

A tabela 6.1 mostra os 22 elementos medidos neste trabalho. Destes, 15 foram determinados pela técnica ICP-MS e 9 pela PIXE. O $\mathrm{Cu}$ e o $\mathrm{Zn}$ foram identificados com as duas técnicas. A maioria dos elementos medidos pelo ICP não foram determinados pelo método PIXE por estarem com concentrações abaixo dos limites de detecção desta na amostra. 
As concentrações elementares do soro de cada doador, incluindo as duplicatas realizadas durante as medidas, podem ser vistas no Apêndice G.

a)

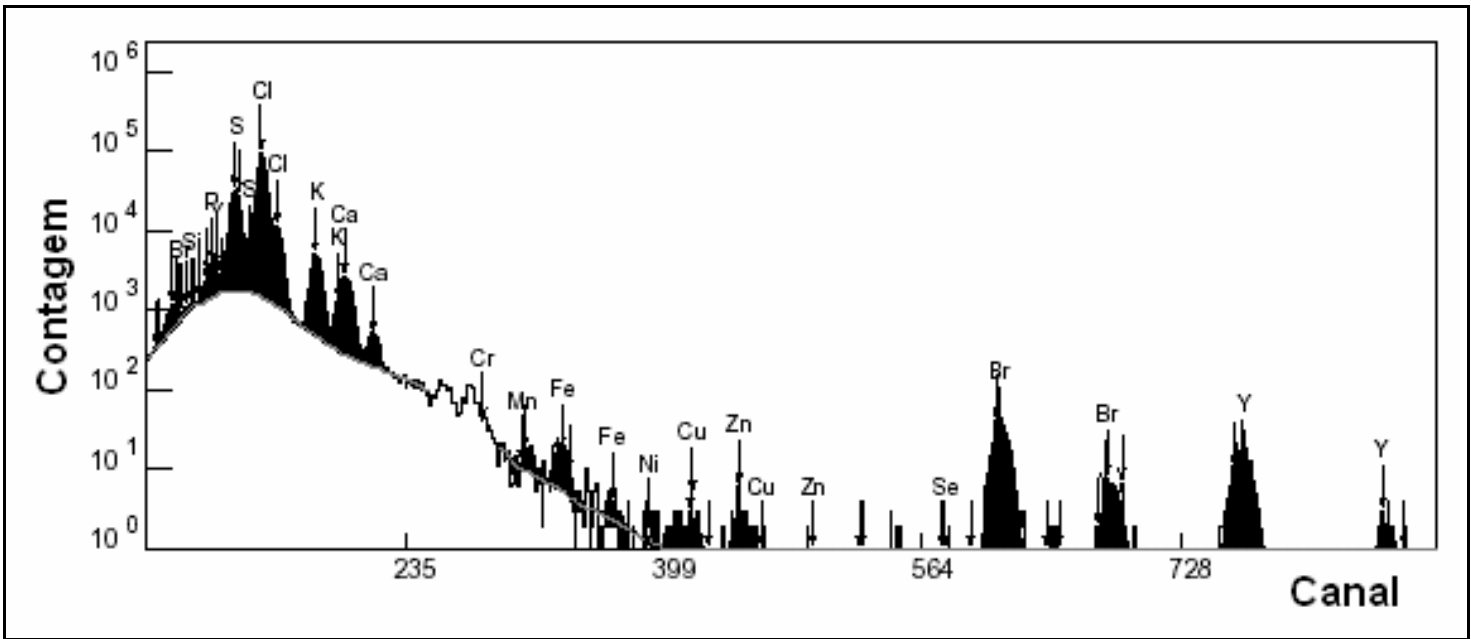

b)

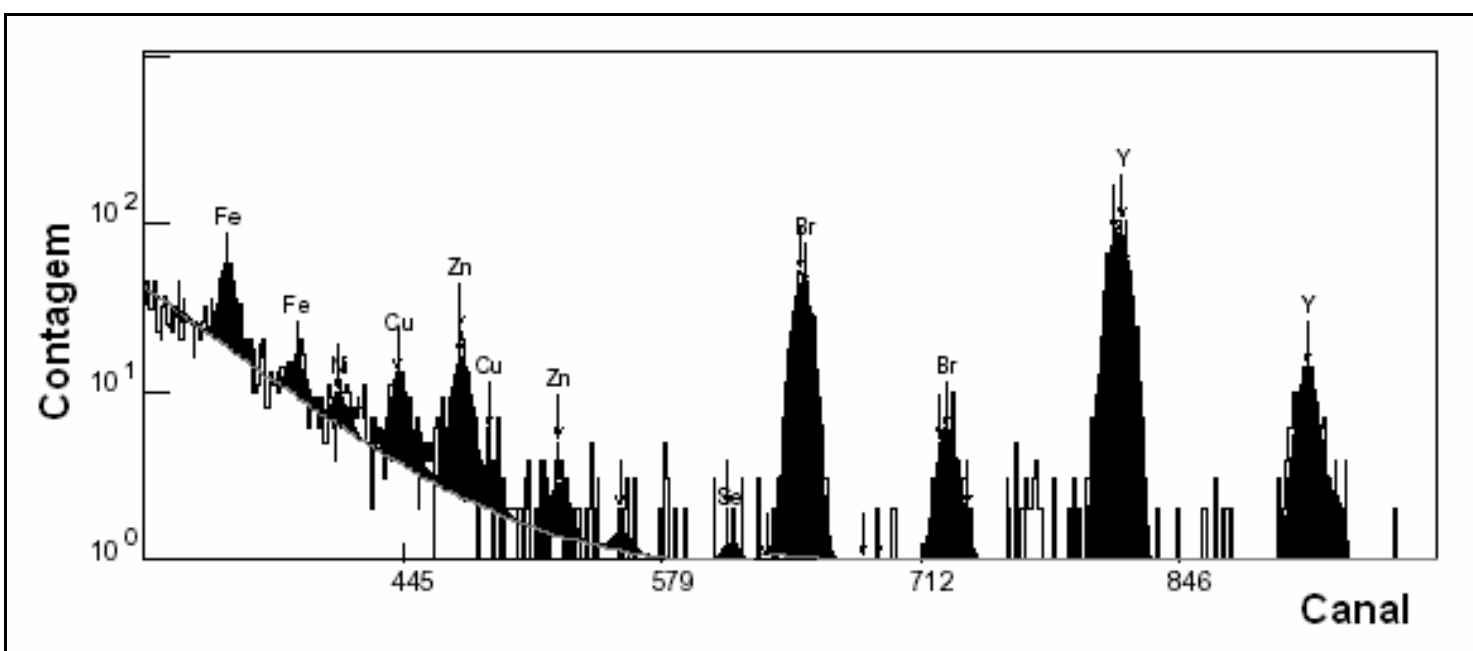

Figura 6.1 Espectros PIXE de baixa (a) e alta energia (b) para uma amostra de soro. Eles foram analisados pelo programa AXIL. 
Tabela 6.1 Elementos medidos neste trabalho pelas duas técnicas utilizadas. O $\mathrm{Cu}$ e o $\mathrm{Zn}$ foram obtidos pelas duas técnicas.

\begin{tabular}{cc}
\hline ICP-MS & PIXE \\
\hline $\mathrm{Al}$ & \\
$\mathrm{Be}$ & $\mathbf{P}$ \\
& $\mathrm{S}$ \\
& $\mathrm{Cl}$ \\
& $\mathrm{K}$ \\
$\mathrm{V}$ & $\mathrm{Ca}$ \\
$\mathrm{Cr}$ & \\
$\mathrm{Mn}$ & \\
$\mathrm{Co}$ & $\mathrm{Fe}$ \\
$\mathrm{Ni}$ & \\
$\mathrm{Cu}$ & \\
$\mathrm{Zn}$ & $\mathrm{Cu}$ \\
$\mathrm{Se}$ & $\mathrm{Zn}$ \\
$\mathrm{Mr}$ & \\
$\mathrm{Cd}$ & $\mathrm{Br}$ \\
$\mathrm{Sn}$ & \\
$\mathrm{Tl}$ & \\
$\mathrm{Pb}$ & \\
&
\end{tabular}

Embora tenha sido identificado um grande número de elementos, os resultados obtidos para alguns, aqueles que apresentaram concentrações menores que os limites de detecção (LD) e/ou quantificação (LQ), foram cuidadosamente analisados levando em conta sua incerteza e a precisão instrumental. Os casos mais críticos foram o $\mathrm{Al} \mathrm{e} \mathrm{o} \mathrm{Be.} \mathrm{Estes} \mathrm{elementos} \mathrm{foram}$ detectados no soro de apenas 20 doadores com $65 \%$ e $25 \%$ dos dados abaixo do LD, respectivamente, e nenhum valor acima do LQ. Além destes dois, outros 6 elementos revelaram concentrações menos confiáveis: o Tl, com 30\% abaixo do LD e $70 \%$ abaixo do LQ; o V, no qual quase todos os dados estavam abaixo da quantificação (93\%); o $\mathrm{Pb}$, de 28 medidas, $21 \%$ estão abaixo da detecção e $36 \%$ abaixo da quantificação; o $\mathrm{Cr}, 17 \%$ das medidas abaixo do LD e 33\% abaixo do LQ; o Sn, $11 \%$ abaixo do LD e 22\% do LQ; por fim o $\mathrm{Cd}$, que teve apenas duas medidas abaixo do limite de quantificação. Dessa forma, optamos 
por apresentar e estudar também estes dados, os quais podem fornecer informações importantes.

As duplicatas medidas pelo método ICP-MS apresentaram alguns problemas para as amostras processadas após algumas horas de funcionamento do equipamento (doadores 17, 18 e 20), quando o drift instrumental estava muito elevado, principalmente para os elementos que apresentaram concentrações elementares abaixo do LD e/ou LQ.

\subsection{Comportamento dos $D$ ados}

Para a análise estatística dos resultados, determinou-se inicialmente a distribuição de probabilidade que melhor descreve os dados experimentais visando a redução destas em funções distribuição de probabilidade biparamétricas que possam ser usadas com confiança na descrição dos resultados de concentrações elementares.

Na prática, métodos gráficos como histogramas e gráficos de probabilidades podem ser utilizados para avaliar se os dados experimentais de populações desconhecidas descrevem bem alguma distribuição de probabilidade [Martinez-Espinosa, 2004]. Por isso, o tratamento estatístico dos dados com a determinação de médias e desvios padrão foi precedida de uma análise gráfica, na forma de histogramas de probabilidade, que permitiram uma inspeção visual e intuitiva dos resultados. Na figura 6.2 observa-se que o $\mathrm{Cl}$ e o $\mathrm{Mn}$, aparentemente são normalmente distribuídos, enquanto outros como o $\mathrm{Al}$ e o $\mathrm{Co}$, apresentam uma distribuição assimétrica. Entretanto, uma avaliação ma is criteriosa usando testes estatísticos é necessária. 

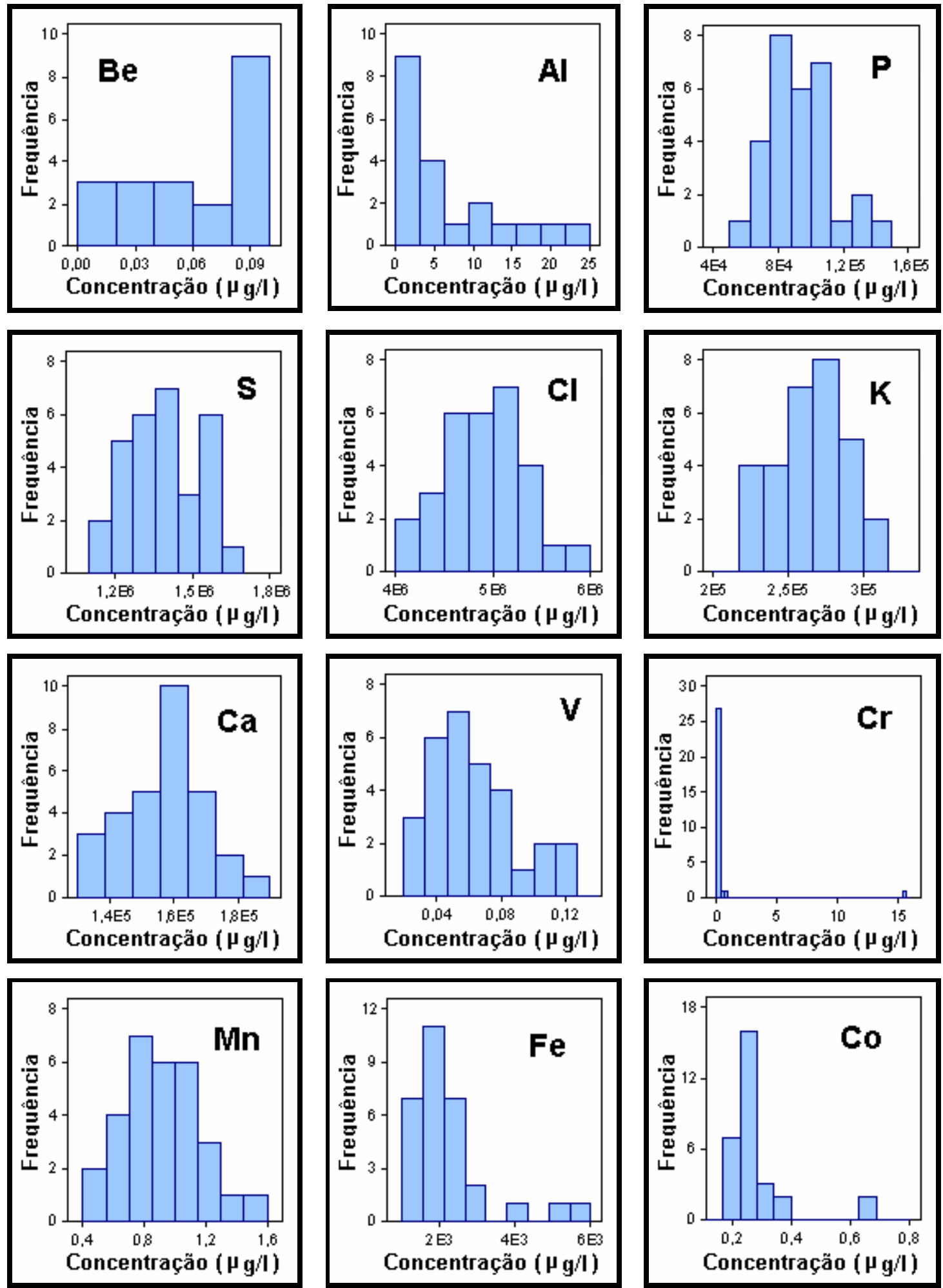

Figura 6.2 Histogramas das concentrações elementares medidas em 30 amostras de soro. 

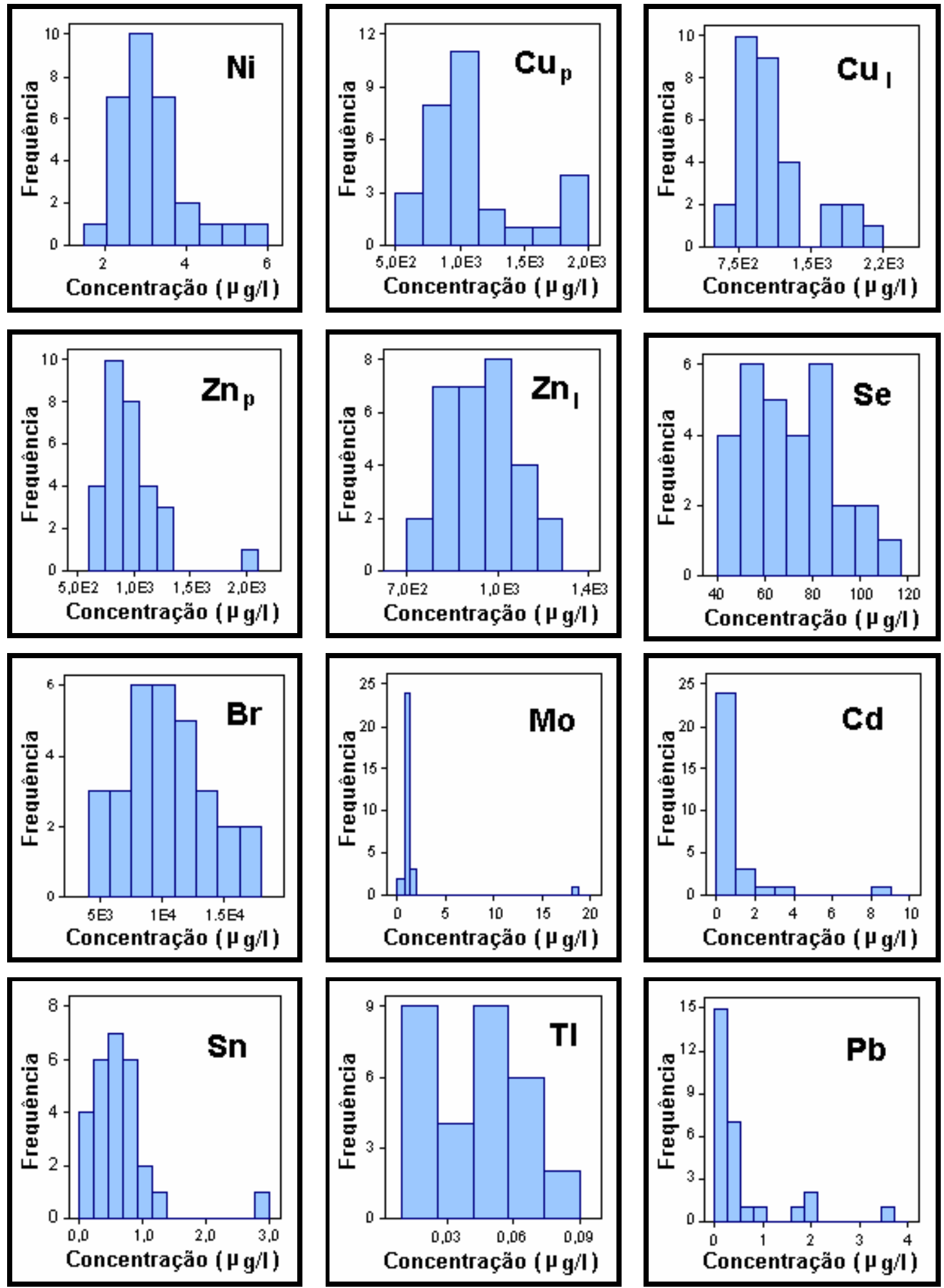

Figura 6.2 Histogramas das concentrações elementares medidas em 30 amostras de soro. 


\subsection{Testes de N ormalidade}

Na literatura, é possível encontrar vários testes de normalidade como D’AgostinoPearson, Kolmogorov-Smirnov, Cramér-von Mises, Anderson-Darling e Shapiro-Wilk, que verificam se a distribuição de um conjunto de dados descreve uma distribuição normal [Santos, 2003]. Cabe observar que, para grandes amostras, as diferenças entre os métodos são mínimas, porém para pequenas amostras elas podem ser significativas [MartinezEspinosa, 2004]. O teste de normalidade de Shapiro-Wilk, também conhecido com teste W, é o mais adequado para o nosso estudo, pois é um teste indicado para amostras com $\mathrm{N}<50$, apesar de alguns autores atestarem que ele também pode ser usado para $\mathrm{N}>50$ [Conover, 1980]. Como exemplo podemos citar o trabalho de Leotti (2005), o qual mostra que quando um conjunto de dados provém de uma distribuição normal, independentemente do tamanho da amostra (variando de 15 a 100), o teste de Shapiro-Wilk tem percentual de acerto superior a 99\%, enqua nto em distribuições com os dados aproximadamente simétricos, mas não-normais, o acerto chega a aproximadamente $10 \%$ para $\mathrm{N}=30$ e $40 \%$ para $\mathrm{N}=100$, valores baixos, mas ainda superiores aos resultados dos demais testes utilizados. Este trabalho também mostra que quanto mais assimétrica a distribuição, melhor o desempenho dos testes. Neste caso, também se evidenciou uma superioridade do teste de Shapiro-Wilk em relação aos demais, independente do número de amostras. Além disso, para $\mathrm{N}$ maiores a qualidade do teste aumenta significativamente, chegando a aproximadamente $20 \%$ para $\mathrm{N}=30$ e $80 \%$ para $\mathrm{N}=100$, para amostras levemente assimétricas, e aproximadamente $85 \%$ para $\mathrm{N}=30$ e $100 \%$ para $\mathrm{N}=100$, para amostras bastante assimétricas.

Além desses testes bem consagrados na literatura, essa verificação pode ser feita também utilizando o teste de Bera-Jarque baseado nos coeficientes de Assimetria (Skewness) e Curtose (Kurtosis), que indicam o grau de assimetria e achatamento da distribuição, respectivamente [Soares, 2003].

Neste trabalho, o teste $\mathrm{W}$ foi aplicado aos dados de soro usando um programa de estatística SPSS 13 (Statistical Package for Social Sciences). Este programa também fornece os valores de Assimetria e Curtose da distribuição. Os valores obtidos em cada teste e os valores tabelados para o teste $\mathrm{W}$ podem ser vistos no Apêndice $\mathrm{H}$. 


\subsubsection{Testes de A ssimetria e Curtose}

O coeficiente de Assimetria é uma medida de simetria, ou seja, ela indica o quanto a distribuição é assimétrica. Se a distribuição possui uma "cauda" mais longa à direita da ordenada máxima, diz-se que a distribuição tem uma assimetria positiva. Se ocorrer o inverso, tem-se uma Assimetria negativa. Caso a "cauda" à direita e à esquerda sejam iguais, a distribuição em questão é simétrica. A Curtose indica o grau de "achatamento" da curva da função distribuição. Uma distribuição com ordenada máxima muito alta é denominada leptocúrtica e uma com ordenada muito baixa, do tipo "achatada", é denominada mesocúrtica. O programa SPSS utiliza as equações 5.1 e 5.2 para calcular os termos de Assimetria e Curtose, respectivamente. De acordo com este programa, quando esses coeficientes estão próximos de zero e as relações Assimetria/Erro padrão e Curtose/Erro padrão estão entre - 2 e +2 os dados são normalmente distribuídos.

$$
\begin{gathered}
A=\frac{\sum_{i=1}^{N}\left(x_{i}-\bar{x}\right)^{3}}{(N-1) \cdot s^{3}} \\
C=\frac{\sum_{i=1}^{N}\left(x_{i}-\bar{x}\right)^{4}}{(N-1) \cdot s^{4}}
\end{gathered}
$$

onde $x_{i}$ é o valor da iésima amostra, $\bar{x}$ é a média, $s$ o desvio padrão e $N$ o número de amostras.

\subsubsection{Teste de Shapiro-W ilk}

O teste de normalidade de Shapiro-Wilk é quantitativo e mede a relação de linearidade entre os dados e os escores normais. Ele é baseado numa função de distribuição que consiste em uma variável aleatória $X_{1}, X_{1}, \ldots, X_{n}$ de tamanho $\mathrm{N}$, associada a uma função de distribuição 
$F(x)$ desconhecida [Conover, 1980]. Este teste estatístico é obtido dividindo o quadrado de uma combinação linear apropriada da ordem estatística da amostra por uma usual estimativa de variância simétrica, como mostra a equação 5.3. Estas razões são escalares e de origem invariante e, portanto, a estatística é apropriada para um teste de hipóteses de normalidade [Shapiro,1965 e Conover, 1980]. Valores da estatística W pequenos e próximos de um evidenciam a normalidade [Soares, 2003].

Ao calcular o teste $\mathrm{W}$, o programa SPSS fornece os valores da estatística com suas significâncias (p-value). Estes valores são comparados com os valores tabelados do teste de Shapiro-Wilk. Para serem aceitas pelo teste de W, as distribuições precisam apresentar os valores da estatística maiores que os valores tabelados para a significância de 5\%, nível estabelecido neste trabalho, e a significância fornecida pelo SPSS precisa ser superior a $5 \%$.

$$
W=\frac{\left(\sum_{i=1}^{N} a_{i} x_{i}\right)^{2}}{\sum_{i=1}^{N}\left(x_{i}-\bar{x}\right)^{2}}
$$

onde $x_{i}$ são os valores da amostra e $a_{i}$ são constantes generalizadas das médias, variâncias e covariâncias da amostra de tamanho $N$ de uma distribuição normal.

\subsubsection{Indícios de N ormalidade}

A figura 6.3 mostra os histogramas com as curvas gaussianas para os elementos que passaram no teste de normalidade com nível de significância de 5\% e também nos testes de Assimetria e Curtose. Olhando a figura 62 podemos perceber a presença de outliers $^{1}$ em algumas distribuições. As principais causas que levam ao aparecimento de outliers são: erros de medição, erros de execução e variabilidade inerente aos elementos da população. Numa

\footnotetext{
${ }^{1}$ Medidas observadas em experimentos geralmente apresentam outliers, valores muito afastados do corpo da curva. Esses pontos apresentam mais de 3 desvios padrão do valor médio, fora dos limites, e podem não ser características da distribuição.
} 
distribuição estatística, em que todos os pontos são equivalentes, a exclusão de um valor não pode alterar significativamente a estatística realizada (média, desvio padrão, ect). Se a eliminação alterar estes valores, o ponto não é equivalente aos outros da amostra, e geralmente é descartado. No nosso caso, excluindo estes pontos da distribuição, além da diferença na estatística, os dados do $\mathrm{Zn}_{\mathrm{p}}$ (medido pelo método PIXE), Mo e Sn passam a descrever uma distribuição normal, o que não acontecia antes. Por outro lado, a exclusão de um ponto do $\mathrm{Cr}$ e dois do Co não torna estas distribuições normais, por isso estas permaneceram da mesma maneira. Estes foram os critérios utilizados para eliminar pontos do conjunto de dados destes elementos. 

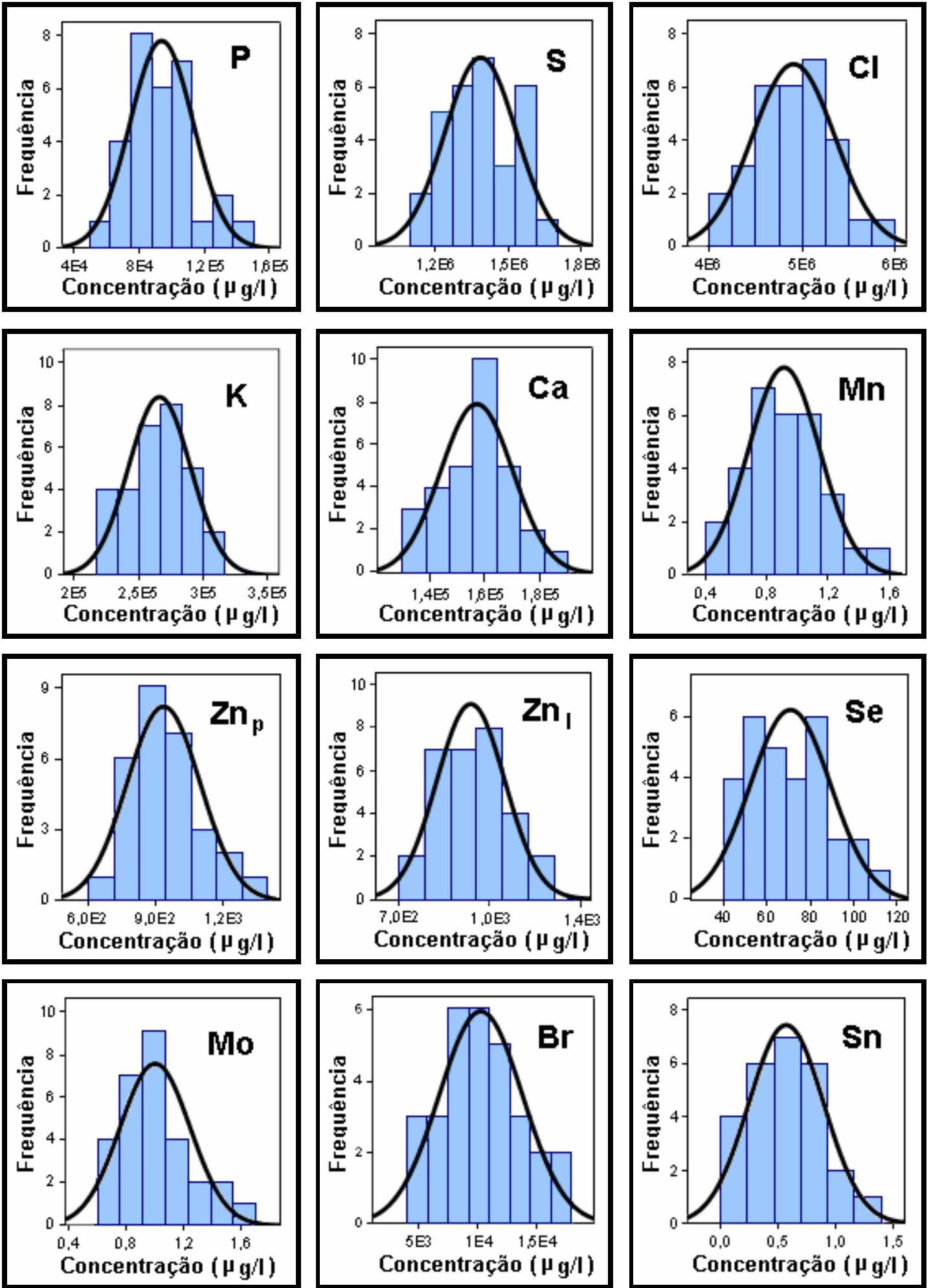

Figura 6.3 Histogramas das concentrações elementares com indícios de normalidade. Estas distribuições passaram nos testes de normalidade de Shapiro-Wilk, Assimetria e Curtose. 


\subsubsection{Indícios de L ognormalidade}

Como visto nos trabalhos de Majewska (1999) e Kubala-Kukus (2004), é comum concentrações elementares em materiais biológicos descreverem uma distribuição assimétrica, e mais precisamente uma lognormal. Por este motivo, esta foi a segunda distribuição testada.

Um caminho simples para verificar se um conjunto de dados descreve uma distribuição lognormal é fazer o histograma da transformação logarítmica da concentração dos dados (eq. 6.4), que por definição da distribuição lognormal, deve ser normalmente distribuída. O teste de wilk foi aplicado novamente em todas as distribuições, incluindo as que já haviam passado no teste de normalidade, mas desta vez para testar a distribuição transformada.

$$
x^{\prime}=\ln x
$$

Os histogramas da figura 6.4 mostram os elementos que apresentaram indícios de uma lognormalidade, uma vez que suas transformadas passaram no teste W com nível de significância de 5\% e também nos testes de Assimetria e Curtose. Usando o mesmo critério estabelecido anteriormente, excluindo um outlier da distribuição do $\mathrm{Cr}$, do $\mathrm{Zn}$, do Mo e dois do Co, estes elementos passam a descrever uma distribuição lognormal. Praticamente metade dos elementos medidos neste trabalho ( $\mathrm{P}, \mathrm{S}, \mathrm{Cl}, \mathrm{K}, \mathrm{Ca}, \mathrm{Mn}, \mathrm{Zn}, \mathrm{Se}, \mathrm{Br}$ e Mo) é bem descrita pelas duas distribuições, normal e lognormal. Fato já citado na literatura por Limpert (2001), em seu trabalho que diz que uma distribuição pode ser normal e lognormal simultaneamente. 

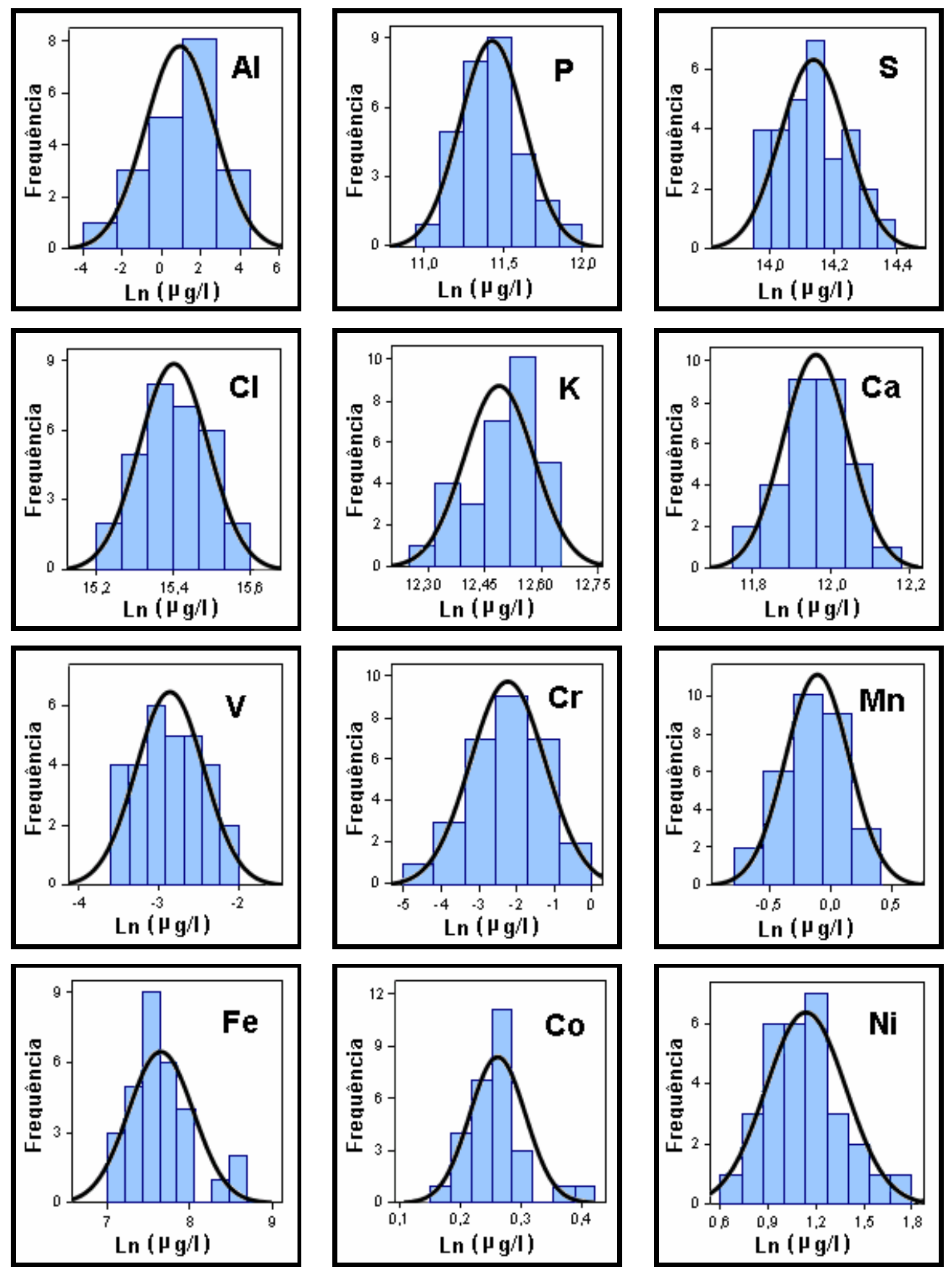

Figura 6.4 Histogramas das concentrações elementares com indícios de lognormalidade. A transformada destas distribuições $\left(x^{\prime}=\ln x\right)$ passou no teste de normalidade de Shapiro-Wilk. 

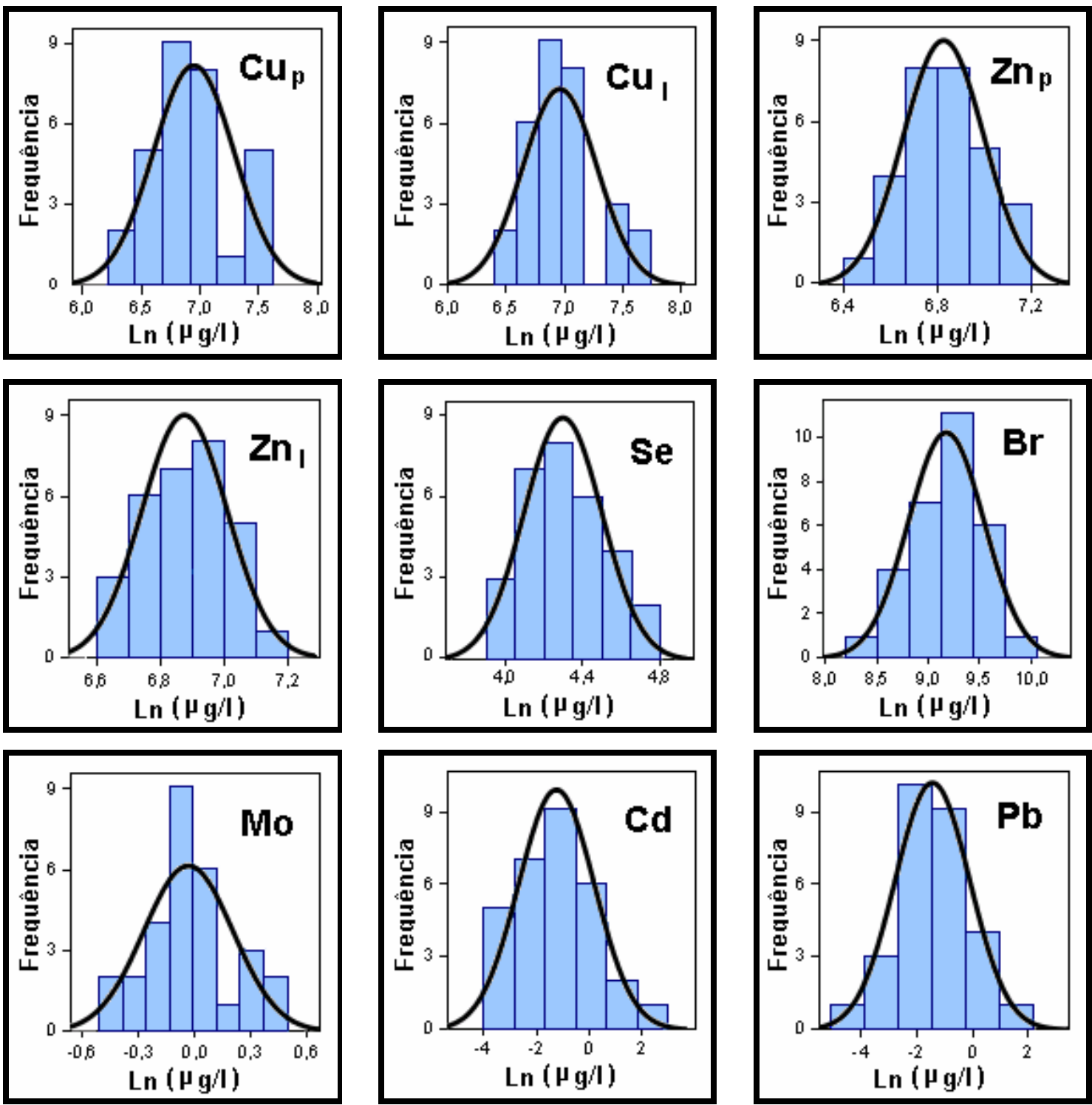

Figura 6.4 Histogramas das concentrações elementares com indícios de lognormalidade. A transformada destas distribuições $\left(\mathrm{x}^{\prime}=\ln \mathrm{x}\right)$ passou no teste de normalidade de Shapiro-Wilk com significância de 5\% e também nos testes de Assimetria e Curtose.

\subsubsection{D istribuiç̧ões não $D$ eterminadas}

Os dados das concentrações de $\mathrm{Tl}$ e Be e suas transformadas logarítmicas não passaram no teste de Shapiro-Wilk com nível de significância de 5\%, embora tenham passado nos testes 
de Assimetria e Curtose, com exceção da distribuição transformada do segundo elemento que não passou no teste de Assimetria. Entretanto as concentrações de $\mathrm{Tl}$ e Be passaram no teste de normalidade com $2 \%$ e $1 \%$ de significância, respectivamente. A formação da distribuição de Be pode ter sido prejudicada pela proximidade das concentrações ele mentares com o limite de detecção além do reduzido número de medidas. O histograma deste elemento mostra várias medidas com o mesmo valor, um indicativo de que apenas ruídos foram detectados, o que não acontece com o $\mathrm{Tl}$, que apresenta um "estilo" de distribuição normal, apesar de também apresentar concentrações próximas ao LD.
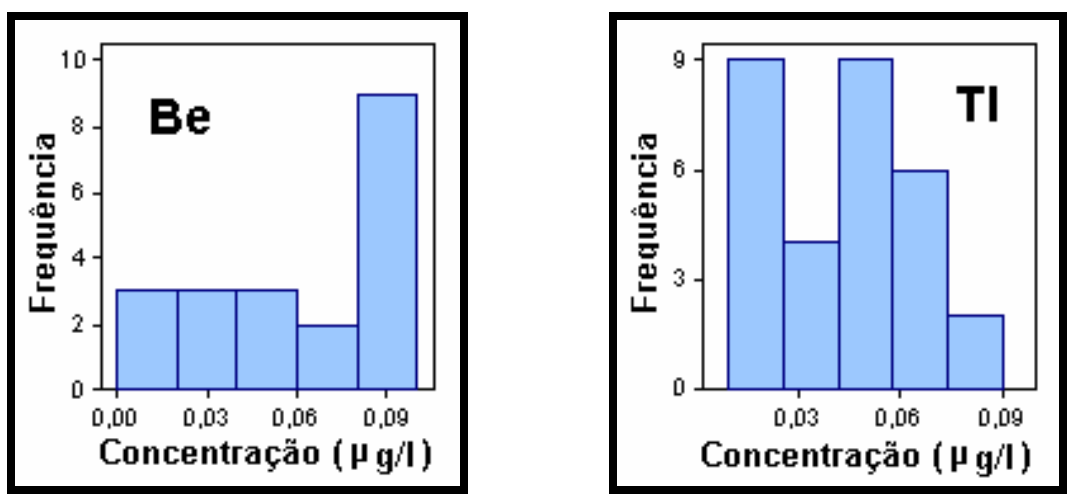

Figura 6.5 Elementos que não passaram em todos os testes aplicados.

Apesar da maioria das distribuições e/ou suas transformações logarítmicas terem passado no teste $\mathrm{W}$ e possuírem os parâmetros de Assimetria e Curtose dentro do esperado para uma distribuição normal e/ou lognormal, dependendo do caso, um estudo mais detalhado ainda é necessário para confirmar a distribuição dos elementos, principalmente para o Be e o Tl que não passaram nos testes de normalidade com nível de significância de 5\%. Os elementos que apresentaram dupla característica, ou seja, indícios de normalidade e lognormalidade também devem ser estudados em mais detalhes. A aplicação de outros testes de normalidade, pelo menos três, também pode ajudar a melhorar as estatísticas e garantir o resultado dos testes estatísticos. Além do teste $\mathrm{W}$ outros testes como os de D'AgostinoPearson, de Kolmogorov-Smirnov e de Anderson-Darling podem ser utilizados para este estudo [Kubala-Kukus, 2003]. 
Este trabalho não tinha inicialmente por objetivo realizar estatísticas das amostras, entretanto no decorrer do estudo de viabilidade e desenvolvimento de metodologia esses dados foram compilados com uma "população" de jovens adultos aparentemente sadios, conforme questionário de histórico de saúde, gerando resultados que podem ter significado estatístico, mas ainda dependentes de um controle mais rigoroso de saúde e aumento dos indivíduos estudados.

\subsection{Tratamento E statístico}

Como citado anteriormente, as distribuições mais usadas em mecanismos biológicos são as normais e as lognormais. $\mathrm{O}$ fato de a distribuição normal possuir propriedades aditivas, enquanto a distribuição lognormal possui propriedades multiplicativas, é a princ ipal diferença entre as duas. Uma distribuição normal é simétrica e pode ser caracterizada pela média aritmética $(\bar{x})$ e pelo desvio padrão $(\sigma)$ da variável de origem. A probabilidade de se encontrar os valores $\bar{x}+\sigma$ e $\bar{x}-\sigma$ é a mesma e os dados são representados por $x=\bar{x} \pm \sigma$. Além disso, suas média, moda e mediana são iguais. Uma lognormal é claramente assimétrica, pois a subtração de três desvios padrão da média resulta em um valor negativo. Estas distribuições são particularmente comuns quando o valor médio é baixo e a variância é grande. Então o intervalo de dados será assimétrico, para ser preciso, multiplicativo ou divisível pelo desvio padrão em torno da média. Neste caso os dados são descritos por $x=\bar{x} * / \sigma$. O intervalo $x=\bar{x} * / \sigma$ cobre uma probabilidade de $68,3 \%$ enquanto $x=\bar{x}^{*} / \sigma^{2}$ e $x=\bar{x}^{*} / \sigma^{3}$ correspondem, respectivamente, a 95,5\% e a 99,7\% dos dados, exatamente os valores varridos por uma distribuição normal entre $\sigma, 2 \sigma$ e $3 \sigma$. A média e o desvio padrão geométrico de uma distribuição lognormal são descritos pelas equações 6.5 e 6.6, respectiva mente [Limpert, 2001 e Aitchison, 1969].

$$
\begin{gathered}
M=e^{\bar{x}^{\prime}+\frac{\sigma_{\bar{x}^{\prime}}^{2}}{2}} \\
\sigma_{g}=e^{\sigma_{\bar{x}}}
\end{gathered}
$$


onde $M$ é a mediana das distribuições, $\bar{x}^{\prime}$ é o valor médio dos logaritmos da variável, $\sigma_{\bar{x}^{\prime}}$ é o desvio padrão dos logaritmos e $\sigma_{g}$ é o desvio padrão geométrico da distribuição.

A tabela 6.2 mostra as médias, as medianas e os desvios padrão das distribuições. Para os elementos que apresentaram indícios de lognormalidade os parâmetros foram calculados usando as equações anteriores, próprias para distribuições lognormais [Aitchison, 1969].

Observando a tabe la, nota-se que os desvios padrão geométricos das distribuiç̧ões com indícios de lognormais variaram de 1,1 a 5,8, com vários valores em torno de 1,1. De acordo com Limpert (2001), valores abaixo de 1,2 são muito comuns e de grande interesse em ciências. Entretanto essas distribuições lognormais são difíceis de serem distinguidas das distribuições normais.

As duas técnicas utilizadas foram eficientes na determinação de $\mathrm{Cu}$ e $\mathrm{Zn}$, resultando em valores coerentes entre si. Além disso, como esperado, suas distribuições também concordaram para os dois métodos.

Com este estudo foi possível medir a concentração elementar de vários elementos em soro sanguíneo, estudar suas distribuições e assim fazer uma análise estatística adequada para cada caso, entretanto devemos lembrar também que algumas concentrações podem não ser tão confiáveis, por estarem muito próximas do LD, e necessitam mais estudos. 
Tabela 6.2 Valores de mínimo (Mín), máximo (Máx), média (M), mediana(Md) e desvio padrão (SD) foram determinados usando o programa SPSS com exceção das M, Md e SD das distribuições lognormais que foram calculados no programa Excel. Os termos entre parênteses $N$ e $L n$, representam normal e lognormal, respectivamente. As unidades das concentrações, quando não mencionadas entre parênteses, estão em $\mu \mathrm{g} / \mathrm{l}$.

\begin{tabular}{|c|c|c|c|c|c|c|c|c|c|}
\hline Elemento & Mín & Máx & $M(N)$ & $M d(N)$ & $S D(N)$ & $M(L n)$ & $M d(L n)$ & $S D_{g}(L n)$ & $N$ \\
\hline $\mathrm{Be}$ & 0,009 & 0,099 & & 0,076 & & & & & 20 \\
\hline$\overline{A l}$ & 0,047 & 22,5 & & & & 11,6 & 2,5 & 5,8 & 20 \\
\hline $\mathbf{P}(\mathrm{mg} / \mathrm{l})$ & 58 & 145 & 94 & 93 & 19 & 94 & 92 & 1,2 & 30 \\
\hline $\mathbf{S}(\mathrm{g} / \mathrm{l})$ & 1,15 & 1,70 & 1,39 & 1,37 & 0,14 & 1,39 & 1,38 & 1,1 & 30 \\
\hline $\mathbf{C l}(\mathrm{g} / \mathrm{l})$ & 4,12 & 5,83 & 4,91 & 4,87 & 0,44 & 4,91 & 4,89 & 1,1 & 30 \\
\hline $\mathbf{K}(\mathrm{mg} / \mathrm{l})$ & 219 & 306 & 266 & 268 & 24 & 266 & 265 & 1,1 & 30 \\
\hline $\mathbf{C a}(\mathrm{mg} / \mathrm{l})$ & 131 & 187 & 157 & 157 & 13 & 157 & 156 & 1,1 & 30 \\
\hline $\mathbf{V}$ & 0,029 & 0,126 & & & & 0,063 & 0,057 & 1,5 & 30 \\
\hline $\mathrm{Cr}$ & 0,013 & 0,81 & & & & 0,18 & 0,11 & 2,7 & $29^{*}$ \\
\hline Mn & 0,51 & 1,48 & 0,91 & 0,89 & 0,23 & 0,91 & 0,88 & 1,3 & 30 \\
\hline $\mathrm{Fe}(\mathrm{mg} / \mathrm{l})$ & 1,12 & 5,68 & & & & 2,26 & 2,09 & 1,5 & 30 \\
\hline Co & 0,182 & 0,395 & & & & 0,262 & 0,258 & 1,2 & $28^{\star \star}$ \\
\hline $\mathrm{Ni}$ & 1,97 & 5,85 & & & & 3,21 & 3,11 & 1,3 & 30 \\
\hline Cup (mg/l) & 0,54 & 1,96 & & & & 1,08 & 1,02 & 1,4 & 30 \\
\hline $\mathrm{Cu}_{\mathbf{l}}(\mathrm{mg} / \mathrm{l})$ & 0,63 & 2,21 & & & & 1,11 & 1,05 & 1,4 & 30 \\
\hline $\mathbf{Z n}_{\mathbf{p}}(\mathrm{mg} / \mathrm{l})$ & 0,64 & 1,32 & 0,94 & 0,92 & 0,16 & 0,97 & 0,95 & 1,2 & $29^{*}$ \\
\hline $\mathbf{Z n}_{\mathbf{l}}(\mathrm{mg} / \mathrm{l})$ & 0,78 & 1,21 & 0,98 & 0,97 & 0,13 & 0,98 & 0,97 & 1,1 & 30 \\
\hline $\mathrm{Se}$ & 42 & 109 & 71 & 68 & 18 & 71 & 69 & 1,3 & 30 \\
\hline $\mathrm{Br}(\mathrm{mg} / \mathrm{l})$ & 4,2 & 18,0 & 10,3 & 9,8 & 3,5 & 10,3 & 9,7 & 1,4 & 30 \\
\hline Mo & 0,62 & 1,58 & 1,00 & 0,98 & 0,24 & 1,00 & 0,97 & 1,3 & $29^{*}$ \\
\hline Cd & 0,026 & 8,60 & & & & 0,81 & 0,29 & 4,2 & 30 \\
\hline Sn & 0,04 & 1,34 & 0,57 & 0,51 & 0,32 & & & & $26^{*}$ \\
\hline TI & 0,015 & 0,081 & 0,044 & 0,048 & 0,021 & 0,045 & 0,038 & 1,8 & 30 \\
\hline$\overline{\mathrm{Pb}}$ & 0,01 & 3,70 & & & & 0,61 & 0,25 & 3,8 & 28 \\
\hline
\end{tabular}




\subsection{Comparação com a L iteratura}

A figura 6.6 compara as concentrações obtidas neste trabalho com os valores encontrados na literatura. O gráfico foi construído usando medianas e as barras representam o intervalo entre os valores máximos e mínimos.

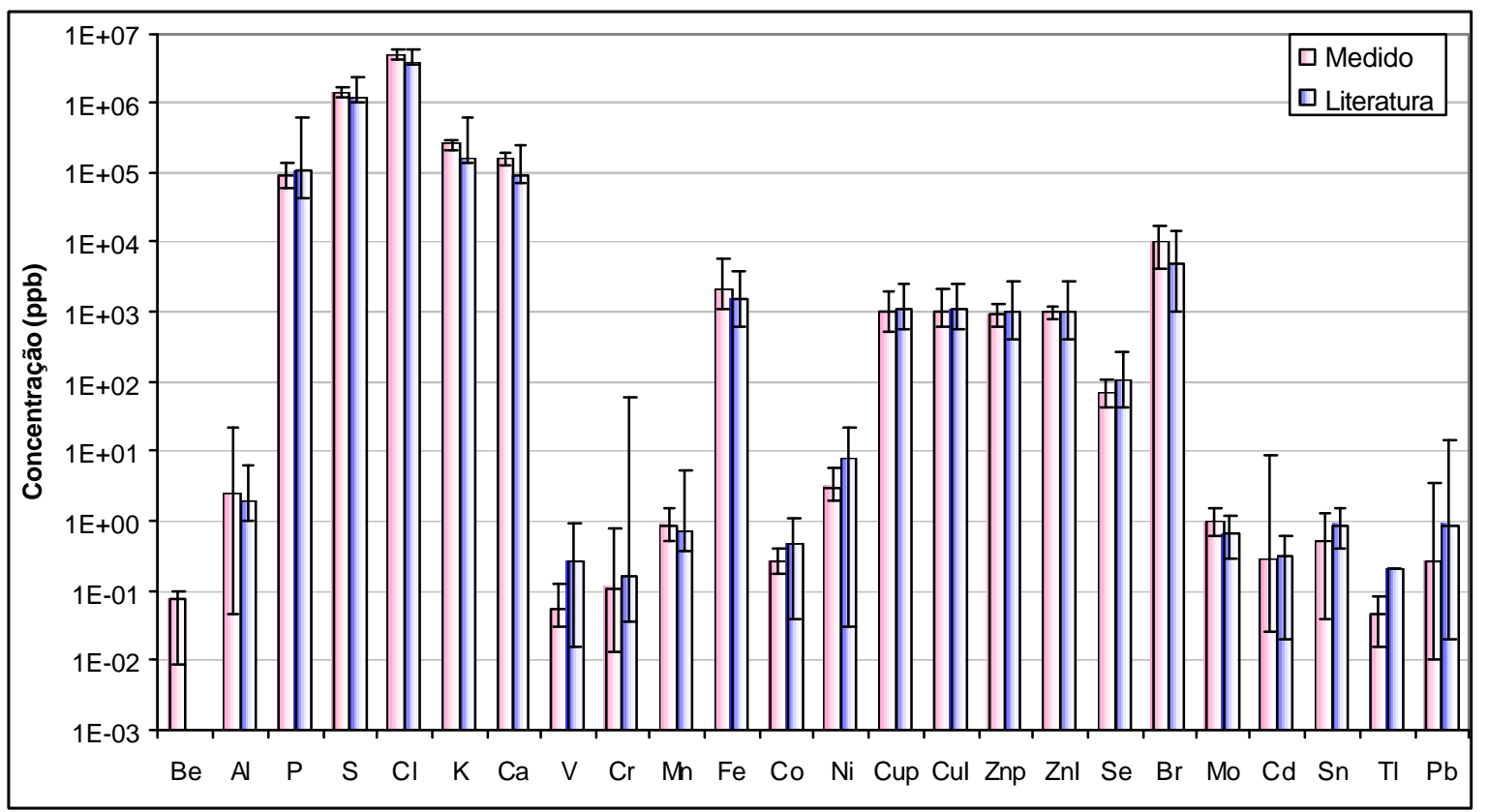

Figura 6.6 Medianas das concentrações elementares em soro comparadas com valores da literatura. As barras de erro indicam valores de máximo e mínimo. Os índices P e I representam as técnicas PIXE e ICP, respectivamente.

Foram medidos 22 elementos alcançando 9 ordens de grandeza em um único trabalho, com resultados de boa qualidade e com a vantagem de medir a concentração de Be, ainda não encontrada na literatura. Observando a figura é possível notar que apesar do problema enfrentado com a proximidade da concentração de alguns elementos, como o Be, $\mathrm{Al}, \mathrm{V}, \mathrm{Cr}, \mathrm{Sn}$ e Tl, com o limite de detecção, os dados concordam com os valores da literatura, com exceção do $\mathrm{Tl}$, que se encontra um pouco abaixo. Entretanto deve ser lembrado que o gráfico compara populações diferentes com hábitos diferentes. 
Aqui também é possível observar que, em geral, as barras de máximo-mínimo deste trabalho são menores que as da literatura, fato esperado uma vez que a revisão bibliográfica realizada neste engloba populações de vários trabalhos e lugares do mundo, enquanto este trabalho é especifico de uma única população com alguns critérios de seleção mencionados anteriormente. 


\section{Conclusão}

Os métodos PIXE e ICP-MS são muito importantes no estudo da composição química de diversos materiais e também bastante competitivos com outras técnicas, principalmente pelas suas capacidades analíticas. As concentrações elementares medidas neste trabalho alcançaram com sucesso os valores usualmente conseguidos na literatura, da ordem de $\mathrm{mg} / \mathrm{l}$ para o PIXE e da ordem de $\mu \mathrm{g} / 1$ para o ICP-MS. No entanto, é possível alcançar limites de detecção ainda menores usando um substrato que resulte um menor fundo na análise PIXE e diminuindo a diluição soro na preparação das amostras para as análises com ICP-MS. Além disso, com esta combinação PIXE-ICP é possível medir praticamente todos os elementos da tabela periódica com qualidade.

Entretanto, existem desvantagens de se trabalhar com amostras de soro, pois a preparação do analito é trabalhosa e exige cuidados especiais. O soro não adere bem a alguns substratos como, por exemplo, o Kimfol e o Mylar, bastante utilizados em análises PIXE, e também precipita em meio ácido ou básico dificultando a preparação para o ICP-MS que inclui adição de padrões ácidos na preparação. Entretanto, solucionados estes problemas ${ }^{1}$, o objetivo principal deste trabalho de desenvolver uma metodologia de análise de soro pelos métodos PIXE e ICP-MS foi desenvolvido com sucesso. Ao todo foram identificados 22 elementos alcançando 9 ordens de magnitude, quantidades pouco encontradas na literatura em um único trabalho. Dentre esses, além de elementos traço, também foram medidos alguns elementos majoritários que são de grande importância em análises clínicas como o Ferro, por exemplo. Vale destacar também que outros elementos ainda podem ser identificados pelo método ICP-MS com a disponibilidade de padrões e materiais de referência.

\footnotetext{
${ }^{1}$ Usando o Nuclepore como substrato e evitando a adição de ácido (usado para manter os padrões em meio ácido) nas amostras.
} 
Este trabalho mostrou que os métodos são complementares, uma vez que o ICP mede concentrações elementares muito baixas e o PIXE mede bem elementos com número atômico entre 13 e 26, região afetada por inúmeras interferências no ICP. No nosso caso, dois elementos foram medidos pelos dois procedimentos, o $\mathrm{Cu}$ e o $\mathrm{Zn}$, isto permitiu que analisássemos separadamente os resultados encontrados por ambos. De posse desta análise foi possível comparar as técnicas e comprovar que elas foram igualmente eficientes na determinação destes elementos.

A qualidade das medidas foi garantida com calibrações do equipamento e com o uso de materiais de referencia de soro sanguíneos certificados. Como a calibração quantitativa do método PIXE é realizada por meio de um ajuste semiempírico para os elementos com Z>10, ele não exige calibração para cada elemento de forma independente como o ICP-MS. Além disso, este último requer materiais de referência para todos os elementos medidos, procedimento que pode ser introduzido também no método PIXE para garantir a qualidade da análise de cada elemento individualmente. Dos elementos medidos pelo método PIXE neste trabalho, apenas dois estavam presentes nos materiais de referência utilizados, o $\mathrm{Cu}$ e o $\mathrm{Zn}$.

Os resultados das concentrações elementares concordaram com a literatura, mas os valores medidos pelo método ICP-MS para alguns elementos, como o $\mathrm{Be}, \mathrm{Al}, \mathrm{V}, \mathrm{Cr}$, Sn e Tl, ficaram muito próximos dos limites de detecção e/ou quantificação da técnica, entretanto foi possível ainda estudar suas distribuições. Apenas a concentração de $\mathrm{Tl}$ ficou um pouco abaixo dos valores da literatura, porém esta variação pode ser proveniente de características populacionais diferentes.

Este trabalho não tinha inicialmente objetivo de realizar estatísticas das amostras, entretanto no decorrer do estudo esses dados foram compilados com uma "população" limitada de jovens adultos e os resultados possibilitaram o estudo das distribuições dos elementos que constituem as amostras de soro. O Sn, por exemplo, apresentou indícios de uma distribuição normal, enquanto outros elementos apresentaram indícios de uma lognormal, como o $\mathrm{Al}, \mathrm{V}, \mathrm{Cr}, \mathrm{Fe}, \mathrm{Co}, \mathrm{Ni}, \mathrm{Cu}_{\mathrm{P}}, \mathrm{Cu}_{\mathrm{I}}, \mathrm{Cd}$ e $\mathrm{Pb}$ e quase metade dos elementos medidos apresentaram características das duas distribuições, normal e lognormal, como o P, S, Cl, K, $\mathrm{Ca}, \mathrm{Mn}, \mathrm{Zn}_{\mathrm{P}}, \mathrm{Zn}_{\mathrm{I}}$, Se, Br, Mo. Entretanto, para tal resultado, os outliers contidos na distribuição de $\mathrm{Zn}$, Mo, Sn, Cr e Co foram excluídos do conjunto de dados para que estas distribuições e/ou suas transformações passassem no teste de normalidade. $\mathrm{O} \mathrm{Be}, \mathrm{Tl}$ e suas 
transformadas passaram nos testes de Assimetria e Curtose, com exceção da distribuição transformada do primeiro elemento que não passou no teste de Assimetria. Entretanto, esses elementos e suas transformadas não passaram no teste W com nível de significância de 5\%, valor estabelecido neste trabalho. Este estudo mostrou resultados que podem ter significado estatístico, mas ainda dependentes de um controle rigoroso de saúde e aumento do número de indivíduos estudados. Além disso, critérios cuidadosos devem ser tomados neste tipo de análise para evitar qualquer possível ambigüidade ou dúvida quanto à distribuição dos elementos no soro sanguíneo.

Alguns problemas enfrentados no decorrer do mestrado, como por exemplo, a dificuldade na importação dos materiais de referência de soro e sangue total, a demora na aprovação do Comitê de Ética e o laboratório Lamfi em manutenção durante 7 meses, dificultaram o andamento do trabalho, impossibilitando a conclusão da análise elementar em sangue total. Entretanto este estudo faz parte de nossas perspectivas futuras juntamente com um estudo mais detalhado da composição química do sangue e do soro sanguíneo e de suas distribuições. É importante também diminuir o LD de alguns elementos nas amostras a serem analisadas pelo ICP-MS. Será importante também a separar os dados de homens e mulheres, o que não foi feito neste trabalho, principalmente, por falta de estatística suficiente.

A colaboração do Hospital Universitário da USP, do laboratório de Qúmica e ICP do Instituto de Geociências e do laboratório Lamfi com esta pesquisa foram de extrema importância na realização do trabalho. $\mathrm{O}$ contato com o hospital possibilitou a aprovação do comitê de ética necessário para este tipo de estudo e forneceu informações importantes de procedimentos anteriormente desconhecidos. Os laboratórios também foram importantíssimos, fornecendo os equipamentos para as medidas e o conhecimento dos técnicos disponíveis a ajudar e discutir os problemas enfrentados. Em conjunto com os grupos envolvidos foi discutido o protocolo de coleta de amostra, os materiais a serem usados, sobre a importância do estado de saúde dos doadores, a necessidade de autorização dos doadores por escrito e o procedimento experimental adotado. 


\section{R eferências}

8.1 ABNT-INMETRO - Guia para a expressão da incerteza de medição (1998).

8.2 Aburaya, J.H., Padronização de amostras espessas para análise PIXE, Dissertação de mestrado, IFUSP, São Paulo, (2005).

8.3 Afarideh, H., Amirabadi, A., Hadji-Saeid, S.M., Mansourian, N., Kaviani, K. e Zibafar, E. Nuclear Instruments and Methods in Physics Research B, 109/110, 270-277 (1996).

8.4 Aitchison, J. e Brown, J.A.C., The Lognormal Distribution, Cambridge University Press (1969).

8.5 Ak Celik, H., Aydin, H.H., Ozsaran, A., Kilincsoy, N., Batur, Y. e Ersoz, B., Clinical Biochemistry, 35, 477-481 (2002).

8.6 Aldape, F. e Flores, J., International Journal of PIXE, 6, 205 (1996).

8.7 Bambynek, W. et. al., Rev Mod Phys, 44, 716 (1972).

8.8 Bárány, E., Bergdahl, I.A., Bratteby, L.E., Lundh, T., Samuelson, G., Schütz, A., Skerfving, S. e Oskarsson, A., Toxicology Letters, 134, 177-184 (2002a).

8.9 Bárány, E., Bergdahl, I.A., Bratteby, L.E., Lundh, T., Samuelson, G., Schütz, A., Skerfving, S. e Oskarsson, A, The Science of the Total Environment, 286, 129$141(2002 b)$. 
8.10 Bárány, E., Bergdahl, I.A., Bratteby, L.E., Lundh, T., Samuelson, G., Schütz, A., Skerfving, S. e Oskarsson, A., Environmental Research, A89, $72-84$ (2002c).

8.11 Beguin, Y., Delbrouck, J., Roelandts, I. e Weber, G., Chemistry in Medicine and Biology, 3, 383-389 (1984).

8.12 Besteman, A.D., Bryan, G.K., Lau, N. e Winefordner, J.D., Microchemical Journal, 61, 240-246 (1999).

8.13 Bevington, P.R., Data Reduction And Error Analysis For The Physical Sciences, New York (1969).

8.14 Bleise, A, Smodis B. Intercomparison run NAT-3 for the determination of trace and minor elements in urban dust artificailly loaded on air filters. IAEA NAHRES-43, Vienna (2003).

8.15 Carré, M., Poussel, E. e Mermet, J.M., Journal of Analytical Atomic Spectrometry, 7, 791-797 (1992).

8.16 Conover, W.J., Practical Nonparametric Statistics, $2^{\natural}$ ed., New York: Wiley (1980).

8.17 Cornelis, R., Versieck, J., Mees, L., Hoste, J. e Barbier, F., Biol. Trace Element Res., 3, 257-263 (1981).

8.18 Cornelis, R., Borguet, F. e De Kimpe, J., Analytica Chimica Acta, 283, 183-189 (1993).

8.19 Cornelis, R., Sabbioni, E. e Van der Venne, M.T., The Science of the Total Environment, 158, 191-226 (1994).

8.20 Correia, A.L., Histórico da Deposição de Elementos Traço na Bacia Amazônica Ocidental ao Longo do Século XX, Tese de Doutorado, Instituto de Física, USP, São Paulo (2003). 
8.21 Currie, L.A., Analytical Chemistry, 40 (3), 586-593, (1968).

8.22 D'Haese, P.C., Van de Vyver, F.L., Wolff, F.A. e Broe, M.E., Clin. Chem., 31, 24-29 (1985)

8.23 Dombovári, J., Varga, Zs., Becker, J.S., Mátyus, J., Kakuk, Gy. e Papp, L., Atomic Spectroscopy, 22(4), July/August, 330-335 (2001).

8.24 Furusawa, H.A., Razão Isotópica de Enxofre em Material Atmosférico por ICPMS de Alta Resolução, Tese de Doutorado, Instituto de Química, USP, São Paulo (1999).

8.25 Giné-Rosias, M.F., Espectrometria de Massas com Fonte de Plasma (ICP-MS), CGP/CENA. Piracicaba, Brasil. (1999)

8.26 Harkins, W.D., The Building of Atoms and the New Periodic System, Science, Dec 26, 581 (1919).

8.27 Hasegawa, T., Inagaki, K. e Haraguchi, H., Analytical Sciences, 17, 979-982 (2001).

8.28 Hattendorf, B. e Günther, D., J. Anal. At. Spectrom., 15, 1125-1131 (2000).

8.29 Hecht, L., The ABC of Cosmic Humbuggery. 21 $1^{\text {st }}$ Century Science \& Tecnology, 16-3, (2003). [http://www.21stcenturysciencetech.com/articles/fall\%202003/ Humbuggery.html].

8.30 Helene, O.A.M. e Vanin, V.R., Tratamento Estatístico de Dados, São Paulo/SP, Brasil, pp. 96 (1981).

8.31 Hernández-Caraballo, E.A. e Marcó-Parra, L.M., Spectrochimica Acta Part B, 58, 2205-2213 (2003). 
8.32 IAEA, Intercomparison of PIXE spectrometry software packages -Tecdoc 1342 (2003).

8.33 Inagaki, K. e Haraguchi, H., Analyst, 125, 191-196 (2000).

8.34 Janasi, V.A., Andrade, S. e Ulbrich, H.H.G.J., Bol. IG-USP, Ser. Cient., 26, 45-58 (1995).

8.35 Jenkins, R., Gould R.W. and Gedke, D., Quantitative X-ray Spectrometry, Marcel Dekker, New York, USA. (1981).

8.36 Johansson, T.B., Akselsson, K.R. and Johansson, S.A.E., Nucl. Instr. Meth., 84, 141 (1970).

8.37 Johansson, S.A.E. and Johansson, T.B., Nucl. Instr. and Meth., 137, 476-516, (1976).

8.38 Johansson S.A.E. e Campbell, J.L., PIXE: A Novel Technique for Elemental Analysis, Wiley, New York (1988).

8.39 Kim, S.H., Kim, J.S., Shin, S. e Keen, C.L., Nutrition, 19, 240-243 (2003).

8.40 Kubala-Kukus, A., Kuternoga, E., Brasiewicz, J. e Pajek, M., Spectrochimica Acta, B 59, 1711-1716 (2004).

8.41 Kumar, R.A., John Kennedy, V., Sasikah, K., Jude, A.L.C., Ashok, M. e Moretto, Ph., Nuclear Instruments and Methods in Physics Research B, 190, 449-452 (2002).

8.42 Leighton, R.B. Principles of Modern Physics. McGraw-Hill (1959).

8.43 Leotti, V.B., Birck, A.R. e Riboldi, J., Comparação dos Testes de Aderência à Normalidade Kolmogorov-Smirnov, Anderson-Darling, Cramer-Von Mises e Shapiro-Wilk por Simulação, anais 11 Simpósio de Estatística Aplicada à Experimentação Agronômica (SEAGRO), Londrina, PR (2005). 
8.44 Lide, D.R., Ed. The CRC Handbook of Chemistry and Physics, 82nd Edition (2002).

8.45 Lim, H.B., Han, M.S. e Lee, K.J., Analytica Chimica Acta, 320, 185-189 (1996).

8.46 Limpert, E., Stahel, W.A. e Abbt, M., Bioscience, 51 n5, 341-352 (2001).

8.47 Maenhaut, W., De Reu, L., Van Rinsvelt, H.A. e Cafmeyer, J., Nuclear Instruments and Methods, 168, 557-562 (1980).

8.48 Maenhaut, W., Reu, L., Van Rinsvelt, H.A., Roessler, G.S., Swanson, J.W. e Williams, M.D., IEEE Transactions on Nuclear Science. NS-28-2, 1386-91 (1981).

8.49 Maenhaut, W., Ottar, B. e Pacyna, J.M., Control and Fate of Atmospheric Heavy Metals, NATO ARW Series, Kluver Ac. Pub. Amsterdam, 259-301, (1988).

8.50 Majewska, U., Brasiewicz, J., Banás, D., Kubala-Kukus, A., Gozdz., S., Pajek, M., Zadrozna, M., Jaskóla, M. e Czyzewski, T., Nuclear Instruments and Methods in Physics Research, B 150, 254-259 (1999).

8.51 Margulis, W., Implantação do Método de Análise por PIXE e Aplicação na Análise de Aerossóis, Tese de mestrado, Departamento de Física, PUC. Rio de Janeiro (1977).

8.52 Martinez-Espinosa, M., Calil Junior, C., Lahr, F.A.R., Scientia Forestalis, 66, 7683 (2004).

8.53 Mc Leon, J.A., Minnich, M.G., Iacom, L.A., LuiI, H. e Montaser, A., Journal of Analytical Atomic Spectrometry, v. 13, 829-842, (1998).

8.54 Miura, Y., Nakai, K., Sera, K. e Sato, M., Nuclear Instruments and Methods in Physics Research B, 150, 218-221 (1999). 
8.55 Montaser, A., Inductively Coupled Plasma Mass Spectrometry, USA, (1998).

8.56 Mousavi-Yeganeh, S., Ebrahimy-Fakhar, F. e Enayati, F., Nuclear Instruments and Methods in Physics Research B, 3, 364-367 (1984).

8.57 Navarro, M.S., A implantação de rotina, e seu refinamento, para a determinação de elementos terras raras em materiais geológicos por ICP-OES e ICP-MS. Aplicação ao caso dos granitóides de Piedade-Ibiúna (SP) e Cunhaporanga (PR), Tese de Mestrado, IGUSP, (2004).

8.58 Neubauer, K. e Völlkopf, U., Atomic Spectroscopy, 20(2), 64-68 (1999).

8.59 Pande, M.B.S., Nagabhushan, P., Hegde, M.L., Sathyanarayana Rao, T.S. e Jagannatha Rao, K.S., Computers in Biology and Medicine, 1-19 (2004).

8.60 Pedreira Filho, W.R., Determinação de Impurezas Metálicas em Óxidos de Terras Raras de Alta Pureza Pela Espectrometria de Massa (Setor Magnético) com Fonte de Plasma Induzida por Argônio (HR IC P-MS) e Cromatografia Líquida de Alto Desempenho (HPLC), Tese de Doutorado, IPEN, USP, São Paulo (2000).

8.61 Peretz, A., Nève, J. e Famaey, J.P., J. Trace Elem. Electrolytes Health Dis., 3, 103-108 (1989).

8.62 Petrucci, F., Violante, N., Senofonte, O., De Gregorio, M., Alimonti, A., Carola, S., Forte, G. e Cristaudo, A., Microchemical Journal, 76, 131-140 (2004).

8.63 Pinho, A.G., at al, An. Acad. Brasil. Ciên., 51(3), 365-393, (1979).

8.64 Potts, P.J., A Handbook of Silicate Rock Analysis, Blackie Academic \& Professional (1987).

8.65 Rodushkin, I., Ödman, F. e Branth, S., Fresenius J. Anal. Chem., 364, 338-346 (1999). 
8.66 Rodushkin, I., Ödman, F., Olofsson, R. e Axelsson, M.D., J. Anal. At. Spectrom., 15, 937-944 (2000).

8.67 Santos, A.C. e Ferreira, D.F., Ciênc. Agrotec., Lavras, 27, n.2, 432-437 (2003).

8.68 Sato, K. e Kawashita, K., Revista do Instituto de Geociências-USP, São Paulo, 2, 57-77 (2002).

8.69 Shapiro, S.S. e Wilk, M.B., Biometrika, 52, n.3/4, 591-611 (1965).

8.70 Skoog, D.A., Holler, F.J. e Nieman, T.A., Princípios de Análise Instrumental, Bookman, (2002).

8.71 Soares, V.L.M.P., Aplicação e Implantação do Controle Estatístico de Processo em Pintura Industrial, Dissertação de Mestrado, Universidade Federal de Santa Catarina, Florianópolis (2003).

8.72 St’astná, M., Nemcová, I. e Zýka, J., Analytical Letters, 32(13), 2531-2543 (1999).

8.73 Tabacniks, M.H., Calibração do sistema PIXE-SP de análise elementar, Dissertação de mestrado, Instituto de Física, USP, São Paulo (1983).

8.74 Tabacniks, M.H., Desenvolvimento de metodologia para análise de filtros de fibras de vidro pelo método PIXE, Tese de Doutorado, Instituto de Física, USP, São Paulo (1991).

8.75 Tabacniks, M.H., et al, PIXE for Thin Film Analysis, Research Report RJ 10000 (89089) IBM-ARC, (1996).

8.76 Tabacniks, M.H. Os Elementos na Matéria, Tese de Livre Docência, Instituto de Física, USP, São Paulo, (2005). 
8.77 Tanaka, V.S.P., Análise Elementar sub-ppb de Amostras Líquidas pelos Métodos PIXE e STXRF, Tese de Mestrado, Instituto de Física, USP, São Paulo, (2006).

8.78 Tanner, S.D. e Baranov, V.I., Atomic Spectroscopy, 20(2), 45-52 (1999).

8.79 Tanner, S.D., Baranov, V.I. e Völlkopf, U., J. Anal. At. Spectrom., 15, 1261-1269 (2000).

8.80 Thompson, A.C. e Vaughan, D., ed. X-Ray Data Booklet, Lawrence Berkeley National Laboratory, Berkeley, CA, USA, (2001), $2^{\text {nd }}$. Ed. (http://xdb.lbl.gov).

8.81 Ulrich, J.C., Determinação de Impurezas em Compostos de Urânio por meio da Técnica de Espectrometria de Massas de Alta Resolução com Fonte de Plasma Indutivo (HR-ICPMS), Dissertação de Mestrado, IPEN, São Paulo (2001).

8.82 Walsh, J.N., Chemical Geology, 95, 113-121 (1992).

8.83 Van Espen, P., Janssens, K. \& Swenters, I. AXIL X-Ray Analysis software, Canberra Packard, Benelux, (1986).

8.84 Van Renterghem, D., Cornelis, R. e Van Holder, R., Anal. Chim. Acta, 257, 1-5 (1992).

8.85 Vanhoe, H., Vandecasteele, C., Versieck, J. e Dams, R., Analytica Chimica Acta, 244, 259-267 (1991).

8.86 Vanhoe, H., University of Gent, Belgium (1992).

8.87 Vanhoe, H., Dams, R., Vandecasteele, C. e Versieck, J., Analytica Chimica Acta, 281, 401-411 (1993a).

8.88 Vanhoe, H., Van Allemeersch, F., Versieck, J. e Dams, R., Analyst, 118, 10151019 (1993b). 
8.89 Vanhoe, H., Dams, R. e Versieck, J., Journal of Analytical Atomic Spectrometry, 9, 23-31 (1994).

8.90 Veiga, M.A.M.S., Determinação de Elementos Traço por AAS e ICP-MS Após Extração no Ponto Nuvem, Usando Dietil-Ditiofosfato Como agente Quelante, Tese de Doutorado, Universidade Federal de Santa Catarina, Florianópolis (2000).

8.91 Verlinden, M., Van Sprundel, M., Van der Auwera, J.C. e Eylenbosch, W.J., Biol. Trace Element Res., 5, 91-102 (1983a).

8.92 Verlinden, M., Van Sprundel, M., Van der Auwera, J.C. e Eylenbosch, W.J., Biol. Trace Element Res., 5, 103-113 (1983b).

8.93 Vermeir, G., Vandecasteele, C., Temmerman, E., Dams, R. e Versieck, J., Microchim. Acta, III, 305-313 (1988).

8.94 Verrastro, T., Lorenzi, T.F. e Wendel Neto, S. Hematologia e Hemoterapia, Ed. Atheneu, São Paulo, Brasil (1996).

8.95 Versieck, J., Barbier, F., Speecke, A. e Hoste, J., Acta Endocrinol., 76, 783-788 (1974a).

8.96 Versieck, J., Barbier, F., Speecke, A. e Hoste, J., Clin. Chem., 76, 783-788 (1974b).

8.97 Versieck, J., Hoste, J., Barbier, F., Michels, H. e Rudder, J., Clin. Chem., 23, 1301-1305 (1977).

8.98 Versieck, J., Hoste, J., Barbier, F., Steyaert, H., Rudder, J. e Michels, H., Clin. Chem., 24, 303 (1978a).

8.99 Versieck, J., Hoste, J., Barbier, F., Vanballenberghe, L., Rudder, J. e Cornelis, R., Clin. Chem. Acta, 87, 135-140 (1978b). 
8.100 Versieck, J. e Cornelis, R., Anal. Chim. Acta, 116, 217-254 (1980a).

8.101 Versieck, J. e Cornelis, R., N. Enhl. J. Med., 302, 468-469 (1980b).

8.102 Versieck, J., Hoste, J., Vanballenberghe, L. e Barbier, F., Atomkern-energie Kerntechnik, 44, 717-723 (1984).

8.103 Versieck, J. e Vanballenberghe, L., Trace Elements in Man and Animals, TEMA 5. Common-wealth Agricultural Bureaux, 650-652 (1985b).

8.104 Versieck, J., Vanballenberghe, L., Kesel., A., Hoste, J., Wallaeys, B., Vandenhaute, J., Baeck, N., Steyaert, H., Byrne, A.R. e Sunderman, F.W., Anal. Chim. Acta, 204, 63-75 (1988).

8.105 Versieck, J., Vanballenberghe, L., Wittoek, A., Vermeir, G. e Vandecasteele, C., Biol. Trace Element Res., 27, 683-689 (1990).

8.106 Versieck, J. e Vanballenberghe, L., Anal. Chem., 63, 1143-1146 (1991).

8.107 Versieck, J., Vanballenberghe, L., Wittoek, A. e Vanhoe, H., J. Radioanal. Nucl. Chem., 168, 243-248 (1993).

8.108 Villela, G.G., Bacila, M. e Tastaldi, H., Bioquímica, Ed. Guanabara, Rio de Janeiro, Brasil (1961).

8.109 Vuolo, J.H., Fundamentos da Teoria de Erros, São Paulo/SP, Brasil, $2^{\mathrm{a}}$ edição, 152-153 (1996).

8.110 Xilei, L., Van Renterghem, D., Cornelis, R. e Mees, L., Anal. Chim. Acta, 211, 231-241 (1988).

8.111 Weber, G., Robaye, G., Bartsch, P., Collignon, A., Beguin, Y., Roelandts, I. e Delbrouck, J.M., Nucl. Instr. Methods Phys. Res., B3, 326-331 (1984). 
8.112 Zarkadas, Ch., Karydas, A.G. e Paradellis, T., Spectrochimica Acta Part B, 56, 2219-2228 (2001).

8.113 Ziegler, J.F., Biersack, J.P. and Littmark, U., The Stopping and Range of Ions in Solids, vol 1, Pergamon Press, New York (1985). 


\section{A pêndice A}

As tabelas A.1 e A.2 mostram os resultados da revisão bibliográfica sobre as concentrações elementares em soro e sangue total. Nelas podem ser vistos, para cada elemento $(E l)$, os valores mínimos (Mín) e máximos (Máx) junto com suas medianas $(M d)$, médias $(M)$ e desvios padrão $(S D)$ encontrados em cada trabalho. A mediana calculada neste trabalho $\left(M d_{c}\right)$, ou seja, mediana das médias foi usada na compilação dos gráficos de soro e sangue do capítulo 2.

Tabela A.1 - Concentração elementar em soro enc ontrada na literatura. As unidades das concentrações estão especificadas entre parênteses.

\begin{tabular}{|c|c|c|c|c|c|c|}
\hline$E I$ & Min & Máx & Md & $M(S D)$ & $\overline{M d_{C}}$ & Referências \\
\hline \multirow{9}{*}{$\operatorname{Li}(\mu \mathrm{g} / \mathrm{l})$} & 0.5 & 1.0 & & 0.7 & \multirow{9}{*}{1.5} & \multirow{9}{*}{ Vanhoe, 1991} \\
\hline & 6 & 22 & & 11 & & \\
\hline & 2 & 17 & & 8 & & \\
\hline & 6.7 & 33.3 & & 13.5 & & \\
\hline & 1.2 & 7.3 & & 2.8 & & \\
\hline & 0.50 & 2.98 & & 1.11 & & \\
\hline & 0.2 & 10.8 & & 1.5 & & \\
\hline & 0.22 & 0.97 & & 0.59 & & \\
\hline & 0.33 & 0.85 & & $0.59^{*}$ & & \\
\hline \multirow{4}{*}{$\mathrm{B}(\mu \mathrm{g} / \mathrm{l})$} & 8.3 & 48.1 & & 22.3 & \multirow{4}{*}{23} & \multirow{4}{*}{ Vanhoe, 1993a } \\
\hline & & & & $24(4)$ & & \\
\hline & & & & $30(2)$ & & \\
\hline & 4.1 & 25.8 & & $13.9(6.9)$ & & \\
\hline \multirow{3}{*}{$\mathrm{Na}(\mathrm{g} / \mathrm{l})$} & & & & 3.13 & \multirow{3}{*}{3.13} & Hasegawa, 2001 \\
\hline & & & & $3.32(0.26)$ & & Maenhaut, 1981 \\
\hline & 2.906 & 3.247 & & $3.111(0.094)$ & & Pande, 2004 \\
\hline \multirow{5}{*}{$\begin{array}{c}\mathrm{Mg} \\
(\mathrm{mg} / \mathrm{l})\end{array}$} & 17.1 & 21.3 & & 19.2 & \multirow{5}{*}{17.5} & Lim, 1996 \\
\hline & & & & 17.5 & & Hasegawa, 2001 \\
\hline & 13.0 & 21.0 & & $17.0^{*}$ & & Ak Celik, 2002 \\
\hline & 19.0 & 26.7 & & $21.9(2.2)$ & & Pande, 2004 \\
\hline & & & & $8.3(4.7)$ & & Miura, 1999 \\
\hline$\overline{\mathrm{Al}}(\mu \mathrm{g} / \mathrm{l})$ & 0.98 & 1.74 & & $\begin{array}{c}1.36^{*} \\
2.0(0.4)\end{array}$ & 1.9 & $\begin{array}{c}\text { Dombovári, } 2001 \\
\text { D'Haese, } 1985\end{array}$ \\
\hline
\end{tabular}


Apêndice A

\begin{tabular}{|c|c|c|c|c|c|}
\hline & 2.1 & 6.2 & $3.7(1.2)$ & & Versieck, 1980b \\
\hline & 1.59 & 2.12 & 1.83 & & Versieck, 1988 \\
\hline $\mathrm{Si}(\mathrm{mg} / \mathrm{l})$ & & & $1.36(0.72)$ & & Miura, 1999 \\
\hline \multirow{4}{*}{$\mathrm{P}(\mathrm{mg} / \mathrm{l})$} & & & $628(46)$ & \multirow{4}{*}{109} & Kumar, 2002 \\
\hline & & & 120 & & Hasegawa, 2001 \\
\hline & & & $44(17)$ & & Miura, 1999 \\
\hline & 71 & 124 & $99(12)$ & & Pande, 2004 \\
\hline \multirow{4}{*}{$\mathrm{S}(\mathrm{g} / \mathrm{l})$} & & & $1.204(0.041)^{\mathrm{a}}$ & \multirow{4}{*}{1.19} & Zarkadas 2001 \\
\hline & & & $1.062(0.055)$ & & Zainauas, 2001 \\
\hline & & & $2.31(0.16)$ & & Kumar, 2002 \\
\hline & 1.00 & 1.43 & $1.17(0.12)$ & & Pande, 2004 \\
\hline \multirow{4}{*}{$\mathrm{Cl}(\mathrm{g} / \mathrm{l})$} & & & $3.77(0.12)^{a}$ & \multirow{4}{*}{3.88} & Zarkadas 2001 \\
\hline & 3.50 & 4.50 & $4.00^{*}$ & & \\
\hline & & & $5.85(0.27)$ & & Kumar, 2002 \\
\hline & & & $3.49(0.21)$ & & Maenhaut, 1981 \\
\hline \multirow{7}{*}{$\mathrm{K}(\mathrm{mg} / \mathrm{l})$} & & & $165.7(4.1)^{\mathrm{a}}$ & \multirow{7}{*}{161} & Zarkadas. 2001 \\
\hline & & & $161.0(7.0)$ & & Zarkadas, 2001 \\
\hline & & & 149.4 & & Afarideh, 1996 \\
\hline & & & $141.8(7.2)^{\mathrm{a}}$ & & Maenhaut, 1980 \\
\hline & & & $639(70)$ & & Kumar, 2002 \\
\hline & & & 151 & & Hasegawa, 2001 \\
\hline & & & $187(11)$ & & Maenhaut, 1981 \\
\hline \multirow{8}{*}{$\mathrm{Ca}(\mathrm{mg} / \mathrm{l})$} & & & $92.8(3.6)^{a}$ & \multirow{8}{*}{93} & Zarkades 2001 \\
\hline & & & $91.0(3.0)$ & & Zarkadas, 2001 \\
\hline & & & 106.6 & & Afarideh, 1996 \\
\hline & & & $82.0(2.7)^{\mathrm{a}}$ & & Maenhaut, 1980 \\
\hline & & & $259(19)$ & & Kumar, 2002 \\
\hline & & & 93.1 & & Hasegawa, 2001 \\
\hline & 72.1 & 100.2 & $88.2(8.0)$ & & Pande, 2004 \\
\hline & & & $97.0(3.0)$ & & Maenhaut, 1981 \\
\hline Sc ng/l & & & $1.73(0.20)$ & & Xilei, 1988 \\
\hline $\mathrm{Ti}(\mathrm{mg} / \mathrm{l})$ & & & $1.38(0.40)$ & & Kumar, 2002 \\
\hline \multirow{2}{*}{$\mathrm{V}(\mu \mathrm{g} / \mathrm{l})$} & 0.024 & 0.939 & $0.482^{*}$ & \multirow{2}{*}{0.256} & Cornelis 1981 \\
\hline & 0.016 & 0.139 & $0.031(0.010)$ & & Comens, 1981 \\
\hline \multirow{3}{*}{$\mathrm{Cr}(\mu \mathrm{g} / \mathrm{l})$} & 42.8 & 59.3 & $51.5^{*}$ & \multirow{3}{*}{0.160} & Dombovári, 2001 \\
\hline & 0.0382 & 0.351 & $0.160(0.083)$ & & Versieck, 1978a \\
\hline & 0.061 & 0.079 & 0.069 & & Versieck, 1988 \\
\hline \multirow{3}{*}{$\mathrm{Mn}(\mu \mathrm{g} / \mathrm{l})$} & 2.27 & 5.05 & $3.66^{*}$ & \multirow{3}{*}{0.7} & Dombovári, 2001 \\
\hline & 0.38 & 1.04 & $0.57(0.13)$ & & Versieck, 1974a,b \\
\hline & 0.67 & 0.73 & 0.70 & & Versieck, 1988 \\
\hline \multirow[t]{5}{*}{$\mathrm{Fe}(\mathrm{mg} / \mathrm{l})$} & & & $2.050(0.071)^{a}$ & \multirow[t]{5}{*}{1.57} & Zarkadas 2001 \\
\hline & & & $1.120(0.060)$ & & Zarkadas, ¿001 \\
\hline & & & 1.65 & & Afarideh, 1996 \\
\hline & 0.80 & 2.71 & 1.57 & & Lim, 1996 \\
\hline & 064 & 285 & $150(018)$ & & Hernónde \\
\hline
\end{tabular}




\begin{tabular}{|c|c|c|c|c|c|c|}
\hline & & & & & & Caraballo, 2003 \\
\hline & 1.28 & 2.05 & & $1.67^{*}$ & & Dombovári, 2001 \\
\hline & & & & $2.458(0.066)^{a}$ & & Maenhaut, 1980 \\
\hline & & & & $3.80(0.60)$ & & Kumar, 2002 \\
\hline & & & & 1.20 & & Hasegawa, 2001 \\
\hline & 0.50 & 1.70 & & $1.10^{*}$ & & Ak Celik, 2002 \\
\hline & 0.89 & 2.62 & & $1.28(0.50)$ & & Pande, 2004 \\
\hline \multirow{5}{*}{$\operatorname{Co}(\mu g / l)$} & 0.22 & 0.88 & & $0.55^{*}$ & \multirow{5}{*}{0.49} & Dombovári, 2001 \\
\hline & $<0.2$ & 1.1 & 0.48 & $0.49(0.10)$ & & Bárány, 2002a,b \\
\hline & 0.0394 & 0.271 & & $0.108(0.060)$ & & Versieck, 1978a \\
\hline & 0.273 & 0.382 & & 0.327 & & Versieck, 1988 \\
\hline & & & & $0.53(0.1)$ & & Bárány, 2002c \\
\hline \multirow{3}{*}{$\mathrm{Ni}(\mu \mathrm{g} / \mathrm{l})$} & & & & 21 & \multirow{3}{*}{8.18} & Afarideh, 1996 \\
\hline & 0.03 & 16.33 & & $8.18^{*}$ & & Dombovári, 2001 \\
\hline & & & & 0.23 & & Versieck, 1988 \\
\hline \multirow{15}{*}{$\mathrm{Cu}(\mathrm{mg} / \mathrm{l})$} & & & & $\frac{1.270(0.042)^{a}}{1.200(0.030)}$ & \multirow{15}{*}{1.08} & Zarkadas, 2001 \\
\hline & & & & 1.34 & & Afarideh 1996 \\
\hline & 0.75 & 1.03 & & 0.87 & & Lim, 1996 \\
\hline & 0.89 & 1.52 & & $1.13(0.060)$ & & $\begin{array}{c}\text { Hernández- } \\
\text { Caraballo, 2003 }\end{array}$ \\
\hline & & & & $0.822(0.033)^{a}$ & & Maenhaut, 1980 \\
\hline & & & & $1.90(0.20)$ & & Kumar, 2002 \\
\hline & & & & 0.75 & & Hasegawa, 2001 \\
\hline & 0.70 & 1.55 & & $1.12^{*}$ & & Ak Celik, 2002 \\
\hline & 0.55 & 2.60 & 1.00 & $1.10(0.20)$ & & Bárány, 2002a,b \\
\hline & 0.57 & 1.21 & & $0.89(0.19)$ & & Pande, 2004 \\
\hline & & & & $0.92(0.16)$ & & Miura, 1999 \\
\hline & 0.73 & 2.00 & & $1.07(0.24)$ & & Versieck, 1974b \\
\hline & & & & $0.95(0.38)$ & & Weber, 1984 \\
\hline & 0.97 & 1.04 & & 1.01 & & Versieck, 1988 \\
\hline & & & & $1.17(0.16)$ & & Peretz, 1989 \\
\hline \multirow[t]{11}{*}{$\mathrm{Zn}(\mathrm{mg} / \mathrm{l})$} & & & & $0.957(0.039)^{\mathrm{a}}$ & \multirow[t]{11}{*}{1.00} & Zarkadas, 2001 \\
\hline & & & & $0.900(0.020)$ & & Zarkadas, 2001 \\
\hline & & & & 1.04 & & Afarideh, 1996 \\
\hline & 0.90 & 1.29 & & 1.15 & & Lim, 1996 \\
\hline & 0.81 & 1.99 & & $1.32(0.12)$ & & $\begin{array}{c}\text { Hernández- } \\
\text { Caraballo, 2003 }\end{array}$ \\
\hline & & & & $1.067(0.033)^{a}$ & & Maenhaut, 1980 \\
\hline & & & & $2.70(0.50)$ & & Kumar, 2002 \\
\hline & & & & 0.65 & & Hasegawa, 2001 \\
\hline & 0.70 & 1.50 & & $1.10^{*}$ & & Ak Celik, 2002 \\
\hline & 0.52 & 1.50 & 0.99 & $1.00(0.10)$ & & Bárány, 2002a,b \\
\hline & 0.392 & 0.654 & & $0.588(0.065)$ & & Pande, 2004 \\
\hline
\end{tabular}




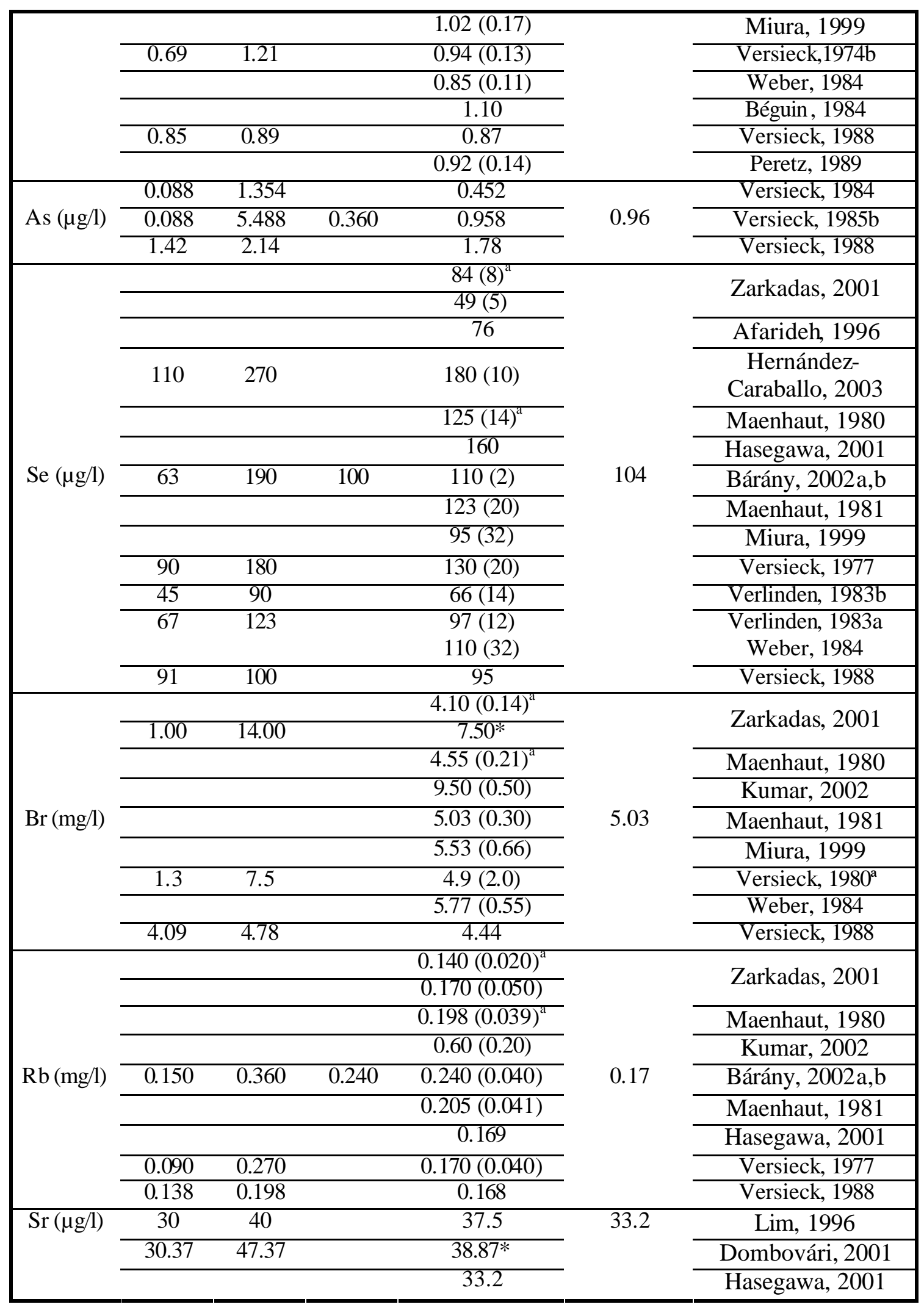




\begin{tabular}{|c|c|c|c|c|c|c|}
\hline & 12.8 & $\overline{48.4}$ & & $26(10)$ & & Vanhoe, 1992 \\
\hline & 14.4 & 30.7 & & $22.2(4.8)$ & & Versieck, 1993 \\
\hline \multirow{5}{*}{$\operatorname{Mo}(\mu \mathrm{g} / \mathrm{l})$} & 0.73 & 1.19 & & $0.96^{*}$ & \multirow{5}{*}{0.68} & Dombovári, 2001 \\
\hline & 0.30 & 0.86 & & $0.61(0.17)$ & & Vanhoe, 1994 \\
\hline & & & & 1.4 & & Hasegawa, 2001 \\
\hline & 0.28 & 1.17 & & $0.58(0.21)$ & & Versieck, 1978b \\
\hline & 0.61 & 0.75 & & 0.68 & & Versieck, 1988 \\
\hline \multirow{2}{*}{$\mathrm{Rh}(\mu \mathrm{g} / \mathrm{l})$} & & & & $0.11(0.06)$ & \multirow{2}{*}{0.105} & Bárány, 2002c \\
\hline & $<0.1$ & 0.58 & $<0.1$ & $<0.1$ & & Bárány, 2002a,b \\
\hline \multirow{2}{*}{$\operatorname{Pd}(\mu \mathrm{g} / \mathrm{l})$} & $<0.2$ & 3 & $<0.2$ & $<0.2$ & \multirow{2}{*}{0.215} & Bárány, 2002a,b \\
\hline & & & & $0.23(0.08)$ & & Bárány, 2002c \\
\hline \multirow{2}{*}{$\operatorname{Ag}(\mu \mathrm{g} / \mathrm{l})$} & & & & 0.2 & \multirow{2}{*}{0.142} & Hasegawa, 2001 \\
\hline & & & & $0.084(0.004)$ & & Xilei, 1988 \\
\hline \multirow{3}{*}{$\mathrm{Cd}(\mu \mathrm{g} / \mathrm{l})$} & 0.02 & 0.62 & & $0.32^{*}$ & \multirow{3}{*}{0.32} & Dombovári, 2001 \\
\hline & 0.154 & 0.227 & & 0.182 & & Versieck, 1988 \\
\hline & & & & $0.45(0.1)$ & & Bárány, 2002c \\
\hline \multirow{3}{*}{$\mathrm{Sn}(\mu \mathrm{g} / \mathrm{l})$} & 0.66 & 1.46 & & $1.02(0.26)$ & \multirow{3}{*}{0.9} & Vanhoe, 1994 \\
\hline & & & & $0.90(0.07)$ & & Vanhoe, 1992 \\
\hline & 0.400 & 0.636 & & $0.505(0.096)$ & & Versieck, 1991 \\
\hline \multirow{3}{*}{$\mathrm{Sb}(\mu \mathrm{g} / \mathrm{l})$} & 0.095 & 0.165 & & $0.137(0.028)$ & \multirow{3}{*}{0.137} & Vanhoe, 1994 \\
\hline & 0.01 & 3.1 & & $1.6^{*}$ & & vaminoe, 1994 \\
\hline & & & & $0.014(0.001)$ & & $\begin{array}{c}\text { Van Renterghem, } \\
1992\end{array}$ \\
\hline \multirow{3}{*}{$\mathrm{I}(\mu \mathrm{g} / \mathrm{l})$} & 40 & 81 & & $58(12)$ & \multirow{3}{*}{58} & \multirow{3}{*}{ Vanhoe, 1993b } \\
\hline & 30 & 83 & & $58(16)$ & & \\
\hline & & & & $58(2)$ & & \\
\hline \multirow{6}{*}{ Cs $(\mu \mathrm{g} / \mathrm{l})$} & 0.50 & 0.96 & & $0.70(0.12)$ & \multirow{6}{*}{0.83} & \\
\hline & 0.45 & 2.06 & & $1.26^{*}$ & & Vanhoe, 1994 \\
\hline & & & & 0.66 & & Hasegawa, 2001 \\
\hline & & & & $1.6(0.5)$ & & Maenhaut, 1981 \\
\hline & 0.45 & 1.18 & & $0.74(0.20)$ & & Versieck, 1977 \\
\hline & 0.70 & 1.12 & & 0.91 & & Versieck,1988 \\
\hline \multirow{2}{*}{$\mathrm{Ba}(\mu \mathrm{g} / \mathrm{l})$} & 0.23 & 2.35 & & $1.04(0.65)$ & \multirow{2}{*}{1.02} & Vanhoe, 1994 \\
\hline & & & & $1.00(0.28)$ & & Vanhoe, 1992 \\
\hline $\mathrm{La}(\mathrm{ng} / \mathrm{l})$ & 56 & 73.2 & & $62.7(7.1)$ & & Inagaki, 2000 \\
\hline $\mathrm{Ce}(\mathrm{ng} / \mathrm{l})$ & 187 & 235 & & $214(22)$ & & \\
\hline $\operatorname{Pr}(\mathrm{ng} / \mathrm{l})$ & 9.6 & 13.5 & & $11.1(1.5)$ & & \\
\hline $\mathrm{Nb}(\mathrm{ng} / \mathrm{l})$ & 28.4 & 39.8 & & $33.7(4.2)$ & & \\
\hline $\mathrm{Sm}(\mathrm{ng} / \mathrm{l})$ & 4.6 & 7.4 & & $5.8(1.1)$ & & \\
\hline $\mathrm{Eu}(\mathrm{ng} / \mathrm{l})$ & 0.66 & 1.08 & & $0.82(0.19)$ & & \\
\hline $\mathrm{Gd}(\mathrm{ng} / \mathrm{l})$ & 5.8 & 8.7 & & $7.2(1.4)$ & & \\
\hline $\mathrm{Tb}(\mathrm{ng} / \mathrm{l})$ & 1.11 & 1.64 & & $1.30(0.22)$ & & \\
\hline Dy (ng/l) & 8.8 & 11.2 & & $9.6(1.1)$ & & \\
\hline Ho (ng/l) & 2.15 & 3.44 & & $2.55(0.54)$ & & \\
\hline $\operatorname{Er}(n g / l)$ & 7.8 & 12.4 & & $9.5(1.9)$ & & \\
\hline Tm (ng/l) & 1.35 & 2.34 & & $1.69(0.42)$ & & \\
\hline
\end{tabular}




\begin{tabular}{|c|c|c|c|c|c|c|}
\hline$\overline{\mathrm{Yb}(\mathrm{ng} / \mathrm{l})}$ & 10.4 & 17.8 & & $13.2(3.2)$ & & \\
\hline $\mathrm{Lu}(\mathrm{ng} / \mathrm{l})$ & 1.92 & 3.11 & & $2.46(0.58)$ & & \\
\hline \multirow{2}{*}{$\mathrm{W}(\mu \mathrm{g} / \mathrm{l})$} & $<0.05$ & 1.8 & 0.087 & $0.14(0.20)$ & \multirow{2}{*}{0.094} & Bárány, 2002a,b \\
\hline & & & & $0.048(0.03)$ & & Bárány, 2002c \\
\hline $\operatorname{Ir}(\mu \mathrm{g} / \mathrm{l})$ & & & & 0.001 & & Petrucci, 2004 \\
\hline \multirow{3}{*}{$\operatorname{Pt}(\mu \mathrm{g} / \mathrm{l})$} & $<0.1$ & 2 & $<0.1$ & $<0.1$ & \multirow{3}{*}{0.34} & Bárány, 2002a,b \\
\hline & & & & 0.002 & & Petrucci, 2004 \\
\hline & & & & $0.68(0.8)$ & & Bárány, 2002c \\
\hline $\mathrm{Au}(\mathrm{ng} / \mathrm{l})$ & & & & $6.6(1.1)$ & & $\begin{array}{c}\text { Van Renterghem, } \\
1992\end{array}$ \\
\hline \multirow{7}{*}{$\mathrm{Hg}(\mu \mathrm{g} / \mathrm{l})$} & $<0.3$ & 1.5 & 0.44 & $0.48(0.20)$ & \multirow{3}{*}{0.55} & Bárány, 2002a,b \\
\hline & $<0.2$ & 0.71 & & $0.46^{*}$ & & \multirow{2}{*}{ Vanhoe, 1994} \\
\hline & 0.05 & 4.8 & & $2.4^{*}$ & & \\
\hline & & & & $0.5(0.2)$ & & Bárány, 2002c \\
\hline & 0.236 & 0.863 & & $0.551(0.256)$ & & Vermier, 1988 \\
\hline & 0.56 & 0.64 & & $0.60(0.04)$ & & \multirow{2}{*}{ Versieck, 1990} \\
\hline & 0.404 & 2.456 & & $1.156(0.554)$ & & \\
\hline $\mathrm{Tl}(\mu \mathrm{g} / \mathrm{l})$ & $<0.2$ & 0.21 & $<0.2$ & $<0.2$ & 0.2 & Bárány, 2002a,b \\
\hline \multirow{6}{*}{$\mathrm{Pb}(\mu \mathrm{g} / \mathrm{l})$} & 0.02 & 2.7 & & $1.36^{*}$ & \multirow{6}{*}{0.89} & Dombovári, 2001 \\
\hline & $<0.1$ & 3.7 & 0.33 & $0.42(0.4)$ & & Bárány, 2002a,b \\
\hline & $<0.1$ & 0.71 & & $0.41^{*}$ & & Vanhoe 1994 \\
\hline & 0.02 & 14.5 & & $7.26^{*}$ & & vannoe, 1994 \\
\hline & & & & $0.28(0.1)$ & & Bárány, 2002c \\
\hline & & & & $4.21(0.42)$ & & Vanhoe, 1992 \\
\hline \multirow[b]{2}{*}{$\operatorname{Bi}(\mu \mathrm{g} / \mathrm{l})$} & $<0.007$ & 0.067 & & $0.037^{*}$ & \multirow[b]{2}{*}{0.063} & Vanhoe 1994 \\
\hline & 0.1 & 6 & & $3.1^{*}$ & & 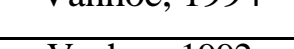 \\
\hline
\end{tabular}

* Média calculada a partir dos valores de máximo e mínimo.

${ }^{a}$ Média Ponderada de duas médias (desvio padrão ponderado). 
Tabela A.2 - Concentração elementar em sangue total encontrada na literatura. As unidades das concentrações estão especificadas entre parênteses.

\begin{tabular}{|c|c|c|c|c|c|c|}
\hline$E I$ & Min & Máx & Md & $M(S D)$ & $\overline{M d_{C}}$ & Referências \\
\hline \multirow{3}{*}{$\operatorname{Li}(\mu \mathrm{g} / \mathrm{l})$} & 0.82 & 5.0 & & $2.195(0.057)^{\mathrm{a}}$ & \multirow{3}{*}{2.45} & Rodushkin, 2000 \\
\hline & 1.2 & 3.4 & 2.3 & $2.3(0.5)$ & & Rodushkin, 1999 \\
\hline & 3 & 38 & & $\frac{20.5^{*}}{2.6(0.2)}$ & & Besteman, 1999 \\
\hline \multirow{2}{*}{$\mathrm{Be}(\mathrm{ng} / \mathrm{l})$} & 25 & 32 & & $31.0(1.9)^{\mathrm{a}}$ & \multirow{2}{*}{73.5} & Rodushkin, 2000 \\
\hline & 75 & 278 & 83 & $116(80)$ & & Rodushkin, 1999 \\
\hline \multirow{2}{*}{$\mathrm{B}(\mu \mathrm{g} / \mathrm{l})$} & 4.3 & 43 & & $4.57(0.50)^{\mathrm{a}}$ & \multirow{2}{*}{7.8} & Rodushkin, 2000 \\
\hline & 6 & 33 & 7 & $11(7)$ & & Rodushkin, 1999 \\
\hline \multirow{2}{*}{$\mathrm{Na}(\mathrm{g} / \mathrm{l})$} & 1.71 & 2.05 & & $1.88^{*}$ & \multirow[b]{2}{*}{1.56} & \multirow[b]{2}{*}{ Besteman, 1999} \\
\hline & & & & $1.240(0.060)$ & & \\
\hline $\begin{array}{c}\mathrm{Mg} \\
(\mathrm{mg} / \mathrm{l})\end{array}$ & 27.1 & 45.5 & & $\begin{array}{c}36.3^{*} \\
28.70(0.10)\end{array}$ & 32.5 & Besteman, 1999 \\
\hline \multirow{2}{*}{$\operatorname{Al}(\mu \mathrm{g} / \mathrm{l})$} & 2.6 & 24 & & $2.81(0.20)^{a}$ & \multirow{2}{*}{20} & Rodushkin, 2000 \\
\hline & 5 & 192 & 15 & $38(56)$ & & Rodushkin, 1999 \\
\hline \multirow{2}{*}{$\mathrm{Si}(\mathrm{mg} / \mathrm{l})$} & 0.270 & 3.800 & & $0.305(0.010)^{\mathrm{a}}$ & \multirow{2}{*}{1.6} & Rodushkin, 2000 \\
\hline & 1.0 & 8.0 & 2.3 & $3.0(1.9)$ & & Rodushkin, 1999 \\
\hline \multirow[t]{2}{*}{$\mathrm{P}(\mathrm{mg} / \mathrm{l})$} & 67 & 449 & & $20(99)$ & \multirow[t]{2}{*}{290} & $\begin{array}{c}\text { Mousavi-Yeganeh, } \\
1984\end{array}$ \\
\hline & 325 & 455 & 375 & $378(36)$ & & Rodushkin, 1999 \\
\hline $\mathrm{S}(\mathrm{g} / \mathrm{l})$ & 0.10 & 0.74 & & $0.39(0.20)$ & & $\begin{array}{c}\text { Mousavi-Y eganeh, } \\
1984\end{array}$ \\
\hline $\mathrm{Cl}(\mathrm{g} / \mathrm{l})$ & 0.75 & 2.62 & & $1.72(0.69)$ & & $\begin{array}{c}\text { Mousavi-Yeganeh, } \\
1984\end{array}$ \\
\hline \multirow{2}{*}{$\mathrm{K}(\mathrm{g} / \mathrm{l})$} & 0.44 & 1.18 & & $0.81(0.31)$ & \multirow{2}{*}{1.66} & $\begin{array}{c}\text { Mousavi-Yeganeh, } \\
1984\end{array}$ \\
\hline & 1.45 & 1.92 & & $\begin{array}{c}1.68^{*} \\
1.66(0.12)\end{array}$ & & Besteman, 1999 \\
\hline $\mathrm{Ca}(\mathrm{mg} / \mathrm{l})$ & 80 & 258 & & $181(65)$ & & $\begin{array}{c}\text { Mousavi-Yeganeh, } \\
1984\end{array}$ \\
\hline $\mathrm{Sc}(\mathrm{ng} / \mathrm{l})$ & 4 & 11 & & $10.59(0.97)^{\mathrm{a}}$ & & Rodushkin, 2000 \\
\hline \multirow{2}{*}{$\operatorname{Ti}(\mu \mathrm{g} / \mathrm{l})$} & 0.34 & 2.2 & & $0.55(0.17)^{a}$ & \multirow{2}{*}{0.82} & Rodushkin, 2000 \\
\hline & $<0.17$ & 2.95 & 0.8 & $1.1(0.8)$ & & Rodushkin, 1999 \\
\hline \multirow{2}{*}{ V (ng/l) } & 21 & 162 & & $24.3(7.9)^{a}$ & \multirow{2}{*}{33} & Rodushkin, 2000 \\
\hline & $<12$ & 228 & 29 & $42(46)$ & & Rodushkin, 1999 \\
\hline \multirow{2}{*}{$\operatorname{Cr}(\mu \mathrm{g} / \mathrm{l})$} & 0.47 & 0.99 & & $0.593(0.044)^{a}$ & \multirow{2}{*}{0.56} & Rodushkin, 2000 \\
\hline & $<0.4$ & 1.2 & 0.51 & $0.53(0.29)$ & & Rodushkin, 1999 \\
\hline \multirow{4}{*}{$\operatorname{Mn}(\mu \mathrm{g} / \mathrm{l})$} & 8.5 & 8.8 & & $8.56(0.36)^{a}$ & \multirow{4}{*}{25} & Rodushkin, 2000 \\
\hline & 7 & 18 & 12 & $12(3)$ & & Rodushkin, 1999 \\
\hline & 1.6 & 75 & & $38^{*}$ & & Besteman, 1999 \\
\hline & & & & $62(8)$ & & \\
\hline $\mathrm{Fe}(\mathrm{g} / \mathrm{l})$ & 0.18 & 0.46 & & $0.30(0.11)$ & 0.38 & $\begin{array}{c}\text { Mousavi-Yeganeh, } \\
1984\end{array}$ \\
\hline
\end{tabular}




\begin{tabular}{|c|c|c|c|c|c|c|}
\hline & 0.236 & $\overline{0.614}$ & $\overline{0.476}$ & $0.474(0.068)$ & & Rodushkin, 1999 \\
\hline \multirow{4}{*}{$\operatorname{Co}(\mu \mathrm{g} / \mathrm{l})$} & 0.052 & 0.36 & & $\begin{array}{c}0.0679 \\
(0.0068)^{\mathrm{a}}\end{array}$ & \multirow{4}{*}{0.21} & Rodushkin, 2000 \\
\hline & 0.01 & 0.91 & & $0.46^{*}$ & & St’astná, 1999 \\
\hline & $<0.022$ & 0.255 & 0.092 & $0.091(0.061)$ & & Rodushkin, 1999 \\
\hline & $<0.2$ & 0.9 & 0.31 & $0.32(0.1)$ & & Bárány, 2002a,b \\
\hline \multirow{2}{*}{$\mathrm{Ni}(\mu \mathrm{g} / \mathrm{l})$} & & & & $0.55(0.14)^{a}$ & \multirow{2}{*}{1,7} & Rodushkin, 2000 \\
\hline & 0.6 & 6.8 & 2.7 & $2.8(1.3)$ & & Rodushkin, 1999 \\
\hline \multirow{5}{*}{$\mathrm{Cu}(\mathrm{mg} / \mathrm{l})$} & 1.0 & 15.1 & & $4.2(2.8)$ & \multirow{5}{*}{1.0} & $\begin{array}{c}\text { Mousavi-Yeganeh, } \\
1984\end{array}$ \\
\hline & 1.000 & 1.010 & & $1.007(0.026)^{\mathrm{a}}$ & & Rodushkin, 2000 \\
\hline & 0.80 & 1.60 & & $1.20^{*}$ & & St'astná, 1999 \\
\hline & 0.59 & 1.47 & 0.83 & $0.90(0.20)$ & & Rodushkin, 1999 \\
\hline & 0.61 & 1.90 & 0.92 & $0.95(0.10)$ & & Bárány, 2002a \\
\hline \multirow{7}{*}{$\mathrm{Zn}(\mathrm{mg} / \mathrm{l})$} & 2.3 & 7.5 & & $5.5(1.3)$ & \multirow{7}{*}{6.0} & $\begin{array}{c}\text { Mousavi-Yeganeh, } \\
1984\end{array}$ \\
\hline & 4.74 & 4.89 & & $4.79(0.10)^{a}$ & & Rodushkin, 2000 \\
\hline & 4.0 & 8.0 & & $6.0^{*}$ & & St'astná, 1999 \\
\hline & 3.5 & 9.1 & 5.8 & $5.9(1.0)$ & & Rodushkin, 1999 \\
\hline & 4.80 & 9.30 & & $7.05^{*}$ & & \\
\hline & & & & $8.5(1.4)$ & & Besteman, 1999 \\
\hline & 3.10 & 9.80 & 6.10 & $6.10(0.90)$ & & Bárány, 2002a,b \\
\hline \multirow{2}{*}{$\mathrm{Ga}(\mathrm{ng} / \mathrm{l})$} & 14 & 30 & & $19.8(4.8)^{a}$ & \multirow{2}{*}{23.4} & Rodushkin, 2000 \\
\hline & $<30$ & 86 & 15 & $27(21)$ & & Rodushkin, 1999 \\
\hline Ge $(\mu \mathrm{g} / \mathrm{l})$ & & & & $<0.1^{\mathrm{a}}$ & & Rodushkin, 2000 \\
\hline As $(\mu \mathrm{g} / \mathrm{l})$ & 0.78 & 0.88 & & $0.844(0.048)^{\mathrm{a}}$ & & Rodushkin, 2000 \\
\hline \multirow{4}{*}{$\operatorname{Se}(\mu \mathrm{g} / \mathrm{l})$} & 108 & 117 & & $109.8(2.7)^{a}$ & \multirow{4}{*}{115} & Rodushkin, 2000 \\
\hline & 138 & 277 & 167 & $176(30)$ & & Rodushkin, 1999 \\
\hline & & & & $120(20)$ & & $\begin{array}{c}\text { Mousavi-Yeganeh, } \\
1984\end{array}$ \\
\hline & 55 & 180 & 110 & $110(20)$ & & Bárány, 2002a,b \\
\hline \multirow{3}{*}{$\mathrm{Br}(\mathrm{mg} / \mathrm{l})$} & 0.8 & 35.2 & & $7.9(2.7)$ & \multirow{3}{*}{7.9} & $\begin{array}{c}\text { Mousavi-Yeganeh, } \\
1984\end{array}$ \\
\hline & 14.00 & 14.00 & & $14.00(0.63)^{a}$ & & Rodushkin, 2000 \\
\hline & 3.3 & 23.4 & 6.6 & $7.9(4.6)$ & & Rodushkin, 1999 \\
\hline \multirow{4}{*}{$\mathrm{Rb}(\mathrm{mg} / \mathrm{l})$} & 2.190 & 2.210 & & $2.204(0.017)^{a}$ & \multirow{4}{*}{2.51} & Rodushkin, 2000 \\
\hline & 0.90 & 4.14 & & $2.52^{*}$ & & St'astná, 1999 \\
\hline & 1.90 & 3.20 & 2.50 & $2.50(0.30)$ & & Rodushkin, 1999 \\
\hline & 1.50 & 4.40 & 2.80 & $2.90(0.50)$ & & Bárány, 2002a,b \\
\hline \multirow{3}{*}{$\operatorname{Sr}(\mu \mathrm{g} / \mathrm{l})$} & 14 & 26 & & $16.40(0.89)^{a}$ & \multirow{3}{*}{16.4} & Rodushkin, 2000 \\
\hline & 16 & 95 & & $56^{*}$ & & St'astná, 1999 \\
\hline & 7 & 25 & 12 & $13(4)$ & & Rodushkin, 1999 \\
\hline \multirow{2}{*}{ Y (ng/l) } & 24 & 59 & - & $24.54(0.99)^{\mathrm{a}}$ & \multirow{2}{*}{80} & Rodushkin, 2000 \\
\hline & 42 & 308 & 129 & $136(74)$ & & Rodushkin, 1999 \\
\hline \multirow[t]{2}{*}{$\mathrm{Zr}(\mu \mathrm{g} / \mathrm{l})$} & 0.041 & 0.173 & & $\begin{array}{c}0.0461 \\
(0.0029)^{\mathrm{a}}\end{array}$ & \multirow[t]{2}{*}{1.9} & Rodushkin, 2000 \\
\hline & 0.2 & 9.7 & 3.9 & $3.8(1.9)$ & & Rodushkin, 1999 \\
\hline
\end{tabular}




\begin{tabular}{|c|c|c|c|c|c|c|}
\hline \multirow{2}{*}{$\mathrm{Nb}(\mathrm{ng} / \mathrm{l})$} & 17 & 20 & & $19.40(0.89)^{a}$ & \multirow{2}{*}{30} & Rodushkin, 2000 \\
\hline & $<8$ & 179 & 38 & $40(31)$ & & Rodushkin, 1999 \\
\hline \multirow{2}{*}{ Mo $(\mu \mathrm{g} / \mathrm{l})$} & 0.23 & 1.06 & & $0.805(0.017)^{\mathrm{a}}$ & \multirow{2}{*}{0.92} & Rodushkin, 2000 \\
\hline & 0.21 & 5.41 & 0.90 & $1.03(0.090)$ & & Rodushkin, 1999 \\
\hline$\overline{\mathrm{Ru}(\mathrm{ng} / \mathrm{l})}$ & $<24$ & 102 & 54 & $54(17)$ & & Rodushkin, 1999 \\
\hline $\mathrm{Rh}(\mu \mathrm{g} / \mathrm{l})$ & $<0.1$ & 0.38 & $<0.1$ & $<0.1$ & & Bárány, 2002a,b \\
\hline $\mathrm{Pd}(\mathrm{ng} / \mathrm{l})$ & 9 & 125 & 35 & $48(9)$ & & Rodushkin, 1999 \\
\hline \multirow{2}{*}{$\operatorname{Ag}(\mathrm{ng} / \mathrm{l})$} & 34 & 37 & & $36.88(0.98)^{a}$ & \multirow{2}{*}{61} & Rodushkin, 2000 \\
\hline & $<45$ & 272 & 77 & $86(57)$ & & Rodushkin, 1999 \\
\hline \multirow{3}{*}{$\mathrm{Cd}(\mu \mathrm{g} / \mathrm{l})$} & 0.105 & 0.109 & & $\begin{array}{c}0.1066 \\
(0.0070)^{\mathrm{a}}\end{array}$ & \multirow{3}{*}{0.12} & Rodushkin, 2000 \\
\hline & 0.1 & 2 & & 1.0 & & St'astná, 1999 \\
\hline & $<0.030$ & 0.317 & 0.109 & $0.116(0.093)$ & & Rodushkin, 1999 \\
\hline \multirow{3}{*}{$\operatorname{Sn}(\mu \mathrm{g} / \mathrm{l})$} & & & & $0.39(0.23)^{\mathrm{a}}$ & \multirow{3}{*}{0.51} & Rodushkin, 2000 \\
\hline & 120 & 140 & & $130^{*}$ & & St'astná, 1999 \\
\hline & $<0.4$ & 1.2 & 0.53 & $0.51(0.27)$ & & Rodushkin, 1999 \\
\hline \multirow{3}{*}{$\mathrm{Sb}(\mu \mathrm{g} / \mathrm{l})$} & 0.040 & 0.044 & & $\begin{array}{c}0.0432 \\
(0.0018)^{\mathrm{a}}\end{array}$ & \multirow{3}{*}{0.26} & Rodushkin, 2000 \\
\hline & 0.3 & 3 & & $1.7^{*}$ & & St'astná, 1999 \\
\hline & 0.077 & 0.842 & 0.212 & $0.258(0.159)$ & & Rodushkin, 1999 \\
\hline \multirow{2}{*}{$\operatorname{Te}(\mu \mathrm{g} / \mathrm{l})$} & 0.023 & 0.052 & & $\begin{array}{c}0.0462 \\
(0.0018)^{\mathrm{a}}\end{array}$ & \multirow{2}{*}{0.150} & Rodushkin, 2000 \\
\hline & $<0.050$ & 0.572 & 0.226 & $0.254(0.155)$ & & Rodushkin, 1999 \\
\hline \multirow{2}{*}{$\mathrm{I}(\mu \mathrm{g} / \mathrm{l})$} & 73 & 77 & & $76.1(5.3)^{\mathrm{a}}$ & \multirow{2}{*}{72} & Rodushkin, 2000 \\
\hline & 35 & 118 & 65 & $68(19)$ & & Rodushkin, 1999 \\
\hline \multirow{3}{*}{ Cs $(\mu \mathrm{g} / \mathrm{l})$} & 3.17 & 3.20 & & $3.190(0.041)^{\mathrm{a}}$ & \multirow{3}{*}{3.8} & Rodushkin, 2000 \\
\hline & 0.5 & 7 & & $3.8^{*}$ & & St'astná, 1999 \\
\hline & 2.5 & 7.5 & 3.8 & $3.9(0.9)$ & & Rodushkin, 1999 \\
\hline \multirow{2}{*}{$\mathrm{Ba}(\mu \mathrm{g} / \mathrm{l})$} & 7.4 & 260 & & $7.46(0.30)^{a}$ & \multirow{2}{*}{75} & Rodushkin, 2000 \\
\hline & 16 & 365 & 104 & $142(86)$ & & Rodushkin, 1999 \\
\hline \multirow{2}{*}{$\mathrm{La}(\mu \mathrm{g} / \mathrm{l})$} & 0.084 & 4.2 & & $0.101(0.013)^{a}$ & \multirow{2}{*}{1.7} & Rodushkin, 2000 \\
\hline & 1.2 & 8.2 & 2.8 & $3.3(1.7)$ & & Rodushkin, 1999 \\
\hline \multirow{2}{*}{$\mathrm{Ce}(\mu \mathrm{g} / \mathrm{l})$} & 0.1 & 34 & & $\begin{array}{c}0.1002 \\
(0.0050)^{\mathrm{a}}\end{array}$ & \multirow[t]{2}{*}{23} & Rodushkin, 2000 \\
\hline & 6 & 113 & 37 & $45(24)$ & & Rodushkin, 1999 \\
\hline $\operatorname{Pr}(n g / l)$ & 19 & 47 & & $21.0(2.0)^{\mathrm{a}}$ & & Rodushkin, 2000 \\
\hline $\mathrm{Nd}(\mathrm{ng} / \mathrm{l})$ & 54 & 1160 & & $54.2(1.0)^{\mathrm{a}}$ & & Rodushkin, 2000 \\
\hline Sm (ng/l) & 13 & 87 & & $14.48(0.99)^{a}$ & & Rodushkin, 2000 \\
\hline $\mathrm{Eu}(\mathrm{ng} / \mathrm{l})$ & 3 & 15 & & $9.00(0.71)^{a}$ & & Rodushkin, 2000 \\
\hline Gd(ng/l) & 4 & 31 & & $9.40(0.89)^{a}$ & & Rodushkin, 2000 \\
\hline $\mathrm{Tb}(\mathrm{ng} / \mathrm{l})$ & 1 & 6 & & $3.50(0.71)^{\mathrm{a}}$ & & Rodushkin, 2000 \\
\hline Dy (ng/l) & 5 & 8 & & $5.60(0.89)^{\mathrm{a}}$ & & Rodushkin, 2000 \\
\hline Ho (ng/l) & 1.2 & 1.5 & & $1.230(0.095)^{\mathrm{a}}$ & & Rodushkin, 2000 \\
\hline $\operatorname{Er}(\mathrm{ng} / \mathrm{l})$ & 4 & 4 & & $4.00(0.71)^{a}$ & & Rodushkin, 2000 \\
\hline Tm (ng/l) & 0.7 & 0.7 & & $0.70(0.14)^{a}$ & & Rodushkin, 2000 \\
\hline $\mathrm{Yb}(\mathrm{ng} / \mathrm{l})$ & 2.4 & 4.1 & & $2.88(0.42)^{a}$ & & Rodushkin, 2000 \\
\hline $\mathrm{Lu}(\mathrm{ng} / \mathrm{l})$ & 0.5 & 0.8 & & $0.650(0.071)^{a}$ & & Rodushkin, 2000 \\
\hline
\end{tabular}




\begin{tabular}{|c|c|c|c|c|c|c|}
\hline \multirow[t]{2}{*}{$\mathrm{Hf}(\mu \mathrm{g} / \mathrm{l})$} & 0.002 & 0.003 & & $\begin{array}{c}0.00250 \\
(0.00071)^{\mathrm{a}}\end{array}$ & \multirow[t]{2}{*}{0.75} & Rodushkin, 2000 \\
\hline & $<0.1$ & 6.5 & 0.48 & $1.5(2.4)$ & & Rodushkin, 1999 \\
\hline Ta (ng/l) & 2.5 & 7.6 & 3.4 & $3.6(1.9)$ & \multirow{3}{*}{21} & Rodushkin, 1999 \\
\hline \multirow{2}{*}{ W (ng/l) } & 6 & 16 & & $6.38(0.98)^{\mathrm{a}}$ & & Rodushkin, 2000 \\
\hline & $<20$ & 184 & 25 & $36(39)$ & & Rodushkin, 1999 \\
\hline \multirow{2}{*}{$\operatorname{Re}(\mathrm{ng} / \mathrm{l})$} & 0.6 & 0.6 & & $0.600(0.071)^{\mathrm{a}}$ & \multirow{2}{*}{1.1} & Rodushkin, 2000 \\
\hline & $<0.6$ & 5.2 & 1.4 & $1.6(0.9)$ & & Rodushkin, 1999 \\
\hline \multirow{3}{*}{ Ir (ng/l) } & & & & $0.2(0.1)^{\mathrm{a}}$ & \multirow{3}{*}{0.8} & Rodushkin, 2000 \\
\hline & $<1.2$ & 2.9 & 0.6 & $0.8(0.6)$ & & Rodushkin, 1999 \\
\hline & & & & 1 & & Petrucci, 2004 \\
\hline \multirow{3}{*}{$\mathrm{Pt}(\mathrm{ng} / \mathrm{l})$} & 1.0 & 1.1 & & $1.020(0.089)^{\mathrm{a}}$ & \multirow{3}{*}{5.1} & Rodushkin, 2000 \\
\hline & $<1.2$ & 98 & 0.6 & $5.1(1.8)$ & & Rodushkin, 1999 \\
\hline & & & & 6 & & Petrucci, 2004 \\
\hline \multirow{2}{*}{$\mathrm{Au}(\mathrm{ng} / \mathrm{l})$} & 9 & 9 & & $9.00(0.89)^{\mathrm{a}}$ & \multirow{2}{*}{24} & Rodushkin, 2000 \\
\hline & 7 & 217 & 18 & $38(51)$ & & Rodushkin, 1999 \\
\hline \multirow{4}{*}{$\mathrm{Hg}(\mu \mathrm{g} / \mathrm{l})$} & 0.62 & 0.68 & & $0.668(0.018)^{\mathrm{a}}$ & \multirow{4}{*}{1.6} & Rodushkin, 2000 \\
\hline & 1.2 & 10 & & $5.6^{*}$ & & St'astná, 1999 \\
\hline & 0.44 & 6.47 & 1.7 & $2.0(1.3)$ & & Rodushkin, 1999 \\
\hline & $<0.7$ & 6.1 & 1.1 & $1.2(0.6)$ & & Bárány, 2002a,b \\
\hline \multirow{3}{*}{$\mathrm{Tl}$ (ng/l) } & 5 & 18 & & $11.50(0.71)^{a}$ & \multirow{3}{*}{35} & Rodushkin, 2000 \\
\hline & 150 & 600 & & $38^{*}$ & & St'astná, 1999 \\
\hline & 21 & 62 & 33 & $35(9)$ & & Rodushkin, 1999 \\
\hline \multirow{4}{*}{$\mathrm{Pb}(\mu \mathrm{g} / \mathrm{l})$} & 9 & 9.1 & & $9.01(0.19)^{\mathrm{a}}$ & \multirow{4}{*}{18} & Rodushkin, 2000 \\
\hline & 40 & 290 & & $165^{*}$ & & St'astná, 1999 \\
\hline & 4 & 43 & 15 & $17(8)$ & & Rodushkin, 1999 \\
\hline & 3.5 & 170 & 16 & $19(10)$ & & Bárány, 2002a,b \\
\hline \multirow{3}{*}{$\mathrm{Bi}(\mathrm{ng} / \mathrm{l})$} & 5 & 15 & & $5.20(0.99)^{\mathrm{a}}$ & \multirow{3}{*}{8.8} & Rodushkin, 2000 \\
\hline & 100 & 800 & & $500 *$ & & St'astná, 1999 \\
\hline & $<4.5$ & 29 & 7.3 & $8.8(6.2)$ & & Rodushkin, 1999 \\
\hline \multirow{2}{*}{ Th (ng/l) } & 1.0 & 66 & & $1.01(0.20)^{\mathrm{a}}$ & \multirow{2}{*}{42} & Rodushkin, 2000 \\
\hline & 8 & 200 & 67 & $84(46)$ & & Rodushkin, 1999 \\
\hline \multirow{2}{*}{$\mathrm{U}(\mathrm{ng} / \mathrm{l})$} & 2 & 12 & & $7.00(0.71)^{a}$ & \multirow{2}{*}{11} & Rodushkin, 2000 \\
\hline & 8 & 35 & 13 & $15(6)$ & & Rodushkin, 1999 \\
\hline
\end{tabular}

* Média calculada a partir dos valores de máximo e mínimo.

a Média Ponderada de duas médias (desvio padrão ponderado). 


\section{A pêndice B}

Os coeficientes $a-h$ (tabela B.1) necessários para calcular os valores da perda de energia proposta por Ziegler et. al. $(1985)^{1}$ são tabelados em função de cada elemento químico, e os resultados dados em $\mathrm{keV} / \mathrm{mg} / \mathrm{cm}^{2}$.

Tabela B.1 Coeficientes para o calculo da perda de energia proposta por Ziegler et. al. (1985).

\begin{tabular}{|c|c|c|c|c|c|c|c|c|}
\hline $\mathbf{Z}$ & $\mathbf{a}$ & $\mathbf{b}$ & c & d & e & f & g & $\mathbf{h}$ \\
\hline 1 & 0,009183 & 0,00535 & 0,69741 & 0,48493 & 316,07 & 1,0143 & 9329,3 & 0,053989 \\
\hline 2 & 0,11393 & 0,005198 & 1,0822 & 0,39252 & 1081 & 1,0645 & 4068,5 & 0,017699 \\
\hline 3 & 0,85837 & 0,005015 & 1,6044 & 0,38844 & 1337,3 & 1,047 & 2659,2 & 0,01898 \\
\hline 4 & 0,8781 & 0,005105 & 5,4232 & 0,2032 & 1200,6 & 1,0211 & 1401,8 & 0,038529 \\
\hline 5 & 1,4608 & 0,004884 & 2,338 & 0,44249 & 1801,3 & 1,0352 & 1784,1 & 0,02024 \\
\hline 6 & 3,2579 & 0,004915 & 2,7156 & 0,36473 & 2092,2 & 1,0291 & 2643,6 & 0,018237 \\
\hline 7 & 0,59674 & 0,005084 & 4,2073 & 0,30612 & 2394,2 & 1,0255 & 4892,1 & 0,016006 \\
\hline 8 & 0,75253 & 0,005031 & 4,0824 & 0,30067 & 2455,8 & 1,0181 & 5069,7 & 0,017426 \\
\hline 9 & 1,226 & 0,005139 & 3,2246 & 0,32703 & 2525 & 1,0143 & 7563,6 & 0,019469 \\
\hline 10 & 1,0332 & 0,005165 & 3,004 & 0,33889 & 2338,6 & 0,99997 & 6991,2 & 0,021799 \\
\hline 11 & 6,0972 & 0,004429 & 3,1929 & 0,45763 & 1363,3 & 0,95182 & 2380,6 & 0,081835 \\
\hline 12 & 14,013 & 0,004365 & 2,2641 & 0,36326 & 2187,4 & 0,99098 & 6264,8 & 0,0462 \\
\hline 13 & 0,039001 & 0,004542 & 5,5463 & 0,39562 & 1589,2 & 0,95316 & 816,16 & 0,047484 \\
\hline 14 & 2,072 & 0,004452 & 3,5584 & 0,53933 & 1515,2 & 0,93161 & 1790,3 & 0,035198 \\
\hline 15 & 17,575 & 0,003835 & 0,078694 & 1,2388 & 2806 & 0,97284 & 1037,6 & 0,012879 \\
\hline 16 & 16,126 & 0,003832 & 0,054164 & 1,3104 & 2813,3 & 0,96587 & 1251,4 & 0,011847 \\
\hline 17 & 3,217 & 0,004458 & 3,6696 & 0,5091 & 2734,6 & 0,96253 & 2187,5 & 0,016907 \\
\hline 18 & 2,0379 & 0,005578 & 3,0743 & 0,54773 & 3505 & 0,97575 & 1714 & 0,011701 \\
\hline 19 & 0,74171 & 0,004305 & 1,1515 & 0,95083 & 917,21 & 0,8782 & 389,93 & 0,18926 \\
\hline 20 & 9,1316 & 0,004381 & 5,4611 & 0,31327 & 3891,8 & 0,97933 & 6267,9 & 0,015196 \\
\hline 21 & 7,2247 & 0,004372 & 6,1017 & 0,37511 & 2829,2 & 0,95218 & 6376,4 & 0,020398 \\
\hline 22 & 0,147 & 0,004846 & 6,3485 & 0,41057 & 2164,1 & 0,94028 & 5292,6 & 0,050263 \\
\hline 23 & 5,0611 & 0,003987 & 2,6174 & 0,57957 & 2218,9 & 0,92361 & 6323 & 0,025669 \\
\hline 24 & 0,53267 & 0,004297 & 0,39005 & 1,2725 & 1872,7 & 0,90776 & 64,166 & 0,030107 \\
\hline 25 & 0,47697 & 0,004304 & 0,31452 & 1,3289 & 1920,5 & 0,90649 & 45,576 & 0,027469 \\
\hline 26 & 0,027426 & 0,003544 & 0,031563 & 2,1755 & 1919,5 & 0,90099 & 23,902 & 0,025363 \\
\hline 27 & 0,16383 & 0,004304 & 0,073454 & 1,8592 & 1918,4 & 0,89678 & 27,61 & 0,023184 \\
\hline 28 & 4,2562 & 0,004374 & 1,5606 & 0,72067 & 1546,8 & 0,87958 & 302,02 & 0,040944 \\
\hline 29 & 2,3508 & 0,004324 & 2,882 & 0,50113 & 1837,7 & 0,89992 & 2377 & 0,04965 \\
\hline 30 & 3,1095 & 0,003846 & 0,11477 & 1,5037 & 2184,7 & 0,89309 & 67,306 & 0,016588 \\
\hline 31 & 15,322 & 0,004031 & 0,65391 & 0,67668 & 3001,7 & 0,92484 & 3344,2 & 0,016366 \\
\hline 32 & 3,6932 & 0,004481 & 8,608 & 0,27638 & 2982,7 & 0,9276 & 3166,6 & 0,030874 \\
\hline 33 & 7,1373 & 0,004313 & 9,4247 & 0,27937 & 2725,8 & 0,91597 & 3166,1 & 0,025008 \\
\hline 34 & 4,8979 & 0,004294 & 3,7793 & 0,50004 & 2824,5 & 0,91028 & 1282,4 & 0,017061 \\
\hline 35 & 1,3683 & 0,004302 & 2,5679 & 0,60822 & 6907,8 & 0,9817 & 628,01 & 0,006806 \\
\hline 36 & 1,8301 & 0,004298 & 2,9057 & 0,6038 & 4744,6 & 0,94722 & 936,64 & 0,009224 \\
\hline
\end{tabular}




\begin{tabular}{|c|c|c|c|c|c|c|c|c|}
\hline $\mathbf{Z}$ & $\mathbf{a}$ & b & c & d & e & f & g & h \\
\hline 37 & 0,42056 & 0,004117 & 0,01695 & 2,3616 & 2252,7 & 0,89192 & 39,752 & 0,027757 \\
\hline 38 & 30,78 & 0,003774 & 0,55813 & 0,76818 & 7113,2 & 0,97697 & 1604,4 & 0,006527 \\
\hline 39 & 11,576 & 0,004212 & 7,0244 & 0,37764 & 4713,5 & 0,94264 & 2493,2 & 0,01127 \\
\hline 40 & 6,2406 & 0,004192 & 5,2701 & 0,49453 & 4234,6 & 0,93232 & 2063,9 & 0,011844 \\
\hline 41 & 0,33073 & 0,004124 & 1,7246 & 1,1062 & 1930,2 & 0,86907 & 27,416 & 0,038208 \\
\hline 42 & 0,017747 & 0,004172 & 0,14586 & 1,7305 & 1803,6 & 0,86315 & 29,669 & 0,032123 \\
\hline 43 & 3,7229 & 0,004177 & 4,6286 & 0,56769 & 1678 & 0,86202 & 3091 & 0,03244 \\
\hline 44 & 0,13998 & 0,004133 & 0,25573 & 1,4241 & 1919,3 & 0,86326 & 72,797 & 0,032235 \\
\hline 45 & 0,2859 & 0,004139 & 0,31301 & 1,3424 & 1954,8 & 0,86175 & 115,18 & 0,029342 \\
\hline 46 & 0,76002 & 0,004218 & 3,386 & 0,76285 & 1867,4 & 0,85805 & 69,994 & 0,036448 \\
\hline 47 & 6,3957 & 0,004194 & 5,4689 & 0,41378 & 1712,6 & 0,85397 & 18493 & 0,056471 \\
\hline 48 & 3,4717 & 0,004134 & 3,2337 & 0,63788 & 1116,4 & 0,81959 & 4766 & 0,1179 \\
\hline 49 & 2,5264 & 0,004228 & 4,532 & 0,53562 & 1030,8 & 0,81652 & 16252 & 0,19722 \\
\hline 50 & 7,3683 & 0,004101 & 4,6791 & 0,51428 & 1160 & 0,82454 & 17965 & 0,13316 \\
\hline 51 & 7,7197 & 0,004388 & 3,242 & 0,68434 & 1428,1 & 0,83398 & 1786,7 & 0,066512 \\
\hline 52 & 16,78 & 0,004192 & 9,3198 & 0,29568 & 3370,9 & 0,90289 & 7431,7 & 0,02616 \\
\hline 53 & 4,2132 & 0,00421 & 4,6753 & 0,57945 & 3503,9 & 0,89261 & 1468,9 & 0,014359 \\
\hline 54 & 4,0818 & 0,004214 & 4,4425 & 0,58393 & 3945,3 & 0,90281 & 1340,5 & 0,013414 \\
\hline 55 & 0,18517 & 0,003622 & 0,000588 & 3,5315 & 2931,3 & 0,88936 & 26,18 & 0,026393 \\
\hline 56 & 4,8248 & 0,004146 & 6,0934 & 0,57026 & 2300,1 & 0,86359 & 2980,7 & 0,038679 \\
\hline 57 & 0,49857 & 0,004105 & 1,9775 & 0,95877 & 786,55 & 0,78509 & 806,6 & 0,40882 \\
\hline 58 & 3,2754 & 0,004218 & 5,768 & 0,54054 & 6631,3 & 0,94282 & 744,07 & 0,008303 \\
\hline 59 & 2,9978 & 0,00409 & 4,5299 & 0,62025 & 2161,2 & 0,85669 & 1268,6 & 0,043031 \\
\hline 60 & 2,8701 & 0,004096 & 4,2568 & 0,6138 & 2130,4 & 0,85265 & 1704,1 & 0,39385 \\
\hline 61 & 10,853 & 0,004115 & 5,8907 & 0,46834 & 2857,2 & 0,8755 & 3654,2 & 0,029955 \\
\hline 62 & 3,6407 & 0,004178 & 4,8742 & 0,57861 & 1267,7 & 0,82211 & 3508,2 & 0,24174 \\
\hline 63 & 17,645 & 0,004099 & 6,5855 & 0,32734 & 3931,3 & 0,90754 & 5156,7 & 0,036278 \\
\hline 64 & 7,5309 & 0,004081 & 4,9389 & 0,50679 & 2519,7 & 0,85819 & 3314,6 & 0,030514 \\
\hline 65 & 5,4742 & 0,004083 & 4,897 & 0,41113 & 2340,1 & 0,85296 & 2342,7 & 0,035662 \\
\hline 66 & 4,2661 & 0,004067 & 4,5032 & 0,55257 & 2076,4 & 0,84151 & 1666,6 & 0,040801 \\
\hline 67 & 6,8313 & 0,004049 & 4,3987 & 0,51675 & 2003 & 0,83437 & 1410,4 & 0,03478 \\
\hline 68 & 1,2707 & 0,004055 & 4,6295 & 0,57428 & 1626,3 & 0,81858 & 995,68 & 0,055319 \\
\hline 69 & 5,7561 & 0,004049 & 4,357 & 0,52496 & 2207,3 & 0,83796 & 1579,5 & 0,027165 \\
\hline 70 & 14,127 & 0,00406 & 5,8304 & 0,37755 & 3645,9 & 0,87823 & 3411,8 & 0,016392 \\
\hline 71 & 6,6948 & 0,00406 & 4,9361 & 0,47961 & 2719 & 0,85249 & 1885,8 & 0,019713 \\
\hline 72 & 3,0619 & 0,004051 & 3,5803 & 0,59082 & 2346,1 & 0,83713 & 1222 & 0,020072 \\
\hline 73 & 10,811 & 0,003301 & 4,3767 & 0,76512 & 2003,7 & 0,82269 & 1110,6 & 0,024958 \\
\hline 74 & 2,7101 & 0,004096 & 1,2289 & 0,98598 & 1232,4 & 0,79066 & 155,42 & 0,047294 \\
\hline 75 & 0,52345 & 0,004024 & 1,4038 & 0,8551 & 1461,4 & 0,79677 & 503,34 & 0,036789 \\
\hline 76 & 0,4616 & 0,00402 & 1,3014 & 0,87043 & 1473,5 & 0,79687 & 443,09 & 0,036301 \\
\hline 77 & 0,97814 & 0,004037 & 2,0127 & 0,7225 & 1890,8 & 0,81747 & 930,7 & 0,02769 \\
\hline 78 & 3,2086 & 0,004051 & 3,6658 & 0,53618 & 3091,2 & 0,85602 & 1508,1 & 0,015401 \\
\hline 79 & 2,0035 & 0,004043 & 7,4882 & 0,3561 & 4461,3 & 0,88836 & 3966,5 & 0,012839 \\
\hline 80 & 15,43 & 0,003943 & 1,1237 & 0,70703 & 4595,7 & 0,88437 & 1576,5 & 0,008853 \\
\hline 81 & 3,1512 & 0,004052 & 4,0996 & 0,5425 & 3246,3 & 0,85772 & 1691,8 & 0,015058 \\
\hline 82 & 7,1896 & 0,004059 & 8,6927 & 0,35842 & 4760,6 & 0,88833 & 2888,3 & 0,011029 \\
\hline 83 & 9,3209 & 0,004054 & 11,543 & 0,32027 & 4866,2 & 0,89124 & 3213,4 & 0,011935 \\
\hline 84 & 29,242 & 0,00392 & 0,16864 & 1,1226 & 5688 & 0,89812 & 1033,3 & 0,00713 \\
\hline 85 & 1,8522 & 0,003997 & 3,1556 & 0,65096 & 3755 & 0,86383 & 1602 & 0,012042 \\
\hline 86 & 3,222 & 0,004004 & 5,9024 & 0,52678 & 4040,2 & 0,86804 & 1658,4 & 0,011747 \\
\hline 87 & 9,3412 & 0,003966 & 7,921 & 0,42977 & 5180,9 & 0,88773 & 2173,2 & 0,009201 \\
\hline 88 & 36,183 & 0,0036 & 0,58341 & 0,86747 & 6990,2 & 0,91082 & 1417,1 & 0,006219 \\
\hline 89 & 5,9284 & 0,00397 & 6,4082 & 0,52122 & 4619,5 & 0,88083 & 2323,5 & 0,011627 \\
\hline 90 & 5,2454 & 0,003974 & 6,7969 & 0,48542 & 4586,3 & 0,87791 & 2481,5 & 0,011282 \\
\hline
\end{tabular}


Apêndice B

\begin{tabular}{ccccccccc}
\hline $\mathbf{Z}$ & $\mathbf{a}$ & $\mathbf{b}$ & $\mathbf{c}$ & $\mathbf{d}$ & $\mathbf{e}$ & $\mathbf{f}$ & $\mathbf{g}$ & $\mathbf{h}$ \\
91 & 33,702 & 0,00369 & 0,47257 & 0,89235 & 5295,7 & 0,8893 & 2053,3 & 0,009191 \\
92 & 2,7589 & 0,003981 & 3,2092 & 0,66122 & 2505,4 & 0,82863 & 2065,1 & 0,022816 \\
\hline
\end{tabular}




\section{A pêndice $C$}

Este apêndice mostra os certificados do Triton-X, do EDTA, dos 3 materiais de referência de soro do Instituto Nacional de Saúde Pública - Québec (ICP04S-06, ICP02S-05 e QMEQAS05S-03) e também dos padrões de ítrio, de selênio e do multielementar MICPG2, materiais utilizados neste trabalho. 
Your contact person:

Scheila $M$ de Oliveira

Telephone:

00551146165431

Telefax:

00551146140109

Date of print:

04.11 .2005

\subsubsection{Triton ${ }^{\circledR}$ X-100 GR pro analysi Ph Eur Batch L757043}

Assay (HPLC)

Identity (IR-spectrum)

Appearance

$\mathrm{pH}$-value ( $10 \mathrm{~g} / \mathrm{l}$, water)

Density (d 20/4)

Acidity or alkalinity

Point of turbidity

Chloride $(\mathrm{Cl})$

Sulphate $\left(\mathrm{SO}_{4}\right)$

Heavy metals (as $\mathrm{Pb}$ )

$\mathrm{Al}$ (Aluminium)

B (Boron)

Ba (Barium)

$\mathrm{Ca}$ (Calcium)

Cd (Cadmium)

Co (Cobalt)

$\mathrm{Cr}$ (Chromium)

$\mathrm{Cu}$ (Copper)

$\mathrm{Fe}$ (Iron)

Mg (Magnesium)

Mn (Manganese)

$\mathrm{Ni}$ (Nickel)

$\mathrm{Pb}$ (Lead)

Sr (Strontium)

$\mathrm{Zn}$ (Zinc)

Ethylene oxide (GC)

Dioxane (GC)
Spec. Values

Batch Values

\begin{tabular}{ll}
\hline $\begin{array}{l}97.0-105.0 \quad \% \\
\text { passes test }\end{array}$ & 104.9 \\
$\begin{array}{l}\text { Almost clear, almost colorless to } \\
\text { sligthly yellowish liquid }\end{array}$ & passes test \\
passes test &
\end{tabular}

( $\leq 100$ Hazen).

$6.0-8.0$

6.9

$1.064-1.067$

1.065

passes test

$63-69$

${ }^{\circ} \mathrm{C}$

$\leq 50$

ppm

$\leq 50$

$\leq 10$

$\leq 5$

$\leq 5$

$\leq 5$

$\leq 10$

$\leq 5$

$\leq 5$

$\leq 5$

$\leq 5$

$\leq 5$

$\leq 5$

$\leq 5$

$\leq 5$

$\leq 5$

$\leq 5$

$\leq 5$

$\leq 1$

$\leq 5$

ppm

ppm

ppm

ppm

ppm

ppm

ppm

ppm

ppm

ppm

ppm

ppm

ppm

ppm

ppm

ppm

ppm

ppm

ppm passes test

$67 \quad{ }^{\circ} \mathrm{C}$

$<50 \quad$ ppm

$<50 \quad$ ppm

$<10 \quad$ ppm

$\leq 5 \quad$ ppm

$\leq 5 \quad \mathrm{ppm}$

$\leq 5 \quad$ ppm

$\leq 10 \quad$ ppm

$\leq 5 \quad$ ppm

$\leq 5 \quad \mathrm{ppm}$

$\leq 5 \quad \mathrm{ppm}$

$\leq 5 \quad$ ppm

$\leq 5 \quad$ ppm

$\leq 5 \quad$ ppm

$\leq 5 \quad \mathrm{ppm}$

$\leq 5 \quad \mathrm{ppm}$

$\leq 5 \quad$ ppm

$\leq 5 \quad$ ppm

$\leq 5 \quad$ ppm

$\leq 1 \quad$ ppm

$\leq 5 \quad \mathrm{ppm}$ 


\section{Certificate of Analysis}

Your contact person:

Scheila M de Oliveira

Telephone:

00551146165431

Telefax:

00551146140109

Date of print:

16.11.2005

\subsubsection{Titriplex® || GR for analysis (ethylenedinitrilotetraacetic acid) ACS,Reag. Ph Eur \\ Batch K33440017}

Assay (complexometric)

Identity (IR-spectrum)

Appearance

in ammonia insoluble components

Heavy metals (as $\mathrm{Pb}$ )

$\mathrm{Ca}$ (Calcium)

$\mathrm{Fe}$ (Iron)

Mg (Magnesium)

Nitrilotriacetic acid

Sulfated ash

Water (according to Karl Fischer)

Test date (DD.MM.YYYY):

Minimum shelf life (DD.MM.YYYY):
Spec. Values

Batch Values

\begin{tabular}{llll}
\hline $\begin{array}{l}99.4-100.6 \quad \% \\
\text { conforms }\end{array}$ & $\begin{array}{l}99.6 \\
\text { conforms } \\
\text { passes test }\end{array}$ & \\
\multicolumn{2}{l}{$\begin{array}{l}\text { White to almost white, fine } \\
\text { crystalline to crystalline powder. }\end{array}$} & & \\
$\leq 0.005$ & $\%$ & $\leq 0.005$ & $\%$ \\
$\leq 0.001$ & $\%$ & $\leq 0.001$ & $\%$ \\
$\leq 0.001$ & $\%$ & $<0.0005$ & $\%$ \\
$\leq 0.001$ & $\%$ & $\leq 0.001$ & $\%$ \\
$\leq 5$ & ppm & $<5$ & $\mathrm{ppm}$ \\
$\leq 0.1$ & $\%$ & $\leq 0.1$ & $\%$ \\
$\leq 0.1$ & $\%$ & $\leq 0.1$ & $\%$ \\
$\leq 0.2$ & $\%$ & $\leq 0.2$ & $\%$
\end{tabular}

28.06.2004

30.06 .2009 


\section{Biological Reference Material - Evaluation Report -}

Control ID \#: ICP04S-06

Material:

Human serum

Date released: 2004-06-18

Median

\begin{tabular}{|l|}
\hline $\mathrm{Ag}$ \\
$\mathrm{Al}$ \\
$\mathrm{As}$ \\
$\mathrm{Ba}$ \\
$\mathrm{Be}$ \\
$\mathrm{Cd}$ \\
$\mathrm{Co}$ \\
$\mathrm{Cr}$ \\
$\mathrm{Cu}$ \\
$\mathrm{Hg}$ \\
$\mathrm{Mn}$ \\
$\mathrm{Mo}$ \\
$\mathrm{Ni}$ \\
$\mathrm{Pb}$ \\
$\mathrm{Pt}$ \\
$\mathrm{Sb}$ \\
$\mathrm{Se}$ \\
$\mathrm{Sn}$ \\
$\mathrm{Te}$ \\
$\mathrm{Tl}$ \\
$\mathrm{U}$ \\
$\mathrm{V}$ \\
$\mathrm{Zn}$ \\
\hline
\end{tabular}

Std. Dev.

Nb Labs

\begin{tabular}{c|}
0.31 \\
9.2 \\
4.3 \\
0.26 \\
0.35 \\
0.15 \\
0.20 \\
0.13 \\
100 \\
0.25 \\
0.52 \\
2.1 \\
2.1 \\
1.2 \\
0.09 \\
0.44 \\
21 \\
0.16 \\
0.68 \\
0.08 \\
0.04 \\
0.75 \\
110
\end{tabular}

11 16 9 11 13 12 15 9 16 6 17 12 13 15 6 11 15 8 7 11 7 4 16 


\section{Biological Reference Material - Evaluation Report -}

Control ID \#: ICP02S-05

Material:

Human serum

Date released: 2002-07-03

Median Std. Dev. Nb Labs

\begin{tabular}{|c|c|c|c|}
\hline $\mathrm{Ag}$ & 5.0 & 2.0 & 10 \\
$\mathrm{Al}$ & 37.9 & 15.3 & 13 \\
$\mathrm{As}$ & 13.0 & 5.6 & 9 \\
$\mathrm{Ba}$ & 1.5 & 0.1 & 6 \\
$\mathrm{Be}$ & 16.9 & 1.5 & 13 \\
$\mathrm{Cd}$ & 1.0 & 0.3 & 11 \\
$\mathrm{Co}$ & 4.6 & 0.8 & 15 \\
$\mathrm{Cr}$ & 0.8 & 0.4 & 8 \\
$\mathrm{Cu}$ & 1600 & 134 & 15 \\
$\mathrm{Hg}$ & 1.7 & 0.7 & 9 \\
$\mathrm{Mn}$ & 3.8 & 0.9 & 11 \\
$\mathrm{Mo}$ & 2.1 & 1.1 & 12 \\
$\mathrm{Ni}$ & 4.3 & 1.2 & 11 \\
$\mathrm{~Pb}$ & 10.3 & 0.6 & 11 \\
$\mathrm{Pt}$ & 0.40 & 0.46 & 5 \\
$\mathrm{Sb}$ & 1.0 & 0.3 & 10 \\
$\mathrm{Se}$ & 240 & 20 & 15 \\
$\mathrm{Sn}$ & 3.3 & 1.3 & 10 \\
$\mathrm{Te}$ & 9.3 & 1.3 & 7 \\
$\mathrm{Tl}$ & 1.2 & 0.1 & 12 \\
$\mathrm{U}$ & 0.44 & 0.16 & 6 \\
$\mathrm{~V}$ & 6.4 & 11.6 & 8 \\
$\mathrm{Zn}$ & 2013 & 241 & 18 \\
\hline & & & \\
\hline
\end{tabular}

Concentrations in $\mathrm{ug} / \mathrm{L}$ 


\section{Biological Reference Material}

\section{- Evaluation Report -}

Control ID \#: $\quad$ QMEQAS05S-03

Material:

Human serum

Date released: 2005-03-18

Median

Std. Dev.

Nb Labs

\begin{tabular}{|l|}
\hline $\mathrm{Ag}$ \\
$\mathrm{Al}$ \\
$\mathrm{As}$ \\
$\mathrm{Ba}$ \\
$\mathrm{Be}$ \\
$\mathrm{Cd}$ \\
$\mathrm{Co}$ \\
$\mathrm{Cr}$ \\
$\mathrm{Cu}$ \\
$\mathrm{Hg}$ \\
$\mathrm{Mn}$ \\
$\mathrm{Mo}$ \\
$\mathrm{Ni}$ \\
$\mathrm{Pb}$ \\
$\mathrm{Pt}$ \\
$\mathrm{Sb}$ \\
$\mathrm{Se}$ \\
$\mathrm{Sn}$ \\
$\mathrm{Te}$ \\
$\mathrm{Tl}$ \\
$\mathrm{U}$ \\
$\mathrm{V}$ \\
$\mathrm{Zn}$ \\
\hline
\end{tabular}

2.1
120
4.2
2.8
3.4
6.3
0.91
4.3
1100
2.9
2.4
4.6
3.1
200
0.34
2.6
140
7.0
3.9
2.3
0.10
4.7
1200

0.81 20

3.8

0.73

0.96

0.97

0.21

0.66

97

0.83

0.66

1.0

2.0

25

0.16

0.48

13

1.5

1.5

0.25

0.017

8.2

110

15

20

18

16

17

17

18

14

20

12

22

17

18

19

10

14

20

14

12

16

10

11

19

Concentrations in $\mathbf{u g} / \mathbf{L}$ 


\section{Certificate of Analysis \\ Certipur ${ }^{\circledast}$ Reference Material}

\section{Yttrium ICP Standard $1000 \mathrm{mg} / \mathrm{I}$ Y CertiPUR ${ }^{\circledR}$}

\subsection{8 .0100}

Lot No.: OC524564

This Certificate of Analysis is based on the data from the Merck Calibration Laboratory for ICP-OES, according to DIN EN ISO / IEC 17025.

Accredited by the DKD (Deutscher Kalibrierdienst), the accreditation body at PTB (Physikalisch-Technische Bundesanstalt).

DAR Reg.-No.:

DKD-K-14302

Ref. Calibration Certificate: $\quad$ 011/DKD-K-14302/05-03

Composition: Yttrium nitrate in nitric acid Suprapur $2-3 \%$

Assay:

$990 \mathrm{mg} / \mathrm{kg}$

$1004 \mathrm{mg} / \mathrm{l}$ (calculated)

Analysis: ICP-OES

Measurement $\quad \pm 3 \mathrm{mg} / \mathrm{kg}( \pm 0.3 \%)$

Uncertainty: This value represents the expanded uncertainty $(U)$ for a coverage probability of $95 \%$. Refer to page 2 for further details.

Traceability: This ICP Standard has been measured applying high precision ICP-OES in comparison to the corresponding NIST SRM ${ }^{\circledR} 3167$ a, lot 790412

Trace impurities $\mu \mathrm{g} / \mathrm{ml}$ :

$\begin{array}{llllllll}\mathrm{Ag}<0.02 & \mathrm{Cr}<0.02 & \mathrm{In}<0.02 & \mathrm{Ni}<0.02 & \mathrm{Sb}<0.02 & \mathrm{TI}<0.02 \\ \mathrm{Al}<0.05 & \mathrm{Cu}<0.02 & \mathrm{Ir}<0.02 & \mathrm{Os}<0.20 & \mathrm{Sc}<0.02 & \mathrm{Tm}<0.02 \\ \mathrm{As}<0.20 & \mathrm{Dy}<0.02 & \mathrm{~K}<0.20 & \mathrm{P}<0.20 & \mathrm{Se}<0.20 & \mathrm{U} & <0.02 \\ \mathrm{Au}<0.02 & \mathrm{Er}<0.02 & \mathrm{La}<0.02 & \mathrm{~Pb}<0.05 & \mathrm{Si}<0.20 & \mathrm{~V} & <0.02 \\ \mathrm{~B}<0.05 & \mathrm{Eu}<0.02 & \mathrm{Li}<0.02 & \mathrm{Pd}<0.02 & \mathrm{Sm}<0.02 & \mathrm{~W}<0.05 \\ \mathrm{Ba}<0.02 & \mathrm{Fe}<0.05 & \mathrm{Lu}<0.02 & \mathrm{Pr}<0.02 & \mathrm{Sn}<0.02 & \mathrm{Y} & * \\ \mathrm{Be}<0.02 & \mathrm{Ga}<0.02 & \mathrm{Mg}<0.02 & \mathrm{Pt}<0.02 & \mathrm{Sr}<0.02 & \mathrm{Yb}<0.02 \\ \mathrm{Bi}<0.20 & \mathrm{Gd}<0.05 & \mathrm{Mn}<0.02 & \mathrm{Rb}<0.02 & \mathrm{Ta}<0.05 & \mathrm{Zn}<0.02 \\ \mathrm{Ca}<0.10 & \mathrm{Ge}<0.02 & \mathrm{Mo}<0.02 & \mathrm{Re}<0.02 & \mathrm{~Tb}<0.02 & \mathrm{Zr}<0.02 \\ \mathrm{Cd}<0.02 & \mathrm{Hf}<0.02 & \mathrm{Na}<0.10 & \mathrm{Rh}<0.02 & \mathrm{Te}<0.20 & & \\ \mathrm{Ce}<0.02 & \mathrm{Hg}<0.02 & \mathrm{Nb}<0.05 & \mathrm{Ru}<0.02 & \mathrm{Th}<0.02 & & \\ \mathrm{Co}<0.02 & \mathrm{Ho}<0.02 & \mathrm{Nd}<0.02 & \mathrm{~S}<0.20 & \mathrm{Ti}<0.05 & \end{array}$

Date of release:

10. March 2005

Minimum shelf life: $\quad 31$. March 2008
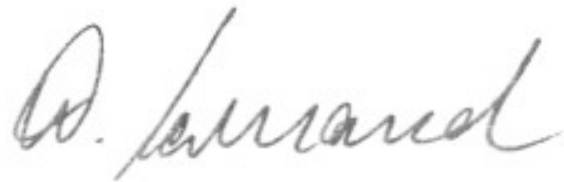


\section{Certificado de Análise}

Número: 7087

Solução Padrăo de Selênio para ICP-AES - $1,000 \mathrm{mg} / \mathrm{g}$

Fabricante: Laboratórios Químicos e Metrológicos Quimlab Ltda

Número de Lote: F507112

Data de Fabricação: 07/2005

Data de Validade: 07/2007

Valor : $1,000 \mathrm{mg} \cdot \mathrm{g}^{-1}+\mathrm{l}-0,003 \mathrm{mg} \cdot \mathrm{g}^{-1}$

Rastreado ao Padrão:

Standard Reference Material 3149 - Selenium

National Institute of Standards and Technology - NIST - USA

Niveis de Contaminantes $(\mu \mathrm{g} / \mathrm{g})$ :

\begin{tabular}{|c|c|cc|}
\hline $\mathrm{Ag}$ & $<0,04$ & $\mathrm{Mg}$ & $<0,02$ \\
\hline $\mathrm{Al}$ & $<0,03$ & $\mathrm{Mn}$ & $<0,02$ \\
\hline $\mathrm{As}$ & $<0,12$ & $\mathrm{Mo}$ & $<0,04$ \\
\hline $\mathrm{B}$ & $<0,05$ & $\mathrm{Nb}$ & $<0,11$ \\
\hline $\mathrm{Ba}$ & $<0,05$ & $\mathrm{Ni}$ & $<0,05$ \\
\hline $\mathrm{Be}$ & $<0,02$ & $\mathrm{P}$ & $<0,15$ \\
\hline $\mathrm{Bi}$ & $<0,08$ & $\mathrm{~Pb}$ & $<0,08$ \\
\hline $\mathrm{Ca}$ & $<0,05$ & $\mathrm{~S}$ & $<0,10$ \\
\hline $\mathrm{Cd}$ & $<0,01$ & $\mathrm{Sb}$ & $<0,32$ \\
\hline $\mathrm{Co}$ & $<0,02$ & $\mathrm{Si}$ & $<0,10$ \\
\hline $\mathrm{Cr}$ & $<0,02$ & $\mathrm{Sn}$ & $<0,30$ \\
\hline $\mathrm{Cs}$ & $<0,01$ & $\mathrm{Te}$ & $<0,34$ \\
\hline $\mathrm{Cu}$ & $<0,02$ & $\mathrm{Ti}$ & $<0,08$ \\
\hline $\mathrm{Hg}$ & $<0,002$ & $\mathrm{~V}$ & $<0,02$ \\
\hline $\mathrm{K}$ & $<0,05$ & $\mathrm{Zn}$ & $<0,01$ \\
\hline $\mathrm{Li}$ & $<0,01$ & $\mathrm{Zr}$ & $<0,03$ \\
\hline
\end{tabular}




\title{
Certificado de Análise
}

\author{
Número: 7427
}

Solução Padrão Multielementar MICPG2 - 100,00 $\mu \mathrm{g} / \mathrm{g}$

Fabricante: Laboratórios Químicos e Metrológicos Quimlab Ltda

Número de Lote: F50973

Data de Fabricação: 09/2005

Data de Validade: 09/2006

Concentrações:

\begin{tabular}{|c|c|c|}
\hline Elemento & Concentração $(\mu \mathrm{g} / \mathrm{g})$ & Incerteza $(\mu \mathrm{g} / \mathrm{g})$ \\
\hline $\mathrm{Al}$ & 100,26 & $+1-0,30$ \\
\hline B & 100,07 & $+1-0,30$ \\
\hline $\mathrm{Ba}$ & 99,98 & $+1-0,30$ \\
\hline $\mathrm{Be}$ & 100,05 & $+1-0,30$ \\
\hline $\mathrm{Bi}$ & 100,16 & $+1-0,30$ \\
\hline $\mathrm{Ca}$ & 100,26 & $+1-0,30$ \\
\hline $\mathrm{Cd}$ & 100,06 & $+1-0,30$ \\
\hline Co & 100,00 & $+1-0,30$ \\
\hline $\mathrm{Cr}$ & 100,17 & $+1-0,30$ \\
\hline $\mathrm{Cu}$ & 10004 & $+1-0,30$ \\
\hline $\mathrm{Fe}$ & 100,21 & $+1-0,30$ \\
\hline $\mathrm{K}$ & 100,43 & $+1-0,30$ \\
\hline $\mathrm{Li}$ & 100,06 & $+1-0,30$ \\
\hline $\mathrm{Mg}$ & 100,45 & $+1-0,30$ \\
\hline $\mathrm{Mn}$ & 100,26 & $+1-0,30$ \\
\hline Mo & 99,97 & $+1-0,30$ \\
\hline $\mathrm{Na}$ & 99,97 & $+1-0,30$ \\
\hline $\mathrm{Ni}$ & 100,19 & $+1-0,30$ \\
\hline $\mathrm{P}$ & 100,01 & $+1-0,30$ \\
\hline $\mathrm{Pb}$ & 100,56 & $+1-0,30$ \\
\hline Sn & 100,34 & $+1-0,30$ \\
\hline $\mathrm{Sr}$ & 99,94 & $+1-0,30$ \\
\hline $\mathrm{Ti}$ & 100,05 & $+1-0,30$ \\
\hline $\mathrm{TI}$ & 100,12 & $+1-0,30$ \\
\hline $\mathrm{V}$ & 100,16 & $+1-0,30$ \\
\hline $\mathrm{Zn}$ & 100,03 & $+1-0,30$ \\
\hline
\end{tabular}




\section{A pêndice D}

Valores padronizados (Tabela D.1) para a distribuição $z$ com probabilidades de valores entre 0 e $z$. estes valores independem do número de amostras [Bevington, 1969].

Tabela D.1 Probabilidades para uma distribuição z com valores entre 0 e z.

\begin{tabular}{|c|c|c|c|c|c|c|c|c|c|c|}
\hline$z$ & 0,00 & 0,01 & 0,02 & 0,03 & 0,04 & 0,05 & 0,06 & 0,07 & 0,08 & 0,09 \\
\hline $\mathbf{0 , 0}$ & 0,0000 & 0,0040 & 0,0080 & 0,0120 & 0,0160 & 0,0199 & 0,0239 & 0,0279 & 0,0319 & 0,0359 \\
\hline 0,1 & 0,0398 & 0,1438 & 0,0478 & 0,0517 & 0,0557 & 0,0596 & 0,0636 & 0,0675 & 0,0714 & 0,0753 \\
\hline 0,2 & 0,0793 & 0,0832 & 0,0871 & 0,0910 & 0,0948 & 0,0987 & 0,1026 & 0,1064 & 0,1103 & 0,1141 \\
\hline 0,3 & 0,1179 & 0,1217 & 0,1255 & 0,1293 & 0,1331 & 0,1368 & 0,1406 & 0,1443 & 0,1480 & 0,1517 \\
\hline 0,4 & 0,1554 & 0,1591 & 0,1628 & 0,1664 & 0,1700 & 0,1736 & 0,1772 & 0,1808 & 0,1844 & 0,1879 \\
\hline 0,5 & 0,1915 & 0,1950 & 0,1985 & 0,2019 & 0,2054 & 0,2088 & 0,2123 & 0,2157 & 0,2190 & 0,2224 \\
\hline 0,6 & 0,2257 & 0,2291 & 0,2324 & 0,2357 & 0,2389 & 0,2422 & 0,2454 & 0,2486 & 0,2517 & 0,2549 \\
\hline $\mathbf{0 , 7}$ & 0,2580 & 0,2611 & 0,2642 & 0,2673 & 0,2704 & 0,2734 & 0,2764 & 0,2794 & 0,2823 & 0,2852 \\
\hline $\mathbf{0 , 8}$ & 0,2881 & 0,2910 & 0,2939 & 0,2967 & 0,2995 & 0,3023 & 0,3051 & 0,3078 & 0,3106 & 0,3133 \\
\hline 0,9 & 0,3159 & 0,3186 & 0,3212 & 0,3238 & 0,3264 & 0,3289 & 0,3315 & 0,3340 & 0,3365 & 0,3389 \\
\hline 1,0 & 0,3413 & 0,3438 & 0,3461 & 0,3485 & 0,3508 & 0,3531 & 0,3554 & 0,3577 & 0,3599 & 0,3621 \\
\hline 1,1 & 0,3643 & 0,3665 & 0,3686 & 0,3708 & 0,3729 & 0,3749 & 0,3770 & 0,3790 & 0,3810 & 0,3830 \\
\hline 1,2 & 0,3849 & 0,3869 & 0,3888 & 0,3907 & 0,3925 & 0,3944 & 0,3962 & 0,3980 & 0,3997 & 0,4015 \\
\hline 1,3 & 0,4032 & 0,4049 & 0,4066 & 0,4082 & 0,4099 & 0,4115 & 0,4131 & 0,4147 & 0,4162 & 0,4177 \\
\hline 1,4 & 0,4192 & 0,4207 & 0,4222 & 0,4236 & 0,4251 & 0,4265 & 0,4279 & 0,4292 & 0,4306 & 0,4319 \\
\hline 1,5 & 0,4332 & 0,4345 & 0,4357 & 0,4370 & 0,4382 & 0,4394 & 0,4406 & 0,4418 & 0,4429 & 0,4441 \\
\hline 1,6 & 0,4452 & 0,4463 & 0,4474 & 0,4484 & 0,4495 & 0,4505 & 0,4515 & 0,4525 & 0,4535 & 0,4545 \\
\hline 1,7 & 0,4554 & 0,4564 & 0,4573 & 0,4582 & 0,4591 & 0,4599 & 0,4608 & 0,4616 & 0,4625 & 0,4633 \\
\hline 1,8 & 0,4641 & 0,4649 & 0,4656 & 0,4664 & 0,4671 & 0,4678 & 0,4686 & 0,4693 & 0,4699 & 0,4706 \\
\hline 1,9 & 0,4713 & 0,4719 & 0,4726 & 0,4732 & 0,4738 & 0,4744 & 0,4750 & 0,4756 & 0,4761 & 0,4767 \\
\hline 2,0 & 0,4772 & 0,4778 & 0,4783 & 0,4788 & 0,4793 & 0,4798 & 0,4803 & 0,4808 & 0,4812 & 0,4817 \\
\hline 2,1 & 0,4821 & 0,4826 & 0,4830 & 0,4834 & 0,4838 & 0,4842 & 0,4846 & 0,4850 & 0,4854 & 0,4857 \\
\hline 2,2 & 0,4861 & 0,4864 & 0,4868 & 0,4871 & 0,4875 & 0,4878 & 0,4881 & 0,4884 & 0,4887 & 0,4890 \\
\hline 2,3 & 0,4893 & 0,4896 & 0,4898 & 0,4901 & 0,4904 & 0,4906 & 0,4909 & 0,4911 & 0,4913 & 0,4916 \\
\hline 2,4 & 0,4918 & 0,4920 & 0,4922 & 0,4925 & 0,4927 & 0,4929 & 0,4931 & 0,4932 & 0,4934 & 0,4936 \\
\hline 2,5 & 0,4938 & 0,4940 & 0,4941 & 0,4943 & 0,4945 & 0,4946 & 0,4948 & 0,4949 & 0,4951 & 0,4952 \\
\hline 2,6 & 0,4953 & 0,4955 & 0,4956 & 0,4957 & 0,4959 & 0,4960 & 0,4961 & 0,4962 & 0,4963 & 0,4964 \\
\hline 2,7 & 0,4965 & 0,4966 & 0,4967 & 0,4968 & 0,4969 & 0,4970 & 0,4971 & 0,4972 & 0,4973 & 0,4974 \\
\hline 2,8 & 0,4974 & 0,4975 & 0,4976 & 0,4977 & 0,4977 & 0,4978 & 0,4979 & 0,4979 & 0,4980 & 0,4981 \\
\hline 2,9 & 0,4981 & 0,4982 & 0,4982 & 0,4983 & 0,4984 & 0,4984 & 0,4985 & 0,4985 & 0,4986 & 0,4986 \\
\hline 3,0 & 0,4987 & 0,4987 & 0,4987 & 0,4988 & 0,4988 & 0,4989 & 0,4989 & 0,4989 & 0,4990 & 0,4990 \\
\hline 3,1 & 0,4990 & 0,4991 & 0,4991 & 0,4991 & 0,4992 & 0,4992 & 0,4992 & 0,4992 & 0,4993 & 0,4993 \\
\hline 3,2 & 0,4993 & 0,4993 & 0,4994 & 0,4994 & 0,4994 & 0,4994 & 0,4994 & 0,4995 & 0,4995 & 0,4995 \\
\hline 3,3 & 0,4995 & 0,4995 & 0,4995 & 0,4996 & 0,4996 & 0,4996 & 0,4996 & 0,4996 & 0,4996 & 0,4997 \\
\hline 3,4 & 0,4997 & 0,4997 & 0,4997 & 0,4997 & 0,4997 & 0,4997 & 0,4997 & 0,4997 & 0,4997 & 0,4998 \\
\hline 3,5 & 0,4998 & & & & & & & & & \\
\hline
\end{tabular}


Apêndice D

\begin{tabular}{ccccccccccc}
\hline$z$ & $\mathbf{0 , 0 0}$ & $\mathbf{0 , 0 1}$ & $\mathbf{0 , 0 2}$ & $\mathbf{0 , 0 3}$ & $\mathbf{0 , 0 4}$ & $\mathbf{0 , 0 5}$ & $\mathbf{0 , 0 6}$ & $\mathbf{0 , 0 7}$ & $\mathbf{0 , 0 8}$ & $\mathbf{0 , 0 9}$ \\
$\mathbf{4 , 0}$ & 0,49997 & & & & & & & & & \\
$\mathbf{4 , 5}$ & 0,499997 & & & & & & & & \\
$\mathbf{5 , 0}$ & 0,4999997 & & & & & & & & & \\
\hline
\end{tabular}




\section{A pêndice $\mathbf{E}$}

A tabela E.1 mostra as concentrações elementares determinadas, com o método ICPMS, para os materiais de referência (ICP04S-06, QMEQAS05S-03 e ICP02S-05) em dois dias diferentes. Os valores finais estabelecidos para cada padrão podem ser vistos na tabela E.2, onde a média e o desvio padrão dos resultados representam o ICP04S-06 e o QMEQAS05S03. No primeiro caso, estes valores foram conseguidos calculando a média das médias dos períodos de máquina, uma das 3 leituras do primeiro dia e a outra das 2 leituras do segundo dia, e fazendo a propagação de erros das duas incertezas. Isto não foi necessário para o segundo padrão, analisado apenas uma vez em cada ciclo de análises. Por outro lado, o único valor obtido para o ICP02S-05 foi acompanhado por uma incerteza estimada, calculada a partir do desvio padrão relativo do material medido mais vezes. Esta estimativa também foi utilizada para obter a incerteza dos dados individuais que compõem a tabela E.1. Apenas os elementos $\mathrm{CU}_{\mathrm{p}}$ e $\mathrm{Zn}_{\mathrm{p}}$ foram determinados pelo método PIXE, os únicos presentes nos materiais acima do limite de detecção desta técnica, e seus valores também podem ser vistos na tabela E.2. Neste caso, as incertezas também foram estimadas a partir de desvio padrão relativo de 5 leituras de uma mesma amostra.

A comparação dos resultados deste trabalho com os valores certificados dos materiais de referência foi realizada com um teste estatístico, o teste z. O resultado, tabela E.3, mostra a qualidade dos dados. 
Tabela E.1 Concentrações elementares dos materiais de referência medidos pelo método ICP-MS.

\begin{tabular}{|c|c|c|c|c|c|c|c|c|}
\hline \multirow{4}{*}{$\begin{array}{c}\text { Padrão } \\
\text { Dia } \\
\text { Be }\end{array}$} & \multicolumn{3}{|c|}{ 04S-06 } & \multicolumn{2}{|c|}{ 04S-05 } & \multirow{4}{*}{$\begin{array}{c}\mathbf{0 5 S}-\mathbf{0 3} \\
\mathbf{1} \\
3,05 \\
(0,25)\end{array}$} & \multirow{4}{*}{$\begin{array}{c}\mathbf{0 5 S - 0 3} \\
\mathbf{2} \\
2,84 \\
(0,23)\end{array}$} & \multirow{4}{*}{$\begin{array}{c}\text { 02S-05 } \\
\mathbf{2} \\
13,0 \\
(1,1)\end{array}$} \\
\hline & \multicolumn{3}{|c|}{1} & \multicolumn{2}{|c|}{2} & & & \\
\hline & 2,29 & 2,68 & 2,25 & 2,49 & 2,98 & & & \\
\hline & $(0,18)$ & $(0,22)$ & $(0,18)$ & $(0,20)$ & $(0,24)$ & & & \\
\hline \multirow[t]{2}{*}{ Al } & 116,1 & 141,4 & 132,5 & 130,0 & 148 & 126,8 & 131,5 & 28,9 \\
\hline & $(7,8)$ & $(9,5)$ & $(8,9)$ & $(8,8)$ & (10) & $(8,6)$ & $(8,9)$ & $(1,9)$ \\
\hline \multirow[t]{2}{*}{ V } & 2,34 & 2,30 & 1,93 & 2,97 & 4,9 & 2,81 & 3,61 & 0,92 \\
\hline & $(0,52)$ & $(0,52)$ & $(0,43)$ & $(0,67)$ & $(1,1)$ & $(0,63)$ & $(0,81)$ & $(0,21)$ \\
\hline $\mathrm{Cr}$ & $\begin{array}{c}2,44 \\
(0,72)\end{array}$ & $5,2(1,5)$ & $\begin{array}{c}1,79 \\
(0,53)\end{array}$ & $\begin{array}{r}2,90 \\
(0,85)\end{array}$ & $\begin{array}{c}3,7 \\
(1,1)\end{array}$ & $\begin{array}{c}4,0 \\
(1,2)\end{array}$ & $\begin{array}{c}4,8 \\
(1,4)\end{array}$ & $\begin{array}{c}0,86 \\
(0,25)\end{array}$ \\
\hline \multirow[t]{2}{*}{ Mn } & 1,94 & 1,93 & 1,48 & 2,07 & 2,47 & 1,81 & 2,17 & 4,54 \\
\hline & $(0,19)$ & $(0,18)$ & $(0,14)$ & $(0,20)$ & $(0,24)$ & $(0,17)$ & $(0,21)$ & $(0,43)$ \\
\hline \multirow[t]{2}{*}{ Co } & 1,737 & 1,824 & 1,629 & 1,947 & 2,048 & 0,703 & 0,792 & 4,81 \\
\hline & $(0,056)$ & $(0,059)$ & $(0,053)$ & $(0,063)$ & $(0,066)$ & $(0,023)$ & $(0,026)$ & $(0,16)$ \\
\hline \multirow[t]{2}{*}{$\mathbf{N i}$} & 31,3 & 25,6 & 30,0 & 41,4 & 47,2 & 4,61 & 5,76 & 6,38 \\
\hline & $(2,2)$ & $(1,8)$ & $(2,1)$ & $(2,9)$ & $(3,3)$ & $(0,32)$ & $(0,40)$ & $(0,44)$ \\
\hline \multirow[t]{2}{*}{$\mathrm{Cu}$} & 2608 & 2750 & 2802 & 3096 & 3051 & 1098 & 1180 & 1806 \\
\hline & (47) & (50) & (51) & (56) & (56) & (20) & (21) & (33) \\
\hline \multirow[t]{2}{*}{$\mathbf{Z n}$} & 1969 & 1882 & 1952 & 2177 & 1979 & 1299 & 1328 & 2187 \\
\hline & (72) & (69) & (72) & (80) & (73) & (48) & (49) & (80) \\
\hline \multirow[t]{2}{*}{ Se } & 287 & 225 & 272 & 266 & 230 & 212 & 125 & 277 \\
\hline & (23) & (18) & (22) & (22) & (19) & (17) & (10) & (22) \\
\hline \multirow[t]{2}{*}{ Mo } & 15,29 & 14,74 & 14,51 & 16,40 & 15,60 & 4,84 & 5,07 & 2,243 \\
\hline & $(0,35)$ & $(0,33)$ & $(0,33)$ & $(0,37)$ & $(0,35)$ & $(0,11)$ & $(0,11)$ & $(0,051)$ \\
\hline \multirow[t]{2}{*}{ Cd } & 1,588 & 1,509 & 1,542 & 1,546 & 1,522 & 6,411 & 6,055 & 0,996 \\
\hline & $(0,022)$ & $(0,021)$ & $(0,022)$ & $(0,022)$ & $(0,021)$ & $(0,090)$ & $(0,085)$ & $(0,014)$ \\
\hline \multirow[t]{2}{*}{ Sn } & 4,03 & 3,81 & 3,87 & 3,75 & 3,28 & 8,00 & 7,36 & 2,87 \\
\hline & $(0,19)$ & $(0,18)$ & $(0,18)$ & $(0,18)$ & $(0,15)$ & $(0,38)$ & $(0,35)$ & $(0,14)$ \\
\hline \multirow[t]{2}{*}{ TI } & 1,869 & 1,940 & 1,878 & 2,045 & 2,066 & 2,490 & 2,626 & 1,288 \\
\hline & $(0,020)$ & $(0,020)$ & $(0,020)$ & $(0,021)$ & $(0,022)$ & $(0,026)$ & $(0,028)$ & $(0,014)$ \\
\hline \multirow[t]{2}{*}{$\mathbf{P b}$} & 21,5 & 30,8 & 29,8 & 22,2 & 22,3 & 171 & 164 & 8,46 \\
\hline & $(2,2)$ & $(3,2)$ & $(3,1)$ & $(2,3)$ & $(2,3)$ & (18) & (17) & $(0,87)$ \\
\hline
\end{tabular}


Tabela E.2 Médias das concentrações elementares dos materiais de referência medidas neste trabalho e suas respectivas incertezas.

\begin{tabular}{|c|c|c|c|}
\hline Elemento & $0^{04 S-06}{ }^{1}$ & $\mathbf{0 5 S}^{-03}{ }^{2}$ & $02 \mathrm{~S}-05^{3}$ \\
\hline $\mathbf{B e}$ & $2,57(0,21)$ & $2,94(0,15)$ & $13,02(0,98)$ \\
\hline Al & $134,6(9,1)$ & $129,1(3,3)$ & $28,9(1,9)$ \\
\hline $\mathbf{V}$ & $3,06(0,69)$ & $3,21(0,57)$ & $0,923(0,066)$ \\
\hline $\mathrm{Cr}$ & $3,22(0,95)$ & $4,38(0,54)$ & $0,86(0,14)$ \\
\hline Mn & $2,03(0,19)$ & $1,99(0,26)$ & $4,54(0,43)$ \\
\hline Co & $1,864(0,060)$ & $0,747(0,062)$ & $4,81(0,15)$ \\
\hline $\mathbf{N i}$ & $36,6(2,5)$ & $5,19(0,81)$ & $6,38(0,42)$ \\
\hline $\mathrm{Cu}$ & $2897(53)$ & $1139(58)$ & 1806 (19) \\
\hline $\mathrm{Cu}_{\mathrm{p}}$ * & 2694 (145) & - & $1780(96)$ \\
\hline $\mathbf{Z n}$ & 2006 (74) & $1314(21)$ & 2187 (47) \\
\hline $\mathbf{Z} \mathbf{n}_{\mathbf{p}} *$ & $2074(504)$ & - & $2072(503)$ \\
\hline $\mathrm{Se}$ & $255(21)$ & $168(62)$ & $277(22)$ \\
\hline Mo & $15,42(0,35)$ & $4,96(0,16)$ & $2,243(0,048)$ \\
\hline Cd & $1,540(0,022)$ & $6,23(0,25)$ & $0,996(0,010)$ \\
\hline Sn & $3,71(0,18)$ & $7,68(0,45)$ & $2,873(0,084)$ \\
\hline Tl & $1,976(0,021)$ & $2,558(0,097)$ & $1,288(0,009)$ \\
\hline $\mathbf{P b}$ & $24,8(2,5)$ & $167,4(5,1)$ & $8,457(0,031)$ \\
\hline
\end{tabular}

${ }^{1}$ Média ponderada (desvio padrão ponderado). $\quad{ }^{2}$ Média (desvio padrão). $\quad{ }^{3}$ Valor medido (incerteza relativa) * Apenas estes dois elementos, $\mathrm{Cu}_{\mathrm{p}}$ e $\mathrm{Zn}_{\mathrm{p}}$, foram medidos pelo PIXE, uma vez que os outros estão em concentrações abaixo do limite de detecção desta técnica.

Tabela E.3 Comparação dos valores medidos com os certificados dos materiais de referência usando o teste $\mathrm{z}$.

\begin{tabular}{cccccc}
\hline Elemento & $\mathbf{0 4 S - 0 6}$ & $\begin{array}{c}\text { ICP-MS } \\
\mathbf{0 5 S - 0 3}\end{array}$ & $\mathbf{0 2 S - 0 5}$ & $\mathbf{0 4 S - 0 6}$ & $\mathbf{0 5 S - 0 3}$ \\
$\mathbf{B e}$ & 0,18 & $-0,47$ & $-2,2$ & & \\
$\mathbf{A l}$ & 0,35 & 0,45 & $-0,59$ & & \\
$\mathbf{~}$ & 0,20 & $-0,18$ & $-0,47$ & & \\
$\mathbf{C r}$ & 0,76 & 0,10 & 0,14 & & \\
$\mathbf{M n}$ & $-0,13$ & $-0,58$ & 0,74 & & \\
$\mathbf{C o}$ & $-0,17$ & $-0,74$ & 0,26 & & \\
$\mathbf{N i}$ & 2,4 & 0,97 & 1,6 & & \\
$\mathbf{C u}$ & 1,9 & 0,35 & 1,5 & $-0,034$ & 1,1 \\
$\mathbf{Z n}$ & 1,7 & 1,0 & 0,71 & 0,53 & 0,11 \\
$\mathbf{S e}$ & 0,85 & 0,45 & 1,2 & & \\
$\mathbf{M o}$ & 0,20 & 0,35 & 0,13 & & \\
$\mathbf{C d}$ & $-0,40$ & $-0,067$ & $-0,013$ & & \\
$\mathbf{S n}$ & 4,2 & 0,43 & $-0,33$ & & \\
$\mathbf{T l}$ & $-0,30$ & 0,96 & 0,88 & & \\
$\mathbf{P b}$ & 3,1 & $-1,3$ & $-3,1$ & & \\
\hline
\end{tabular}




\section{A pêndice $F$}

A coleta das amostras só foi realizada pós certos cuidados estabelecidos pelo Comitê de Ética em Pesquisa do Hospital Universitário da USP de São Paulo. Por isso, cada doador assinou uma carta de consentimento autorizando a doação do sangue e respondeu um questionário sobre o próprio estado de saúde, mostrados a seguir. 


\section{TERMO DE CONSENTIMENTO LIVRE E ESCLARECIDO}

\section{Registro das explicações do pesquisador ao participante a respeito da pesquisa.}

Prezado(a) Senhor(a):

Eu, Manfredo Harri Tabacniks, Físico, Professor Doutor do Instituto de Física da Universidade de São Paulo, RG 6. 125.955, quero convidá-lo (la) para participar de um estudo acadêmico que deverá resultar no desenvolvimento de um método para dosagem de pequenas quantidades de metais em sangue.

É necessário que o senhor(a) compreenda que este estudo destina-se á;

1. Desenvolver novas maneiras de medir pequenas quantidades de metal que todos nós possuímos no sangue.

2. Desejamos colher $35 \mathrm{ml}$ de sangue após um período de jejum, para realizar as dosagens de metais. A coleta será feita por um técnico especializado e os eventuais desconfortos que podem ocorrer são a dor da punção e um eventual arroxeamento abaixo da pele junto à punção.

3. Você está sendo convidado(a), e sua participação é voluntária. Você não terá qualquer benefício em participar na pesquisa. Os dados da pesquisa são importantes na geração de conhecimentos que beneficiarão o desenvolvimento de novos tratamentos e métodos de diagnóstico, no futuro;

4. O sangue coletado será usado exclusivamente nesta pesquisa. Os dados gerados na análise dos metais no sangue serão transformados em trabalhos científicos que poderão ser apresentados em congressos ou publicados em revistas especializadas. O sigilo de sua identidade será mantido.

Este documento, em duas vias, ficará uma em poder do Comitê de Ética em Pesquisa do Hospital Universitário de São Paulo (CEP-HU) e outra comigo para garantir as condições citadas acima. Caso decida colaborar no estudo, necessito da sua assinatura. Estou à disposição para quaisquer esclarecimentos adicionais. Agradeço a sua atenção e colaboração e disponibilizo abaixo os endereços e telefones para contato:

Prof. Manfredo Harri Tabacniks

Endereço: Rua do Matão, Travessa R No. 187 - CEP 05508-090 - São Paulo/SP

Telefone: (11) 30916861 - Instituto de Física - E-mail: manfredo@if.usp.br

Comitê de Ética em Pesquisa do Hospital Universitário de São Paulo (CEP-HU)

Endereço: Av. Prof. Lineu Prestes, 2565 - Cidade Universitária

CEP 05508-900 - São Paulo/SP - Telefones: 3039-9457 ou 3039-9479 - E-mail: cep@ hu.usp.br.

\section{CONSENTIMENTO PÓS-INFORMADO.}

Compreendo os objetivos da pesquisa, o que é esperado de mim e concordo em participar de forma voluntária da mesma.

Entendo que as informações serão confidenciais, não haverá identificação nominal, a não ser que eu deseje e que não sofrerei nenhum tipo de sanção ou prejuízo, caso desista de participar desta pesquisa.

Considero que todas as informações foram prestadas pela pesquisadora e que fui convidado para participar deste estudo.

Declaro que, após convenientemente esclarecido pelo pesquisador e ter entendido o que me foi explicado, consinto em participar do presente Projeto de Pesquisa.

São Paulo, de de 200 . 


\section{HISTÓRICO DA SAÚDE}

Dados do sujeito de pesquisa

\begin{tabular}{l|l|l}
\hline Nome & N. de registro \\
\hline Função & Unidade de serviço & Identificação \\
\hline Data e nascimento & Sexo & Cor \\
\hline Naturalidade & Estado civil & \\
\hline Endereço & Fone \\
\hline Endereço de parente & Fone \\
\hline \multicolumn{2}{l|}{} &
\end{tabular}

E últimas funções exercidas e o maior tempo de serviço

\begin{tabular}{l|c|c|l|l|l} 
Histórico da família - Pais e Avos Maternos e/ou Paternos \\
\hline \multicolumn{1}{c|}{ Algum parente contraiu } & Sim & Grau de parentesco & \multicolumn{1}{|c|}{ Algum parente contraiu } & Sim & Grau de parentesco \\
\hline Câncer & & & Doença renal & & \\
\hline Diabete & & & Epilepsia & & \\
\hline Doença cardíaca & & Lepra & & \\
Doença digestiva & Sífilis & & \\
Doença mental & & Tuberculose & & \\
\hline & & Hiper. arterial (pressão alta) & & \\
\cline { 2 - 5 }
\end{tabular}

Histórico do funcionário

\begin{tabular}{|c|c|c|c|c|c|c|c|}
\hline Marcar itens que contraiu & Sim & não & desconhece & Marcar os itens que contraiu & $\operatorname{sim}$ & não & desconhece \\
\hline Catapora (Varicela & & & & Câimbra (pernas/pés) & & & \\
\hline Caxumba & & & & Bócio (papo) & & & \\
\hline Coqueluche (Tosse comprida) & & & & Claustrofobia (medo de locais fechados) & & & \\
\hline Difteria (Crupe) & & & & Diabete & & & \\
\hline Escarlatina & & & & Doença cardíaca & & & \\
\hline Paralisia infantil & & & & Doença de fígado & & & \\
\hline Rubéola & & & & Doença de pele & & & \\
\hline Sarampo & & & & Doença de rins/pedras & & & \\
\hline Artrite/Febre reumática & & & & Doença do estômago & & & \\
\hline Deformidade óssea/articular & & & & Doença nervosa & & & \\
\hline Dor de coluna & & & & Doença venérea & & & \\
\hline Dor nas juntas & & & & Dor de cabeça freqüente/Enxaqueca & & & \\
\hline Perda de braço/perna/pés & & & & Dor de dente/gengiva & & & \\
\hline Dificuldade de urinar & & & & Dor de garganta & & & \\
\hline Urina várias vezes à noite/Micção noturna & & & & Dor de ouvido & & & \\
\hline Evacua normalmente & & & & Dor no peito & & & \\
\hline Afta/Sapinho/Estomatite & & & & Hérnia & & & \\
\hline Alergia & & & & Meningite & & & \\
\hline Amnésia (perda de memória) & & & & Pneumonia & & & \\
\hline Asma/Bronquite & & & & Sinusite & & & \\
\hline Ataque Epilético & & & & Varizes & & & \\
\hline
\end{tabular}

Hiper. arterial (pressão alta)

\section{Somente para mulheres}

Responda cada item

Tipo de parto

Quantas vezes ficou grávida

Idade em que terminou a menstruação
Responda cada item

Sofreu aborto

Método anticoncepcional usado

\section{Hábitos}

\begin{tabular}{l|c|c|c|c}
\hline \multicolumn{1}{c|}{ Marcar cada item } & sim & não & que quantidade & com que freqüência \\
\hline Fuma (cigarro/charuto, etc.) & & & & \\
\hline Bebidas alcoólicas & & & & \\
\hline Faz uso de medicamentos & & & & \\
\hline Pratica esporte (qual modalidade) & & & & \\
\hline
\end{tabular}

\section{Informações complementares}

\begin{tabular}{l|c|c|c|c}
\hline \multicolumn{1}{c|}{ Marcar cada item } & sim & não & \multicolumn{1}{c|}{ qual } & quando \\
\hline Submeteu-se a alguma cirurgia & & & & \\
\hline Sofreu algum acidente & & & & \\
\hline Teve alguma doença além das anotadas & & & & \\
\hline Tratou-se sem orientação médica & & & & \\
\hline
\end{tabular}

\section{Declaração sobre o atual estado de saúde, com as próprias palavras}




\section{A pêndice G}

Concentrações elementares medidas pelos métodos PIXE (Tabela G.1) e ICP-MS (Tabelas G.2 e G.3) de cada doador individualmente. As tabelas também mostram as concentrações das duplicatas. As incertezas relativas podem ser vistas entre parênteses.

Tabela G.1 Concentrações elementares medidas pelo método PIXE. A letra D representa os doadores.

\begin{tabular}{cccccccccc}
\hline $\mathbf{D}$ & $\mathbf{P}$ & $\mathbf{S}$ & $\mathbf{C l}$ & $\mathbf{K}$ & $\mathbf{C a}$ & $\mathbf{F e}$ & $\mathbf{C u}$ & $\mathbf{Z n}$ & $\mathbf{B r}$ \\
& $\left(\mathbf{x 1 0}^{\mathbf{3}}\right)$ & $\left(\mathbf{x 1 0}^{\mathbf{3}}\right)$ & $\left(\mathbf{x 1 0}^{\mathbf{6}}\right)$ & $\left(\mathbf{x 1 0}^{\mathbf{3}}\right)$ & $\left(\mathbf{x 1 0}^{\mathbf{3}}\right)$ & $\left(\mathbf{x 1 0}^{\mathbf{3}}\right)$ & $\left(\mathbf{x 1 0}^{\mathbf{3}}\right)$ & $\left(\mathbf{x 1 0}^{\mathbf{3}}\right)$ & $(\mathbf{x 1 0})$ \\
\hline $\mathbf{1}$ & 126 & 1326 & 4,74 & 256 & 154,4 & 1,92 & 1,96 & 0,95 & 16,9 \\
& $(11)$ & $(64)$ & $(0,18)$ & $(11)$ & $(8,0)$ & $(0,48)$ & $(0,47)$ & $(0,24)$ & $(2,7)$ \\
$\mathbf{2}$ & 93,7 & 1308 & 4,87 & 281 & 154,8 & 1,12 & 0,91 & 0,74 & 5,87 \\
& $(8,4)$ & $(63)$ & $(0,18)$ & $(12)$ & $(8,0)$ & $(0,28)$ & $(0,22)$ & $(0,18)$ & $(0,94)$ \\
$\mathbf{3}$ & 128 & 1368 & 5,16 & 261 & 167,2 & 2,05 & 1,84 & 2,01 & 8,6 \\
& $(12)$ & $(66)$ & $(0,19)$ & $(11)$ & $(8,7)$ & $(0,51)$ & $(0,44)$ & $(0,50)$ & $(1,4)$ \\
$\mathbf{4}$ & 112 & 1343 & 5,22 & 129 & 156,1 & 1,26 & 1,38 & 0,87 & 8,2 \\
& $(10)$ & $(64)$ & $(0,19)$ & $(12)$ & $(8,1)$ & $(0,32)$ & $(0,33)$ & $(0,22)$ & $(1,3)$ \\
$\mathbf{5}$ & 82,6 & 1599 & 5,58 & 187 & 172,2 & 1,90 & 0,56 & 1,10 & 6,1 \\
& $(7,4)$ & $(77)$ & $(0,21)$ & $(12)$ & $(9,0)$ & $(0,48)$ & $(0,13)$ & $(0,28)$ & $(1,0)$ \\
$\mathbf{6}$ & 102,6 & 1389 & 5,06 & 248 & 160,4 & 2,32 & 0,99 & 0,86 & 7,9 \\
& $(9,2)$ & $(67)$ & $(0,19)$ & $(10)$ & $(8,3)$ & $(0,58)$ & $(0,24)$ & $(0,22)$ & $(1,3)$ \\
$\mathbf{7}$ & 95,6 & 1599 & 5,34 & 289 & 158,9 & 1,2 & 0,73 & 1,10 & 9,8 \\
& $(8,6)$ & $(77)$ & $(0,20)$ & $(12)$ & $(8,3)$ & $(0,30)$ & $(0,17)$ & $(0,27)$ & $(1,6)$ \\
$\mathbf{8}$ & 80,2 & 1548 & 5,38 & 300 & 167,7 & 2,06 & 0,92 & 0,90 & 12,0 \\
& $(7,2)$ & $(74)$ & $(0,20)$ & $(13)$ & $(8,7)$ & $(0,51)$ & $(0,22)$ & $(0,22)$ & $(1,9)$ \\
$\mathbf{9}$ & 78,5 & 1264 & 4,38 & 239 & 140,2 & 1,88 & 1,15 & 1,22 & 10,5 \\
& $(7,1)$ & $(61)$ & $(0,16)$ & $(10)$ & $(7,3)$ & $(0,47)$ & $(0,28)$ & $(0,31)$ & $(1,7)$ \\
$\mathbf{1 0}$ & 101,2 & 1468 & 5,19 & 283 & 156,2 & 1,64 & 0,78 & 0,74 & 12,6 \\
& $(9,1)$ & $(70)$ & $(0,19)$ & $(12)$ & $(8,1)$ & $(0,41)$ & $(0,19)$ & $(0,18)$ & $(2,0)$ \\
$\mathbf{1 1}$ & 94,5 & 1582 & 5,83 & 292 & 171,8 & 2,35 & 0,75 & 0,89 & 14,7 \\
& $(8,5)$ & $(76)$ & $(0,22)$ & $(12)$ & $(8,9)$ & $(0,59)$ & $(0,18)$ & $(0,22)$ & $(2,4)$ \\
$\mathbf{1 2}$ & 74,5 & 1190 & 4,58 & 219,3 & 131,0 & 1,39 & 0,89 & 0,64 & 14,5 \\
& $(6,7)$ & $(57)$ & $(0,17)$ & $(9,2)$ & $(6,8)$ & $(0,35)$ & $(0,21)$ & $(0,16)$ & $(2,3)$ \\
$\mathbf{1 3}$ & 145 & 1459 & 5,25 & 293 & 174,7 & 1,41 & 1,89 & 0,93 & 18,0 \\
& $(13)$ & $(70)$ & $(0,19)$ & $(12)$ & $(9,1)$ & $(0,35)$ & $(0,45)$ & $(0,23)$ & $(2,9)$ \\
$\mathbf{1 4}$ & 103,5 & 1225 & 4,84 & 257 & 144,2 & 1,39 & 1,64 & 0,79 & 13,3 \\
& $(9,3)$ & $(59)$ & $(0,18)$ & $(11)$ & $(7,5)$ & $(0,35)$ & $(0,39)$ & $(0,20)$ & $(2,1)$ \\
& & & & & & & & & \\
\hline & & & & & & & & &
\end{tabular}




\begin{tabular}{|c|c|c|c|c|c|c|c|c|c|}
\hline D & $\begin{array}{c}\mathbf{P} \\
\left(\mathbf{x 1 0 ^ { 3 }}\right)\end{array}$ & $\begin{array}{c}S \\
\left(\times 10^{3}\right)\end{array}$ & $\begin{array}{c}\mathrm{Cl} \\
\left(\mathrm{x}^{6} 0^{6}\right)\end{array}$ & $\underset{\left(\mathbf{x 1 0 ^ { 3 }}\right)}{\mathbf{K}}$ & $\begin{array}{c}\mathbf{C a} \\
\left(\mathbf{x 1 0 ^ { 3 }}\right)\end{array}$ & $\begin{array}{c}\mathbf{F e} \\
\left(\mathbf{x 1 0 ^ { 3 }}\right)\end{array}$ & $\begin{array}{c}\mathrm{Cu} \\
\left(\mathbf{x 1 0}^{3}\right)\end{array}$ & $\begin{array}{c}\mathbf{Z n} \\
\left(\mathbf{x} 10^{3}\right)\end{array}$ & $\begin{array}{c}\mathbf{B r} \\
\left(\mathbf{x 1 0}^{3}\right)\end{array}$ \\
\hline 15 & 86,7 & 1230 & 4,17 & 223,9 & 139,3 & 1,85 & 0,95 & 0,99 & 12,1 \\
\hline & $(7,8)$ & (59) & $(0,15)$ & $(9,4)$ & $(7,2)$ & $(0,46)$ & $(0,23)$ & $(0,25)$ & $(1,9)$ \\
\hline 16 & 93,0 & 1569 & 5,13 & 227 & 171,5 & 1,91 & 1,11 & 1,32 & 8,2 \\
\hline & $(8,4)$ & (75) & $(0,19)$ & (12) & $(8,9)$ & $(0,48)$ & $(0,27)$ & $(0,33)$ & $(1,3)$ \\
\hline 17 & 81,1 & 1385 & 4,78 & 278 & 157,6 & 2,66 & 0,72 & 1,23 & 4,23 \\
\hline 18 & $\begin{array}{l}(7,3) \\
76,7\end{array}$ & $\begin{array}{c}(66) \\
1372\end{array}$ & $\begin{array}{r}(0,18) \\
4,55\end{array}$ & $\begin{array}{l}(12) \\
275\end{array}$ & $\begin{array}{c}(8,2) \\
157,7\end{array}$ & $\begin{array}{c}(0,66) \\
1,75\end{array}$ & $\begin{array}{c}(0,17) \\
0,86\end{array}$ & $\begin{array}{c}(0,31) \\
0,92\end{array}$ & $\begin{array}{c}(0,68) \\
5,13\end{array}$ \\
\hline 19 & $\begin{array}{c}(6,9) \\
101,2\end{array}$ & $\begin{array}{l}(66) \\
1468\end{array}$ & $\begin{array}{l}(0,17) \\
5,19\end{array}$ & $\begin{array}{l}(12) \\
283\end{array}$ & $\begin{array}{c}(8,2) \\
156,2\end{array}$ & $\begin{array}{c}(0,86) \\
1,93\end{array}$ & $\begin{array}{c}(0,21) \\
1,14\end{array}$ & $\begin{array}{c}(0,23) \\
0,77\end{array}$ & $\begin{array}{c}(0,82) \\
8,7\end{array}$ \\
\hline 20 & $\begin{array}{l}(9,1) \\
98,6\end{array}$ & $\begin{array}{l}(70) \\
1580\end{array}$ & $\begin{array}{r}(0,19) \\
5,44\end{array}$ & $\begin{array}{l}(12) \\
282\end{array}$ & $\begin{array}{c}(8,1) \\
173,6\end{array}$ & $\begin{array}{c}(0,48) \\
2,31\end{array}$ & $\begin{array}{c}(0,27) \\
0,54\end{array}$ & $\begin{array}{c}(0,19) \\
1,12\end{array}$ & $\begin{array}{l}(1,4) \\
5,39\end{array}$ \\
\hline 21 & $\begin{array}{l}(8,9) \\
85,4\end{array}$ & $\begin{array}{c}(76) \\
1369\end{array}$ & $\begin{array}{r}(0,20) \\
4,81\end{array}$ & $\begin{array}{l}(12) \\
256\end{array}$ & $\begin{array}{c}(9,0) \\
158,7\end{array}$ & $\begin{array}{c}(0,58) \\
1,95\end{array}$ & $\begin{array}{c}(0,13) \\
1,05\end{array}$ & $\begin{array}{c}(0,28) \\
0,74\end{array}$ & $\begin{array}{c}(0,86) \\
7,8\end{array}$ \\
\hline 22 & $\begin{array}{l}(7,7) \\
58,3\end{array}$ & $\begin{array}{l}(66) \\
1151\end{array}$ & $\begin{array}{r}(0,18) \\
4,12\end{array}$ & $\begin{array}{c}(11) \\
225,0\end{array}$ & $\begin{array}{c}(8,3) \\
137,9\end{array}$ & $\begin{array}{r}(0,49) \\
1,52\end{array}$ & $\begin{array}{c}(0,25) \\
0,95\end{array}$ & $\begin{array}{c}(0,19) \\
0,95\end{array}$ & $\begin{array}{c}(1,2) \\
6,8\end{array}$ \\
\hline 23 & $\begin{array}{l}(5,3) \\
74,0\end{array}$ & $\begin{array}{l}(55) \\
1337\end{array}$ & $\begin{array}{r}(0,15) \\
4,94\end{array}$ & $\begin{array}{l}(9,5) \\
258\end{array}$ & $\begin{array}{c}(7,2) \\
155,3\end{array}$ & $\begin{array}{c}(0,28) \\
2,47\end{array}$ & $\begin{array}{c}(0,23) \\
1,02\end{array}$ & $\begin{array}{c}(0,24) \\
0,87\end{array}$ & $\begin{array}{c}(1,1) \\
9,8\end{array}$ \\
\hline 24 & $\begin{array}{l}(6,7) \\
117\end{array}$ & $\begin{array}{l}(64) \\
1202\end{array}$ & $\begin{array}{r}(0,18) \\
4,63\end{array}$ & $\begin{array}{l}\text { (11) } \\
227\end{array}$ & $\begin{array}{c}(8,1) \\
147,0\end{array}$ & $\begin{array}{c}(0,62) \\
5,3\end{array}$ & $\begin{array}{c}(0,25) \\
1,95\end{array}$ & $\begin{array}{c}(0,22) \\
0,79\end{array}$ & $\begin{array}{l}(1,6) \\
12,2\end{array}$ \\
\hline 25 & $\begin{array}{l}(11) \\
87,9\end{array}$ & $\begin{array}{l}(58) \\
1321\end{array}$ & $\begin{array}{r}(0,17) \\
4,53\end{array}$ & $\begin{array}{l}(10) \\
248\end{array}$ & $\begin{array}{c}(7,6) \\
152,9\end{array}$ & $\begin{array}{l}(1,3) \\
2,99\end{array}$ & $\begin{array}{c}(0,47) \\
0,64\end{array}$ & $\begin{array}{c}(0,20) \\
0,95\end{array}$ & $\begin{array}{l}(2,0) \\
11,1\end{array}$ \\
\hline 26 & $\begin{array}{l}(7,9) \\
108\end{array}$ & $\begin{array}{c}(63) \\
1698\end{array}$ & $\begin{array}{r}(0,17) \\
5,45\end{array}$ & $\begin{array}{l}\text { (10) } \\
306\end{array}$ & $\begin{array}{c}(8,0) \\
186,7\end{array}$ & $\begin{array}{c}(0,75) \\
2,44\end{array}$ & $\begin{array}{c}(0,15) \\
1,17\end{array}$ & $\begin{array}{c}(0,24) \\
1,03\end{array}$ & $\begin{array}{l}(1,8) \\
9,6\end{array}$ \\
\hline 27 & $\begin{array}{l}(10) \\
80,1\end{array}$ & $\begin{array}{l}(82) \\
1412\end{array}$ & $\begin{array}{r}(0,20) \\
4,59\end{array}$ & $\begin{array}{l}\text { (13) } \\
262\end{array}$ & $\begin{array}{c}(9,7) \\
163,1\end{array}$ & $\begin{array}{c}(0,61) \\
4,0\end{array}$ & $\begin{array}{c}(0,28) \\
0,98\end{array}$ & $\begin{array}{c}(0,26) \\
1,05\end{array}$ & $\begin{array}{l}(1,5) \\
9,4\end{array}$ \\
\hline 28 & $\begin{array}{l}107 \\
(10)\end{array}$ & $\begin{array}{c}1391 \\
(67)\end{array}$ & $\begin{array}{r}4,88 \\
(0,18)\end{array}$ & 274 & 159,9 & 5,7 & 1,07 & 0,87 & 15,3 \\
\hline 29 & 68,7 & 1274 & 4,31 & 257 & 148,9 & 2,78 & 0,98 & 0,83 & 13,4 \\
\hline 30 & $\begin{array}{l}(6,2) \\
72,2 \\
(6,5)\end{array}$ & $\begin{array}{c}(61) \\
1175 \\
(56)\end{array}$ & $\begin{array}{r}(0,16) \\
4,29 \\
(0,16)\end{array}$ & $\begin{array}{l}(11) \\
248 \\
(10)\end{array}$ & $\begin{array}{c}(7,7) \\
135,3 \\
(7,0)\end{array}$ & $\begin{array}{c}(0,69) \\
2,66 \\
(0,66)\end{array}$ & $\begin{array}{c}(0,24) \\
1,02 \\
(0,25)\end{array}$ & $\begin{array}{c}(0,21) \\
1,00 \\
(0,25)\end{array}$ & $\begin{array}{l}(2,1) \\
10,3 \\
(1,6)\end{array}$ \\
\hline
\end{tabular}


Tabela G.2 Concentrações elementares medidas pelo método ICP-MS. A letra D representa os doadores.

\begin{tabular}{|c|c|c|c|c|c|c|c|}
\hline D & $\begin{array}{c}\text { Be } \\
\left(\mathbf{x 1 0 ^ { - 3 }}\right)\end{array}$ & Al & $\mathbf{V}$ & $\mathrm{Cr}$ & Mn & $\begin{array}{c}\text { Co } \\
\left(\mathbf{x 1 0}^{-3}\right)\end{array}$ & $\mathbf{N i}$ \\
\hline 1 & 83,5 & - & 0,099 & 0,182 & 1,16 & 370 & 2,70 \\
\hline & $(6,8)$ & & $(0,022)$ & $(0,053)$ & $(0,12)$ & (11) & $(0,19)$ \\
\hline $2 \mathbf{a}$ & 83,1 & 4,57 & 0,102 & 0,35 & 1,08 & 309,8 & 3,09 \\
\hline & $(6,7)$ & $(0,31)$ & $(0,022)$ & $(0,010)$ & $(0,11)$ & $\begin{array}{l}(9,9) \\
1650\end{array}$ & $(0,21)$ \\
\hline $2 \mathrm{~b}$ & 13,0 & - & 0,050 & 0,140 & 0,694 & 165,0 & 4,29 \\
\hline 2c & $\begin{array}{c}(1,1) \\
-\end{array}$ & - & $\begin{array}{c}(0,011) \\
0,058\end{array}$ & $\begin{array}{c}(0,041) \\
0,085\end{array}$ & $\begin{array}{c}(0,069) \\
0,686\end{array}$ & $\begin{array}{c}(5,3) \\
222,8\end{array}$ & $\begin{array}{c}(0,30) \\
2,06\end{array}$ \\
\hline 3 & - & 0,385 & $\begin{array}{c}(0,013) \\
0,118\end{array}$ & $\begin{array}{c}(0,025) \\
0,070\end{array}$ & $\begin{array}{c}(0,069) \\
1,48\end{array}$ & $\begin{array}{c}(7,1) \\
273,7\end{array}$ & $\begin{array}{r}(0,14) \\
2,52\end{array}$ \\
\hline & & $(0,026)$ & $(0,026)$ & $(0,020)$ & $(0,015)$ & $(8,8)$ & $(0,17)$ \\
\hline 4 & 16,1 & - & 0,0343 & 0,257 & 1,05 & 236,1 & 3,49 \\
\hline 5 & $\begin{array}{l}(1,3) \\
12,1\end{array}$ & 1,222 & $\begin{array}{c}(0,0076) \\
0,051\end{array}$ & $\begin{array}{l}(0,075) \\
0,0179\end{array}$ & $\begin{array}{l}(0,10) \\
0,526\end{array}$ & $\begin{array}{c}(7,6) \\
206,3\end{array}$ & $\begin{array}{r}(0,24) \\
1,97\end{array}$ \\
\hline 6 & $\begin{array}{c}(1,0) \\
-\end{array}$ & $\begin{array}{c}(0,083) \\
0,272\end{array}$ & $\begin{array}{c}(0,011) \\
0,067\end{array}$ & $\begin{array}{c}(0,0052) \\
0,44\end{array}$ & $\begin{array}{c}(0,053) \\
1,31\end{array}$ & $\begin{array}{c}(6,6) \\
214,6\end{array}$ & $\begin{array}{c}(0,14) \\
2,63\end{array}$ \\
\hline & & $(0,018)$ & $(0,015)$ & $(0,13)$ & $(0,13)$ & $(6,9)$ & $(0,18)$ \\
\hline 7 & - & 17,2 & 0,048 & 0,225 & 0,687 & 634 & 2,92 \\
\hline 8 & - & $\begin{array}{l}(1,2) \\
2,52\end{array}$ & $\begin{array}{l}(0,011) \\
0,0371\end{array}$ & $\begin{array}{c}(0,065) \\
0,079\end{array}$ & $\begin{array}{c}(0,069) \\
0,917\end{array}$ & $\begin{array}{c}(20) \\
259,6\end{array}$ & $\begin{array}{c}(0,20) \\
2,55\end{array}$ \\
\hline 9 & - & $\begin{array}{c}(0,17) \\
3,14\end{array}$ & $\begin{array}{r}(0,0082) \\
0,0342\end{array}$ & $\begin{array}{c}(0,023) \\
0,259\end{array}$ & $\begin{array}{c}(0,092) \\
0,844\end{array}$ & $\begin{array}{c}(8,3) \\
211,6\end{array}$ & $\begin{array}{c}(0,18) \\
2,92\end{array}$ \\
\hline & & $(0,21)$ & $(0,0075)$ & $(0,075)$ & $(0,084)$ & $(6,8)$ & $(0,20)$ \\
\hline 10 & - & - & $\begin{array}{c}0,051 \\
(0,011)\end{array}$ & $\begin{array}{l}0,169 \\
(0,049)\end{array}$ & $\begin{array}{c}0,721 \\
(0,072)\end{array}$ & $\begin{array}{c}224,1 \\
(7,2)\end{array}$ & $\begin{array}{c}2,79 \\
(0,19)\end{array}$ \\
\hline 11a & - & - & $\begin{array}{c}0,074 \\
(0,016)\end{array}$ & $\begin{array}{c}0,0136 \\
(0,0039)\end{array}$ & $\begin{array}{c}0,460 \\
(0,046)\end{array}$ & $\begin{array}{c}189,4 \\
(6,1)\end{array}$ & $\begin{array}{c}2,34 \\
(0,16)\end{array}$ \\
\hline $11 b$ & - & - & $\begin{array}{l}0,0364 \\
(0,0080)\end{array}$ & $\begin{array}{c}0,035 \\
(0,010)\end{array}$ & $\begin{array}{l}0,559 \\
(0,056)\end{array}$ & $\begin{array}{c}173,8 \\
(5,6)\end{array}$ & $\begin{array}{c}2,02 \\
(0,14)\end{array}$ \\
\hline $12 a$ & - & 0,793 & 0,045 & 0,115 & 0,517 & 197,2 & 1,89 \\
\hline $12 b$ & $\begin{array}{l}83,5 \\
(6,8)\end{array}$ & - & $\begin{array}{c}0,162 \\
(0,036)\end{array}$ & $\begin{array}{c}0,42 \\
(0,12)\end{array}$ & $\begin{array}{c}1,17 \\
(0,12)\end{array}$ & $\begin{array}{c}(102,3) \\
(9,7)\end{array}$ & $\begin{array}{c}2,85 \\
(0,20)\end{array}$ \\
\hline 13 & $\begin{array}{l}9,04 \\
(0,73)\end{array}$ & - & $\begin{array}{l}0,0345 \\
(0,0076)\end{array}$ & $\begin{array}{c}0,038 \\
(0,011)\end{array}$ & $\begin{array}{l}0,623 \\
(0,062)\end{array}$ & $\begin{array}{c}252,0 \\
(8,1)\end{array}$ & $\begin{array}{c}2,28 \\
(0,16)\end{array}$ \\
\hline 14 & - & $\begin{array}{c}9,30 \\
(0,63)\end{array}$ & $\begin{array}{l}0,0315 \\
(0,0069)\end{array}$ & $\begin{array}{l}0,160 \\
(0,046)\end{array}$ & $\begin{array}{l}0,840 \\
(0,084)\end{array}$ & $\begin{array}{c}222,4 \\
(7,1)\end{array}$ & $\begin{array}{l}2,50 \\
(0,17)\end{array}$ \\
\hline 15 & - & - & $\begin{array}{c}0,049 \\
(0,011)\end{array}$ & $\begin{array}{c}0,0190 \\
(0,0055)\end{array}$ & $\begin{array}{c}0,660 \\
(0,066)\end{array}$ & $\begin{array}{c}242,5 \\
(7,8)\end{array}$ & $\begin{array}{c}2,58 \\
(0,18)\end{array}$ \\
\hline 16 & - & - & $\begin{array}{c}0,0292 \\
(0,0064)\end{array}$ & $\begin{array}{c}0,076 \\
(0,022)\end{array}$ & $\begin{array}{l}0,670 \\
(0,067)\end{array}$ & $\begin{array}{c}215,2 \\
(6,9)\end{array}$ & $\begin{array}{c}3,70 \\
(0,26)\end{array}$ \\
\hline $17 a$ & 2,03 & 2,80 & 0,0244 & 0,0246 & 0,591 & 261,1 & 2,71 \\
\hline $17 b$ & $\begin{array}{c}(0,16) \\
84,5\end{array}$ & $\begin{array}{c}(0,19) \\
-\end{array}$ & $\begin{array}{c}(0,0054) \\
0,056\end{array}$ & $\begin{array}{l}(0,0071) \\
0,00046\end{array}$ & $\begin{array}{c}(0,059) \\
0,847\end{array}$ & $\begin{array}{c}(8,4) \\
241,3\end{array}$ & $\begin{array}{l}(0,19) \\
3,54\end{array}$ \\
\hline & $(6,8)$ & & $(0,012)$ & $(0,00013)$ & $(0,085)$ & $(7,7)$ & $(0,24)$ \\
\hline
\end{tabular}




\begin{tabular}{|c|c|c|c|c|c|c|c|}
\hline D & $\begin{array}{c}\mathbf{B e} \\
\left(\mathbf{x} 10^{-3}\right)\end{array}$ & $\overline{A l}$ & $\bar{V}$ & $\mathrm{Cr}$ & Mn & $\begin{array}{c}\mathrm{Co} \\
\left(\mathbf{x 1 0 ^ { - 3 }}\right)\end{array}$ & $\mathbf{N i}$ \\
\hline 18a & - & 3,60 & 0,055 & 0,112 & 1,03 & 280,3 & 3,42 \\
\hline & & $(0,24)$ & $(0,012)$ & $(0,033)$ & $(0,10)$ & $(9,0)$ & $(0,24)$ \\
\hline $18 b$ & 84,2 & 5,71 & 0,084 & 0,116 & 0,99 & 260,6 & 5,00 \\
\hline & $(6,8)$ & $(0,39)$ & $(0,018)$ & $(0,034)$ & $(0,10)$ & $(8,3)$ & $(0,34)$ \\
\hline 19a & - & 5,26 & 0,0240 & 0,133 & 0,596 & 254,4 & 2,15 \\
\hline 19b & 94,1 & $\begin{array}{c}(0,36) \\
2,82\end{array}$ & $\begin{array}{c}(0,0053) \\
0,123\end{array}$ & $\begin{array}{c}(0,038) \\
0,099\end{array}$ & $\begin{array}{c}(0,060) \\
1,11\end{array}$ & $\begin{array}{c}(8,1) \\
286,2\end{array}$ & $\begin{array}{c}(0,15) \\
3,81\end{array}$ \\
\hline $20 a$ & $\begin{array}{c}(7,6) \\
-\end{array}$ & $(0,19)$ & $\begin{array}{l}(0,027) \\
0,0214\end{array}$ & $\begin{array}{c}(0,029) \\
0,0038\end{array}$ & $\begin{array}{l}(0,11) \\
0,731\end{array}$ & $\begin{array}{c}(9,2) \\
289,6\end{array}$ & $\begin{array}{c}(0,26) \\
3,06\end{array}$ \\
\hline $20 b$ & 98,2 & 11,83 & $\begin{array}{r}(0,0047) \\
0,0379\end{array}$ & $\begin{array}{c}(0,0011) \\
0,110\end{array}$ & $\begin{array}{c}(0,073) \\
0,744\end{array}$ & $\begin{array}{l}(9,3) \\
338\end{array}$ & $\begin{array}{c}(0,21) \\
2,94\end{array}$ \\
\hline 21 & $\begin{array}{l}(8,0) \\
80,8\end{array}$ & $\begin{array}{c}(0,80) \\
22,5\end{array}$ & $\begin{array}{c}(0,0083) \\
0,067\end{array}$ & $\begin{array}{c}(0,032) \\
0,206\end{array}$ & $\begin{array}{c}(0,074) \\
0,893\end{array}$ & $\begin{array}{c}(11) \\
260,6\end{array}$ & $\begin{array}{r}(0,20) \\
3,96\end{array}$ \\
\hline 22 & $\begin{array}{l}(6,5) \\
89,1\end{array}$ & $\begin{array}{c}(1,5) \\
10,20\end{array}$ & $\begin{array}{c}(0,015) \\
0,080\end{array}$ & $\begin{array}{c}(0,060) \\
0,81\end{array}$ & $\begin{array}{c}(0,089) \\
1,05\end{array}$ & $\begin{array}{c}(8,3) \\
280,1\end{array}$ & $\begin{array}{c}(0,27) \\
3,63\end{array}$ \\
\hline 23 & $\begin{array}{l}(7,2) \\
88,8\end{array}$ & $\begin{array}{c}(0,69) \\
20,2\end{array}$ & $\begin{array}{c}(0,018) \\
0,044\end{array}$ & $\begin{array}{l}(0,23) \\
0,145\end{array}$ & $\begin{array}{l}(0,11) \\
0,841\end{array}$ & $\begin{array}{c}(9,0) \\
268,7\end{array}$ & $\begin{array}{c}(0,25) \\
4,58\end{array}$ \\
\hline 24 & $\begin{array}{l}(7,2) \\
97,1\end{array}$ & $\begin{array}{c}(1,4) \\
11,97\end{array}$ & $\begin{array}{c}(0,010) \\
0,049\end{array}$ & $\begin{array}{c}(0,042) \\
0,080\end{array}$ & $\begin{array}{c}(0,084) \\
1,19\end{array}$ & $\begin{array}{l}(8,6) \\
395\end{array}$ & $\begin{array}{r}(0,32) \\
3,44\end{array}$ \\
\hline $25 a$ & $\begin{array}{l}(7,9) \\
87,1\end{array}$ & $\begin{array}{c}(0,81) \\
-\end{array}$ & $\begin{array}{c}(0,011) \\
0,050\end{array}$ & $\begin{array}{l}(0,023) \\
0,0315\end{array}$ & $\begin{array}{r}(0,12) \\
1,00\end{array}$ & $\begin{array}{c}(13) \\
274,4\end{array}$ & $\begin{array}{c}(0,24) \\
3,31\end{array}$ \\
\hline $25 b$ & $\begin{array}{l}(7,1) \\
87,1\end{array}$ & 0,461 & $\begin{array}{c}(0,011) \\
0,068\end{array}$ & $\begin{array}{c}(0,0091) \\
0,073\end{array}$ & $\begin{array}{r}(0,10) \\
1,21\end{array}$ & $\begin{array}{c}(8,8) \\
263,0\end{array}$ & $\begin{array}{r}(0,23) \\
3,70\end{array}$ \\
\hline 26 & $\begin{array}{l}(7,1) \\
79,1 \\
(6,4)\end{array}$ & $\begin{array}{c}(0,031) \\
3,92 \\
(0,27)\end{array}$ & $\begin{array}{c}(0,015) \\
0,069 \\
(0,015)\end{array}$ & $\begin{array}{c}(0,021) \\
0,180 \\
(0,052)\end{array}$ & $\begin{array}{r}(0,12) \\
1,09 \\
(0,11)\end{array}$ & $\begin{array}{c}(8,4) \\
289,2 \\
(9,3)\end{array}$ & $\begin{array}{c}(0,26) \\
3,26 \\
(0,22)\end{array}$ \\
\hline 27 & $\begin{array}{l}87,4 \\
(7,1)\end{array}$ & $\begin{array}{c}0,0472 \\
(0,0032)\end{array}$ & $\begin{array}{c}0,102 \\
(0,023)\end{array}$ & $\begin{array}{c}0,160 \\
(0,046)\end{array}$ & $\begin{array}{c}0,95 \\
(0,10)\end{array}$ & $\begin{array}{c}269,9 \\
(8,6)\end{array}$ & $\begin{array}{c}3,09 \\
(0,21)\end{array}$ \\
\hline 28 & $\begin{array}{l}86,9 \\
(7,0)\end{array}$ & - & $\begin{array}{c}0,062 \\
(0,014)\end{array}$ & $\begin{array}{c}0,096 \\
(0,028)\end{array}$ & $\begin{array}{c}0,894 \\
(0,089)\end{array}$ & $\begin{array}{l}643 \\
(21)\end{array}$ & $\begin{array}{c}3,35 \\
(0,23)\end{array}$ \\
\hline 29a & $\begin{array}{c}104,1 \\
(8,4)\end{array}$ & - & $\begin{array}{c}0,089 \\
(0,020)\end{array}$ & $\begin{array}{c}0,184 \\
(0,053)\end{array}$ & $\begin{array}{r}1,09 \\
(0,11)\end{array}$ & $\begin{array}{c}276,3 \\
(8,8)\end{array}$ & $\begin{array}{r}4,70 \\
(0,32)\end{array}$ \\
\hline 29b & $\begin{array}{l}94,5 \\
(7,7)\end{array}$ & $\begin{array}{c}2,35 \\
(0,16)\end{array}$ & $\begin{array}{c}0,083 \\
(0,018)\end{array}$ & $\begin{array}{c}0,36 \\
(0,10)\end{array}$ & $\begin{array}{l}1,19 \\
(0,12)\end{array}$ & $\begin{array}{c}278,0 \\
(8,9)\end{array}$ & $\begin{array}{c}5,78 \\
(0,40)\end{array}$ \\
\hline 30 & $\begin{array}{l}73,6 \\
(6,0)\end{array}$ & $\begin{array}{l}15,4 \\
(1,0)\end{array}$ & $\begin{array}{c}0,126 \\
(0,028)\end{array}$ & $\begin{array}{l}15,6 \\
(4,5)\end{array}$ & $\begin{array}{r}1,17 \\
(0,12)\end{array}$ & $\begin{array}{c}299,3 \\
(9,6)\end{array}$ & $\begin{array}{c}5,85 \\
(0,40)\end{array}$ \\
\hline
\end{tabular}


Tabela G.3 Concentrações elementares medidas pelo método ICP-MS em ppb. A letra D representa os doadores.

\begin{tabular}{|c|c|c|c|c|c|c|c|c|}
\hline D & $\mathrm{Cu}_{\mathrm{I}}$ & $\mathbf{Z n}_{\text {I }}$ & Se & Mo & Cd & Sn & $\begin{array}{c}\mathrm{Tl} \\
\left(\mathbf{x 1 0 ^ { - 3 }}\right)\end{array}$ & $\mathbf{P b}$ \\
\hline 1 & $\begin{array}{c}1977 \\
(36)\end{array}$ & $\begin{array}{l}793 \\
(29)\end{array}$ & $\begin{array}{c}6,7 \\
(5,2)\end{array}$ & $\begin{array}{c}0,856 \\
(0,020)\end{array}$ & $\begin{array}{l}0,1804 \\
(0,0025)\end{array}$ & $\begin{array}{l}0,895 \\
(0,042)\end{array}$ & $\begin{array}{l}80,52 \\
(0,81)\end{array}$ & $\begin{array}{c}0,328 \\
(0,033)\end{array}$ \\
\hline $2 a$ & 953 & 813 & 71,9 & 1,432 & 11,06 & 0,324 & 71,94 & 0,434 \\
\hline $2 b$ & $\begin{array}{l}(17) \\
923\end{array}$ & $\begin{array}{l}(30) \\
873\end{array}$ & $\begin{array}{l}(5,8) \\
148\end{array}$ & $\begin{array}{c}(0,033) \\
1,602\end{array}$ & $\begin{array}{l}(0,15) \\
6,191\end{array}$ & $\begin{array}{c}(0,015) \\
0,437\end{array}$ & $\begin{array}{l}(0,72) \\
32,37\end{array}$ & $\begin{array}{c}(0,043) \\
0,206\end{array}$ \\
\hline $2 c$ & $\begin{array}{l}(17) \\
941\end{array}$ & $\begin{array}{l}(32) \\
879\end{array}$ & $\begin{array}{l}(12) \\
58,5\end{array}$ & $\begin{array}{c}(0,037) \\
1,670\end{array}$ & $\begin{array}{c}(0,087) \\
6,096\end{array}$ & $\begin{array}{c}(0,021) \\
0,663\end{array}$ & $\begin{array}{l}(0,32) \\
42,06\end{array}$ & $\begin{array}{c}(0,021) \\
0,275\end{array}$ \\
\hline 3 & $\begin{array}{l}(17) \\
1728\end{array}$ & $\begin{array}{l}(33) \\
869\end{array}$ & $\begin{array}{l}(4,7) \\
84,5\end{array}$ & $\begin{array}{c}(0,038) \\
0,831\end{array}$ & $\begin{array}{l}(0,085) \\
0,4247\end{array}$ & $\begin{array}{c}(0,031) \\
0,860\end{array}$ & $\begin{array}{l}(0,42) \\
14,52\end{array}$ & $\begin{array}{c}(0,028) \\
0,111\end{array}$ \\
\hline 4 & $\begin{array}{l}(31) \\
1232\end{array}$ & $\begin{array}{l}(32) \\
857\end{array}$ & $\begin{array}{l}(6,8) \\
77,8\end{array}$ & $\begin{array}{c}(0,019) \\
1,034\end{array}$ & $\begin{array}{c}(0,0059) \\
0,3216\end{array}$ & $\begin{array}{c}(0,040) \\
0,743\end{array}$ & $\begin{array}{l}(0,15) \\
47,00\end{array}$ & $\begin{array}{c}(0,011) \\
0,137\end{array}$ \\
\hline 5 & $\begin{array}{l}(22) \\
656\end{array}$ & $\begin{array}{l}(32) \\
901\end{array}$ & $\begin{array}{l}(6,3) \\
61,9\end{array}$ & $\begin{array}{c}(0,024) \\
1,076\end{array}$ & $\begin{array}{l}(0,0045) \\
0,1929\end{array}$ & $\begin{array}{c}(0,035) \\
0,560\end{array}$ & $\begin{array}{l}(0,47) \\
18,92\end{array}$ & $\begin{array}{c}(0,014) \\
1,88\end{array}$ \\
\hline 6 & $\begin{array}{l}(12) \\
1046\end{array}$ & $\begin{array}{l}(33) \\
926\end{array}$ & $\begin{array}{l}(5,0) \\
105,1\end{array}$ & $\begin{array}{c}(0,025) \\
0,691\end{array}$ & $\begin{array}{c}(0,0027) \\
2,119\end{array}$ & $\begin{array}{c}(0,026) \\
0,746\end{array}$ & $\begin{array}{l}(0,19) \\
29,31\end{array}$ & $\begin{array}{c}(0,019) \\
0,786\end{array}$ \\
\hline 7 & $\begin{array}{l}(19) \\
627\end{array}$ & $\begin{array}{l}(34) \\
1087\end{array}$ & $\begin{array}{l}(8,5) \\
70,8\end{array}$ & $\begin{array}{c}(0,016) \\
1,037\end{array}$ & $\begin{array}{c}(0,030) \\
3,194\end{array}$ & $\begin{array}{c}(0,035) \\
0,656\end{array}$ & $\begin{array}{l}(0,29) \\
15,03\end{array}$ & $\begin{array}{c}(0,079) \\
1,06\end{array}$ \\
\hline 8 & $\begin{array}{l}(11) \\
806 \\
(15)\end{array}$ & $\begin{array}{l}(40) \\
853 \\
(32)\end{array}$ & $\begin{array}{l}(5,7) \\
90,3 \\
(7,3)\end{array}$ & $\begin{array}{c}(0,024) \\
0,808 \\
(0,019)\end{array}$ & $\begin{array}{c}(0,045) \\
1,961 \\
(0,027)\end{array}$ & $\begin{array}{c}(0,031) \\
0,845 \\
(0,040)\end{array}$ & $\begin{array}{l}(0,15) \\
22,90 \\
(0,23)\end{array}$ & $\begin{array}{c}(0,11) \\
0,142 \\
(0,014)\end{array}$ \\
\hline 9 & $\begin{array}{l}961 \\
(17)\end{array}$ & $\begin{array}{l}1209 \\
(45)\end{array}$ & $\begin{array}{l}91,7 \\
(7,4)\end{array}$ & $\begin{array}{c}0,716 \\
(0,016)\end{array}$ & $\begin{array}{c}1,643 \\
(0,023)\end{array}$ & $\begin{array}{l}0,485 \\
(0,023)\end{array}$ & $\begin{array}{l}16,10 \\
(0,16)\end{array}$ & $\begin{array}{c}0,0375 \\
(0,0037)\end{array}$ \\
\hline 10 & $\begin{array}{l}760 \\
(14)\end{array}$ & $\begin{array}{l}809 \\
(30)\end{array}$ & $\begin{array}{l}70,3 \\
(5,7)\end{array}$ & $\begin{array}{l}0,620 \\
(0,014)\end{array}$ & $\begin{array}{l}0,6913 \\
(0,0097)\end{array}$ & $\begin{array}{l}0,489 \\
(0,023)\end{array}$ & $\begin{array}{l}21,01 \\
(0,21)\end{array}$ & $\begin{array}{l}0,125 \\
(0,013)\end{array}$ \\
\hline 11a & 777 & 985 & 81,0 & 1,633 & 0,747 & 0,418 & 11,22 & 0,483 \\
\hline 11b & $\begin{array}{l}(14) \\
749 \\
(13)\end{array}$ & $\begin{array}{l}(36) \\
952 \\
(35)\end{array}$ & $\begin{array}{l}(6,6) \\
82,4 \\
(6,7)\end{array}$ & $\begin{array}{c}(0,038) \\
1,521 \\
(0,035)\end{array}$ & $\begin{array}{c}(0,010) \\
0,706 \\
(0,010)\end{array}$ & $\begin{array}{c}(0,020) \\
0,380 \\
(0,018)\end{array}$ & $\begin{array}{l}(0,11) \\
19,47 \\
(0,19)\end{array}$ & $\begin{array}{c}(0,048) \\
0,097 \\
(0,010)\end{array}$ \\
\hline $12 a$ & $\begin{array}{l}805 \\
(14)\end{array}$ & $\begin{array}{l}908 \\
(34)\end{array}$ & $\begin{array}{l}69,5 \\
(5,6)\end{array}$ & $\begin{array}{l}1,012 \\
(0,023)\end{array}$ & $\begin{array}{l}1,086 \\
(0,015)\end{array}$ & $\begin{array}{l}0,362 \\
(0,017)\end{array}$ & $\begin{array}{l}11,92 \\
(0,12)\end{array}$ & $\begin{array}{c}7,23 \\
(0,72)\end{array}$ \\
\hline $12 b$ & $\begin{array}{l}904 \\
(16)\end{array}$ & $\begin{array}{l}899 \\
(33)\end{array}$ & $\begin{array}{l}44,5 \\
(3,6)\end{array}$ & $\begin{array}{c}0,947 \\
(0,022)\end{array}$ & $\begin{array}{l}1,056 \\
(0,015)\end{array}$ & $\begin{array}{l}0,351 \\
(0,016)\end{array}$ & $\begin{array}{l}63,72 \\
(0,64)\end{array}$ & $\begin{array}{c}0,177 \\
(0,018)\end{array}$ \\
\hline 13 & $\begin{array}{c}1847 \\
(33)\end{array}$ & $\begin{array}{l}923 \\
(34)\end{array}$ & $\begin{array}{c}102,9 \\
(8,3)\end{array}$ & $\begin{array}{l}0,918 \\
(0,021)\end{array}$ & $\begin{array}{l}0,03687 \\
(0,00052)\end{array}$ & $\begin{array}{l}0,528 \\
(0,025)\end{array}$ & $\begin{array}{l}26,24 \\
(0,26)\end{array}$ & $\begin{array}{c}0,227 \\
(0,023)\end{array}$ \\
\hline 14 & $\begin{array}{l}1671 \\
(30)\end{array}$ & $\begin{array}{l}784 \\
(29)\end{array}$ & $\begin{array}{l}85,3 \\
(6,9)\end{array}$ & $\begin{array}{l}0,925 \\
(0,021)\end{array}$ & $\begin{array}{l}0,05236 \\
(0,00073)\end{array}$ & $\begin{array}{l}0,680 \\
(0,032)\end{array}$ & $\begin{array}{l}50,39 \\
(0,50)\end{array}$ & $\begin{array}{c}0,413 \\
(0,041)\end{array}$ \\
\hline 15 & $\begin{array}{l}1043 \\
(19) \\
1150\end{array}$ & $\begin{array}{l}1170 \\
(43) \\
1181\end{array}$ & $\begin{array}{c}84,7 \\
(6,9) \\
109,5\end{array}$ & $\begin{array}{c}1,296 \\
(0,030) \\
0,621\end{array}$ & $\begin{array}{c}0,1141 \\
(0,0016) \\
0,1029\end{array}$ & $\begin{array}{c}0,425 \\
(0,020) \\
0,470\end{array}$ & $\begin{array}{l}20,03 \\
(0,20) \\
18,53\end{array}$ & $\begin{array}{c}0,215 \\
(0,021) \\
0,262\end{array}$ \\
\hline $17 a$ & $\begin{array}{l}(21) \\
909\end{array}$ & $\begin{array}{l}\text { (44) } \\
1160\end{array}$ & $\begin{array}{l}(8,9) \\
77,1\end{array}$ & $\begin{array}{c}(0,014) \\
0,844\end{array}$ & $\begin{array}{c}(0,0014) \\
0,1339\end{array}$ & $\begin{array}{c}(0,022) \\
0,325\end{array}$ & $\begin{array}{l}(0,19) \\
19,07\end{array}$ & $\begin{array}{c}(0,026) \\
0,320\end{array}$ \\
\hline $17 b$ & $\begin{array}{l}(16) \\
873 \\
(16)\end{array}$ & $\begin{array}{l}(43) \\
1121 \\
(41)\end{array}$ & $\begin{array}{l}(6,2) \\
56,8 \\
(4,6)\end{array}$ & $\begin{array}{c}(0,019) \\
0,939 \\
(0,022)\end{array}$ & $\begin{array}{c}(0,0019) \\
0,1358 \\
(0,0019)\end{array}$ & $\begin{array}{c}(0,015) \\
5,22 \\
(0,25)\end{array}$ & $\begin{array}{c}(0,19) \\
76,98 \\
(0,77)\end{array}$ & $\begin{array}{c}(0,032) \\
0,0731 \\
(0,0073)\end{array}$ \\
\hline
\end{tabular}




\begin{tabular}{|c|c|c|c|c|c|c|c|c|}
\hline D & $\mathbf{C u}_{\mathrm{I}}$ & $\mathbf{Z n} \mathbf{n}_{\mathbf{I}}$ & Se & Mo & Cd & Sn & $\begin{array}{c}\mathrm{Tl} \\
\left(\mathbf{x 1 0} 0^{-3}\right)\end{array}$ & $\mathbf{P b}$ \\
\hline $18 \mathrm{a}$ & 856 & 1042 & 84,1 & 1,336 & 0,2035 & 0,427 & 27,65 & 0,289 \\
\hline & (15) & (39) & $(6,8)$ & $(0,031)$ & $(0,0028)$ & $(0,020)$ & $(0,28)$ & $(0,029)$ \\
\hline 18b & 875 & 1096 & 53,8 & 1,490 & 0,2242 & 2,25 & 69,24 & 0,410 \\
\hline & (16) & (41) & $(4,4)$ & $(0,034)$ & $(0,0031)$ & $(0,11)$ & $(0,69)$ & $(0,041)$ \\
\hline 19a & 1189 & 1115 & 53,5 & 0,785 & 0,1417 & 0,425 & 18,76 & 0,100 \\
\hline 19b & $\begin{array}{l}(21) \\
1224\end{array}$ & $\begin{array}{l}(41) \\
1138\end{array}$ & $\begin{array}{l}(4,3) \\
45,4\end{array}$ & $\begin{array}{c}(0,018) \\
0,913\end{array}$ & $\begin{array}{c}(0,0020) \\
0,1579\end{array}$ & $\begin{array}{c}(0,020) \\
1,644\end{array}$ & $\begin{array}{l}(0,19) \\
61,96\end{array}$ & $\begin{array}{l}(0,010) \\
0,0499\end{array}$ \\
\hline $20 a$ & $\begin{array}{l}(22) \\
742\end{array}$ & $\begin{array}{l}(42) \\
815\end{array}$ & $\begin{array}{l}(3,7) \\
77,2\end{array}$ & $\begin{array}{c}(0,021) \\
0,925\end{array}$ & $\begin{array}{c}(0,0022) \\
0,2341\end{array}$ & $\begin{array}{c}(0,077) \\
0,418\end{array}$ & $\begin{array}{l}(0,62) \\
30,03\end{array}$ & $\begin{array}{r}(0,0050) \\
0,0410\end{array}$ \\
\hline 20b & $\begin{array}{l}\text { (13) } \\
790\end{array}$ & $\begin{array}{l}(30) \\
845\end{array}$ & $\begin{array}{l}(6,3) \\
52,0\end{array}$ & $\begin{array}{c}(0,021) \\
1,071\end{array}$ & $\begin{array}{c}(0,0033) \\
0,0971\end{array}$ & $\begin{array}{c}(0,020) \\
0,290\end{array}$ & $\begin{array}{l}(0,30) \\
63,81\end{array}$ & $\begin{array}{c}(0,0041) \\
-\end{array}$ \\
\hline 21 & $\begin{array}{l}(14) \\
1071\end{array}$ & $\begin{array}{l}(31) \\
1017\end{array}$ & $\begin{array}{l}(4,2) \\
57,4\end{array}$ & $\begin{array}{c}(0,025) \\
18,17\end{array}$ & $\begin{array}{c}(0,0014) \\
0,1795\end{array}$ & $\begin{array}{c}(0,014) \\
0,283\end{array}$ & $\begin{array}{l}(0,64) \\
64,70\end{array}$ & 1,97 \\
\hline 22 & $\begin{array}{l}(19) \\
933\end{array}$ & $\begin{array}{l}(38) \\
903\end{array}$ & $\begin{array}{l}(4,7) \\
49,5\end{array}$ & $\begin{array}{l}(0,42) \\
1,077\end{array}$ & $\begin{array}{c}(0,0025) \\
0,2357\end{array}$ & $\begin{array}{l}(0,013) \\
0,0949\end{array}$ & $\begin{array}{l}(0,65) \\
57,96\end{array}$ & $\begin{array}{c}(0,20) \\
0,0084\end{array}$ \\
\hline 23 & $\begin{array}{c}(17) \\
1069\end{array}$ & $\begin{array}{l}(33) \\
1002\end{array}$ & $\begin{array}{l}(4,0) \\
49,6\end{array}$ & $\begin{array}{c}(0,025) \\
0,899\end{array}$ & $\begin{array}{c}(0,0033) \\
0,2176\end{array}$ & $\begin{array}{c}(0,0045) \\
0,0685\end{array}$ & $\begin{array}{l}(0,58) \\
72,97\end{array}$ & $\begin{array}{c}(0,0008) \\
-\end{array}$ \\
\hline 24 & 2207 & 818 & $\begin{array}{l}(4,0) \\
54,8\end{array}$ & $\begin{array}{l}(0,021) \\
0,920\end{array}$ & $\begin{array}{l}(0,0030) \\
0,2961\end{array}$ & $\begin{array}{l}(0,0032) \\
0,1496\end{array}$ & $\begin{array}{l}(0,7) \\
63,68\end{array}$ & 0,430 \\
\hline $25 a$ & $\begin{array}{l}(40) \\
889\end{array}$ & 1019 & $\begin{array}{l}(4,4) \\
47,5\end{array}$ & $\begin{array}{c}(0,021) \\
1,109\end{array}$ & $\begin{array}{c}(0,0041) \\
0,714\end{array}$ & $\begin{array}{c}(0,00 / 0) \\
-\end{array}$ & $\begin{array}{l}(0,04) \\
47,74\end{array}$ & $\begin{array}{c}(0,043) \\
0,116\end{array}$ \\
\hline $25 b$ & $\begin{array}{l}(16) \\
878\end{array}$ & $\begin{array}{l}(38) \\
1056\end{array}$ & $\begin{array}{l}(3,8) \\
51,0\end{array}$ & $\begin{array}{l}(0,026) \\
1,136\end{array}$ & $\begin{array}{c}(0,010) \\
0,731\end{array}$ & - & $\begin{array}{l}(0,48) \\
51,97\end{array}$ & $\begin{array}{l}(0,012) \\
0,0550\end{array}$ \\
\hline 26 & $\begin{array}{c}(16) \\
1084 \\
(20)\end{array}$ & $\begin{array}{l}(39) \\
1213 \\
(45)\end{array}$ & $\begin{array}{l}(4,1) \\
47,5 \\
(3,8)\end{array}$ & $\begin{array}{c}(0,026) \\
1,326 \\
(0,031)\end{array}$ & $\begin{array}{l}(0,010) \\
0,4747 \\
(0,0066)\end{array}$ & $\begin{array}{c}0,0411 \\
(0,0019)\end{array}$ & $\begin{array}{l}(0,52) \\
55,79 \\
(0,56)\end{array}$ & $\begin{array}{c}(0,0055) \\
0,528 \\
(0,053)\end{array}$ \\
\hline 27 & $\begin{array}{c}1179 \\
(21)\end{array}$ & $\begin{array}{l}1070 \\
(40)\end{array}$ & $\begin{array}{l}62,0 \\
(5,0)\end{array}$ & $\begin{array}{l}0,886 \\
(0,020)\end{array}$ & $\begin{array}{l}0,4354 \\
(0,0061)\end{array}$ & - & $\begin{array}{l}63,15 \\
(0,63)\end{array}$ & $\begin{array}{c}0,0683 \\
(0,0068)\end{array}$ \\
\hline 28 & $\begin{array}{l}1168 \\
(21)\end{array}$ & $\begin{array}{l}1016 \\
(38)\end{array}$ & $\begin{array}{l}83,8 \\
(6,8)\end{array}$ & $\begin{array}{l}1,005 \\
(0,023)\end{array}$ & $\begin{array}{l}0,03561 \\
(0,00050)\end{array}$ & - & $\begin{array}{l}70,47 \\
(0,70)\end{array}$ & $\begin{array}{l}0,0692 \\
(0,0069)\end{array}$ \\
\hline 29a & 914 & 1047 & 42,8 & 0,995 & 0,02672 & 1,346 & 70,74 & 0,101 \\
\hline 29b & $\begin{array}{l}(16) \\
849 \\
(15)\end{array}$ & $\begin{array}{l}(39) \\
905\end{array}$ & $\begin{array}{l}(3,5) \\
40,8\end{array}$ & $\begin{array}{r}(0,023) \\
1,004\end{array}$ & $\begin{array}{l}(0,00037) \\
0,02465\end{array}$ & $\begin{array}{c}(0,063) \\
0,359\end{array}$ & $\begin{array}{l}(0,71) \\
77,68\end{array}$ & $\begin{array}{c}(0,010) \\
0,154\end{array}$ \\
\hline 30 & $\begin{array}{l}995 \\
(18)\end{array}$ & $\begin{array}{l}1007 \\
(37)\end{array}$ & $\begin{array}{l}59,0 \\
(4,8)\end{array}$ & $\begin{array}{c}1,134 \\
(0,026)\end{array}$ & $\begin{array}{l}0,03173 \\
(0,00044)\end{array}$ & $\begin{array}{c}1,032 \\
(0,048)\end{array}$ & $\begin{array}{l}65,98 \\
(0,55)\end{array}$ & $\begin{array}{c}1,77 \\
(0,018)\end{array}$ \\
\hline
\end{tabular}




\section{A pêndice $H$}

Este apêndice mostra os resultados dos testes W, de assimetria e de Curtose aplicados nas concentrações elementares do soro e em suas transformações logarítmicas. A tabela H.1 mostra os valores obtidos para os elementos que passaram nos testes de normalidade, com exceção do Be e Tl e a tabela H.2 mostra os resultados para os elementos que passaram nos testes de lognormalidade, ou seja, as transformadas das concentrações foram aprovadas nos testes. Neste caso, o $\mathrm{Be}$, o $\mathrm{Sn}$ e o $\mathrm{Tl}$ não foram aprovados em pelo menos um dos testes.

Tabela H.1 Resultado dos testes W, Assimetria e Curtose aplicados nas concentrações elementares em soro.

\begin{tabular}{|c|c|c|c|c|c|c|c|c|c|c|}
\hline \multirow[t]{2}{*}{ El. } & \multicolumn{3}{|c|}{ Assimetria } & \multicolumn{3}{|c|}{ Curtose } & \multicolumn{2}{|c|}{ Shapiro Wilk } & \multirow[t]{2}{*}{$\mathrm{N}$} & \multirow[t]{2}{*}{ Ex } \\
\hline & $\mathrm{S}$ & Std & S/Std & $\mathrm{K}$ & $\mathrm{Std}$ & $\mathrm{K} / \mathrm{Std}$ & Est. & Sig. & & \\
\hline $\mathrm{Be}^{*}$ & $-0,382$ & 0,512 & $-0,75$ & $-1,530$ & 0,992 & $-1,5$ & 0,869 & 0,012 & 20 & \\
\hline $\mathrm{P}$ & 0,672 & 0,427 & 1,6 & 0,510 & 0,833 & 0,61 & 0,969 & 0,507 & 30 & \\
\hline $\mathrm{S}$ & 0,319 & 0,427 & 0,75 & $-0,699$ & 0,833 & $-0,84$ & 0,961 & 0,336 & 30 & \\
\hline $\mathrm{Cl}$ & 0,025 & 0,427 & 0,059 & $-0,698$ & 0,833 & $-0,84$ & 0,980 & 0,832 & 30 & \\
\hline $\mathrm{K}$ & $-0,375$ & 0,427 & $-0,88$ & $-0,767$ & 0,833 & $-0,92$ & 0,952 & 0,195 & 30 & \\
\hline $\mathrm{Ca}$ & $-0,013$ & 0,427 & $-0,030$ & $-0,117$ & 0,833 & $-0,14$ & 0,976 & 0,714 & 30 & \\
\hline $\mathrm{Mn}$ & 0,358 & 0,427 & 0,84 & $-0,115$ & 0,833 & $-0,14$ & 0,978 & 0,771 & 30 & \\
\hline $\mathrm{Zn}_{\mathrm{P}}$ & 0,515 & 0,434 & 1,2 & $-0,038$ & 0,845 & $-0,045$ & 0,971 & 0,580 & 29 & 1 \\
\hline $\mathrm{Zn}_{\mathrm{I}}$ & 0,299 & 0,427 & 0,70 & $-1,062$ & 0,833 & $-1,3$ & 0,946 & 0,135 & 30 & \\
\hline $\mathrm{Se}$ & 0,406 & 0,427 & 0,95 & $-0,756$ & 0,833 & $-0,91$ & 0,952 & 0,192 & 30 & \\
\hline $\mathrm{Br}$ & 0,325 & 0,427 & 0,76 & $-0,488$ & 0,833 & $-0,59$ & 0,979 & 0,798 & 30 & \\
\hline Mo & 0,768 & 0,434 & 1,8 & 0,440 & 0,845 & 0,52 & 0,938 & 0,090 & 29 & 1 \\
\hline $\mathrm{Sn}$ & 0,321 & 0,456 & 0,70 & $-0,177$ & 0,887 & $-0,20$ & 0,974 & 0,719 & 26 & 1 \\
\hline $\mathrm{Tl}^{*}$ & $-0,002$ & 0,472 & $-0,0042$ & $-1,340$ & 0,833 & $-1,6$ & 0,924 & 0,033 & 30 & \\
\hline
\end{tabular}

* Elementos que não passaram em pelo menos um dos testes. 
Tabela H.2 Resultado dos testes W, Assimetria e Curtose aplicados na transformação logarítmica dos dados.

\begin{tabular}{|c|c|c|c|c|c|c|c|c|c|c|}
\hline \multirow[t]{2}{*}{ El. } & \multicolumn{3}{|c|}{ Assimetria } & \multicolumn{3}{|c|}{ Curtose } & \multicolumn{2}{|c|}{ Shapiro Wilk } & \multirow[t]{2}{*}{$\overline{\mathrm{N}}$} & \multirow[t]{2}{*}{ E† } \\
\hline & $\mathrm{S}$ & Std & $\mathrm{S} / \mathrm{Std}$ & $\mathrm{K}$ & Std & $\mathrm{K} / \mathrm{Std}$ & Est. & Sig. & & \\
\hline $\mathrm{Al}$ & $-0,680$ & 0,512 & $-1,3$ & $-0,280$ & 0,992 & $-0,28$ & 0,939 & 0,226 & 20 & \\
\hline $\mathrm{Be}^{*}$ & $-1,076$ & 0,512 & $-2,1$ & 0,093 & 0,992 & 0,094 & 0,830 & 0,002 & 20 & \\
\hline $\mathrm{P}$ & 0,113 & 0,427 & 0,26 & 0,006 & 0,833 & 0,0072 & 0,992 & 0,998 & 30 & \\
\hline $\mathrm{S}$ & 0,137 & 0,427 & 0,32 & $-0,786$ & 0,833 & $-0,94$ & 0,968 & 0,484 & 30 & \\
\hline $\mathrm{Cl}$ & $-0,142$ & 0,427 & $-0,33$ & $-0,725$ & 0,833 & $-0,87$ & 0,978 & 0,770 & 30 & \\
\hline K & $-0,524$ & 0,427 & $-1,2$ & $-0,612$ & 0,833 & $-0,73$ & 0,942 & 0,102 & 30 & \\
\hline $\mathrm{Ca}$ & $-0,227$ & 0,427 & $-0,53$ & $-0,156$ & 0,833 & $-0,19$ & 0,973 & 0,617 & 30 & \\
\hline V & 0,097 & 0,427 & 0,23 & $-0,940$ & 0,833 & $-1,1$ & 0,965 & 0,409 & 30 & \\
\hline $\mathrm{Cr}$ & $-0,508$ & 0,434 & $-1,2$ & $-0,016$ & 0,845 & $-0,019$ & 0,958 & 0,298 & 29 & 1 \\
\hline $\mathrm{Mn}$ & $-0,249$ & 0,427 & $-0,58$ & $-0,291$ & 0,833 & $-0,35$ & 0,980 & 0,835 & 30 & \\
\hline $\mathrm{Fe}$ & 0,867 & 0,427 & 2,0 & 1,031 & 0,833 & 1,2 & 0,936 & 0,070 & 30 & \\
\hline Co & 0,486 & 0,441 & 1,1 & 1,154 & 0,858 & 1,3 & 0,956 & 0,284 & 28 & 2 \\
\hline $\mathrm{Ni}$ & 0,632 & 0,427 & 1,5 & 0,465 & 0,833 & 0,56 & 0,972 & 0,588 & 30 & \\
\hline $\mathrm{Cu}_{\mathrm{P}}$ & 0,354 & 0,427 & 0,83 & $-0,093$ & 0,833 & $-0,11$ & 0,945 & 0,124 & 30 & \\
\hline $\mathrm{Cu}_{\mathrm{I}}$ & 0,780 & 0,427 & 1,8 & 0,234 & 0,833 & 0,28 & 0,933 & 0,060 & 30 & \\
\hline $\mathrm{Zn}_{\mathrm{P}}$ & 0,097 & 0,434 & 0,22 & $-0,208$ & 0,845 & $-0,25$ & 0,987 & 0,965 & 29 & 1 \\
\hline $\mathrm{Zn}_{\mathrm{I}}$ & 0,128 & 0,427 & 0,30 & $-1,153$ & 0,833 & $-1,4$ & 0,953 & 0,202 & 30 & \\
\hline $\mathrm{Se}$ & 0,296 & 0,427 & 0,69 & $-0,795$ & 0,833 & $-0,95$ & 0,964 & 0,393 & 30 & \\
\hline $\mathrm{Br}$ & $-0,408$ & 0,427 & $-0,96$ & $-0,368$ & 0,833 & $-0,44$ & 0,976 & 0,725 & 30 & \\
\hline Mo & 0,133 & 0,434 & 0,31 & 0,020 & 0,845 & 0,024 & 0,970 & 0,565 & 29 & 1 \\
\hline $\mathrm{Sn} *$ & $-0,049$ & 0,448 & $-0,11$ & 1,562 & 0,872 & 1,8 & 0,907 & 0,019 & 27 & \\
\hline $\mathrm{Sn} *$ & $-1,434$ & 0,456 & $-3,1$ & 1,743 & 0,887 & 2,0 & 0,857 & 0,002 & 26 & 1 \\
\hline $\mathrm{Tl}^{*}$ & $-0,484$ & 0,427 & $-1,1$ & $-1,299$ & 0,833 & $-1,6$ & 0,888 & 0,004 & 30 & \\
\hline $\mathrm{Cd}$ & 0,318 & 0,427 & 0,74 & $-0,116$ & 0,833 & $-0,14$ & 0,975 & 0,669 & 30 & \\
\hline $\mathrm{Pb}$ & $-0,114$ & 0,441 & $-0,26$ & 0,572 & 0,858 & 0,67 & 0,976 & 0,755 & 28 & \\
\hline
\end{tabular}

* Elementos que não passaram em pelo menos em um dos testes.

$†$ Número de outliers excluídos co conjunto de dados. 